\title{
Design, development and qualification of compact mobile emissions measurement system (CMEMS) for real-time on-board emissions measurement
}

\author{
Aseem Tiwari \\ West Virginia University
}

Follow this and additional works at: https://researchrepository.wvu.edu/etd

\section{Recommended Citation}

Tiwari, Aseem, "Design, development and qualification of compact mobile emissions measurement system (CMEMS) for real-time on-board emissions measurement" (2006). Graduate Theses, Dissertations, and Problem Reports. 1788.

https://researchrepository.wvu.edu/etd/1788

This Thesis is protected by copyright and/or related rights. It has been brought to you by the The Research Repository @ WVU with permission from the rights-holder(s). You are free to use this Thesis in any way that is permitted by the copyright and related rights legislation that applies to your use. For other uses you must obtain permission from the rights-holder(s) directly, unless additional rights are indicated by a Creative Commons license in the record and/ or on the work itself. This Thesis has been accepted for inclusion in WVU Graduate Theses, Dissertations, and Problem Reports collection by an authorized administrator of The Research Repository @ WVU. For more information, please contact researchrepository@mail.wvu.edu. 


\title{
Design, Development and Qualification of \\ Compact Mobile Emissions Measurement System (CMEMS) for \\ Real-time On-board Emissions Measurement
}

\author{
Aseem Tiwari \\ Thesis submitted to the \\ College of Engineering and Mineral Resources \\ at West Virginia University \\ in partial fulfillment of the requirements \\ for the degree of \\ Master of Science \\ in \\ Mechanical Engineering \\ Mridul Gautam, Ph.D., Chair \\ Nigel N. Clark, Ph.D. \\ Benjamin C. Shade, Ph.D. \\ Department of Mechanical and Aerospace Engineering \\ Morgantown, West Virginia
}

Keywords: CMEMS, Heavy Duty Diesel Vehicles, In-use Emissions, System Integration 


\title{
Design, Development and Qualification of \\ Compact Mobile Emissions Measurement System (CMEMS) for \\ Real-time On-board Emissions Measurement
}

Aseem Tiwari

\begin{abstract}
The objective of this study was to design, develop and qualify the Compact Mobile Emissions Measurement System (CMEMS) for real-time on-board measurement of exhaust emissions from heavy-duty diesel vehicles. This study was aimed at developing a system more compact and lighter with respect to the existing Mobile Emissions Measurement System (MEMS), so that the entire system could be mounted on the tail pipe of the test vehicle in order to reduce installation time, power requirements and manpower requirements. This was achieved by judicious selection of commercially available compact solid-state gas analyzers, and development of a sampling system which was significantly smaller than the existing system in the MEMS. Accuracy, linearity, repeatability, interference and response time tests were conducted on all analyzers and components of the sampling system. Pressure and flow rate variation, vibration and inclination tests were also conducted to qualify the system for harsh on-board conditions. Components of the sampling system were selected based on several criteria, such as size, weight, power consumption, robustness and cost. After complete integration, the system was tested on the tail pipe of a Ford F450 Pick-up truck and also in an engine laboratory on a DDC series 60 engine to document the system's performance against the MEMS and the laboratory. On a concentration basis, the CMEMS reported a maximum percentage difference of $5.18 \%$ for $\mathrm{NO}_{x}$ and $3.10 \%$ for $\mathrm{CO}_{2}$ against the MEMS in two on-road tests, which were conducted on a Ford F450 pick-up truck. In addition, the CMEMS also reported a difference of $2.36 \%$ for $\mathrm{NO}_{\mathrm{x}}$ and $2.69 \%$ for $\mathrm{CO}_{2}$ measured on the $\mathrm{g} / \mathrm{s}$ basis against laboratory grade analyzers on seven FTP runs on a 1992 DDC series 60 engine. Differences of $1.87 \%$ for $\mathrm{NO}_{\mathrm{x}}$ and $1.51 \%$ for $\mathrm{CO}_{2}$ were reported on the $\mathrm{g} / \mathrm{s}$ basis against the laboratory grade analyzers when the series 60 engine was exercised on a simulated on-road cycle.
\end{abstract}




\section{Acknowledgment}

I always thank God for any good thing that takes place in my life. This document is one such good thing for which I cannot thank him enough. There are many more people to whom; I owe many special thanks and sincere gratitude in trying this pursuit of education and learning. However, one person to whom I cannot thank enough is Dr. Gautam. He is a special friend with many; including my family; great advisor to some of the best products of the research arena, and immense support for his family. I was privileged to have him as all. Therefore, waiting no longer, I owe this thesis and a greater part of my personal development to Dr. Gautam. But for him, this pursuit would have never come into existence. I also thank Dr. Clark and Dr. Shade for presiding over the defense committee for this thesis document.

Family always stays to my heart's closest. I love my parents and my younger brother and therefore, thank them all for every thing. At this point, I desire to thank Gurudutt for all the professional and emotional support. He inspired me to look beyond my own aspirations and focus on the job at hand. I sincerely thank Petr and Mac for supporting the research project by putting many systems together. Petr is an artist when it comes to fabrication and Mac is brilliant at the engineering analysis. My special thanks to Dan for supervising this project. The entire research group takes immense pride in his commendable research abilities. I was indeed privileged to work with him. I thank Hemanth and Deepak for their support all along, and being there with me whenever I needed help. There were cold winters and hot summers but none of them succeeded to hold these people back. I must thank Michelangelo for being a better half for he assumed a greater responsibility to develop a data acquisition system for this research project. He is a great person with a strong analytical acumen. I thank Ravi for his immense support and good wishes. I also thank Jayant for editing this document and being a strong emotional support all along. I thank Sam for giving insight into many complex problems. I also thank Wesley, Glen, Surangie, Aaron, Mohan and Brandy to render their support in anyway possible. Last but by no means the least, have I thanked Tom, Richard and all the student workers at the EERL for helping me in this project and teaching me lessons of getting the job done. 


\section{Table of Contents}

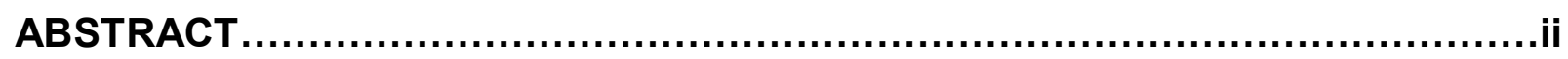

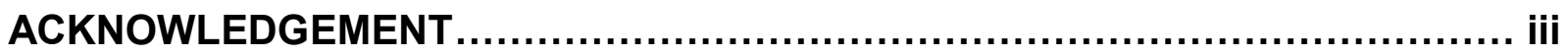

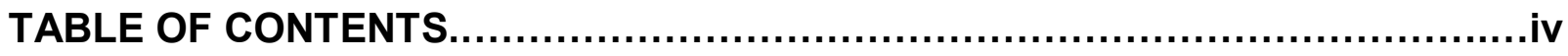

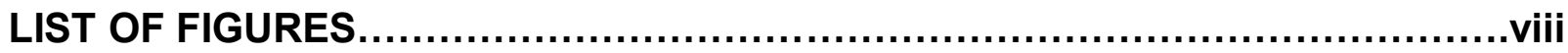

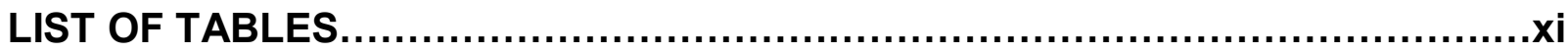

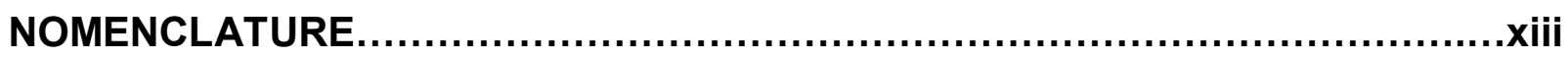

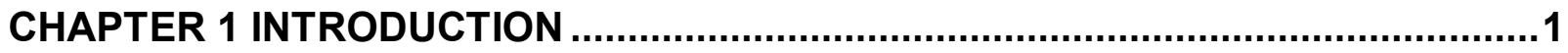

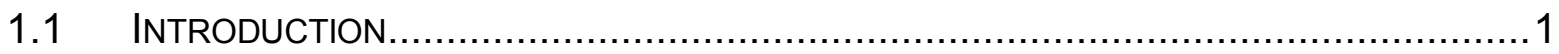

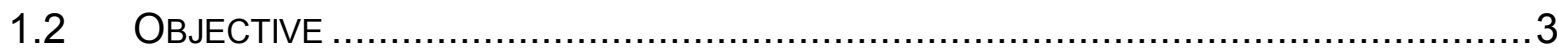

CHAPTER 2 REVIEW OF LITERATURE

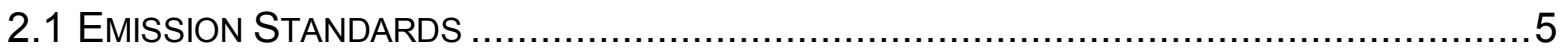

2.2 REQUIREMENTS FOR IN-USE EMISSION MEASUREMENT SYSTEM.............................. 8

2.3 Other PoRTABLE EMISSIONS MEASUREMENT SYSTEMS ...................................10

2.3.1 Simple Portable On-vehicle Testing (SPOT) System, AEI Inc. ...............11

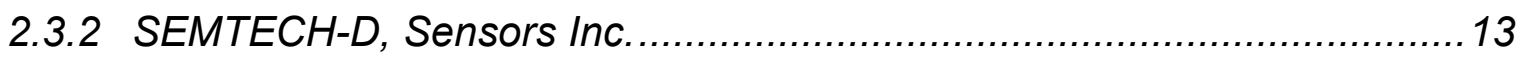

2.3.3 PG 250, Horiba Analytical Instruments Inc...................................... 15

2.3.4 OBS 1000 Series, Horiba Analytical Instruments Inc............................16

2.3.5 Mobile Emissions Measurement System (MEMS), WVU.......................17

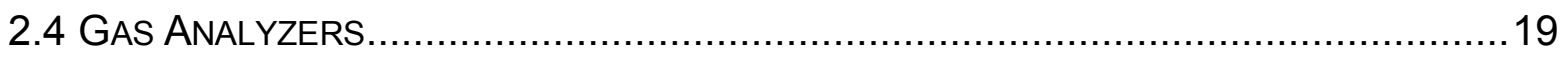

2.4.1 Automotive Micro-Bench (AMBII), Sensors Inc.................................. 19

2.4.2 BE140 AD 5-gas Bench, Horiba Analytical Instruments Inc....................20

2.4.3 MEXA120 NOx Analyzer, Horiba Analytical Instruments Inc...................21

2.4.4 BE220 FS NO Analyzer, Horiba Analytical Instruments Inc....................22

2.4.5 Electrochemical NO sensor, Sensors Inc............................................23

2.5 PRINCIPLES Of GaSEOUS ConCENTRATION DETECTION .....................................2 24

2.5.1 Non Dispersive Infrared Detection .................................................24

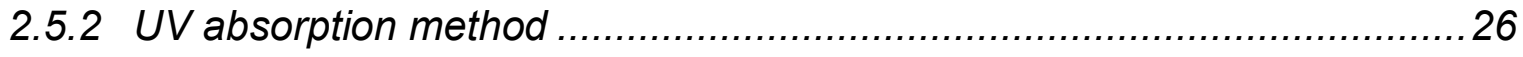


2.5.3 Chemiluminescence Method of Detection...........................................26

2.5.4 Heated Flame Ionization Detection ...............................................2 27

2.5.5 Fourier Transform Infrared Spectroscopy ….................................... 27

2.5.6 Zirconium Oxide $\left(\mathrm{ZrO}_{2}\right) \mathrm{NO}$ and $\mathrm{O}_{2}$ Detection....................................28

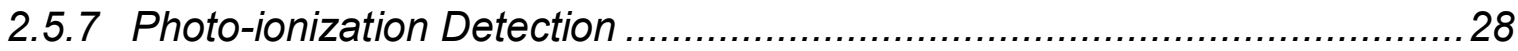

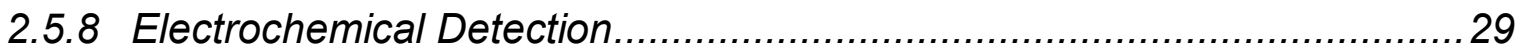

\section{CHAPTER 3 COMPACT MOBILE EMISSION MEASUREMENT SYSTEM (CMEMS)}

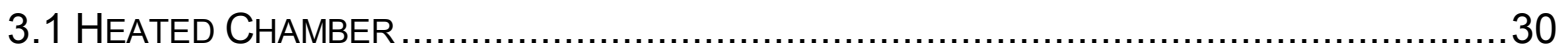

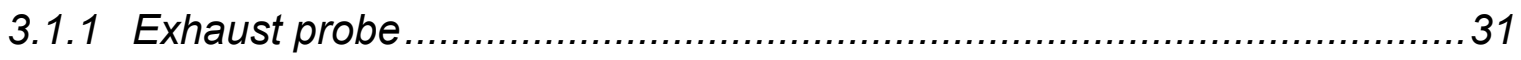

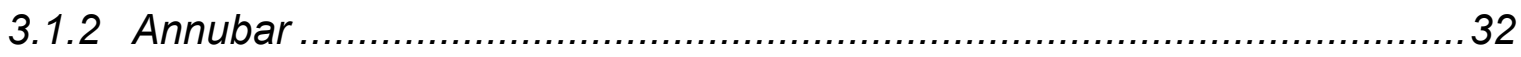

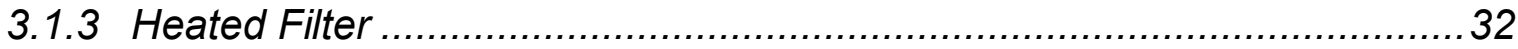

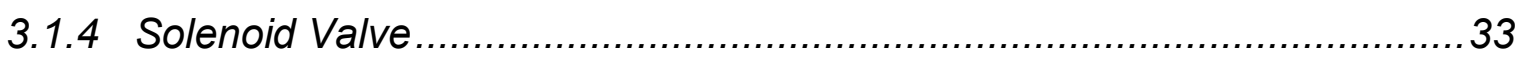

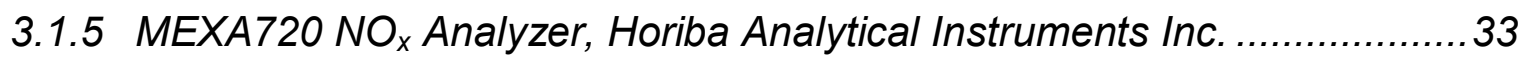

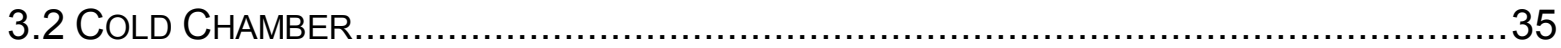

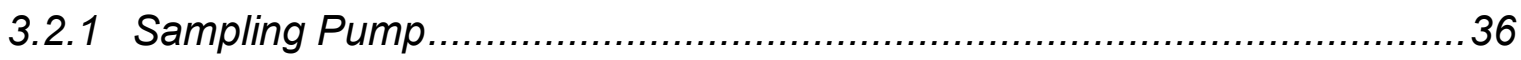

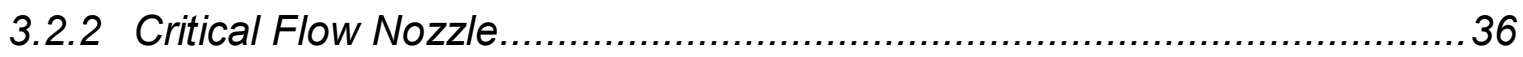

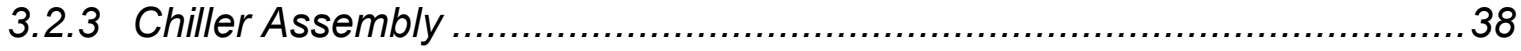

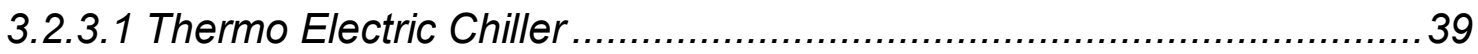

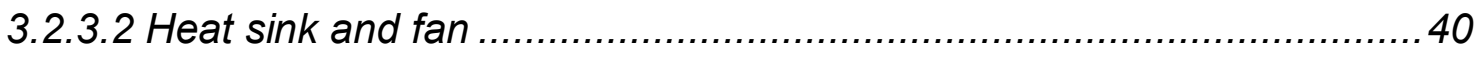

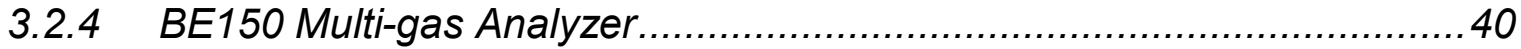

3.2.5 Relative Humidity Sensor, Honeywell Technologies Inc...................... 42

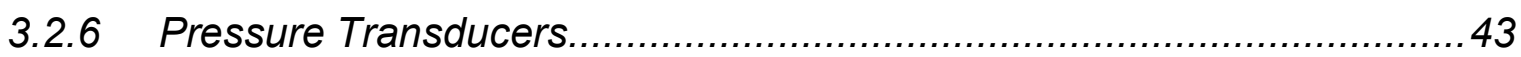

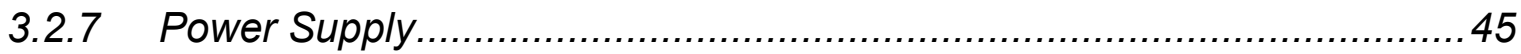

3.2.8 Ambient Temperature, Pressure and RH Measurement ........................45

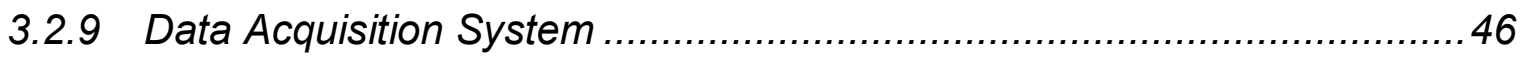

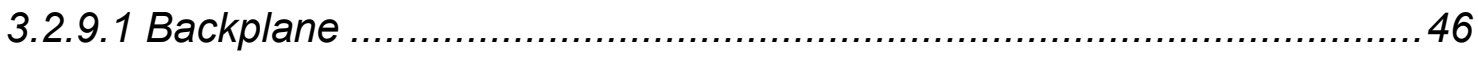

3.2.9.2 Compact Field Point (CFP) processor 2020 .................................. 47

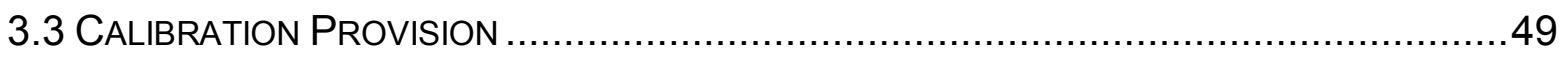

CHAPTER 4 EXPERIMENTAL SETUP AND PROCEDURE ...............................51

4.1 ACCURACY, LINEARITY AND REPEATABILITY TEST .......................................5 


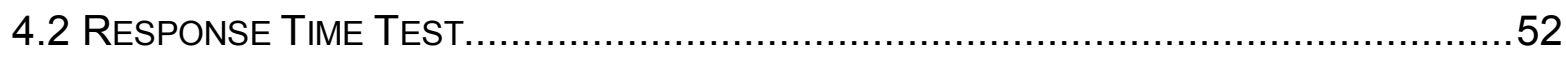

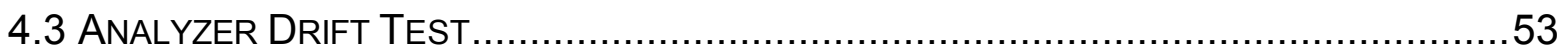

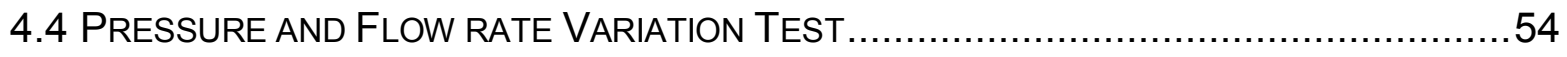

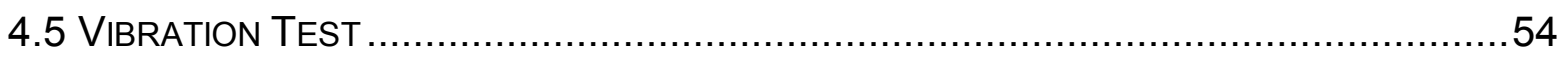

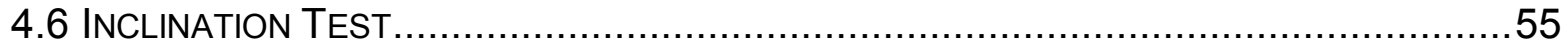

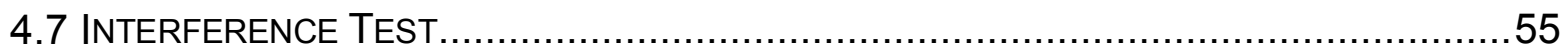

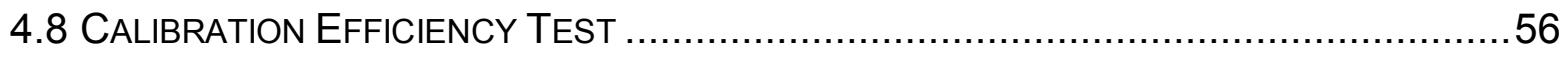

4.9 Test on the Performance of Critical Flow Nozzle (CFN) ….......................57

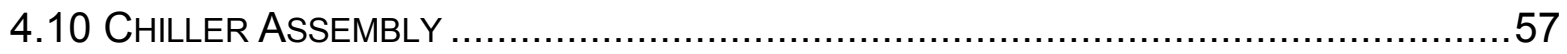

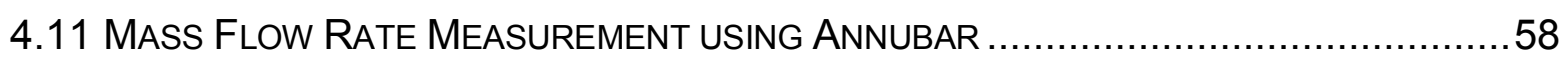

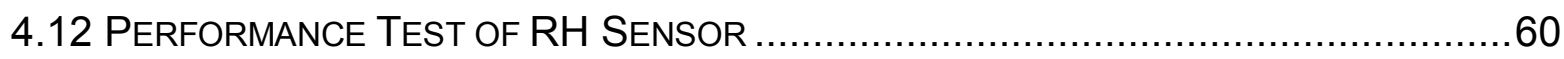

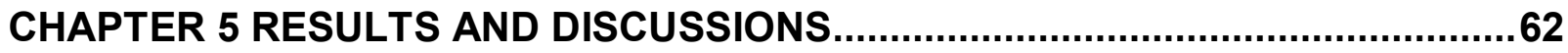

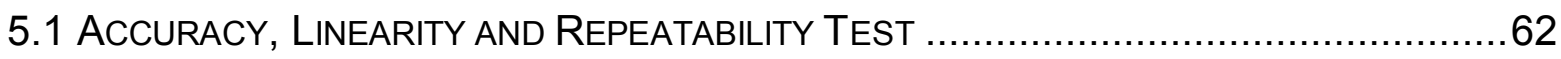

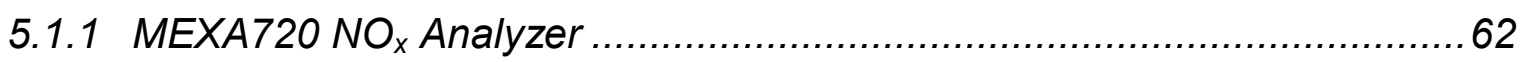

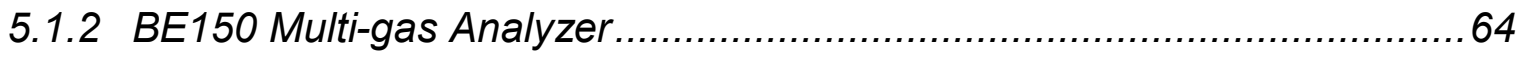

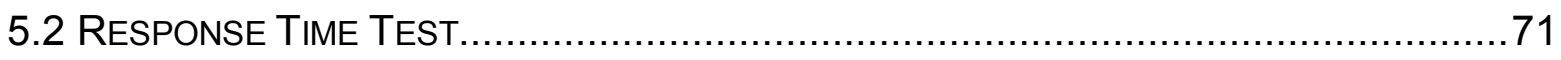

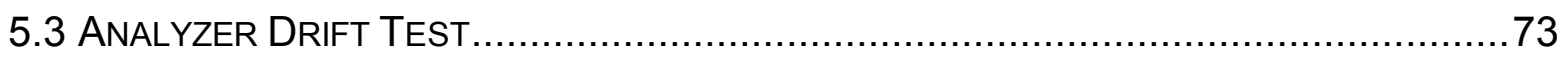

5.4 PRESSURE AND FLOW RATE VARIATION TEST ................................................

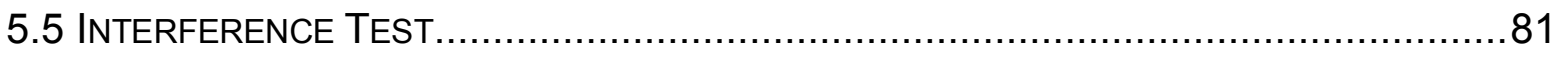

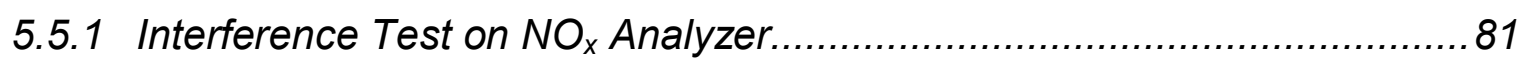

5.5.2 Interference Test on BE150 Multi-gas Analyzer....................................83

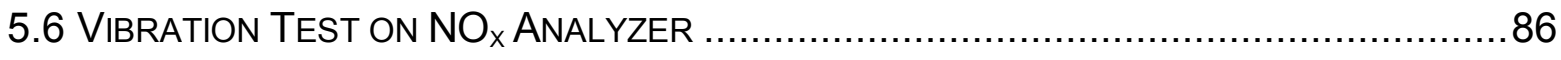

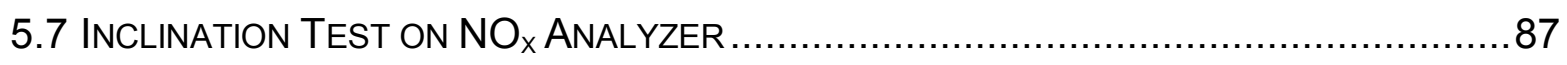

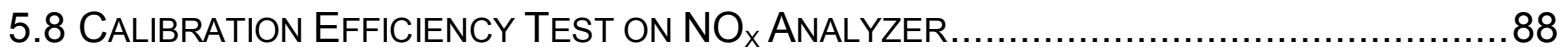

5.9 Test on the Performance of Critical Flow NozZle (CFN) …........................8

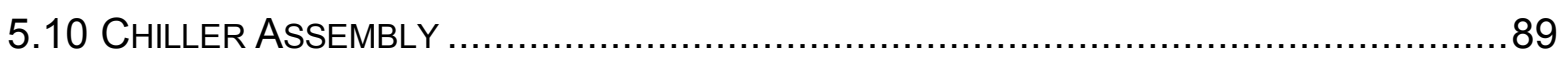

5.11 Volumetric Flow Rate MEASUREMENT USING ANNUBAR .............................. 91

5.12 TEST ON THE PERFORMANCE OF RH SENSOR........................................... 93

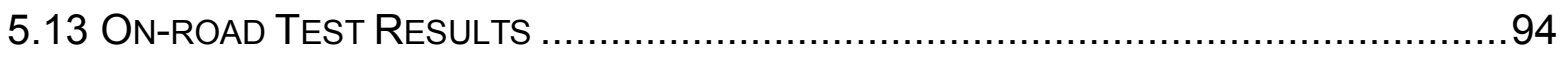

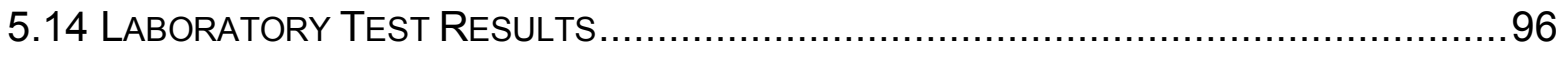

CHAPTER 6 CONCLUSION AND RECOMMENDATIONS....................................113 


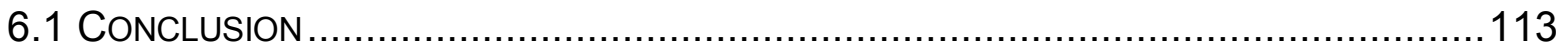

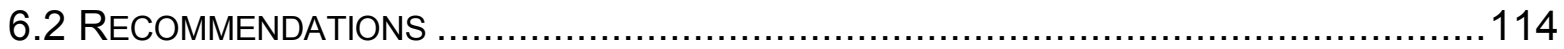

APPENDIX A

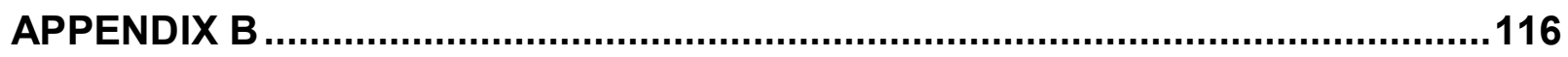

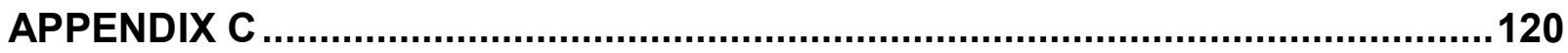

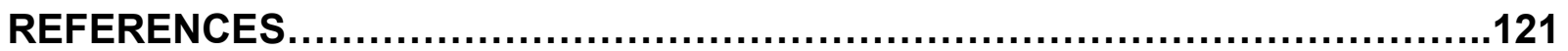




\section{List of Figures}

Figure-1 NTE Zone in the European Stationary Cycle (ESC) 6

Figure-2 Simple Portable On-vehicle Testing (SPOT) system 11

$\begin{array}{lll}\text { Figure-3 Mass flow-rate measurement system of SPOT } & 13\end{array}$

$\begin{array}{lll}\text { Figure-4 Mobile Emissions Measurement System (MEMS) } & 17\end{array}$

Figure-5 Schematic of the working principle of NDIR detection 25

Figure-6 Picture of CMEMS on a Ford 450 truck 30

Figure-7 Sample probe in CMEMS 32

Figure-8 MEXA720 $\mathrm{NO}_{x}$ analyzer 33

Figure-9 Schematic of the cold chamber in CMEMS 35

Figure-10 Design layout of the CFN as per ASME standard 38

Figure-11 Chiller Assembly used in CMEMS 38

$\begin{array}{lll}\text { Figure-12 } & \text { BE150 multi-gas analyzer } & 40\end{array}$

Figure-13 Calibration curve for the RH sensor 43

Figure-14 Schematic of the pressure sensors board 44

Figure-15 Four back plane of CFP 46

Figure-16 Compact Field Point processor $2020 \quad 47$

Figure-17 Compact Field Point Module $\quad 47$

Figure-18 Schematic of the working principle of Horiba SGD-710C 50 gas divider

Figure-19 Schematic of the accuracy, linearity and repeatability 52 test setup

Figure-20 Schematic of the response time test setup 53

Figure-21 Schematic of the test setup with annubar at 10D 59 downstream of the LFE

Figure-22 Schematic of the test setup with annubar at the elbow 60

Figure-23 Schematic of the test setup with annubar at $2 \quad 60$ downstream of the elbow

Figure-24 Schematic of the test setup for performance of the RH sensor 61

Figure-25 Accuracy and linearity on MEXA720 NO 
Figure-26 Accuracy and Linearity (0-100\%) for $\mathrm{CO}_{2} \quad 65$

Figure-27 Accuracy and Linearity (100\%-0) for $\mathrm{CO}_{2} \quad 66$

Figure-28 Accuracy and Linearity (0-100\%) for CO 67

Figure-29 Accuracy and Linearity (100\%-0) for CO 68

Figure-30 Accuracy and Linearity (0-100\%) for HC 69

Figure-31 Accuracy and Linearity (100\%-0) for HC 70

Figure-32 Response time test result on MEXA720 NO analyzer 71

Figure-33 Response time test result for $\mathrm{CO} \quad 72$

Figure-34 Response time test result for $\mathrm{CO}_{2} \quad 72$

Figure-35 Response time test result for $\mathrm{HC} \quad 73$

$\begin{array}{lll}\text { Figure-36 Analyzer drift for NO (0-2000 PPM) } & 74\end{array}$

Figure-37 Analyzer drift for $\mathrm{CO}_{2} \quad 75$

$\begin{array}{lll}\text { Figure-38 Analyzer drift for } \mathrm{CO} & 76\end{array}$

$\begin{array}{lll}\text { Figure-39 Analyzer drift for } \mathrm{HC} & 76\end{array}$

Figure-40 $\quad \mathrm{NO}_{\mathrm{x}}$ comparison for run 1 on a Ford 450 pick-up truck 94

Figure-41 $\mathrm{CO}_{2}$ comparison for run 1 on a Ford 450 pick-up truck 95

Figure-42 $\mathrm{NO}_{\mathrm{x}}$ comparison for run 2 on a Ford 450 pick-up truck 95

Figure-43 $\mathrm{CO}_{2}$ comparison for run 2 on a Ford 450 pick-up truck 96

Figure-44 Data summary of total $\mathrm{NO}_{x}(\mathrm{~g} / \mathrm{s})$ for four on-road cycle 99 runs on a 1992 DDC series 60 engine reported with $95 \%$ confidence

Figure-45 Data summary of total $\mathrm{CO}_{2}(\mathrm{~g} / \mathrm{s})$ for four on-road cycle runs 100 Ron a 1992 DDC series 60 engine reported with 95\% confidence

Figure-46 Data summary of the total $\mathrm{NO}_{\mathrm{x}}(\mathrm{g} / \mathrm{s})$ for seven FTP runs on a 1992 DDC series 60 engine reported with $95 \%$ confidence

Figure-47 Data summary of the total $\mathrm{CO}_{2}(\mathrm{~g} / \mathrm{s})$ for seven FTP runs on a 1992101 DDC series 60 engine reported with $95 \%$ confidence

Figure-48 $\mathrm{NO}_{\mathrm{x}}$ comparison for standard FTP run 1 on a DDC series 60 engine 101

Figure-49 $\mathrm{CO}_{2}$ comparison for standard FTP run 1 on a DDC series 60 engine 102

Figure-50 $\mathrm{NO}_{x}$ comparison for standard FTP run 2 on a DDC series 60 engine 102

Figure-51 $\mathrm{CO}_{2}$ comparison for standard FTP run 2 on a DDC series 60 engine 103 
Figure-52 $\mathrm{NO}_{\mathrm{x}}$ comparison for standard FTP run 3 on a DDC series 60 engine

Figure-53 $\mathrm{CO}_{2}$ comparison for standard FTP run 3 on a DDC series 60 engine 104

Figure-54 $\mathrm{NO}_{x}$ comparison for standard FTP run 4 on a DDC series 60 engine 104

Figure-55 $\mathrm{CO}_{2}$ comparison for standard FTP run 4 on a DDC series 60 engine 105

Figure-56 $\mathrm{NO}_{\mathrm{x}}$ comparison for standard FTP run 5 on a DDC series 60 engine 105

Figure-57 $\mathrm{CO}_{2}$ comparison for standard FTP run 5 on a DDC series 60 engine 106

Figure-58 $\mathrm{NO}_{\mathrm{x}}$ comparison for standard FTP run 6 on a DDC series 60 engine 106

Figure-59 $\mathrm{CO}_{2}$ comparison for standard FTP run 6 on a DDC series 60 engine 107

Figure-60 $\quad \mathrm{NO}_{\mathrm{x}}$ comparison for standard FTP run 7 on a DDC series 60 engine 107

Figure-61 $\mathrm{CO}_{2}$ comparison for standard FTP run 7 on a DDC series 60 engine 108

Figure-62 $\mathrm{NO}_{\mathrm{x}}$ comparison for on-road cycle run 1 on a DDC series 60 engine 108

Figure-63 $\mathrm{CO}_{2}$ comparison for on-road cycle run 1 on a DDC series 60 engine 109

Figure-64 $\mathrm{NO}_{\mathrm{x}}$ comparison for on-road cycle run 2 on a DDC series 60 engine 109

Figure-65 $\mathrm{CO}_{2}$ comparison for on-road cycle run 2 on a DDC series 60 engine 110

Figure-66 $\mathrm{NO}_{\mathrm{x}}$ comparison for on-road cycle run 3 on a DDC series 60 engine 110

Figure-67 $\mathrm{CO}_{2}$ comparison for on-road cycle run 3 on a DDC series 60 engine 111

Figure-68 $\mathrm{NO}_{x}$ comparison for on-road cycle run 4 on a DDC series 60 engine 111

Figure-69 $\mathrm{CO}_{2}$ comparison for on-road cycle run 4 on a DDC series 60 engine 112

Figure-70 Performance curve for Thomas diaphragm pump 118

Figure-71 Performance curve for Gast Mfg. diaphragm pump 119

Figure-72 Performance curve for Air Dimensions mini diaphragm pump 


\section{List of Tables}

Table-1 EPA emissions standards for heavy duty diesel trucks and urban bus engines

$\begin{array}{lll}\text { Table-2 Specification of SEMTECH-D multi-gas analyzer } & 14\end{array}$

$\begin{array}{lll}\text { Table-3 Specification of PG250 multi-gas analyzer } & 16\end{array}$

$\begin{array}{lll}\text { Table-4 Specification of AMBII } & 20\end{array}$

Table-5 Specification of BE140AD multi-gas analyzer 21

Table-6 Specification of MEXA120 NO analyzer 22

Table-7 Specification of BE220FS NO analyzer 23

Table-8 Specification of MEXA720 NO analyzer 34

Table-9 Specification of BE150 multi-gas analyzer 41

Table-10 Specification of RH sensor 42

Table-11 Specification of pressure transducers 45

Table-12 Accuracy, linearity and repeatability test results for NO 63

Table-13 Accuracy and linearity test result for $\mathrm{CO}_{2}$

Table-14 Repeatability test result for $\mathrm{CO}_{2} \quad 66$

$\begin{array}{lll}\text { Table-15 Accuracy and linearity test result for } \mathrm{CO} & 67\end{array}$

$\begin{array}{lll}\text { Table-16 Repeatability test result for } \mathrm{CO} & 68\end{array}$

Table-17 Accuracy and linearity test result for HC 69

$\begin{array}{lll}\text { Table-18 Repeatability test result for HC } & 70\end{array}$

$\begin{array}{lll}\text { Table-19 Analyzer drift test result for MEXA720 NO} & 74\end{array}$

Table-20 Analyzer drift test result for BE150 multi-gas analyzer 75

$\begin{array}{lll}\text { Table-21 Pressure variation test result for high NO concentration } & 77\end{array}$

Table-22 Pressure variation test result for low NO concentration 78

$\begin{array}{lll}\text { Table-23 Flow variation test result for high NO concentration } & 79\end{array}$

$\begin{array}{lll}\text { Table-24 Flow variation test result for low NO concentration } & 79\end{array}$

Table-25 Pressure variation test result for $\mathrm{CO}_{2} \quad 80$

$\begin{array}{lll}\text { Table-26 Flow variation test result for } \mathrm{CO}_{2} & 80\end{array}$

Table-27 Interference test result for NO 81

Table-28 Ammonia interference test result for NO 81 
Table-29 Ammonia interference test result on different

Concentrations of Ammonia

Table-30 Interference test result for $\mathrm{CO}_{2}$

Table-31 Interference test result for $\mathrm{CO} \quad 84$

Table-32 Interference test result for $\mathrm{HC} \quad 84$

Table-33 Water interference test result for $\mathrm{CO}_{2}$

Table-34 Amplitude test result on MEXA720 NO

Table-35 Frequency test result on MEXA720 NO

Table-36 Inclination test result on MEXA720 NO analyzer 87

Table-37 Calibration efficiency test result on NO 88

Table-38 Performance test result for CFN 89

$\begin{array}{lll}\text { Table-39 Performance test result for chiller assembly } & 90\end{array}$

Table-40 Results for volumetric flow-rate measurement in case 1

Table-41 Results for volumetric flow-rate measurement in case $2 \quad 92$

Table-42 Results for volumetric flow-rate measurement in case $3 \quad 92$

Table-43 Results for RH measurement upstream and downstream 93 of the chiller assembly

Table-44 Data summary for $\mathrm{NO}_{\mathrm{x}}(\mathrm{g} / \mathrm{s})$ for seven FTP runs on a DDC series $60 \quad 97$ engine

Table-45 Data summary for $\mathrm{CO}_{2}(\mathrm{~g} / \mathrm{s})$ for seven FTP runs on a DDC series $60 \quad 98$ engine

Table-46 Data summary for $\mathrm{NO}_{\mathrm{x}}(\mathrm{g} / \mathrm{s})$ for four on-road cycle runs on a DDC series 60 engine

Table-47 Data summary for $\mathrm{CO}_{2}(\mathrm{~g} / \mathrm{s})$ for four on-road cycle runs on a DDC series 99 60 engine

Table-48 Specification of laboratory analyzers

Table-49 Specification of BE140AD 5-gas bench

Table-50 Specification of MEXA120 $\mathrm{NO}_{x}$ analyzer

Table-51 Specification of MEXA720 $\mathrm{NO}_{x}$ analyzer

Table-52 Specification of BE150 multi-gas analyzer

Table-53 Annubar flow-rate and $\mathrm{NO}_{x}$ and $\mathrm{CO}_{2}$ in $\mathrm{g} / \mathrm{s}$ sample calculations 


\section{Nomenclature}

\begin{tabular}{ll} 
AC & Alternating Current \\
ASME & American Society of Mechanical Engineers \\
CARB & California Air Resources Board \\
CO & Carbon Monoxide \\
CO $_{2}$ & Carbon Dioxide \\
CFP & Compact Field Point \\
CFR & Code of Federal Regulations \\
CMEMS & Compact Mobile Emissions Measurement System \\
DC & Direct Current \\
DDC & Detroit Diesel Corporation \\
ECU & Engine/Electronic Control Unit \\
EERL & Engine and Emissions Research Laboratory \\
EPA & Environmental Protection Agency \\
ESC & European Stationary Cycle \\
FTP & Federal Test Procedure \\
FTIR & Fourier Transform Infra Red \\
GPS & Global Positioning System \\
HC & Hydrocarbon \\
LHDDE & Light Heavy-duty Diesel Engine \\
MHDDE & Medium Heavy-duty Diesel Engine \\
HHDDE & Heavy Heavy-duty Diesel Engine \\
LFE & Laminar Flow Element \\
LPM & Liters per Minute \\
MEMS & Mobile Emission Measurement System \\
NDIR & Non-Dispersive Infra Red Radiation \\
NO & Nitrogen Dioxide \\
NO & Oxides of Nitrogen \\
PM & Particulate Matter \\
PPM & Parts Per Million \\
RH & Relative Humidity \\
SCFM & Standard Cubic Feet per Minute \\
S-HDDE & Settling-Heavy Duty Diesel Engine \\
SPOT & Simple Portable On-vehicle Testing System \\
TEC & Thermo Electric Chiller \\
THC & Total Hydrocarbons \\
WVU & West Virginia University \\
ZrO & Zirconium Oxide \\
& \\
\hline
\end{tabular}




\section{Chapter 1 Introduction}

\subsection{Introduction}

Today, automotive tail pipe emissions have become the primary source of urban pollution. While the average vehicle emits only small amounts of pollutants, this amount multiplied by more than 150 million vehicles in the United States adds up rapidly. Environmental Protection Agency (EPA) [1] has established primary and secondary standards called the National Ambient Air Quality Standards (NAAQS) to prevent air pollutants from reaching levels that can cause harm. The Clean Air Act [2] requires that specific methods be used for monitoring the criteria pollutants in the air and all states use the same methods.

Engine manufacturers are continually producing more sophisticated emission control components and systems to meet more stringent tailpipe emission standards. Fuel, ignition and exhaust systems have all been modified to aid in this effort. Utilizing electronic fuel injection through computerized engine control systems, today's vehicles produce lower levels of emissions, get better fuel economy and deliver better performance and power than those produced a few years ago. However, heavy duty diesel engines still generate considerable amount of oxides of nitrogen $\left(\mathrm{NO}_{\mathrm{x}}\right)$ and particulate matter (PM) emissions. To meet the emission level standards, engines are tested in a controlled laboratory environment and certified on an engine dynamometer in accordance with CFR Title 40, Part 1065 subpart F [3], and emissions are expressed on a work-specific basis, that is in $\mathrm{g} / \mathrm{bhp}-\mathrm{hr}$. 
In general, test procedures are classified according to the mounting conditions of the test engine and/or the vehicle. The chassis dynamometer method requires that the test vehicle be driven over a specified versus time test schedule. The engine dynamometer method calls for operating the test engine through a specified load and engine speed cycle. The chassis dynamometer method is mainly used for light-duty and medium-duty vehicles such as passenger cars, small-sized trucks whereas the engine dynamometer method is used for heavyduty and heavy heavy-duty vehicles. However, both engine dynamometer testing and chassis dynamometer testing do not give the most accurate picture of real world emissions behavior. Moreover, these tests are expensive and the set-up is considerably long and labor intensive. Thus, there was a realization for a need of an "in-use" emissions measurement system that is light weight and portable to save manpower effort and time. Several systems have been developed in the past by various research organizations to measure engine emissions during in-field operations.

One of them is the In-use Mobile Emissions Measurement System (MEMS) [4] developed at the Engines and Emissions Research Laboratory (EERL) of WVU. This came under the Consent Decrees [5] that were entered into by six Settling Heavy Duty Diesel Engine (S-HDDE) manufacturers (Caterpillar Inc., Cummins Engine Company Inc., Detroit Diesel Corporation, Volvo Truck Corporation, Mack Truck Inc., International Truck and Engine Corporation). The development of MEMS included the measurement of emissions on brake specific ( $\mathrm{g} / \mathrm{bhp}-\mathrm{hr})$ basis towards the requirement of Consent Decrees. This was done by inferring torque 
(ft-lb) from the measured percent load, and engine speed from the engine Electronic Control Unit (ECU) broadcast. In addition, pollutant concentrations, exhaust flow rate and ambient conditions were also measured. The exhaust emissions concentration was measured by MEMS after incorporating a sampling system with miniature gas analyzers. Two gases that were measured by MEMS were $\mathrm{NO}_{\mathrm{x}}$ and $\mathrm{CO}_{2}$. A Zirconium Oxide $\left(\mathrm{ZrO}_{2}\right)$ [6] and an electrochemical sensor were used to record $\mathrm{NO}_{\mathrm{x}}$ and a Non Dispersive Infra Red (NDIR) [8] based detector was used to record carbon dioxide $\left(\mathrm{CO}_{2}\right.$ hereafter $)$ from the tail pipe of heavy duty diesel vehicles. The sampling system also contained a heated filter to remove PM from the raw exhaust, a mini diaphragm vacuum pump to pull the sample at 3 LPM flow rate and a thermoelectric chiller to lower the temperature below the dew point of the exhaust sample. The entire MEMS unit consisted of sampling system, data acquisition system and flow rate measurement system. A global positioning system was also incorporated into MEMS to confirm the vehicle speed and distance measurements.

\subsection{Objective}

The primary objective of this study was to develop a compact emissions measurement system that can record real-time $\mathrm{NO}_{\mathrm{x}}$ and $\mathrm{CO}_{2}$ emissions from heavy-duty diesel vehicles in agreement with the current EPA "in-use" emissions regulations $[7,8]$. The system was aimed at significant reduction in size and weight with respect to the existing MEMS by incorporating both the sampling and data acquisition systems in one unit. This would allow the entire unit to be mounted on 
the exhaust stack by a single operator; hence, saving effort and time. System qualification comprised of testing each analyzer individually on accuracy, linearity and repeatability tests. Additionally, interference checks (for water and different gases), drift check and response time tests with gas bottles of known concentrations were also conducted. Vibration, inclination, pressure and flow variation tests were also included in the experiments to qualify the system for harsh on-road, on-board conditions. Finally, the complete system was tested on a vehicle and in an engine laboratory to compare the measurements with the existing MEMS unit and laboratory grade analyzers. 


\section{Chapter 2 Review of Literature}

\subsection{Emission Standards}

The Consent Decrees [6] were entered into by six heavy duty diesel engine manufacturers (Caterpillar Inc, Cummins Engine Company, Inc., Detroit Diesel Corporation, Volvo Truck Corp., Mack Trucks Inc., and International Truck and Engine Corporation) with United States Environment Protection Agency (EPA). The Consent Decrees came into existence because many heavy-duty diesel engines since early 1990 produced higher than normal $\mathrm{NO}_{x}$ emissions under certain operating conditions. Engine manufacturers incorporated the ECU to electronically control the injection timing to increase the fuel economy which caused an undesirable increase in $\mathrm{NO}_{x}$ emissions. This practice led to a court decision in which six engine manufacturers were required to provide funding aimed at reducing emissions from heavy-duty diesel engines produced in the future. A new steady-state test, termed the supplemental steady-state test identical to the European Stationary Cycle (ESC) [9], was implemented in addition to the FTP test for certification. Engine manufacturers were also required to fund the independent research on portable emissions measurement devices which resulted in the development of the MEMS at WVU. Since the EPA has been working towards a cleaner environment by developing and enforcing regulations that implement environmental laws, it is responsible for researching and setting national standards [2] for a variety of environmental programs, and delegates the responsibility for issuing permits and for monitoring and enforcing compliance. The US EPA has defined the Not-to-Exceed (NTE) zones [9] of operation for certification in the 
Consent Decrees. It is bounded by engine speeds $15 \%$ above the European Stationary Cycle speeds, engine loads greater than $30 \%$ of maximum, and engine power greater than $30 \%$ of maximum. The ESC speed is calculated using:

N 15\% ESC speed $=N_{\text {low }}+0.15\left(N_{\text {high }}-N_{\text {low }}\right)$

$\mathrm{N}_{\text {low }}$ is the speed below the rated speed that corresponds to $50 \%$ of the maximum power and $\mathrm{N}_{\text {high }}$ is above the rated speed that corresponds to $70 \%$ of the maximum power.

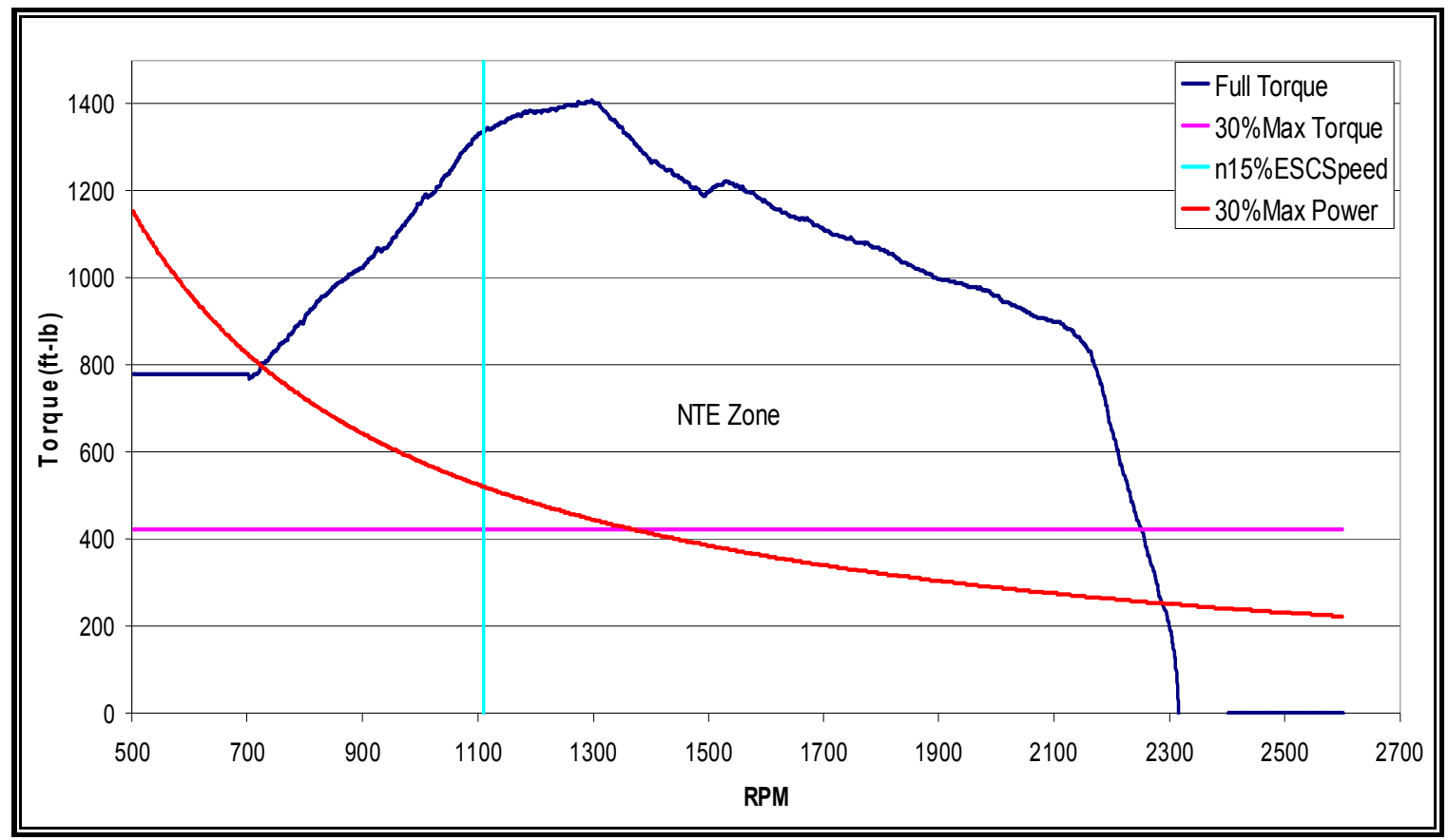

Figure1- NTE zone in European Stationary Cycle (ESC) [10]

Model year 1988-2003 US Federal (EPA) and 1987-2003 California (ARB) emission standards [9] for heavy-duty diesel truck from CFR Title 40, Part 86 , sub-part $\mathrm{N}$ are summarized in the following table: 
Table1- EPA emission standards for heavy duty diesel trucks and urban bus engines $[8,10]$

\begin{tabular}{||c|c|c|c|c||}
\hline Year & HC & CO & NO $_{\mathbf{x}}$ & PM \\
\hline 1988 & 1.3 & 15.5 & 10.7 & 0.60 \\
\hline 1990 & 1.3 & 15.5 & 6.0 & 0.60 \\
\hline 1991 & 1.3 & 15.5 & 5.0 & 0.25 \\
\hline 1994 & 1.3 & 15.5 & 5.0 & 0.10 \\
\hline 1998 & 1.3 & 15.5 & 4.0 & 0.10 \\
\hline \hline
\end{tabular}

The useful life of the engine in compliance with the emission standards adopted by USEPA is as follows [8]:

- LHDDE - 8 years/110,000 miles (whichever occurs first)

- MHDDE - 8 years/185,000 miles

- HHDDE - 8 years/290,000 miles

For the year 2004, EPA adopted new emission standards. The goal was to reduce the $\mathrm{NO}_{x}$ emissions from the heavy-duty engines to approximately 2.0 g/bhp-hr [8]. EPA also revised the useful life of the heavy-duty engine that was as follows:

- LHDDE - 10 years/110,000 miles 
- MHDDE - 10 years/185,000 miles

- HHDDE - 10 years/435,000 miles

The following are the emissions standards that were introduced for the model year 2007 [8]:

- PM - $0.01 \mathrm{~g} / \mathrm{bhp}-\mathrm{hr}$

- $\mathrm{NO}_{\mathrm{x}}-1.20 \mathrm{~g} / \mathrm{bhp}-\mathrm{hr}$

- NMHC - $0.14 \mathrm{~g} / \mathrm{bhp}-\mathrm{hr}$

\subsection{Requirements for In-use Emission Measurement System}

An "in-use" emissions measurement system can measure and produce a faithful picture of a vehicle's emission characteristics [11]. In-use emission tests avoid the expensive and time consuming process involved in setting up the engine on an engine dynamometer and employing test cycles and weighting factors that may not represent a true engine behavior. A well designed in-use system gives accurate measurements of gaseous concentrations, exhaust mass flow and engine power output to express in terms of brake specific emissions. It is understood that, the concentration measurements are most accurate using laboratory grade analyzers; however, the need for a portable emissions measurement system is justified by a demand for real-time on-road performance analysis of a vehicle. To date, WVU's MEMS, Sensor's SEMTECH-D, Horiba's OBS 1000 series, and AEl's SPOT system are some of the portable emissions measurement systems that have undergone extensive independent evaluations. 
The portable emission measurement system for in-use application should possess following features:

1. Compact in size and can be easily mounted in the test site by a single operator.

2. High accuracy levels during harsh on-board operations.

3. The system should record real-time emissions, exhaust mass flow rate and extract the ECU information to convert the measurements into brake specific emissions.

4. The system should have a data acquisition system to acquire emissions data and time-align with the engine power output to account for the delays due to the response time of the analyzer.

5. The system should have a short sample path length to reduce the deskew time, residence time and sample dispersion in the sample line.

5. The system should exhibit low drift during transient cycles against the laboratory grade analyzers.

6. Analyzers in the system should not be position and vibration sensitive.

7. The system should report the emissions data on a standard basis incorporating the ambient conditions (pressure, temperature and $\mathrm{RH}$ ) towards the requirement of the Consent Decrees. 


\subsection{Other Portable Emissions Measurement Systems}

Past developers of the portable emissions measurement system include Southwest Research Institute, Michigan Technological University, University of Minnesota, Caterpillar Inc., Ford Motor Company, General Motors Inc., University of Pittsburgh, U.S Coast Guard, Flemish Institute of Technology, U.S EPA, Horiba LTD, Analytical Engineering Inc. and WVU. Literature review was done on available systems like Simple Portable On-vehicle Testing (SPOT) System developed by Analytical Engineering Inc., SEMTECH-D developed by Sensors Inc., PG 250 and OBS 1000 series developed by Horiba Analytical Instruments Inc., and existing MEMS developed by WVU at the Engines and Emissions Research Laboratory (EERL hereafter). The SPOT system and SEMTECH-D were completely evaluated at the EERL on different laboratory and on-road test cycles after installing both systems on Mack and Caterpillar Trucks. Both systems were also evaluated on bench tests to confirm the accuracy, linearity, repeatability, interference and drift in compliance with the current regulations. 


\subsubsection{Simple Portable On-vehicle Testing (SPOT) System, AEI Inc.}

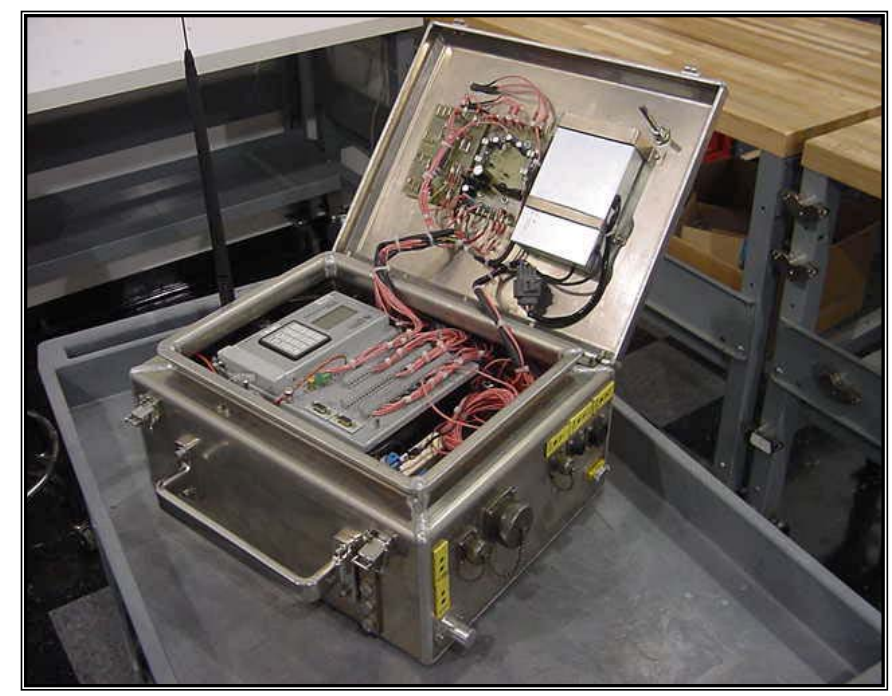

Figure-2 Simple Portable On-Vehicle Testing (SPOT) System [12]

The SPOT system [12] was designed in cooperation with the USEPA to collect on-vehicle real-time emissions data for use in developing accurate models that are necessary to define the environmental impact. This information would be useful in determining the future emissions regulations. This unit was designed to be capable of unattended, long duration testing in the hostile environmental conditions. These parameters were established to assist in reducing the cost of the data collection, allowing a much larger database to be gathered. The system was comprised of two primary components. The box, pictured above, housed a data logger, a cellular modem, GPS, and sensors to record ambient conditions. The box was built from $3 / 8^{\text {th }}$ inch aluminum sheet and had 16 rare earth magnets in the base for vehicular attachment. The datalogger utilized a $512 \mathrm{MB}$ flash card capable of storing 120 hours of $1 \mathrm{~Hz}$ data. These units were used, in the recent past, for collecting 100 five-day on-road 
vehicle tests for the EPA that helped in determining new regulations for 2006. The second component was the mass flow detector, pictured below. Very early in the SPOT developmental stage, several devices that were commercially available for measuring mass flow rate were tested. They were found to be inadequate for testing, other than very short-term duration, due to clogging of the small orifices. Accurate flow measurement was critical to determining emissions on $\mathrm{g} / \mathrm{s}$ basis, so AEI developed its own proprietary flow device. This device used the exhaust flow to create a low-pressure area behind the nosecone to induct the outside air. By measuring the flow of "clean" outside air inducted, it enabled the use of a hot wire anemometer and thus avoided the fouling problem that provided a very accurate determination of exhaust flow rate. The system used a low power $12 \mathrm{~V}$ DC supply that saved great amount of installation time for a generator set. The installation time for the entire system was 15 minutes and could be done by a single operator. The system also had a CR 5000 Campbell Scientific Data Logger to provide real-time data logging capabilities and data storing capacity of up to 1 million data points with the frequency of sampling as $1 \mathrm{~Hz}$. The software used to log the data was PC 9000. The software also had the capability to create its own programs, collect and display data in tabular forms, $\mathrm{X}-\mathrm{Y}$ plotters and histograms. The data logger was connected to a PC via serial interface and also had the option for Ethernet and a small modem. The Spot system was tested on several on-road tests on a Mack heavy-duty diesel truck to evaluate the robustness and accuracy of the SPOT system. 


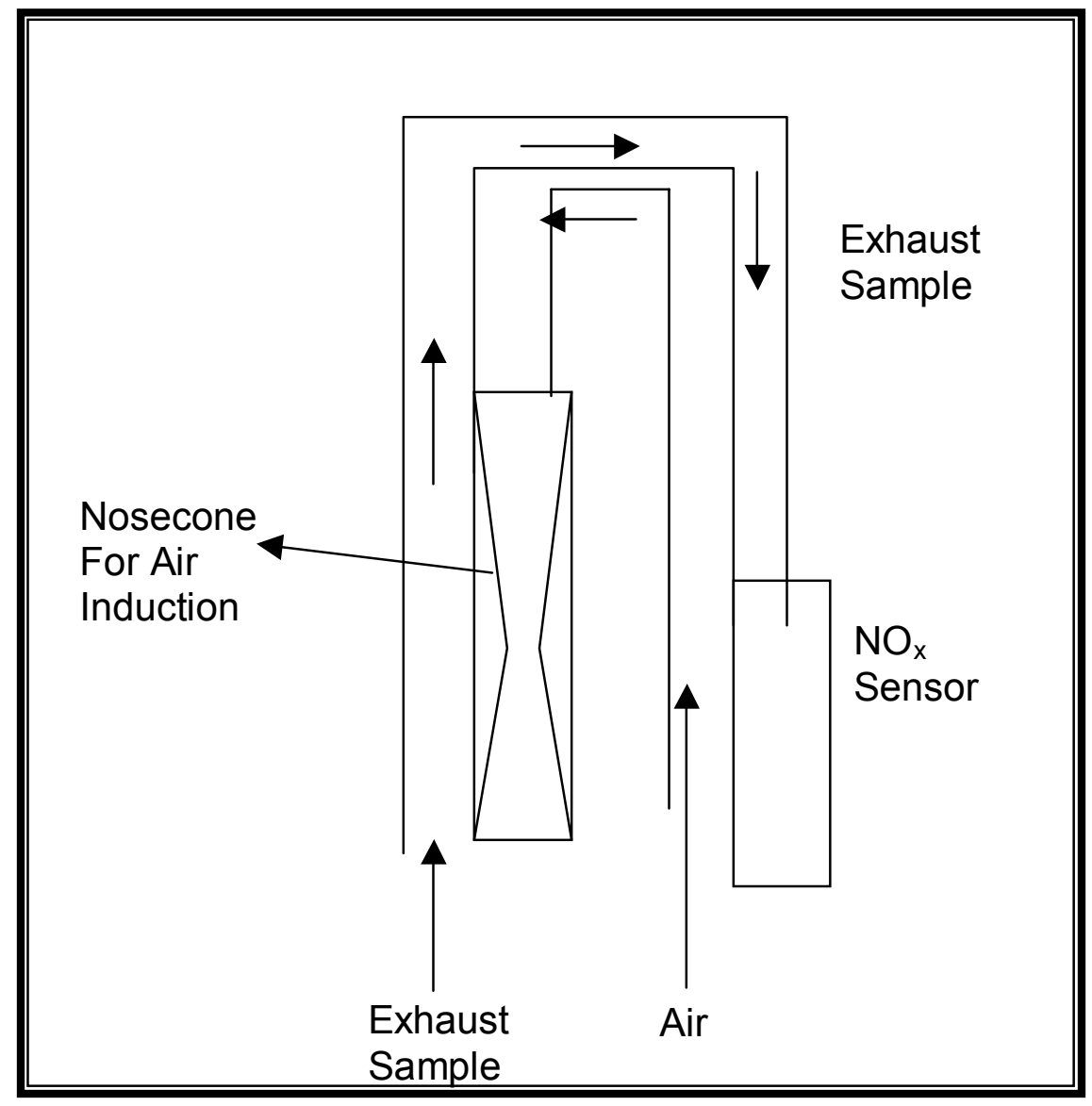

Figure-3 Mass flow rate measurement system of SPOT

\subsubsection{SEMTECH-D, Sensors Inc.}

SEMTECH-D was developed by Sensors Inc. to report real-time onboard diesel emissions. The system employs a Non Dispersive Ultra Violet (NDUV) for $\mathrm{NO}$ and $\mathrm{NO}_{2}$, Flame Ionization Detection (FID) for total hydrocarbon (THC hereafter) and Non Dispersive Infra Red (NDIR) detection technique [13] for the measurement of $\mathrm{CO}$ and $\mathrm{CO}_{2}$. The working principles are explained later in the section on "principle of gaseous concentration detection" (section 2.7). The system employs a sampling system with a heated filter and a moisture removal sub-system. The exhaust is directed in the sampling system using a heated line maintained at $250 \mathrm{~F}$ to prevent the condensation. The 
emission measurements are correlated with the engine and vehicle information from the ECU to help determining in-use emissions in $\mathrm{g} / \mathrm{km}$ or $\mathrm{g} / \mathrm{bhp}$-hr. The system also incorporates a GPS module to provide location and gradient as part of the data file for post processing and analysis. Several bench tests including accuracy, linearity, repeatability, interference and drift were conducted on the system at the EERL. The system was found to be very accurate and linear against the known gas bottle concentrations. The system also exhibited less than $2 \%$ drift on 8 hours of continuous operation after a single attempt of calibration. However, on few occasions the system recorded as high as $6 \%$ drift on the zero concentration.

\section{Specification:}

Table-2 Specifications of SEMTECH-D multi-gas analyzer

\begin{tabular}{|c|c|c|c|c|c|}
\hline $\begin{array}{c}\text { Gases } \\
\text { Measured }\end{array}$ & Principle & Ranges & $\begin{array}{c}\text { Response } \\
\text { Time T90 }\end{array}$ & Accuracy & Resolution \\
\hline NO & NDUV & $\begin{array}{c}0-2500 \\
\text { PPM }\end{array}$ & $<2 \mathrm{sec}$ & \pm 15 PPM & 1 PPM \\
\hline $\mathrm{NO}_{2}$ & NDUV & $\begin{array}{c}0-500 \\
\text { PPM }\end{array}$ & $<2 \mathrm{sec}$ & \pm 10 PPM & 1 PPM \\
\hline $\mathrm{THC}$ & FID & $\begin{array}{c}0-100, \\
1000,10000 \\
\text { PPM }\end{array}$ & $<1 \mathrm{sec}$ & $\begin{array}{l} \pm 2, \\
5,10 \\
\text { PPM }\end{array}$ & $\begin{array}{l}0.1,1 \\
\text { PPM }\end{array}$ \\
\hline $\mathrm{CO}$ & NDIR & $\begin{array}{c}0- \\
2000 P P M \\
0-8 \%\end{array}$ & $<3 \mathrm{sec}$ & $\begin{array}{c} \pm 50 \text { PPM } \\
\pm 0.3\end{array}$ & $\begin{array}{c}10 \text { PPM, } \\
0.001 \%\end{array}$ \\
\hline $\mathrm{CO}_{2}$ & NDIR & $0-20 \%$ & $<3 \mathrm{sec}$ & $\pm 0.1 \%$ & $0.01 \%$ \\
\hline
\end{tabular}




\subsubsection{PG 250, Horiba Analytical Instruments Inc.}

The PG-250 system is a portable analyzer that can simultaneously measure up to five different gas components [14]. The PG-250 uses NDIR detection technique for $\mathrm{CO}, \mathrm{CO}_{2}$ and $\mathrm{SO}_{2}$, chemiluminescence detection technique for $\mathrm{NO}_{x}$, and an optional zirconium oxide sensor for $\mathrm{O}_{2}$ measurements. The working principle is explained in "principle of gaseous concentration detection" section (section 2.7). The instrument can interface directly with a laptop computer through an RS-232C interface to record realtime values. The system has a built-in sample conditioning system with a sample pump, a filter for PM removal and a thermoelectric chiller for the moisture removal to desired accuracy levels for NDIR based detection. The system mandates the use of a $\mathrm{NO}_{x}$ converter because only $\mathrm{NO}$ can be detected by the chemiluminescence process. Furthermore, it is not best suited for the continuous $\mathrm{NO}_{x}$ monitoring application because the chemiluminescence detection is sensitive to the position and on-board vehicle vibrations. 


\section{Specification:}

Table-3 Specifications of PG 250 multi-gas analyzer [14]

\begin{tabular}{|c|c|c|c|c|c|}
\hline $\begin{array}{c}\text { Gases } \\
\text { Measured }\end{array}$ & Principle & Range & $\begin{array}{l}\text { Response } \\
\text { Time T-90 }\end{array}$ & Accuracy & Resolution \\
\hline $\mathrm{NO} \& \mathrm{NO}_{2}$ & $\begin{array}{l}\text { Chemilumi- } \\
\text { nescence }\end{array}$ & $\begin{array}{c}0- \\
2500 / 5000 \\
\text { PPM } \\
\text { (at different } \\
\text { increments) }\end{array}$ & $3-5 \mathrm{sec}$ & $\pm 2 \%$ & 5 PPM \\
\hline $\mathrm{SO}_{2}$ & NDIR & 0 - 1000 PPM & $<3 \mathrm{sec}$ & $\pm 2 \%$ & 5 PPM \\
\hline $\mathrm{CO}$ & NDIR & $\begin{array}{c}0-2000 / 5000 \\
\text { PPM, } 0-2 \% \\
\text { (at different } \\
\text { increments) }\end{array}$ & $3-5 \mathrm{sec}$ & $\pm 2 \%$ & $\begin{array}{c}5 \text { PPM, } \\
0.1 \%\end{array}$ \\
\hline $\mathrm{CO}_{2}$ & NDIR & $0-20 \%$ & $>3 \mathrm{sec}$ & $\pm 2 \%$ & $0.1 \%$ \\
\hline $\mathrm{O}_{2}$ & $\begin{array}{l}\text { Zirconium } \\
\text { Oxide }\end{array}$ & $0-25 \%$ & 3-5 sec & $\pm 2 \%$ & $0.1 \%$ \\
\hline
\end{tabular}

\subsubsection{OBS 1000 Series, Horiba Analytical Instruments Inc.}

An OBS-1000 series system continuously measures real-time $\mathrm{CO}, \mathrm{CO}_{2}$, $\mathrm{HC}, \mathrm{NO}_{\mathrm{x}}$ and $\mathrm{A} / \mathrm{F}$ ratio from the diesel exhaust. The system enables the concentrations to be expressed per unit of distance using a GPS receiver by providing the real-time position and distance data on the driving environment. A heated type MEXA1170 HNDIR measures $\mathrm{CO}, \mathrm{CO}_{2}$ and $\mathrm{HC}$ concentration without water extraction that allows for no water correction factor. $\mathrm{A} \mathrm{ZrO}_{2}$ type 
MEXA720 $\mathrm{NO}_{x}$ analyzer measures $\mathrm{NO}_{x}$ concentration and Air/Fuel ratio. The working principle is explained later in the section on "principle of gaseous concentration detection" (section 2.7). Since it is a zirconia type analyzer, it is not vibration and position sensitive and makes it ideal for on-board emission monitoring application. Software in the data logger performs the calculations based on per unit distance and time and displays the data in tabular form in addition to storing the system inputs for later analysis.

\subsubsection{Mobile Emissions Measurement System (MEMS), WVU}

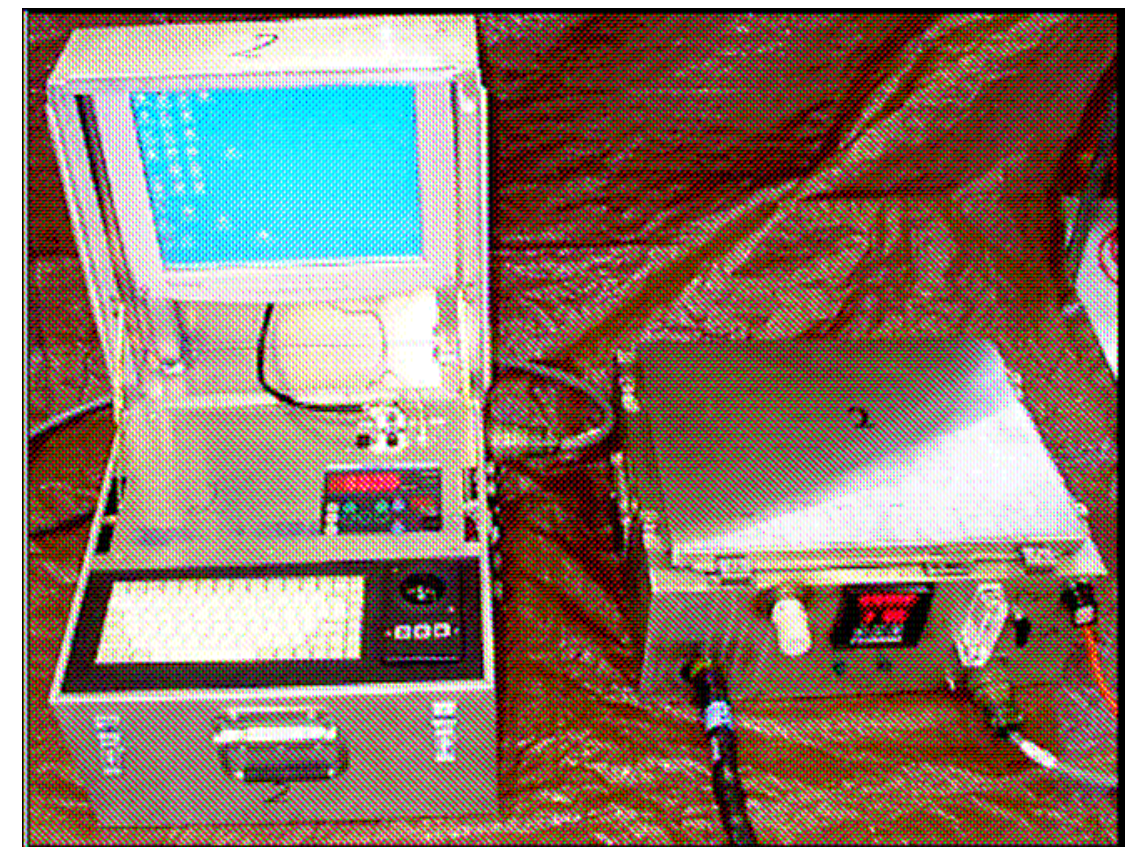

Figure-4 Mobile Emissions Measurement System (MEMS)

MEMS comprises of emissions sampling system, exhaust flow rate measurement unit, data acquisition system, and sensors to measure relative humidity, temperature and pressure. The performance of the complete system was evaluated after several bench tests, laboratory tests and on-road tests. Results were compared against laboratory grade analyzers at WVU EERL and 
WVU transportable laboratory. The current version of the MEMS was capable of reporting cycle integrated, brake-specific $\mathrm{CO}_{2}$ within $3 \%$, and $\mathrm{NO}_{\mathrm{x}}$ within $5 \%$ of laboratory data.

The MEMS developed at WVU was capable of measuring $\mathrm{CO}_{2}$ with accuracy approaching that of most laboratory grade analyzers. The Horiba BE140 NDIR based analyzer was used to measure the $\mathrm{CO}_{2}$ for continuous emission measurement application. This analyzer was qualified after conducting several tests like response time, accuracy, interference with water, $\mathrm{CO}$ and $\mathrm{HC}$. It was capable of providing $5 \mathrm{~Hz}$ continuous data. Furthermore, vibration and inclination encountered during on-road testing did not cause any drift in the response of the solid-state NDIR analyzer making it ideal for harsh on-road conditions. $\mathrm{CO}_{2}$ measurements with the MEMS were within $3 \%$ of laboratory analyzer results integrated over the FTP cycle at the WVU EERL. The accurate determination of $\mathrm{NO}_{x}$ concentration was one of the critical goals of the MEMS. Brake-specific mass emissions of $\mathrm{NO}_{\mathrm{x}}$ were reported by the MEMS within $5 \%$ of laboratory results integrated over an FTP cycle. A zirconium oxide sensor along with a $\mathrm{NO}_{\mathrm{x}}$ converter was selected for the measurement of $\mathrm{NO}_{\mathrm{x}}$, with an electrochemical $\mathrm{NO}$ as backup. The Horiba MEXA-120 analyzer provided T90 response time of less than 5 seconds, accurate measurements and qualified all the tests of accuracy, linearity, repeatability, vibration, inclination, and interference. However, the Horiba MEXA120 analyzer did not provide a $100 \%$ response to $\mathrm{NO}_{2}$. Therefore, a $\mathrm{NO}_{x}$ converter was required to convert $\mathrm{NO}_{2}$ to $\mathrm{NO}$ in order to obtain accurate $\mathrm{NO}_{x}$ 
measurements and that was placed upstream of the thermoelectric chiller to prevent loss of the water-soluble $\mathrm{NO}_{2}$ before being converted to $\mathrm{NO}$.

\subsection{Gas Analyzers}

Literature review was done on the commercially available emissions analyzers like AMBII manufactured by Sensors Inc., BE140 AD 5-gas bench manufactured by Horiba Analytical Instruments Inc., MEXA120 $\mathrm{NO}_{x}$ analyzer manufactured by Horiba Analytical Instruments Inc. and BE220 FS NO analyzer manufactured by Horiba Analytical Instruments Inc.

\subsubsection{Automotive Micro-Bench (AMBII), Sensors Inc.}

The Automotive Micro-bench [15] is a component in SEMTECH-D that detects $\mathrm{CO}, \mathrm{CO}_{2}$ and THC as propane $\left(\mathrm{C}_{3} \mathrm{H}_{8}\right)$ or hexane $\left(\mathrm{C}_{6} \mathrm{H}_{14}\right)$ from the diesel exhaust. It also uses an optional electrochemical cell for oxygen and NO measurements. The micro-bench was designed to reduce the overall system cost by using the low power consumption of 10 watts that in turn allows the user a less expensive power supply. Because of the smaller size of the microbench, the flow rate can be reduced to $0.3 \mathrm{l} / \mathrm{min}$, making it very suitable for onroad emissions measurement application. The AMBII communicates through a serial interface with a computer and it is devised with a program to control the calibration and data retrieval from the analyzer. 


\section{Specification:}

Table-4 Specification of AMBII [15]

\begin{tabular}{|c|c|c|c||}
\hline Gas & Range & Resolution & Accuracy \\
\hline $\mathrm{HC}$ & $\begin{array}{l}0-2000 \mathrm{PPM} \\
0-4000 \mathrm{PPM}\end{array}$ & $\begin{array}{c}1 \mathrm{PPM} \\
1 \mathrm{PPM}\end{array}$ & $\pm 4 \mathrm{PPM}, 3 \%$ \\
\hline $\mathrm{CO}_{2}$ & $16 \%$ & $0.1 \%$ & $\pm 0.3 \%$ \\
\hline $\mathrm{CO}$ & $10 \%$ & $0.01 \%$ & $\pm 0.02 \%$ \\
\hline $\mathrm{NO}_{\mathrm{x}}$ & $0-5000 \mathrm{PPM}$ & $1 \%$ & $\pm 25 \mathrm{PPM}$ \\
\hline $\mathrm{O} 2$ & $25 \%$ & $0.01 \%$ & $\pm 0.1 \%$ \\
\hline
\end{tabular}

\subsubsection{BE140 AD 5-gas Bench, Horiba Analytical Instruments Inc.}

The $\mathrm{BE}-140 \mathrm{AD}[16,17]$ simultaneously measures $\mathrm{CO}, \mathrm{CO}_{2}$ and $\mathrm{HC}$ (as n-hexane) in the diesel exhaust using NDIR detection technique [6]. It consists of solid-state infrared detectors, a microprocessor, and a miniature mechanical component called chopper motor to divide the infra red beam to pass through each detector sequentially. To accurately record concentrations, it requires a moisture removal system which lowers the temperature of diesel exhaust sample much below its dew-point to condense any water vapor present. The unit can be wired for NO measurements using either a BE220 FS or an electrochemical sensor. The microprocessor provides the compensation for atmospheric-pressure and temperature changes, gain adjustment provision and communicates the recordings with a PC via RS-232C interface. 


\section{Specification:}

Table-5 Specification of BE140AD multi-gas analyzer [17]

\begin{tabular}{|c|c|c|c|c||}
\hline \hline Gases & Ranges & Resolution & Accuracy & Interference \\
\hline $\mathrm{CO}$ & $0-10 \%$ & $0.01 \%$ & $\pm 3 \%$ & $\pm 0.02 \%$ \\
\hline $\mathrm{CO}_{2}$ & $0-20 \%$ & $0.01 \%$ & $\pm 3 \%$ & $\pm 0.2 \%$ \\
\hline $\mathrm{HC}$ & $0-10,000 \mathrm{PPM}$ & $1 \mathrm{PPM}$ & $\begin{array}{c}0-2000- \pm 3 \% \\
\text { to } 5000- \pm 5 \% \\
\text { to } 10,000- \pm \\
10 \%\end{array}$ & \pm 4 PPM \\
\hline $\mathrm{NO}$ & $0-5000 \mathrm{PPM}$ & $0.02 \%$ & - & \pm 20 PPM \\
\hline O2 & $0-25 \%$ & $1 \mathrm{PPM}$ & - & - \\
\hline
\end{tabular}

\subsubsection{MEXA120 NOx Analyzer, Horiba Analytical Instruments Inc.}

The Horiba MEXA120 $\mathrm{NO}_{x}$ analyzer uses a zirconium oxide $\left(\mathrm{ZrO}_{2}\right)$ sensor for the $\mathrm{NO}_{x}$ measurement in the diesel exhaust [18]. The unit consists of two internal cavities. The sample gas enters the first cavity where the reduction reaction takes place and the resulting oxygen present in the sample is pumped out in order to ensure a low oxygen concentration within the cavity. The sample stream then enters the second cavity, where the oxygen concentration is lower than the first cavity. The sensor is heated to approximately $900 \mathrm{~F}$ that allows the migration of oxygen ions through the zirconium oxide material. The sample is then dissociated into nitrogen and oxygen. The oxygen generated in this reaction is then pumped out of this second cavity. The current generated by the removal of oxygen is used to determine the NO concentration. This analyzer 
measures only $\mathrm{NO}$, which mandates the use of a $\mathrm{NO}_{x}$ converter. The sensor can be directly inserted into the exhaust flow that eliminates the need for a sample-handling unit and it is also very portable that makes it ideal for in-use application.

\section{Specification:}

Table-6 Specification of MEXA120 NOx analyzer [18]

\begin{tabular}{|c|c|}
\hline Range & $0-5000$ PPM \\
\hline Response Time (T-90) & Within 1 Sec \\
\hline Accuracy & $\begin{array}{c} \pm 30 \text { PPM or } \pm 3 \% \text { of reading, } \\
\text { whichever is larger }\end{array}$ \\
\hline Warm-up Time & 3 minutes \\
\hline Voltage Output & $0-1 \mathrm{~V} \mathrm{DC}$ or $0-5 \mathrm{~V} \mathrm{DC}$ \\
\hline Sampling Temperature Range & -7 to $800^{\circ} \mathrm{C}$ \\
\hline
\end{tabular}

\subsubsection{BE220 FS NO Analyzer, Horiba Analytical Instruments Inc.}

This is an NDIR detection based analyzer with a luft detector [19]. A diaphragm is placed between two chambers in the sample cell. One of the chambers is used as a reference value and the other chamber changes according to the sample concentration. The capacitance of the diaphragm changes as the sample concentration varies because of the variation in the temperature and pressure of the gas in the chamber. The capacitance is then used to deduce the absorption of infrared energy giving the concentration of NO in the sample cell. The measurement range of the analyzer is 0 to 5000 PPM and the output is in the form of an analog signal that ranges from 0 to 5 
volts. This analyzer measures only $\mathrm{NO}$, which mandates the use of a $\mathrm{NO}_{\mathrm{x}}$ converter towards the basic requirement of the continuous $\mathrm{NO}_{\mathrm{x}}$ emission measurement. Moreover the luft detectors are generally sensitive to vibration and therefore not suitable for real-time on-road measurements.

\section{Specification:}

Table-7 Specification of BE220 FS NO analyzer [19]

\begin{tabular}{|c|c|c|c|c||}
\hline $\begin{array}{c}\text { Range } \\
\text { (PPM) }\end{array}$ & Accuracy & Repeatability & $\begin{array}{c}\text { Response } \\
\text { Time }\end{array}$ & Drift \\
\hline $0-2000$ & $\pm 3 \%$ & $\pm 2 \%$ & $\begin{array}{c}5 \text { secs at 3 } \\
\text { LPM }\end{array}$ & $\begin{array}{c}60 \text { PPM over } \\
4 \text { hours }\end{array}$ \\
\hline
\end{tabular}

\subsubsection{Electrochemical NO sensor, Sensors Inc.}

The electrochemical sensor measures NO in the exhaust sample. The sensor is a very small unit and of relatively low cost compared to other NO and $\mathrm{NO}_{\mathrm{x}}$ analyzers. The measurement range of the sensor is 0 to 5000 PPM. The electrochemical cell contains two electrodes separated by an electrolyte in an electric circuit. The sample is pumped into a small manifold containing the cell where the sample migrates through a membrane and reacts with the sensing electrode by either oxidation or reduction. This reaction causes a current to flow between the sensing and the counter electrode, which is proportional to the concentration of NO in the sample and can be measured in the external circuit. 
This sensor has a response to NO only and therefore mandates the use of a $\mathrm{NO}_{\mathrm{x}}$ converter to record continuous $\mathrm{NO}_{x}$ in the diesel exhaust.

\subsection{Principles of Gaseous Concentration Detection}

Principles of gaseous concentration detection were reviewed in order to learn the feasibility of using commercially available analyzers for on-road emissions measurement. Also, this study helped in the better understanding of the available analyzers in the market and enabled more accurate prediction of possible problems with detectors that were selected for testing.

\subsubsection{Non Dispersive Infra Red Detection}

Based on the principle of non-dispersive infrared analysis [8], the detector includes:

- Broad-band infrared light source

- Chopper motor

- Four detectors -- one reference and one each for $\mathrm{CO}, \mathrm{CO}$, and $\mathrm{HC}$. 


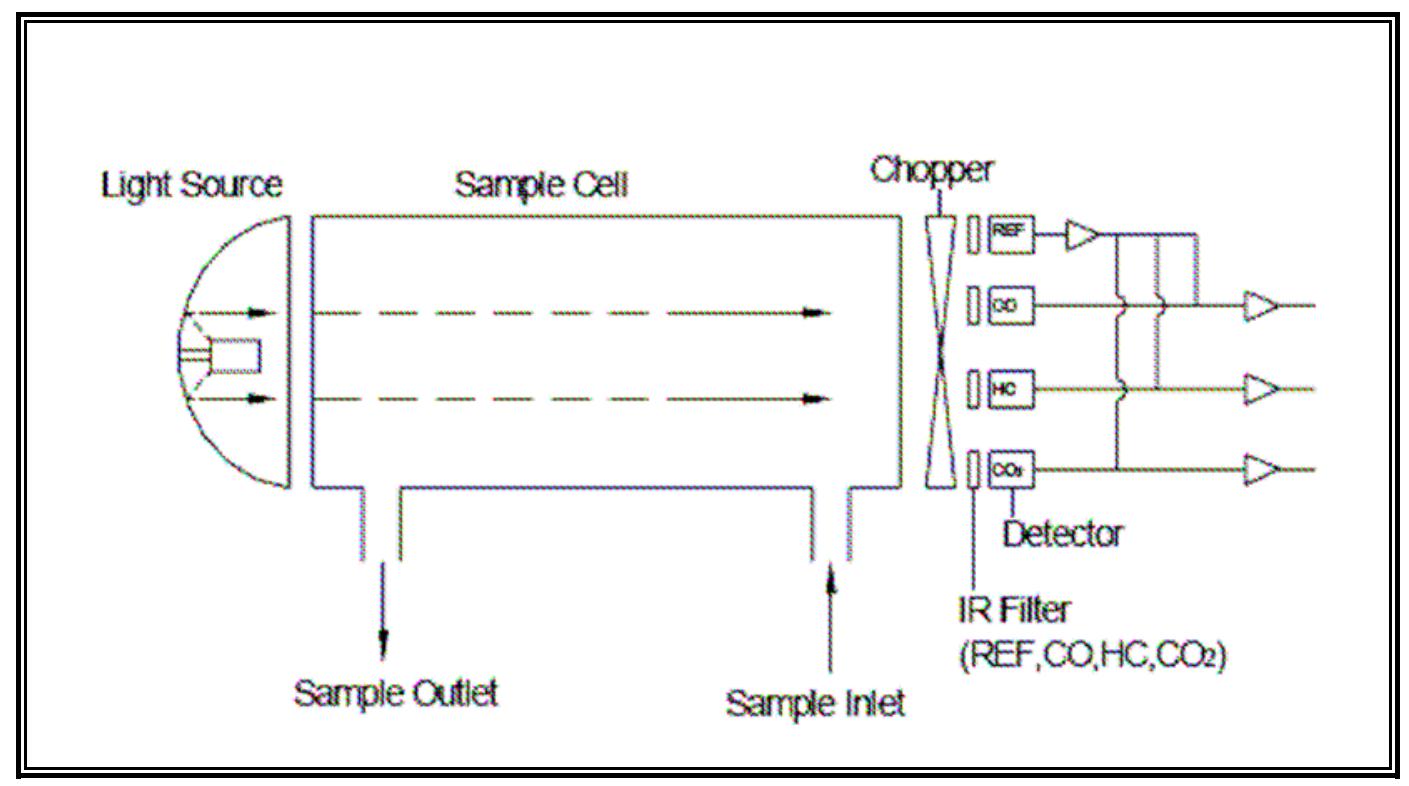

Figure-5 Schematic of the working principle of NDIR detection [20]

Infra red beam emitted from the broad-band infrared source passes through the sample cell containing the gases to be analyzed. When the beam is passed through the sample cell, some of the intensity is lost due to the presence of the gases in the cell. The attenuated beam is modulated by a mechanical device called the chopper motor that sequentially allows the beam into each of the four detectors. Each detector has a narrow band-pass filter that isolates a spectral region specific to the corresponding gas $\left(\mathrm{CO}, \mathrm{CO}_{2}\right.$ or $\left.\mathrm{HC}\right)$ [20]. The reference detector is insensitive to all three gases. When absorbing gases $\left(\mathrm{CO}, \mathrm{CO}_{2}, \mathrm{HC}\right)$ flow through the sample cell, less intensity reaches the sample detectors than the reference detector. Each detector produces an electrical signal corresponding to the changes in energy absorption. The difference between the sample and reference signals represents the concentration of the respective components that generates an output signal. 


\subsubsection{UV absorption method}

The principle of a UV ray absorption method [21] is very similar to that of an infrared ray absorption method. In this technique, the candidate gases absorb the light at different intensities. Two different wavelengths of the ultraviolet energy are transmitted through a single sample cell. Two band-pass filters are used with one to provide energy of a wavelength absorbed by the candidate gas, and another to provide energy of a wavelength that is not absorbed by the candidate gas. The transmitted energy of each wavelength range is measured and compared to determine the candidate gas concentration. The detection technique is mainly employed for $\mathrm{NO}_{x}$ concentration measurements because it can measure both $\mathrm{NO}$ and $\mathrm{NO}_{2}$ and also it eliminates the risk of water vapor and $\mathrm{CO}_{2}$ quenching. The detection technique is fairly robust (independent of vibration and position) and therefore is very well suited for the continuous on-board emission monitoring application.

\subsubsection{Chemiluminescence Method of Detection}

The chemiluminescence detection technique has been developed for the measurement of NO. NO is a relatively unstable molecule which oxidizes to $\mathrm{NO}_{2}$ in the presence of $\mathrm{O}_{3}$ as mentioned in the equations below [22]. $\mathrm{NO}$ in a sample gas reacts with $\mathrm{O}_{3}$ which is prepared by the ozone generator in the reaction chamber. This reaction produces a quantity of light that can be measured using a photomultiplier tube or a solid state device. The intensity of the light in the reaction chamber is proportional the concentration of $\mathrm{NO}$ in the gas sample. This type of detection technique is not best suited for the on-board 
emission monitoring application because of its size and also, it is sensitive to both position and vibration.

$$
\begin{aligned}
& 2 \mathrm{NO}_{2}=2 \mathrm{NO}+\mathrm{O}_{2} \\
& \mathrm{NO}+\mathrm{O}_{3}=\mathrm{NO}_{2}+\mathrm{O}_{2}+\text { light }
\end{aligned}
$$

\subsubsection{Heated Flame Ionization Detection}

This method utilizes a heated flame generated by the ionization reaction of the mixture of hydrogen and helium with the air. Polarized electrodes attract electrons that cause the current to flow proportional to the number of carbon atoms that make up hydrocarbons in the sample stream [23]. The control of the sample gas flow rate is critical to determine the concentration because the number of carbon atoms is measured. Due to this, capillary tubes are commonly used to control the flow rate of all three gases. The HFID based analyzers are very sensitive to the flow rate of the hydrogen and helium mixture and the oxygen.

\subsubsection{Fourier Transform Infrared Spectroscopy}

Fourier transform infrared spectroscopy (FTIR) analyzers are a relatively new method of measuring emissions gases. FTIR devices may be used to measure several gases at once. The infrared energy absorbed over a wide wavelength range, typically 5 to 25 micrometers, is recorded. This data is then converted to concentrations using a Fourier transform. Currently available FTIR analyzers that are capable of measuring emissions gases from engine exhaust are very expensive relative to other available instruments. 


\subsubsection{Zirconium Oxide $\left(\mathrm{ZrO}_{2}\right) \mathrm{NO}$ and $\mathrm{O}_{2}$ Detection}

Zirconium oxide $\left(\mathrm{ZrO}_{2}\right)$ sensor [24] consists of a cell made of zirconia ceramic forming a crystal lattice structure which acts as a solid electrolyte. Typically, the cell is shaped like a test tube where the inner and outer surfaces are each coated with an ultra-thin layer of porous platinum which act as the cathode and anode electrodes. At high temperatures (above 1200F), openings in the crystal lattice permit the movement of oxygen ions. When a sample gas is introduced on one side, oxygen ions migrate within the crystal lattice to form a concentration gradient due to the difference in partial pressures. This concentration gradient of oxygen ions within the $\mathrm{ZrO}_{2}$ lattice produces a voltage potential between the two platinum electrodes which is proportional to the NO concentration in the sample. The equation for the voltage of the signal is as follows:

$$
E=E^{\prime}-[R T / n F] \ln Q
$$

In the above equation, $\mathrm{R}$ is the universal gas constant, $\mathrm{T}$ is the absolute temperature, $\mathrm{n}$ is the number of molecules, $\mathrm{F}$ is the Faraday constant, and $\mathrm{Q}$ is the concentration ratio of products to reactants.

\subsubsection{Photo-ionization Detection}

The sample stream flows through the reaction chamber of the detector where it is continuously irradiated with high energy ultraviolet light. When compounds are present that have a lower ionization potential than that of the irradiation energy (10.2 electron volts with standard lamp), they are ionized. 
The ions formed due to the reaction are collected in an electrical field which produces an ion current proportional to the compound concentration.

\subsubsection{Electrochemical Detection}

Electrochemical sensors are used primarily to detect oxygen and NO. Each sensor is designed specifically for the respective gas detection. An electrochemical sensor consists of an electrolyte, an anode, and a cathode. The electrolyte is normally an aqueous solution of strong inorganic acids. When a chemically reactive gas passes through the electrolyte, it is either oxidized (accepts oxygen and gives up electrons) or reduced (gives up oxygen and accepts electrons), depending upon the gas. The resulting potential difference between the anode and the cathode electrodes causes a current to flow. This current is proportional to the concentration of the gas. 


\section{Chapter3 Compact Mobile Emission Measurement System (CMEMS)}

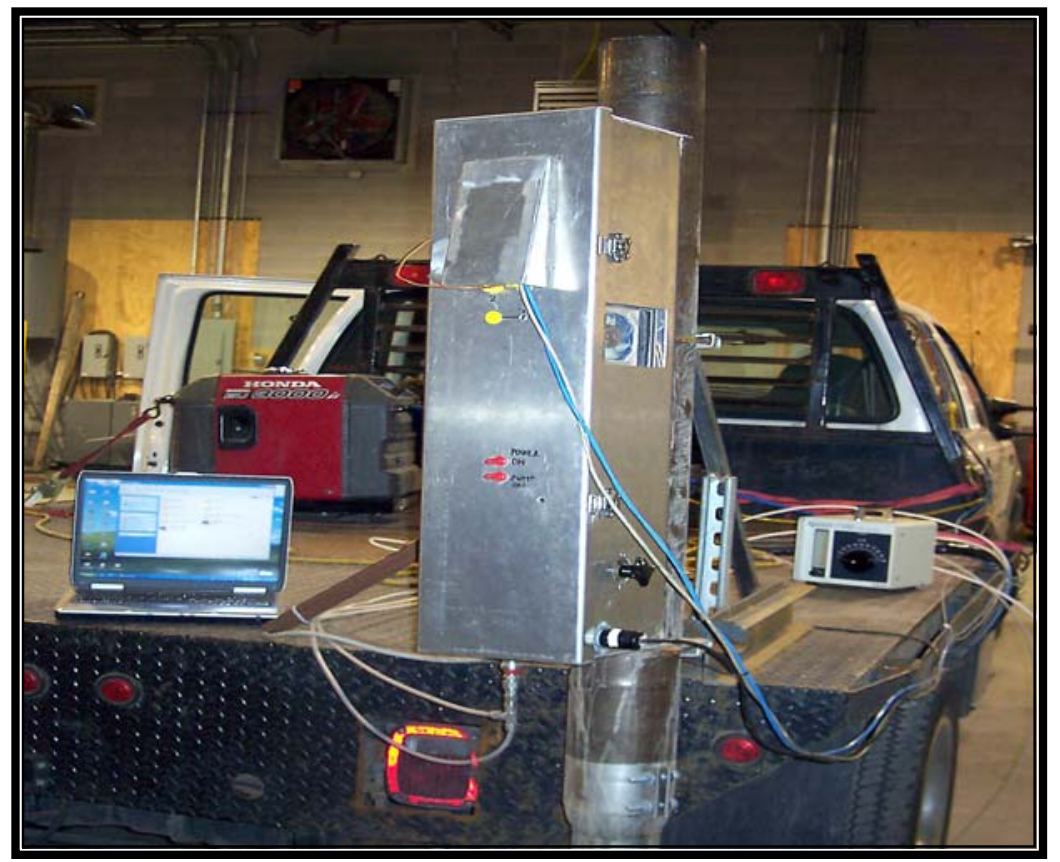

Figure-6 CMEMS installed on a Ford 450 truck

\subsection{Heated Chamber}

The Heated Chamber is the smaller of the two chambers in CMEMS. The chamber is made of $1 / 8$ inch aluminum metal with $1 / 2$ inch offset that acts as an air gap around the aluminum box. The air gap acts as an insulation that significantly reduces the heat transfer caused due to the conduction from the exhaust stack. This chamber consists of an exhaust probe, annubar that measures the volumetric flow rate, a heated filter for PM removal, a solenoid valve for calibration provision and the MEXA720 $\mathrm{NO}_{\mathrm{x}}$ analyzer. In addition, there are pressure transducers that measure the absolute and differential pressures across the heated filter and annubar. 


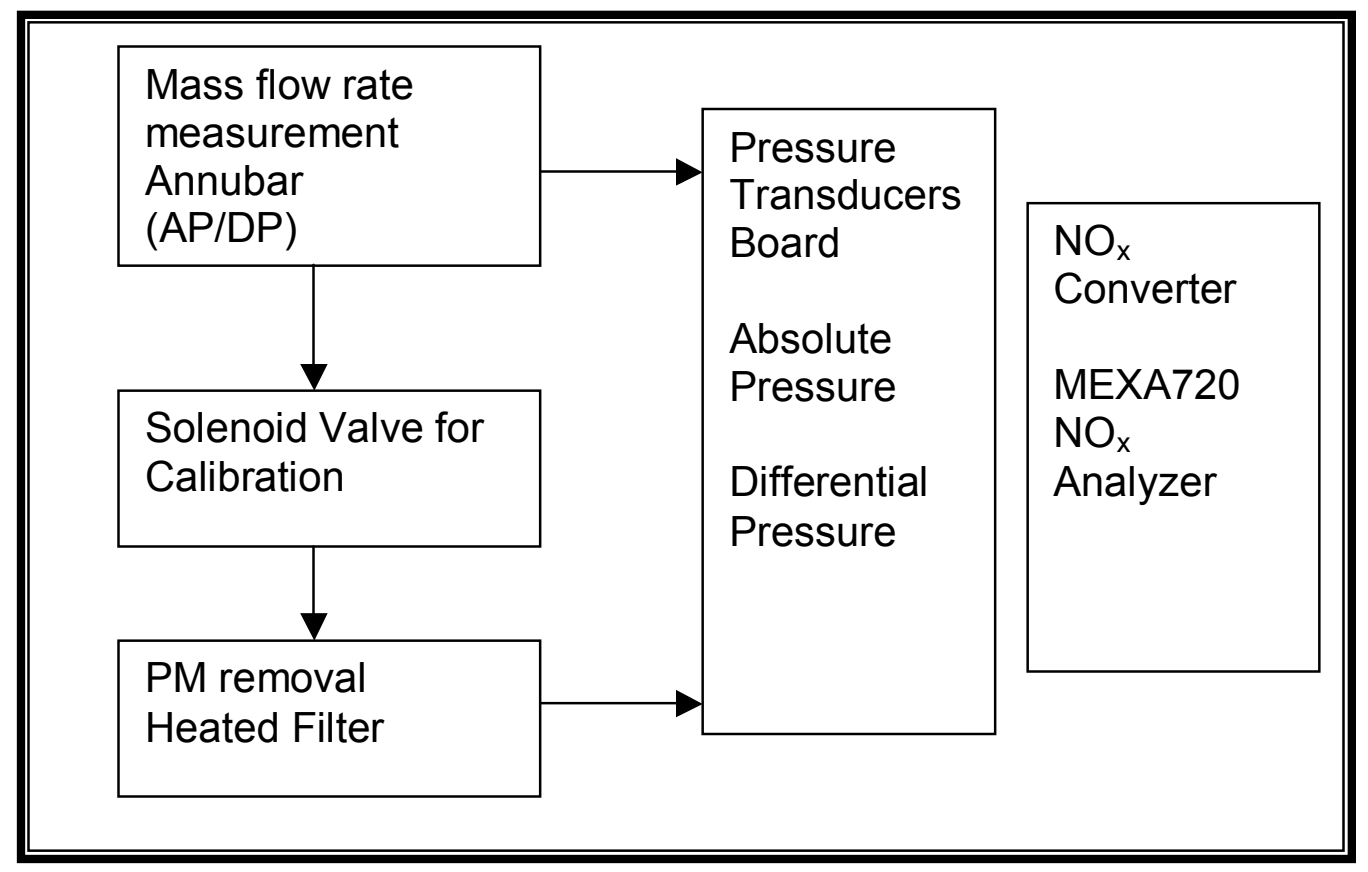

Figure-11 Schematic of the heated chamber in CMEMS

\subsubsection{Exhaust probe}

The sample probe used in CMEMS is a stainless steel probe consisting of nine sampling holes with one set of three holes in line positioned 120 degrees to the other two sets on the surface of the probe. The probe design was in compliance with guidelines mentioned in the CFR Title 40, Part 1065.145 [25]. The probe design was same as the probe used in MEMS designed by Wesley Riddle and Ben Shade. The probe is placed upstream of the heated filter and the raw exhaust after passing through the sample probe enters the heated chamber. 


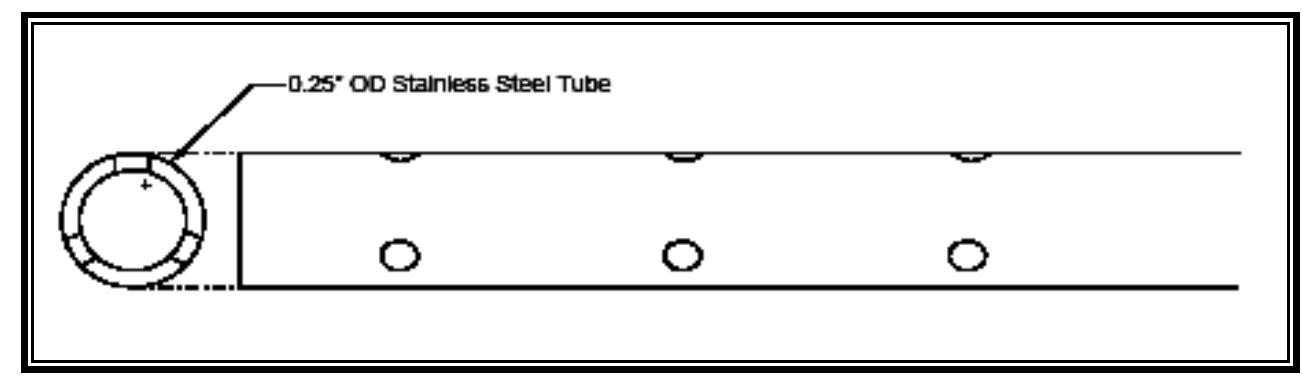

Figure-7 Sample probe used in CMEMS $[4,16]$

\subsubsection{Annubar}

Annubar which is also a type of pitot tube, is used to measure the exhaust volumetric flow rate. The volumetric flow rate is used to convert the emission gas concentration to a mass measurement per time, which can also be converted to a mass measurement per distance or per bhp-hr. Tests were performed by passing high volume of air at different pressures and measurements were compared against the Laminar Flow Element (LFE) at the EERL (refer to the results and discussion section 5.11).

\subsubsection{Heated Filter}

The heated filter assembly was manufactured by Atmo-seal Engineering Inc. It consists of a stainless steel filter holder maintained at $235 \mathrm{~F} \pm 15 \mathrm{~F}$ (as per CFR Title 40, Part 86.110) [26] to prevent the condensation of water vapor present in the diesel exhaust. This in turn prevents the $\mathrm{NO}_{2}$ absorption by the water. The filter holder houses a small filter (1.5x2.25 sq. inches) for PM removal. The whole unit operates on $120 \mathrm{~V}$ AC supply and the power consumption is $200 \mathrm{~W}$. The raw exhaust from the engine stack passes through the filter and PM in the exhaust sample gets deposited on the filter. 


\subsubsection{Solenoid Valve}

A three-way solenoid valve is used to calibrate both MEXA720 and BE150 multi-gas analyzers. One way of the valve connects the outlet with inlet from the gas divider and the other to the inlet from the exhaust. The valve is a "normally open" valve in which case the exhaust sample flows from the engine stack into the sampling system when the valve is not energized. When the valve is energized, the exhaust sample inlet is shut and the gas from the gas divider flows into the sampling system. The solenoid valve is a high temperature (300F) valve to account for the flow of exhaust sample at high temperature.

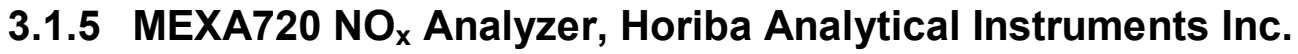

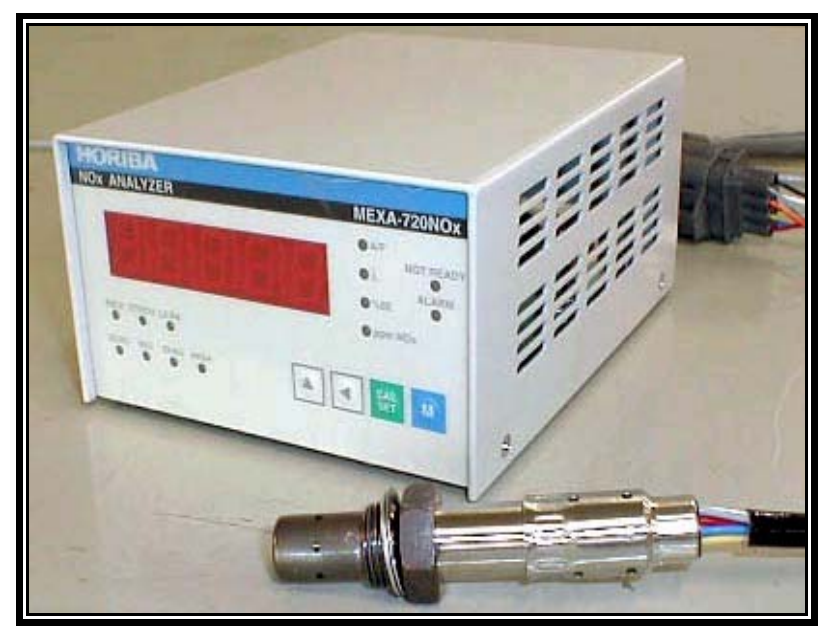

Figure-8 MEXA720 $\mathrm{NO}_{x}$ analyzer [27]

The MEXA720 $\mathrm{NO}_{x}$ analyzer system is lighter and more compact (1/3 the size of MEXA120) that made it ideal for use in the CMEMS. The main criteria for any analyzer to qualify for the system integration were size and weight and MEXA720 satisfied them very well. It is a multi-function portable 
$\mathrm{NO}_{\mathrm{x}}$ analyzer with zirconia-ceramic sensor that can simultaneously measure $\mathrm{NO}, \mathrm{A} / \mathrm{F}$ ratio, $\mathrm{O}_{2}$ and excess air (gamma) ratio. The zirconia enables the sensor to provide high speed response of less than 0.7 seconds and very short warm up time of 3 minutes. The sensor can be directly inserted into the exhaust flow which eliminates the need for a sample-handling unit. The MEXA720 NO analyzer is very portable which enables it to be mounted in a vehicle for onroad R\&D tests. The working principle of the analyzer is same as that of MEXA120 analyzer (refer to the principles of gaseous concentration detection section 2.7.6). The analyzer can measure only $\mathrm{NO}$ and therefore requires a $\mathrm{NO}_{x}$ converter to convert the $\mathrm{NO}_{2}$ to $\mathrm{NO}$ for the desired accuracy levels in the real-time $\mathrm{NO}_{x}$ measurement.

\section{Specification:}

Table-8 Specification of the MEXA720 NO analyzer [27]

\begin{tabular}{|c|c|}
\hline Range & $\begin{array}{c}0-1000,1001-2000, \\
2001-3000 \mathrm{PPM}\end{array}$ \\
\hline Accuracy & $\begin{array}{c} \pm 30 \mathrm{PPM}, \pm 3 \%, \\
\pm 5 \%\end{array}$ \\
\hline Response Time (T-90) & Less than $1 \mathrm{Sec}$ \\
\hline Warm-up Time & 3 minutes \\
\hline Voltage Output & $0-1 \mathrm{~V} \mathrm{DC}$ or $0-5 \mathrm{~V} \mathrm{DC}$ \\
\hline Sampling Temperature Range & -7 to $800^{\circ} \mathrm{C}$ \\
\hline
\end{tabular}




\subsection{Cold Chamber}

The cold chamber consists of a sample diaphragm pump, a critical flow nozzle (CFN), a three terminal $12 \mathrm{~V}$ DC power supply, Compact Field Point (CFP) for data acquisition, pressure transducers for recording the pressure drop across the critical flow nozzle and ambient pressure, relative humidity and temperature sensors for recording chiller performance and ambient conditions and BE150 multi-gas analyzer.

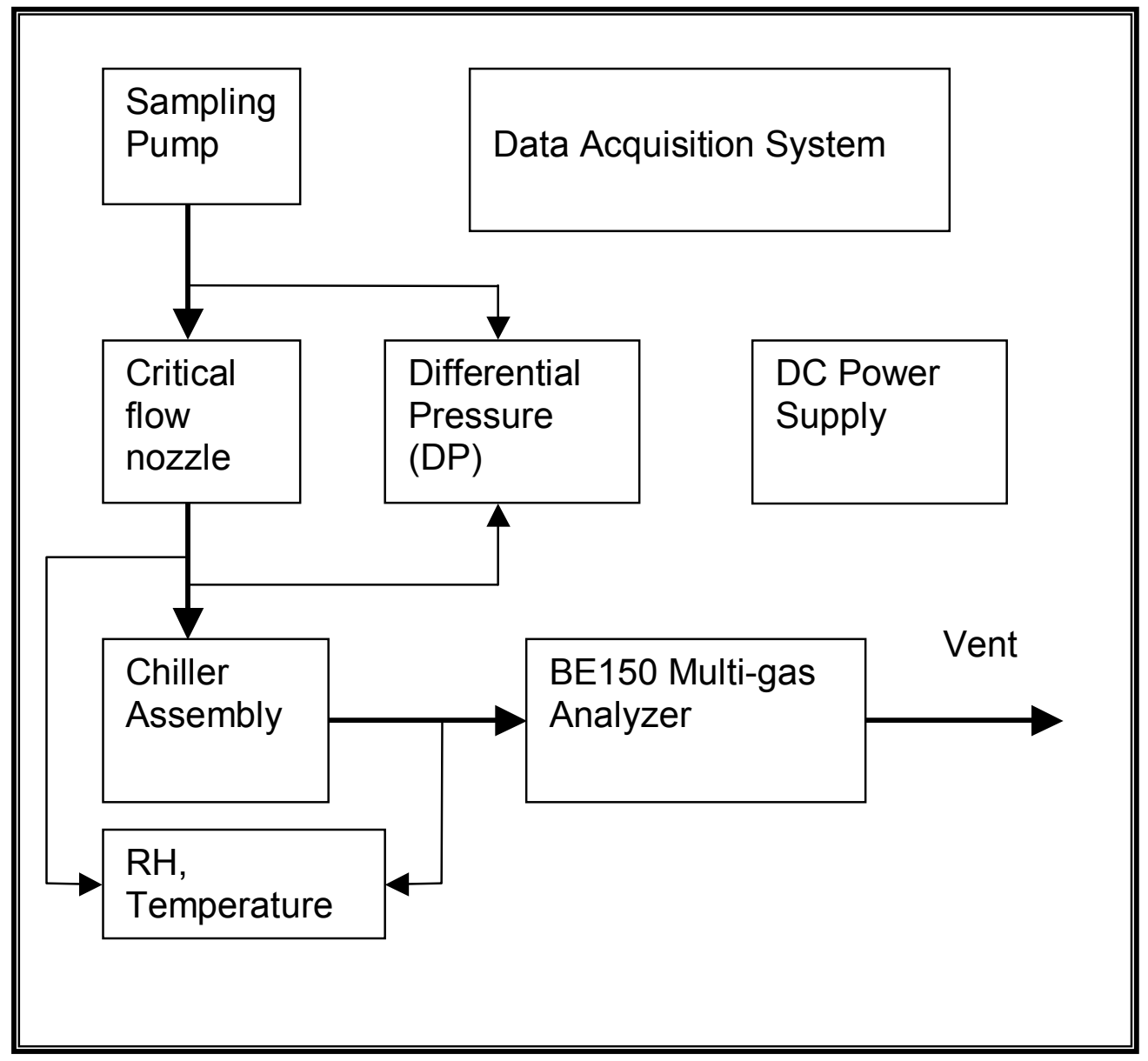

Figure-9 Schematic of the cold chamber in CMEMS 


\subsubsection{Sampling Pump}

The pump is placed downstream of the $\mathrm{NO}_{x}$ analyzer in the heated chamber. The pump pressurizes the exhaust sample to 40PSIA pressure which is more than sufficient to create the required volumetric flow rate of 3 LPM. The

pumps that were tested to qualify for the system integration had to meet several criteria like size, weight and minimum flow rate at choked conditions. The volumetric flow rate became a critical parameter due to the placement of a critical flow nozzle downstream of the pump to create the choke flow. This was towards the requirement of a constant volumetric flow rate for the BE150 multigas analyzer for the desired accuracy levels.

The pumps tested were-

1. Thomas diaphragm pressurizing pump

2. Gast manufacturing pressuring pump

3. Air-Dimensions diaphragm Vacuum pump

The performance curves of all the three pumps are shown in the Appendix B. The pump finally selected was Gast manufacturing pressuring pump which met all the above mentioned criteria successfully.

\subsubsection{Critical Flow Nozzle}

A critical flow nozzle (CFN) is placed downstream of the pump in the sampling system. As discussed earlier, this is towards the requirement of a constant flow rate of 3 LPM for the BE150 analyzer. CFN was selected based on the determination of the throat diameter required to create a constant 3 LPM volumetric flow rate. A needle valve was selected that exhibits the same 
behavior (flow coefficient) of a nozzle. Following are the equations derived from conservation of mass and energy to calculate the throat diameter for the known volumetric flow rate $[28,29]$.

$$
Q=\frac{\dot{m}}{\rho_{1}}=A_{t} \sqrt{\frac{\gamma P_{1}}{\rho_{1}}\left(\frac{2}{\gamma+1}\right)^{\frac{\gamma+1}{\gamma-1}}}
$$

Using $A_{t}=\pi d_{t}^{2} / 4$ and $P_{1} / \rho_{1}=R T_{1}$, the throat diameter $d_{t}$ can be determined with the equation:

$$
\begin{aligned}
& d_{t}^{2}=\frac{4 Q}{c \pi} \sqrt{\frac{1}{R \gamma T_{1}}\left(\frac{\gamma+1}{2}\right)^{\frac{\gamma+1}{\gamma-1}}} \\
& d_{t}{ }^{2}=\frac{4 Q}{c \pi} \sqrt{\frac{1}{R \gamma T_{1}}\left(\frac{\gamma+1}{2}\right)^{\frac{\gamma+1}{\gamma-1}}}
\end{aligned}
$$

If the gas to be measured is air, then $T_{1}=293 \mathrm{~K}, P_{1}=1.013 \times 10^{5} \mathrm{~Pa}$, $\rho_{1}=1.19 \mathrm{~kg} / \mathrm{m}^{3}$, the required throat diameter $d_{t}$ can be calculated. 


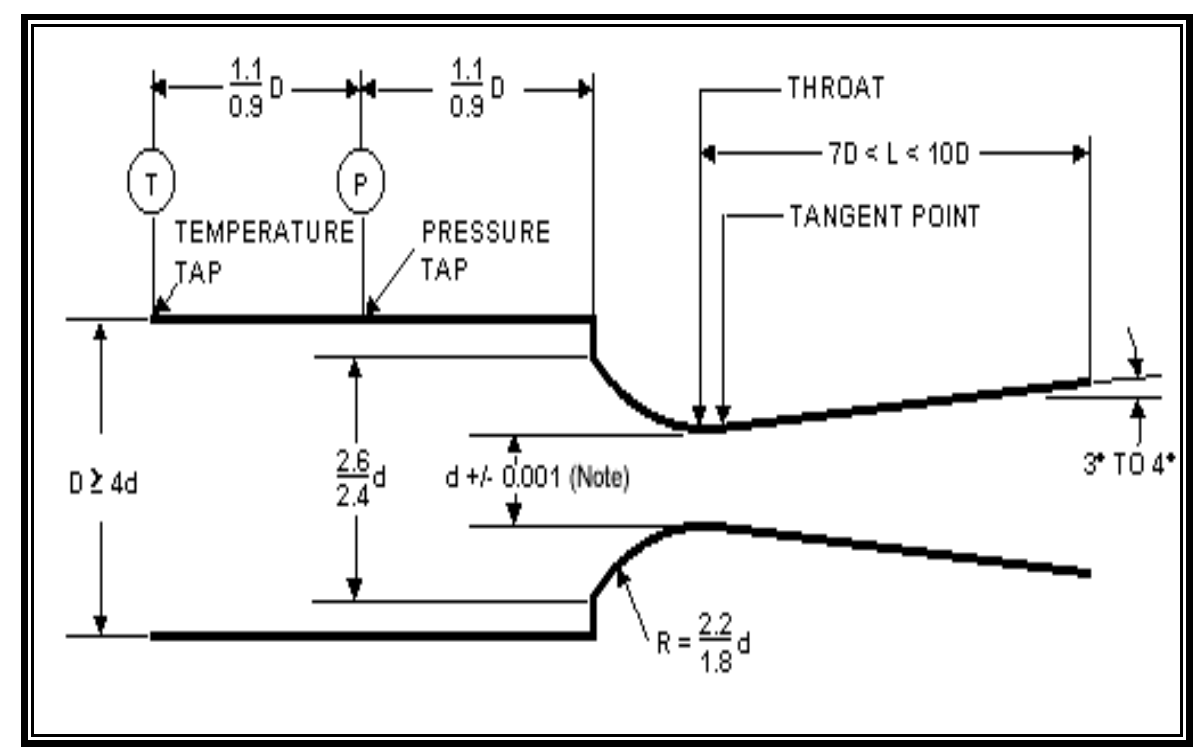

Figure-10 Design layout of the CFN as per ASME standard [28]

\subsubsection{Chiller Assembly}

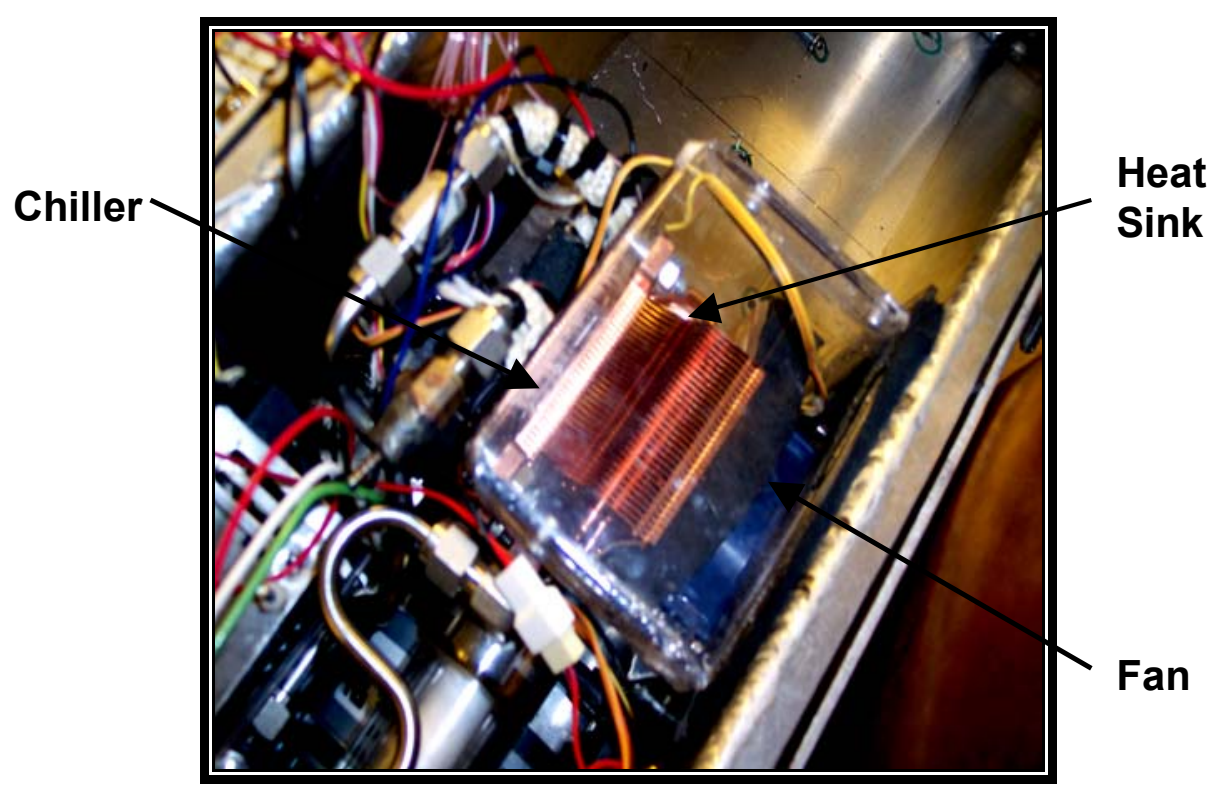

Figure-11 Chiller assembly used in CMEMS

The chiller assembly is a very critical part of the system as the moisture removal is necessary for the BE150 multi-gas analyzer to achieve the desired 
accuracy levels. The chiller assembly is placed downstream of the needle valve and upstream of the analyzer. The chiller assembly comprises of a thermo electric chiller placed on the surface of an aluminum chamber approximately 2 square inches in area, a heat sink and a fan. The sample is passed through the aluminum chamber at 3 LPM flow rate. The cold side of the thermoelectric chiller is in surface contact with the aluminum chamber to cool the exhaust sample much lower to the dew-point of the sample (CFR Title 40, Part 1065.650) [30] in order to condense any water vapor present in the sample. The condensate is drained out using a valve located at the bottom of the aluminum chamber. The hot side of the chiller is attached to a copper heat sink and the heat is dissipated using a medium capacity fan. The aluminum chamber is surrounded by neoprene rubber foam to insulate against the heat transfer from the cold side thereby increasing the effectiveness of the cooling.

\subsubsection{Thermo Electric Chiller}

The Thermo Electric Chiller (TEC) operates on Peltier's principle. During the operation, DC current flows through the TEC resulting in the heat being transferred from one side of the TEC to the other creating a cold and hot side. A single-stage TEC can achieve temperature differences up to $60^{\circ} \mathrm{C}$ but to achieve greater temperature differences up to $85^{\circ} \mathrm{C}$, a dual stage TEC was selected. 


\subsubsection{Heat sink and fan}

A copper heat sink was used in the chiller assembly to transfer the heat from the hot surface of the TEC. A medium capacity $12 \mathrm{~V} \mathrm{DC}$ fan (20 CFM) was mounted along with the heat sink to circulate air around fins of the heat sink for effective heat transfer. Performance tests were conducted on different heat sinks in combination with different fans. The heat sink and fan were oriented in different positions to gain the maximum size reduction and reduce the power consumption. Copper heat sinks with refrigerant tubes in combination with a medium capacity fan were found to be most effective and therefore, were selected for the chiller assembly.

\subsubsection{BE150 Multi-gas Analyzer}

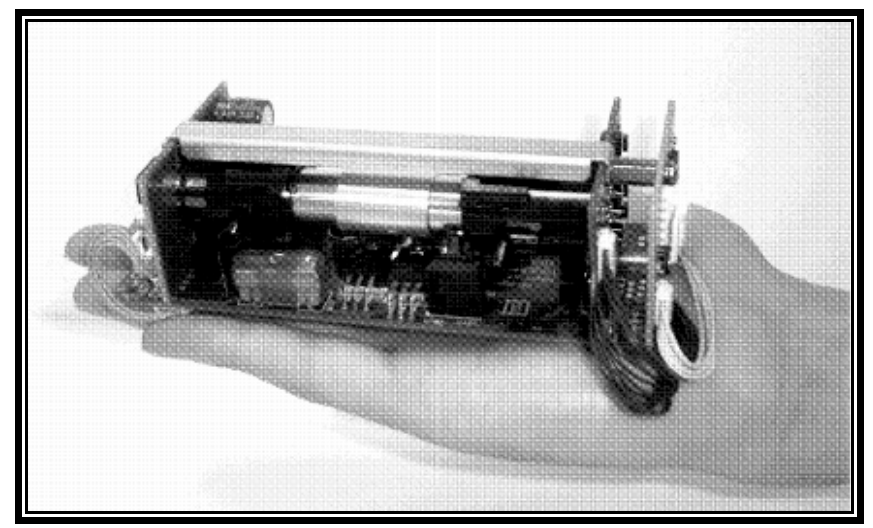

Figure-12 BE150 multi-gas analyzer [25]

The BE150 multi-gas analyzer [31] is a palm top sized NDIR analyzer that measures the $\mathrm{CO}, \mathrm{CO}_{2}$ and $\mathrm{HC}$ in the diesel exhaust simultaneously. Size and weight of the unit were the main criteria that qualified the system for 
system integration in CMEMS. The BE150 analyzer is the smaller version of the BE140 AD 5-gas analyzer used in MEMS with the performance being similar. The voltage requirement of the system was a low $12 \mathrm{~V} \mathrm{DC}$ which made it ideal for in-use measurement application. The BE150 communicates with the compact field point data acquisition controller via RS 232C interface. It also comes with analog ports to connect with $\mathrm{NO}$ and $\mathrm{O}_{2}$ sensors and readings of the external sensors can be output with those of BE150. The working principle is explained in the principle of gaseous concentration detection section under the NDIR detection technique (2.7).

\section{Specification:}

Table-9 Specification of BE150 multi-gas analyzer [31]

\begin{tabular}{||c|c|c|c|c||}
\hline Gases & Range & Resolution & Accuracy & Repeatability \\
\hline $\mathrm{CO}$ & $0-15 \%$ & $0.01 \%$ & $\pm 3 \%$ & $\pm 2 \%$ \\
\hline $\mathrm{CO}_{2}$ & $0-20 \%$ & $0.01 \%$ & $\pm 3 \%$ & $\pm 2 \%$ \\
\hline & & & $0-2000- \pm 3 \%$ & $\pm 2 \%$ \\
$\mathrm{HC}$ & $0-10,000$ PPM & 1 PPM & to $5000- \pm 5 \%$ & $\pm 2 \%$ \\
& & & to $10,000- \pm 10 \%$ & $\pm 3 \%$ \\
\hline $\mathrm{O}_{2}$ & $0-25 \%$ & $0.02 \%$ & - & - \\
\hline $\mathrm{NO}$ & $0-5000 \mathrm{PPM}$ & $1 \mathrm{PPM}$ & - & - \\
\hline
\end{tabular}




\subsubsection{Relative Humidity Sensor, Honeywell Technologies Inc.}

The HIH-3610 Series humidity sensor is designed specifically for the high volume OEM (Original Equipment Manufacturer) users. It allows for the direct input to a controller because of the sensor's linear voltage output. With a typical current draw of only $20 \mathrm{~mA}$, it consumes low power that makes it ideal for any portable emissions measurement system. Using the Honeywell RH sensor, the $\mathrm{RH}$ is measured upstream and downstream of the chiller assembly to record the effectiveness of the cooling. The sensor is also used to record the ambient $\mathrm{RH}$ and temperature to determine the $\mathrm{NO}_{\mathrm{x}}$ correction factor and convert measurements to a standard basis. Performance tests were conducted to record the temperature and $\mathrm{RH}$ by passing the air through a bubbler. The humidified air was then passed through a heated line maintained at 50, 100, 150 and $200 \mathrm{C}$ temperatures. Results were compared against the Edge-Tech dew-point analyzer that uses the chilled mirror technology to qualify the sensor for the system integration.

\section{Specification:}

Table-10 Specification of the RH sensor

\begin{tabular}{|c|c|c|c|}
\hline \hline Accuracy & Linearity & Repeatability & $\begin{array}{c}\text { Response } \\
\text { Time }\end{array}$ \\
\hline $\pm 2 \%$ & $\pm 0.5 \%$ & $\pm 0.5 \%$ & $15 \mathrm{sec}$ \\
\hline
\end{tabular}


The HIH-3610 Series RH sensor came with the calibration sheet as shown in the Figure-26 that enabled the user for a direct calculation of the relative humidity from the voltage output.

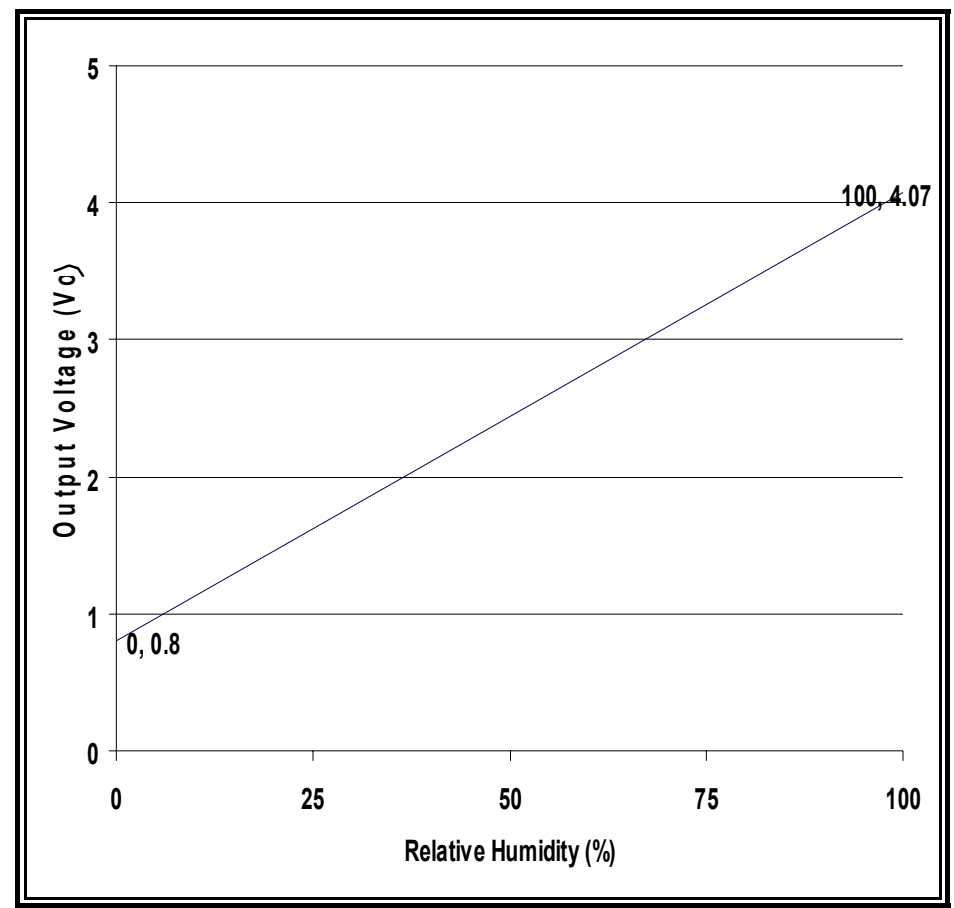

Figure-13 Calibration curve for the $\mathrm{RH}$ sensor [32]

\subsubsection{Pressure Transducers}

The MPX5050D, MPX5010D and MPX4250D series are pressure sensors that employ a microprocessor that operates on analog signal as input to provide analog output signal which is directly proportional to the applied differential pressure [33]. The MPX5050D pressure sensor is used to measure the pressure drop across the heated filter (within 1-4 PSI). The pressure drop can alarm the operator for a filter change before it is clogged completely. The MPX5010D pressure sensor is used to measure the pressure drop across the 
annubar (up to 30 inches of $\mathrm{H}_{2} \mathrm{O}$ ) to determine the volumetric flow rate. The MPX 4250D has the highest range and therefore is used to measure the pressure drop across the critical flow nozzle (around $18 \mathrm{PSI}$ ) to confirm the choke flow. The MPX7200A is used to measure the absolute pressure (around atmospheric) of the exhaust flow.

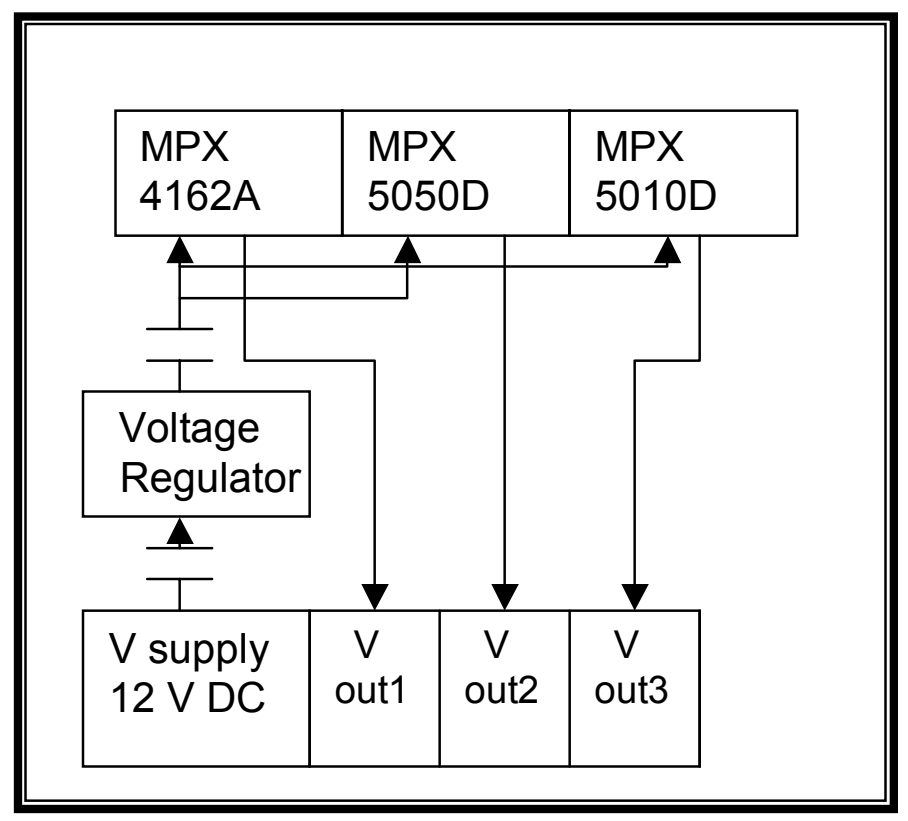

Figure-14 Schematic of the sensor board 


\section{Specification:}

Table-11 Specification of the pressure transducers [33]

\begin{tabular}{||c|c|c|c|c|c||}
\hline Model & $\begin{array}{c}\text { Voltage } \\
\text { Supply }\end{array}$ & $\begin{array}{c}\text { Voltage } \\
\text { Out } \\
\text { Range }\end{array}$ & $\begin{array}{c}\text { Range } \\
\text { (PSI) }\end{array}$ & Accuracy & $\begin{array}{c}\text { Response } \\
\text { Time }\end{array}$ \\
\hline $\begin{array}{c}\text { MPX } \\
5050 \mathrm{D}\end{array}$ & $5 \mathrm{~V}$ & $0.2-4.7 \mathrm{~V}$ & $0-7.25$ & $\pm 5 \% \mathrm{FS}$ & $1 \mathrm{~ms}$ \\
\hline $\begin{array}{c}\text { MPX } \\
5010 \mathrm{D}\end{array}$ & $5 \mathrm{~V}$ & $0.2-4.7 \mathrm{~V}$ & $0-1.45$ & $\pm 5 \% \mathrm{FS}$ & $1 \mathrm{~ms}$ \\
\hline $\begin{array}{c}\text { MPX } \\
4250 \mathrm{D}\end{array}$ & $5 \mathrm{~V}$ & $0.2-4.7 \mathrm{~V}$ & $0-29$ & $\pm 5 \% \mathrm{FS}$ & $1 \mathrm{~ms}$ \\
\hline \begin{tabular}{l} 
MPX7200A \\
\hline
\end{tabular} & $5 \mathrm{~V}$ & $0.2-4.7 \mathrm{~V}$ & $0-29$ & $\pm 5 \% \mathrm{FS}$ & $1 \mathrm{~ms}$ \\
\hline
\end{tabular}

\subsubsection{Power Supply}

A three terminal $12 \mathrm{~V}$ DC with a $19 \mathrm{~A}$ power supply is used to power all the components except the heated filter and the sampling pump because both of these operate on a $120 \mathrm{~V}$ AC supply.

\subsubsection{Ambient Temperature, Pressure and RH Measurement}

Ambient temperature, $\mathrm{RH}$ and pressure were recorded with Honeywell sensors and Motorola MPX 4200A barometric pressure sensor. These parameters were used to convert the test results to a standard condition basis. Ambient pressure and humidity are required to report the corrected $\mathrm{NO}_{\mathrm{x}}$ as per the CFR Title 40, Part 1065.215 [34]. Ambient pressure may also be used to calculate changes in altitude over a test route if high accuracy is not required. 


\subsubsection{Data Acquisition System}

Compact Field Point (CFP) [35] developed by National Instruments was the data acquisition system used in CMEMS. There are several criteria, such as size, type of modules, number of channels, sampling frequency and robustness that have to be met prior to qualification of real-time on-board data acquisition. The following sections give details of each of the modules.

\subsubsection{Backplane}

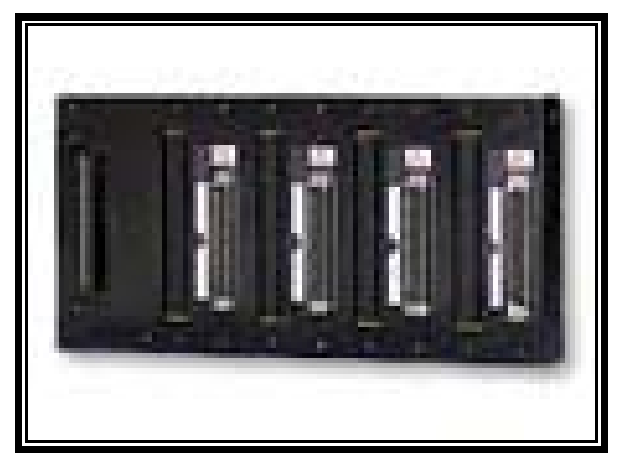

Figure-15 Four back plane of CFP [35]

The backplane is used for mounting different compact field point modules. It has 5 slots to accommodate the controller, 2 analog $\mathrm{I} / \mathrm{O}$ modules, 1 digital output module and 1 thermocouple module. The modules can conveniently be screwed down to the back plane using mounting screws. The backplane comes with a horizontal mounting bracket that provides mounting holes on either side and can easily be mounted in the cold chamber. 


\subsubsection{Compact Field Point (CFP) processor 2020}

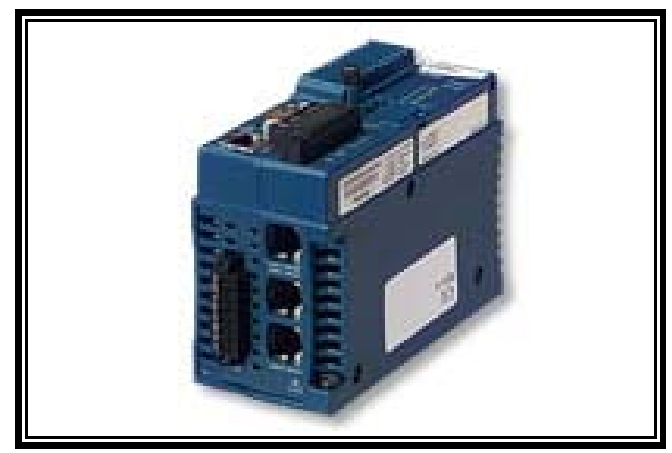

Figure-16 Compact Field Point processor 2020 [35]

The CFP 2020 uses Lab-VIEW 7.1 real-time data acquisition software. With this software, the data is logged real-time by controlling and recording measurements. For this project, data was logged and then communicated realtime with a laptop PC over serial and ethernet interfaces. The CFP-2020 features one ethernet port, four serial ports, a $512 \mathrm{MB}$ of removable compact flash storage, and an extended 32 MB RAM memory that enables a large emissions data file storage without frequent deletion.

\subsubsection{CFP Analogue I/O, Digital Output and Thermocouple Modules}

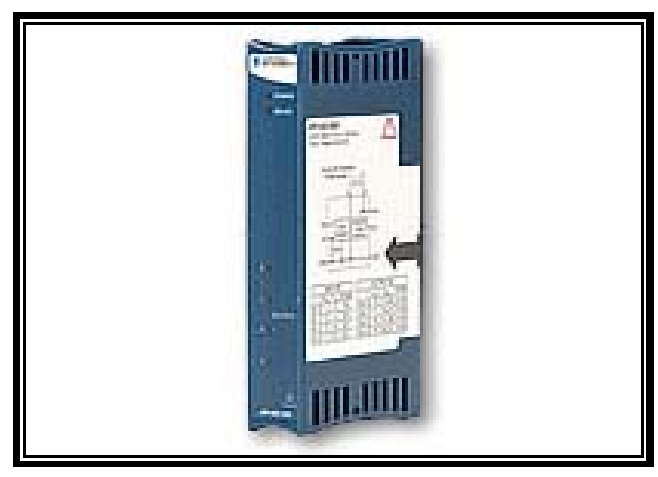

Figure-17 Compact Field Point modules [35] 
The National Instrument's analogue I/O (CFP-AI-100) accurately interfaces with sensors to read the direct voltage or current. There are 8 individually configurable input channels with 12-bit resolution to provide the acquisition for all the pressure and humidity measurements. To make the installation and setup easier, the analog I/O module features a "plug and play" operation [35] that automatically detects and identifies the configuration software. The software also allows the voltage outputs to be written in the engineering units instead of converting to the binary numbers. The module comes with a NIST-traceable [36] calibration certificate ensuring an accurate and reliable analog control.

The Digital output module has 8 differential channels that are used to connect the solid state relays for controlling temperatures of the chiller, heated filter and the $\mathrm{NO}_{\mathrm{x}}$ converter. It is also used to power the solenoid valve for calibration provision by direct input from the module. With built-in signal conditioning, one can easily connect the module to a 5-24 V DC or to a 5-240 V AC signal. The operating temperature ranges from -40 to $70 \mathrm{C}$ to allow for safe integration in the cold chamber of the system. For user's convenience, each channel has a LED to indicate the channel on/off state.

The Thermocouple module (CFP-TC-120) is an 8-channel input module with a 16-bit resolution for the direct measurement of the temperature from standard J, K, T, N, R, S, E, and B type thermocouples. The module has signal conditioning capabilities that prevent the use of an external device for accurate temperature measurements. The operating temperature of the module also 
ranges from -40 to $70 \mathrm{C}$ which allows for safe integration in the cold chamber of the CMEMS.

\subsection{Calibration Provision}

Both MEXA720 and BE50 multi-gas analyzers are calibrated with component gas bottles (NO, $\mathrm{CO}_{2}$ or mixture) at $22 \mathrm{PSI}$ pressure and nitrogen gas as the diluent at $18 \mathrm{PSI}$ pressure. A portable Horiba SGD-710C gas divider is used for the calibration that accurately blends a calibration gas with diluent up to 10 steps (0$100 \%)$ plus a zero. The gas divider reduces the number of gas cylinders needed to calibrate a gas analyzer to just two. The gas divider comes in a tough casing that protects the main unit and the flow meter from shocks and accidental loads. The gas divider works on the capillary flow-rate mixing method as shown in the figure below. It has a pressure regulator and ten calibrated capillaries with identical flow characteristics. The pressure regulator equalizes pressures of component and diluent gases entering the selector. The selector determines the blending ratio of two gases. For example, if the selector is set to 3 , the component gas is introduced into three capillaries while the diluent gas flows through the remaining capillaries. This forms a sample gas with three-tenths of the initial concentration of the component gas. The diluent-gas pressure determines the output flow rate of the standard gas. 


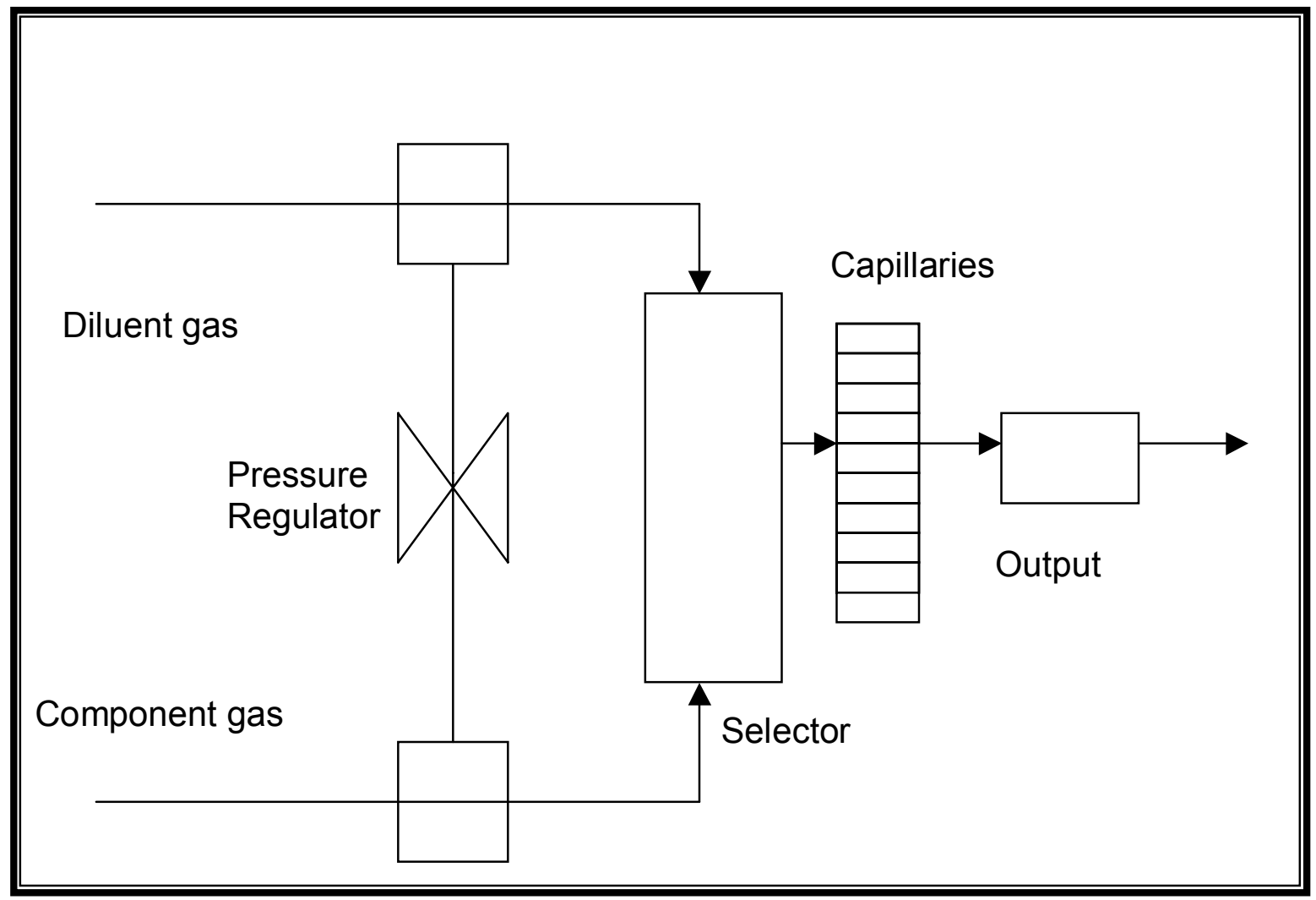

Figure-18 Schematic of the working principle of Horiba SGD-710C gas divider 


\section{Chapter 4 Experimental Setup and Procedure}

\subsection{Accuracy, Linearity and Repeatability Test}

Many steady-state tests were conducted on the MEXA720 $\mathrm{NO}_{\mathrm{x}}$ analyzer and the BE150 multi-gas analyzer to qualify for the on-board measurement application (CFR Title 40, Part 1065.307) [37]. The test setup as shown in the figure consisted of two gas bottles known as the component and the diluent. A Horiba SGD-710C gas divider was used to supply the mixture of component and diluent gases in fractions of 0 to $100 \%$. A zero, mid and span calibration was performed on analyzers before testing. Using this setup, analyzers were subjected to a steadystate test by passing the candidate gas of interest as the component at $22 \mathrm{PSI}$ pressure and nitrogen as the diluent at 18 PSI pressure. Measurements were recorded on analyzers in increments of $10 \%$ by using the gas divider and the

percentage difference to the expected response was tabulated. The mean, standard deviation and coefficient of variation was calculated to record the accuracy, linearity and repeatability. All the measurements were compared to the manufacturer specifications to qualify the analyzer for the system integration. 


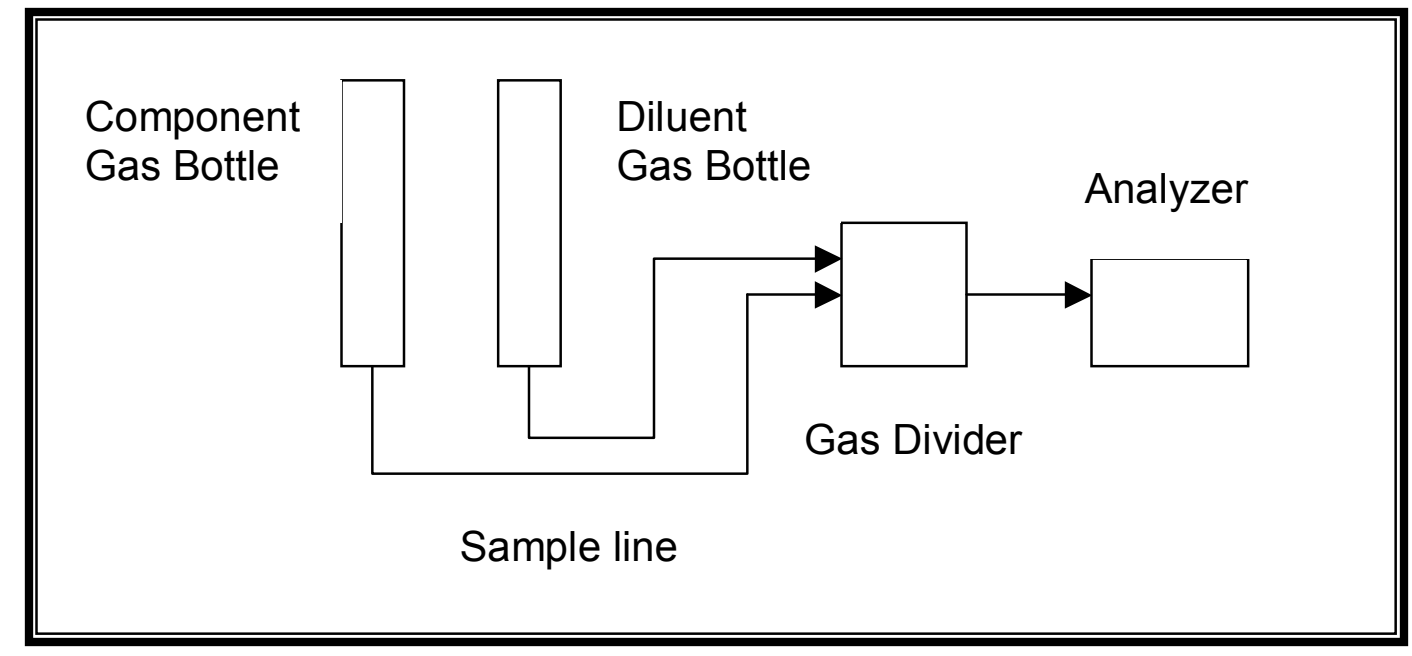

Figure-19 Schematic of the accuracy, linearity and repeatability test setup

\subsection{Response Time Test}

Response time of the analyzer is critical for "in-use" transient emissions measurement as it is necessary to determine the time taken by the analyzer to respond to change in emission concentration levels. Responses of both MEXA720 $\mathrm{NO}_{x}$ and BE150 multi-gas analyzers were tested (CFR Title 40, Part 86.315) [38] by alternately passing a component gas and nitrogen at predetermined time intervals. A computer program in Quick Basic was used to control the timing of a 3way solenoid valve to accurately switch between the component gas and nitrogen. The computer program controlled the valve for $25,20,15,10,5,2$ and 1 second intervals. The response time corresponding to $90 \%$ of the span concentration also known as T-90 was inferred from the plot. A rotameter was placed in the sample line upstream of the analyzer to ensure a constant flow throughout the test. 


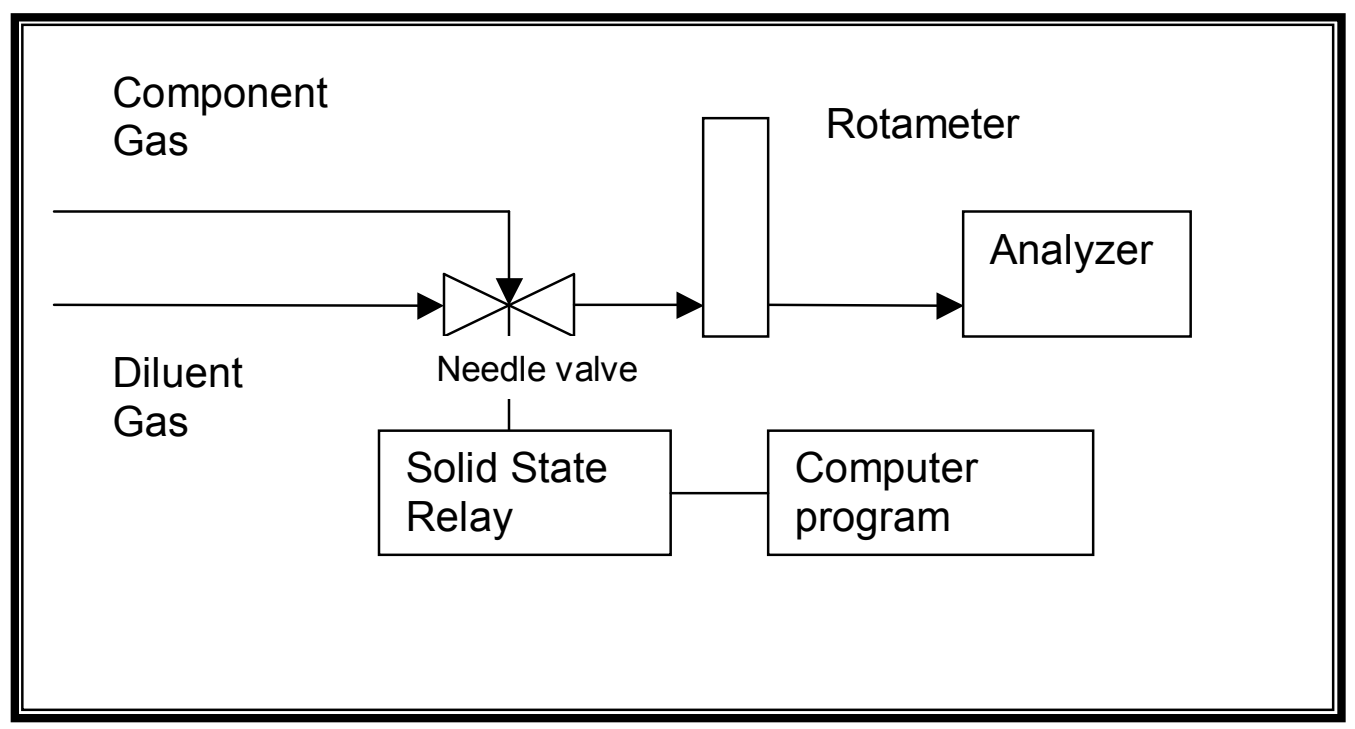

Figure-20 Schematic of the response time test set-up

\subsection{Analyzer Drift Test}

Both MEXA720 NO $\mathrm{N}_{\mathrm{x}}$ and BE150 multi-gas analyzers were tested to record the percentage drift in measurements after a calibration (CFR Title 40, Part 1065.374) [39]. The objective of the test was to confirm the agreement with the calibration for 8 hours and the drift under $\pm 2 \%$ in compliance with the current CFR. The test setup (similar to steady state test setup) consisted of component and diluent gas bottles and a gas divider. A zero, mid and span calibration was carried out with the candidate gas of concern as the component gas and nitrogen as the diluent only once. The component gas was supplied at $22 \mathrm{PSI}$ and the diluent at $18 \mathrm{PSI}$ pressures. Measurements were recorded on the candidate gas from $0-100 \%$ using a gas divider in steps of $10 \%$ after every hour for 8 hours. Results on both analyzers were found to be very accurate and no significant drift was recorded even after 8 hours of continuous operation. 


\subsection{Pressure and Flow rate Variation Test}

The objective of the test was to establish the required pressure and flow rate for calibration purpose to the desired accuracy measurement levels. The test setup was same as that of steady state tests consisting of two gas bottles as component and diluent gases and a gas divider. Both MEXA720 NO $\mathrm{N}_{\mathrm{x}}$ and BE150 multi-gas analyzers were tested by passing the component gas at different pressures varying from 22-18 PSI and flow rates varying from 2-5 LPM. The diluent was set at a constant 18 PSI pressure. Results confirmed no significant drift above 19 PSI and 2 LPM on both analyzers.

\subsection{Vibration Test}

The MEXA720 $\mathrm{NO}_{x}$ analyzer had to be tested under a range of vibrations (both amplitude and frequency), which would be typically experienced in on-road conditions. The analyzer was manually shaken and subjected to large amplitude vibrations and the drift was recorded. The analyzer was also tested on the S-10 pick-up truck of EERL to record the accuracy levels in measurements taken onroad. The vehicle was driven in Morgantown for 30 minutes. Measurements were taken on the analyzer after passing the component gas at $22 \mathrm{PSI}$ and nitrogen as the diluent at $18 \mathrm{PSI}$ while the vehicle was running. Measurements were recorded at 2 minute intervals on each fraction of $10 \%$ of the component gas to record any possible drift due to the vibration. The percentage difference was tabulated and no significant drift was noted, which qualified the analyzer for the system integration. 


\subsection{Inclination Test}

The MEXA720 $\mathrm{NO}_{x}$ analyzer was tilted at different angles from 0 to 90 degrees from the horizontal position. This test was performed to determine the potential drift in measurements due to change in the analyzer orientation. This was done because the position of the analyzer changed when the vehicle would drive uphill and downhill, and also the system could be mounted horizontally or vertically depending upon the stack position. NO as the component gas was supplied at 22 PSI pressure and the diluent at $18 \mathrm{PSI}$ pressure. Measurements were recorded to report no drift in different analyzer orientations.

\subsection{Interference Test}

Interference tests were performed with gases, which typically constitute diesel exhaust. Results from these tests were compared against manufacturer specifications. Interference tests were conducted on both MEXA720 $\mathrm{NO}_{\mathrm{x}}$ and BE150 multi-gas analyzers after they were calibrated. For interference test on the $\mathrm{NO}_{x}$ analyzer, two gas dividers were used: one for the $\mathrm{NO}$ and the other for the interference gas being studied. This allowed interference checks at different concentrations of each of the two gases. Both $\mathrm{NO}$ and interference gases were supplied at pressures of $22 \mathrm{PSI}$. The diluent was supplied at a constant $18 \mathrm{PSI}$ pressure. The analyzer response on all gases was recorded and no drift in the NO measurements were noted. For the BE150 multi-gas analyzer, only one gas divider was used because the mixture of interferences gases of $\mathrm{CO}, \mathrm{CO}_{2}$ and Propane was supplied in one gas bottle (CFR Title 40, Part 1065.350) [40]. The analyzer was calibrated with the mixture of gases as the component gas and the nitrogen as 
the diluent. The bottle pressures were set at 22 PSI for the component and $18 \mathrm{PSI}$ for the diluent. The interference with all gases on the candidate gas was recorded and no significant drift was found in the measurements which successfully met the manufacturer specification.

\subsection{Calibration Efficiency Test}

The manufacturer recommends the calibration of the $\mathrm{NO}_{x}$ analyzer with a bubbler, but it is still optional [27]. The analyzer was calibrated by passing the NO gas through a bubbler. Since some of the NO is absorbed by the water, the concentration of NO is decreased. Therefore, calibration coefficients on the wet basis [36] were set in the analyzer unit based on the calculation below-

$$
\mathrm{C}_{\text {wet }}=\mathrm{C} *\left(\mathrm{P}-\mathrm{P}_{\text {sat }}\right) / \mathrm{P}
$$

In the above equation, $\mathrm{C}_{\text {wet }}$ is the concentration of $\mathrm{NO}$ on wet basis, $\mathrm{C}$ is the measured concentration, $\mathrm{P}$ is the atmospheric pressure and $\mathrm{P}_{\text {sat }}$ is the saturated vapor pressure at the bubbler temperature. After setting coefficients, the analyzer was calibrated with 2000 PPM NO gas as the component at 22 PSI pressure and nitrogen as the diluent at 18 PSI pressure. A Horiba SGD 710C gas divider was used to allow the component gas to flow in set fractions. Measurements were recorded on the analyzer with and without using a bubbler for the calibration and reported no significant drift. 


\subsection{Performance Test of Critical Flow Nozzle (CFN)}

A Critical Flow Nozzle (CFN) was tested using three different pumps, both pressuring and vacuum types (refer to section 3.2.1 on the sample pump), to qualify for the system integration. Since the BE150 multi-gas analyzer requires a constant volumetric flow rate for accuracy purpose, a CFN is placed downstream of the pump and upstream of the analyzer. Tests were conducted to measure the pressure drop across the CFN to confirm the constant flow rate. The volumetric flow rate was measured using a rotameter. A filter was also placed upstream of the pump to account for the restriction offered in the flow to simulate the actual emissions sampling system condition. The pressure drop across the filter was measured as 3 inches of $\mathrm{Hg}$ which did not affect the flow rate across the CFN. Thus, the CFN was qualified on the Gast manufacturing sampling pump for the required constant 3 LPM volumetric flow rate.

\subsection{Chiller Assembly}

Tests were conducted on the chiller assembly to record the effectiveness of cooling. As the chiller assembly consists of an aluminum chamber, TEC, heat sink and a fan, the performance of each of these components had to be tested to qualify the entire assembly for the system integration. The heat sink was a critical component in the assembly that enabled the effective cooling in combination with a fan. Moreover, the performance of the heat sink was also dependent on the orientation. Therefore, the purpose of the test was to qualify the heat sink for mounting constraint free design. To allow for low power consumption by the assembly, different lower power capacity fans were tested. A K-type thermocouple 
was used to measure the upstream and downstream temperature of the sample air that is passed through the assembly. The test also included measurements of temperature by blowing the hot air from the heat gun around the chiller assembly to qualify for temperatures typical of summer time operation. The ultimate objective of the test was to design a chiller assembly that could be mounted in any position (vertical or horizontal) with out significantly affecting the cooling performance. Tests confirmed that the large copper heat sinks with refrigerant tubes were orientation sensitive and could only be vertically mounted. However, the smaller copper heat sinks with refrigerant tubes did not exhibit any significant change in the temperature output irrespective of the orientation. A $12 \mathrm{~V}$ DC medium capacity fan (up to $10 \mathrm{CFM}$ ) was qualified in combination with the smaller heat sink with refrigerant tubes.

\subsection{Mass Flow Rate Measurement using Annubar}

Series of tests were conducted on a 5 inch annubar tube to measure the mass flow rate by passing the high volume of air at different pressures. The objective of these tests was to record any drift in mass flow rate measurements (due to pulsatile nature of the flow near elbow) by placing the annubar at different positions from the elbow. The existing MEMS unit places the annubar at 10 diameters from elbow that requires longer installation time and man power effort. As CMEMS was aimed at reducing the installation time and manpower effort, the annubar was tested at different locations in the 5 inch diameter pipe. Measurements were compared against a 800 CFM Laminar Flow Element (LFE) at the EERL. In the first case, as seen in the schematic of the test set-up, the 
annubar was placed at 10 diameters downstream of the LFE to record the pressure of the fully developed flow. In the second case, the annubar was placed at the center of the elbow and results showed a significant drift in mass flow rates caused due to the pulsatile flow characteristics at the elbow. In the third case, the annubar was placed at 2 diameters downstream of the elbow and exhibited similar flow behavior to that of the first case. Thus, it was inferred that the annubar could be placed near the elbow which would not cause a significant drift in mass flow rate measurements. This, in turn, would save the installation time for the longer pipe used by MEMS. Since the CMEMS had to be mounted on the stack, these tests also helped in designing the position of the annubar in the heated chamber.

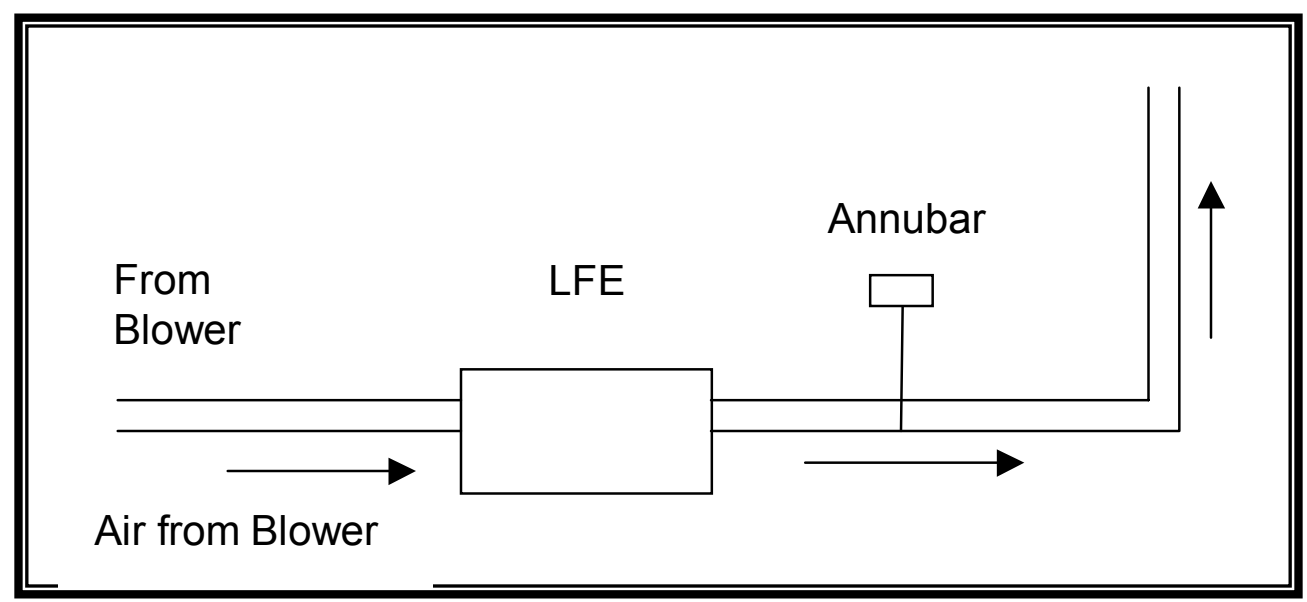

Figure-21 (case 1) Schematic of the test setup with annubar at $10 \mathrm{D}$ downstream of the LFE 


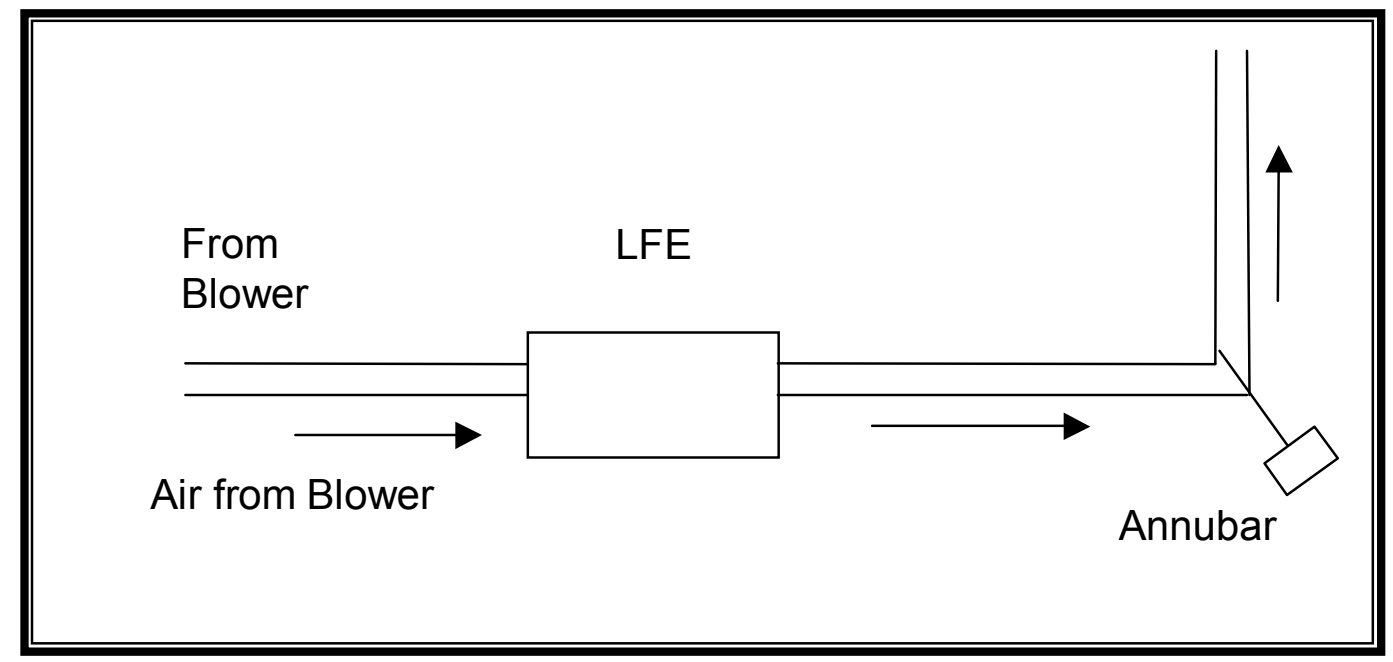

Figure-22 (case 2) Schematic of the test setup with annubar at the elbow

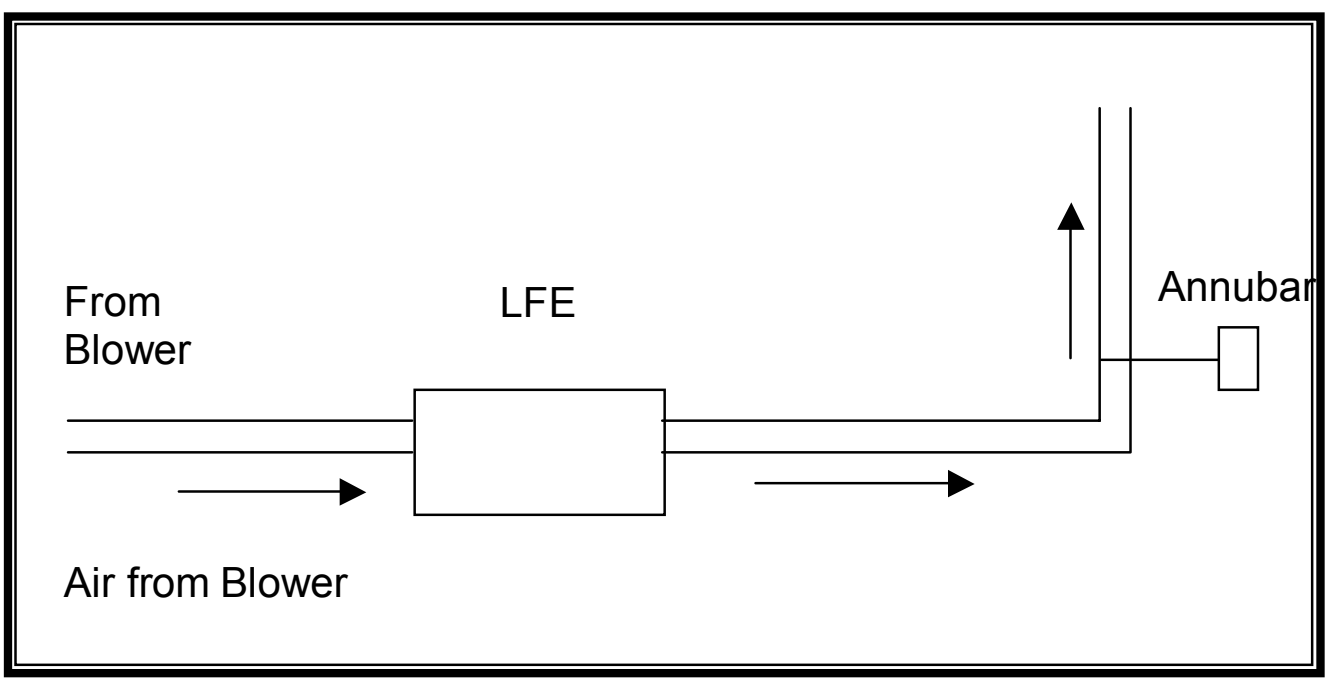

Figure-23 (case 3) Schematic of the test setup with annubar at 2D downstream of the elbow

\subsection{Performance Test of RH Sensor}

The test set-up as shown in the figure had a medium capacity pump (20 LPM) to pressurize the ambient air through a bubbler at 3 LPM flow rate. The humidified 
air was passed through a heated line maintained at 122, 212, $302 \& 392 \mathrm{~F}$. This air was passed through the chiller assembly and the relative humidity with the CMEMS Honeywell sensor was measured upstream and downstream of the assembly. Two J-type thermocouples were used to measure upstream and downstream temperatures of the chiller assembly. The humidity and temperature measurements recorded by the CMEMS Honeywell humidity sensor were compared against the Edge-Tech humidity analyzer.

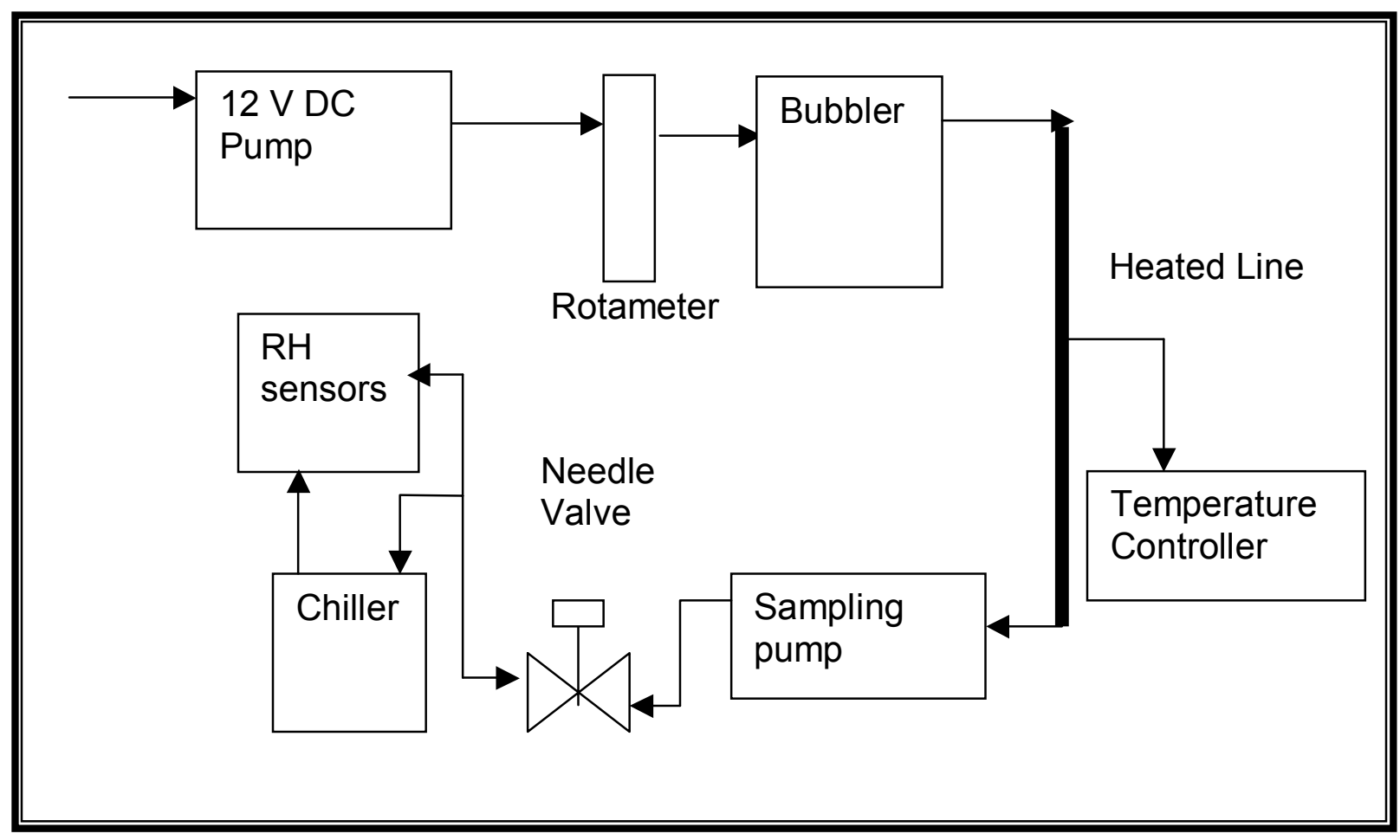

Figure-24 Schematic of the test set-up 


\section{Chapter 5 Results and Discussions}

\subsection{Accuracy, Linearity and Repeatability Test}

\subsubsection{MEXA720 NO Analyzer}

The analyzer was tested on steady-state tests following the procedure for the experimental setup as described in the previous chapter (4.1). The NO was set as the component gas (2000 PPM) at 22 PSI pressure and nitrogen as the diluent at $18 \mathrm{PSI}$ pressure. Measurements were recorded on the analyzer in increments of 10\% (200 PPM) using a gas divider and the absolute percentage difference to the expected response was tabulated. The mean, standard deviation and coefficient of variation was calculated to record the accuracy and linearity for each concentration on three different attempts. Measurements were found to be very accurate with maximum percentage difference of $1.02 \%$. Results were very repeatable with maximum coefficient of variation (COV hereafter) as low as 0.02 . 


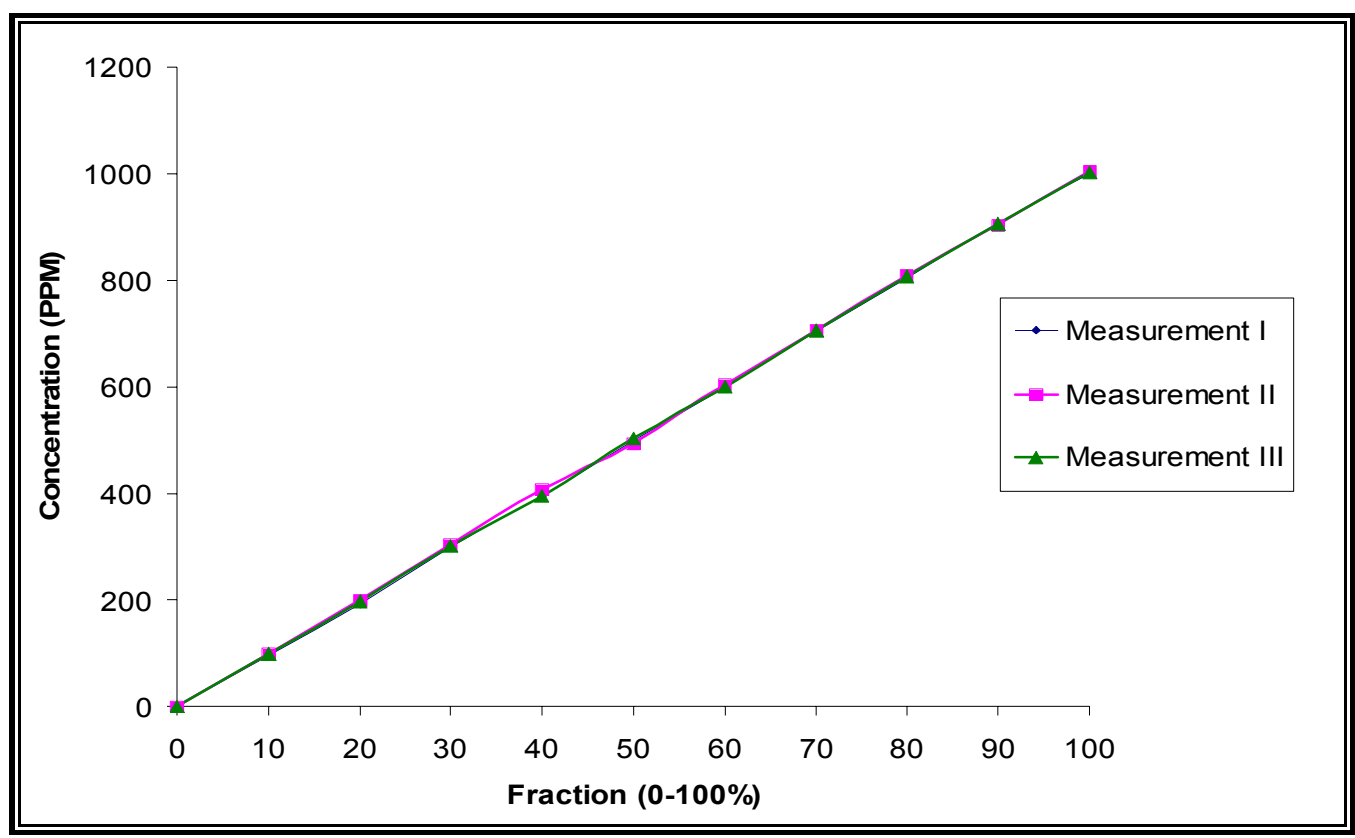

Figure-25 Accuracy and linearity for NO

Table-12 Accuracy, linearity and repeatability test result for NO

\begin{tabular}{|c|c|c|c|c|c|c|c|c|c|}
\hline \multirow{2}{*}{$\begin{array}{c}\text { Bottle Conc. } \\
\text { (PPM) }\end{array}$} & \multicolumn{6}{|c|}{ Measurements I,II \& III } & \multicolumn{3}{|c|}{ Repeatability Parameters } \\
\hline & $\mathrm{I}$ & $\%$ Diff & II & $\%$ Diff & III & $\%$ Diff & Mean & Stand Dev & COV \\
\hline 0 & 0 & 0.00 & 0 & 0.00 & 0 & 0.00 & 0.00 & 0.00 & \\
\hline 100.2 & 96 & 4.19 & 100 & 0.20 & 100 & 0.20 & 98.67 & 2.31 & 0.02 \\
\hline 200.4 & 193 & 3.69 & 201 & 0.30 & 197 & 1.70 & 197.00 & 4.00 & 0.02 \\
\hline 300.6 & 300 & 0.20 & 304 & 1.13 & 302 & 0.47 & 302.00 & 2.00 & 0.01 \\
\hline 400.8 & 396 & 1.20 & 407 & 1.55 & 396 & 1.20 & 399.67 & 6.35 & 0.02 \\
\hline 501 & 498 & 0.60 & 494 & 1.40 & 503 & 0.40 & 498.33 & 4.51 & 0.01 \\
\hline 601.2 & 601 & 0.03 & 605 & 0.63 & 601 & 0.03 & 602.33 & 2.31 & 0.00 \\
\hline 701.4 & 703 & 0.23 & 706 & 0.66 & 706 & 0.66 & 705.00 & 1.73 & 0.00 \\
\hline 801.6 & 805 & 0.42 & 809 & 0.92 & 807 & 0.67 & 807.00 & 2.00 & 0.00 \\
\hline 901.8 & 907 & 0.58 & 903 & 0.13 & 907 & 0.58 & 905.67 & 2.31 & 0.00 \\
\hline \multirow[t]{4}{*}{1002} & 1001 & 0.10 & 1005 & 0.30 & 1003 & 0.10 & 1003.00 & 2.00 & 0.00 \\
\hline & Mean & 1.02 & & 0.66 & & 0.55 & & & \\
\hline & Stand Dev & 1.42 & & 0.51 & & 0.49 & & & \\
\hline & $\mathbf{R}^{2}$ & 0.9999 & & 0.9999 & & 0.9999 & & & \\
\hline
\end{tabular}




\subsubsection{BE150 Multi-gas Analyzer}

For tests on $\mathrm{CO}_{2}$, the same experiment setup as that of $\mathrm{NO}$ was used. The gas bottle containing $20 \% \mathrm{CO}_{2}$ was used as the component gas and nitrogen as the diluent. Whereas for $\mathrm{CO}$ and $\mathrm{HC}$, a gaseous mixture of $\mathrm{CO}_{2}$ (12\%), CO (4\%) and Propane (1007 PPM) was used as the component gas and nitrogen as the diluent for the testing. Responses of each detector in the analyzer were recorded and percentage differences were tabulated. For the accuracy measurement, the maximum percentage difference for $\mathrm{CO}_{2}$ was found to be $0.17 \%$ when measurements were recorded upwards from 0 to $100 \%$ and $0.19 \%$ when measuring downwards from $100 \%$ to 0 . For $\mathrm{CO}$, it was recorded as $0.32 \%$ when measurements were recorded upwards $(0-100 \%)$ and $1.08 \%$ when downwards $(100 \%-0)$. For Propane, the maximum percentage difference was noted as $0.86 \%$ measuring upwards and $1.64 \%$ measuring downwards. Therefore, results confirmed high accuracy and linearity in measurements. For the repeatability measurement, the maximum percentage difference was noted as $0.38 \%$ for $\mathrm{CO}_{2}, 0.83 \%$ for $\mathrm{CO}$ and $0.22 \%$ for Propane. The COV was noted as low as 0.01 for $\mathrm{CO}_{2}, 0.15$ for $\mathrm{CO}$ and zero for Propane, thus confirming very high repeatability. 
Table-13 Accuracy \& linearity test result for $\mathrm{CO}_{2}$

\begin{tabular}{||c|c|c|c|c|c||}
\hline $\begin{array}{c}\text { Bottle } \\
\text { Conc. }\end{array}$ & Measured & \% Diff & Bottle Conc. & Measured & \% Diff \\
\hline$(\%)$ & & & $(\%)$ & & \\
\hline 0 & 0.04 & 0.00 & 20 & 20.08 & 0.40 \\
\hline 2 & 2.01 & 0.50 & 18 & 18.00 & 0.00 \\
\hline 4 & 4.01 & 0.25 & 16 & 16.00 & 0.00 \\
\hline 6 & 6.00 & 0.00 & 14 & 14.03 & 0.21 \\
\hline 8 & 7.99 & 0.12 & 12 & 11.99 & 0.08 \\
\hline 10 & 10.02 & 0.20 & 10 & 9.99 & 0.10 \\
\hline 12 & 12.01 & 0.08 & 8 & 7.98 & 0.25 \\
\hline 14 & 14.00 & 0.00 & 6 & 6.02 & 0.33 \\
\hline 16 & 16.02 & 0.12 & 4 & 4.03 & 0.75 \\
\hline 18 & 18.04 & 0.22 & 2 & 2.00 & 0.00 \\
\hline 20 & 20.07 & 0.35 & 0 & 0.02 & 0.00 \\
\hline & Mean & $\mathbf{0 . 1 7}$ & & Mean & $\mathbf{0 . 1 9}$ \\
\hline & Stand Dev & $\mathbf{0 . 1 6}$ & & Stand Dev & $\mathbf{0 . 2 3}$ \\
\hline & $\mathbf{R}$ & $\mathbf{1 . 0 0}$ & & $\mathbf{R}^{2}$ & $\mathbf{1 . 0 0}$ \\
\hline
\end{tabular}

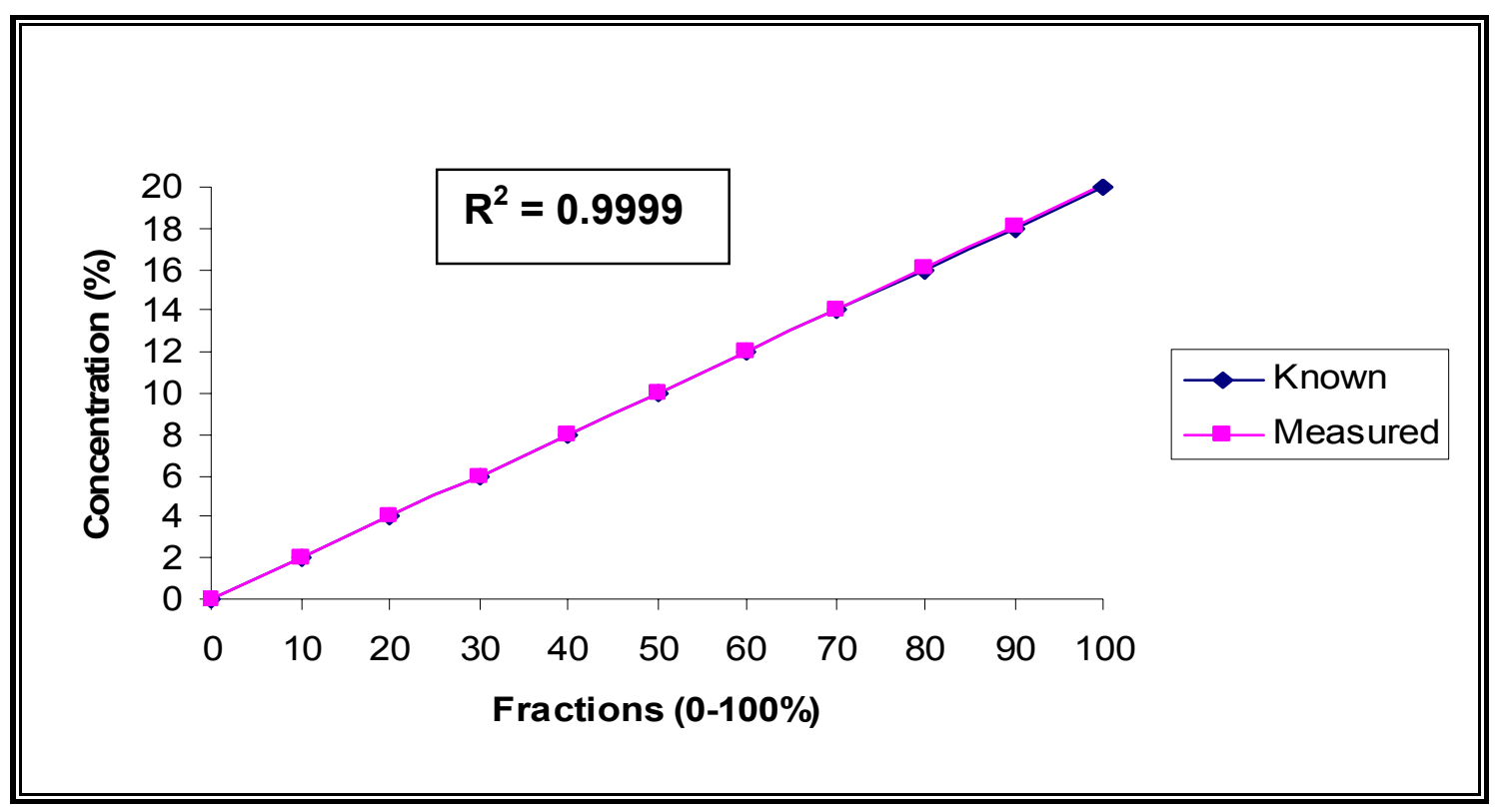

Figure-26 Accuracy and linearity $(0-100 \%)$ for $\mathrm{CO}_{2}$ 


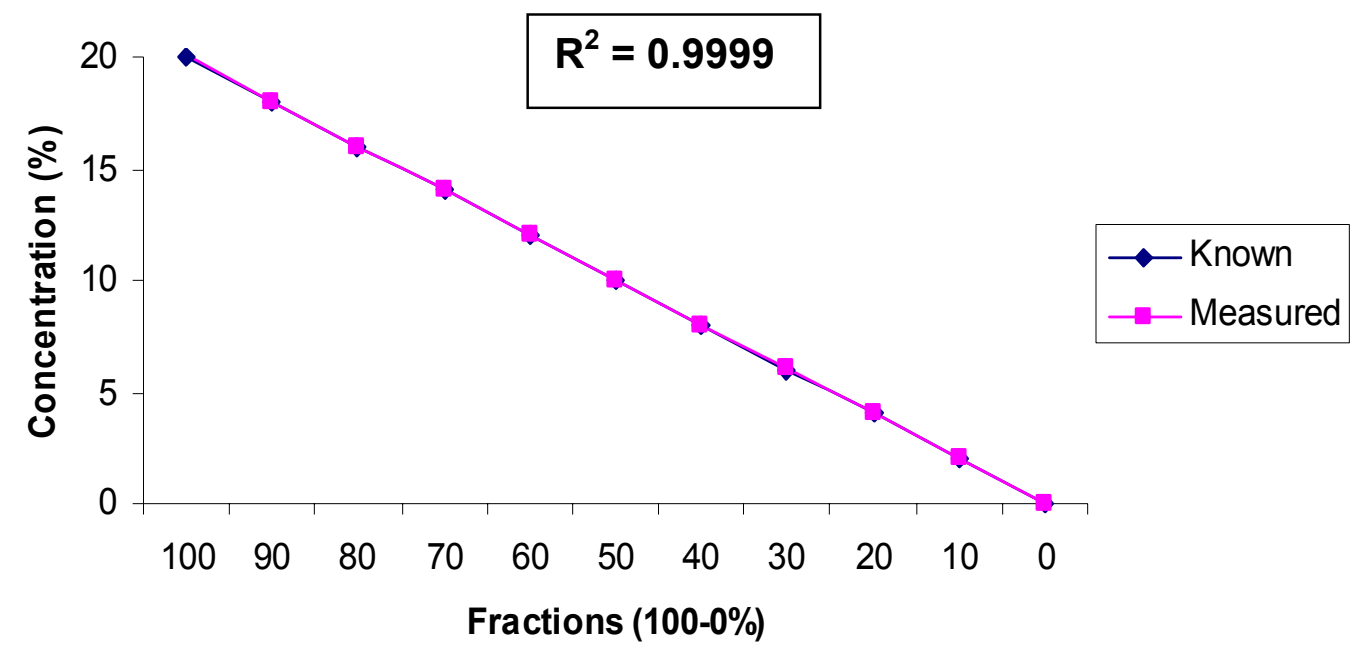

Figure-27 Accuracy and linearity (100\%-0) for $\mathrm{CO}_{2}$

Table-14 Repeatability test result for $\mathrm{CO}_{2}$

\begin{tabular}{||c|c|c|c|c|c|c|c|c|c||}
\hline $\begin{array}{c}\text { Bottle } \\
\text { Conc. }\end{array}$ & \multicolumn{10}{|c||}{ Measurement (I,II\& III) } \\
\hline & I & $\begin{array}{c}\% \\
\text { Diff }\end{array}$ & II & $\begin{array}{c}\% \\
\text { Diff }\end{array}$ & III & $\begin{array}{c}\% \\
\text { Diff }\end{array}$ & Mean & $\begin{array}{c}\text { Stand } \\
\text { Dev }\end{array}$ & COV \\
\hline & $(\%)$ & & $(\%)$ & & $(\%)$ & & & & \\
\hline & 0.04 & 0.00 & 0.03 & 0.00 & 0.03 & 0.00 & 20.08 & 0.05 & 0.00 \\
\hline 0 & & & & & & & & & \\
10 & 9.97 & 0.30 & 9.96 & 0.40 & 9.99 & 0.10 & 9.99 & 0.06 & 0.01 \\
\hline & & & & & & & & & \\
\hline
\end{tabular}


Table-15 Accuracy \& linearity test result for CO

\begin{tabular}{||c|c|c|c|c|c||}
\hline $\begin{array}{c}\text { Bottle } \\
\text { Conc. }\end{array}$ & Measured & \% Diff & $\begin{array}{c}\text { Bottle } \\
\text { Conc. }\end{array}$ & Measured & \% Diff \\
\hline $\mathbf{( \% )}$ & & & $\mathbf{( \% )}$ & & \\
\hline 0.00 & 0.01 & 0.00 & 4.00 & 4.02 & 0.50 \\
\hline 0.40 & 0.39 & 2.50 & 3.60 & 3.58 & 0.56 \\
\hline 0.80 & 0.81 & 1.25 & 3.20 & 3.19 & 0.31 \\
\hline 1.20 & 1.21 & 0.83 & 2.80 & 2.81 & 0.36 \\
\hline 1.60 & 1.60 & 0.00 & 2.40 & 2.38 & 0.83 \\
\hline 2.00 & 2.00 & 0.00 & 2.00 & 1.98 & 1.00 \\
\hline 2.40 & 2.39 & 0.42 & 1.60 & 1.57 & 1.88 \\
\hline 2.80 & 2.82 & 0.71 & 1.20 & 1.21 & 0.83 \\
\hline 3.20 & 3.21 & 0.31 & 0.80 & 0.81 & 1.25 \\
\hline 3.60 & 3.60 & 0.00 & 0.40 & 0.41 & 2.50 \\
\hline 4.00 & 4.01 & 0.25 & 0.00 & 0.00 & 0.00 \\
\hline & Mean & $\mathbf{0 . 3 2}$ & & $\mathbf{M e a n}^{\prime}$ & $\mathbf{1 . 0 8}$ \\
\hline & Stand Dev & $\mathbf{0 . 3 3}$ & & Stand Dev & $\mathbf{0 . 8 0}$ \\
\hline & $\mathbf{R}$ & $\mathbf{1 . 0 0 0 0}$ & & $\mathbf{R}^{2}$ & $\mathbf{0 . 9 9 9 7}$ \\
\hline
\end{tabular}

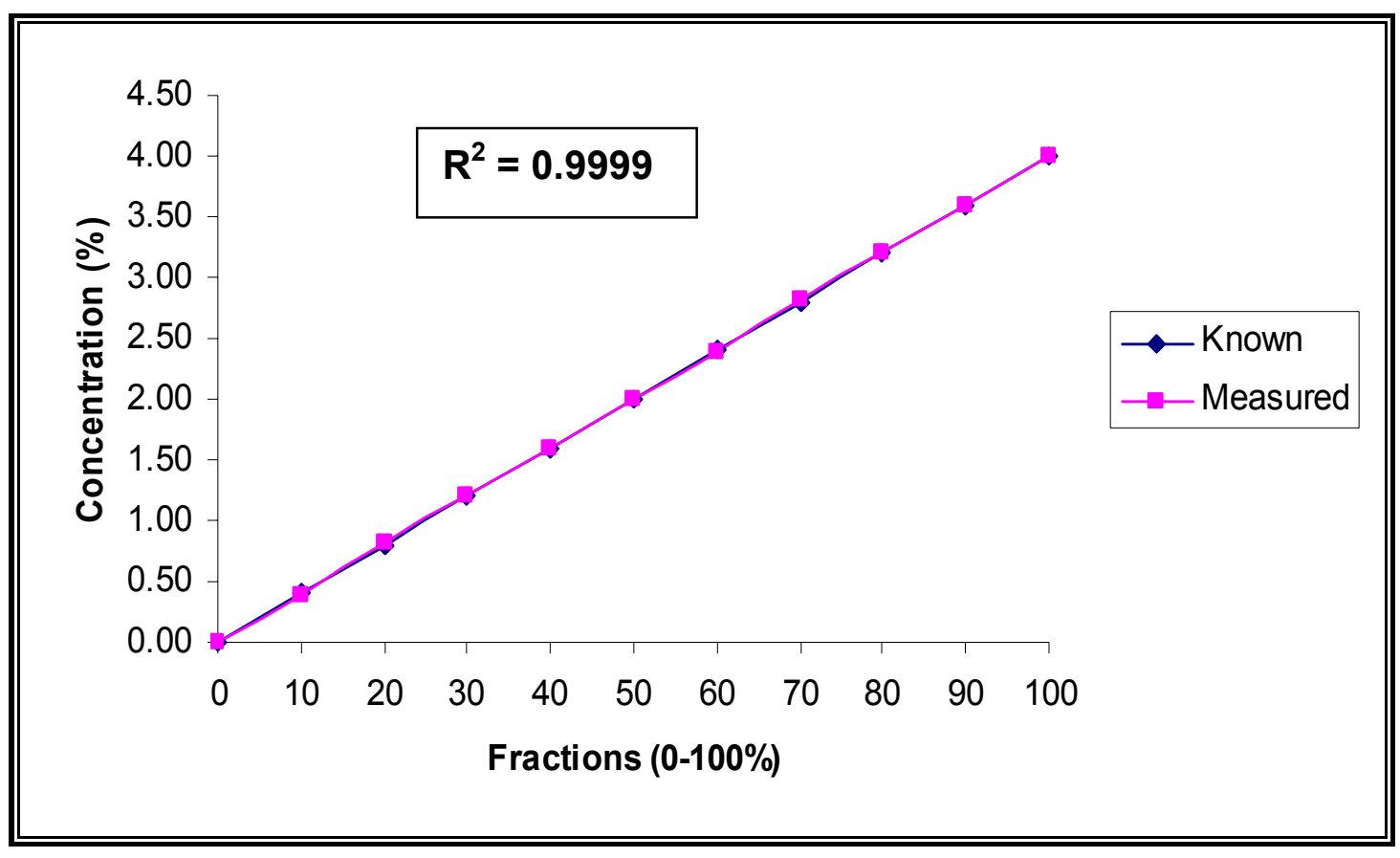

Figure-28 Accuracy and linearity (0-100\%) for CO 


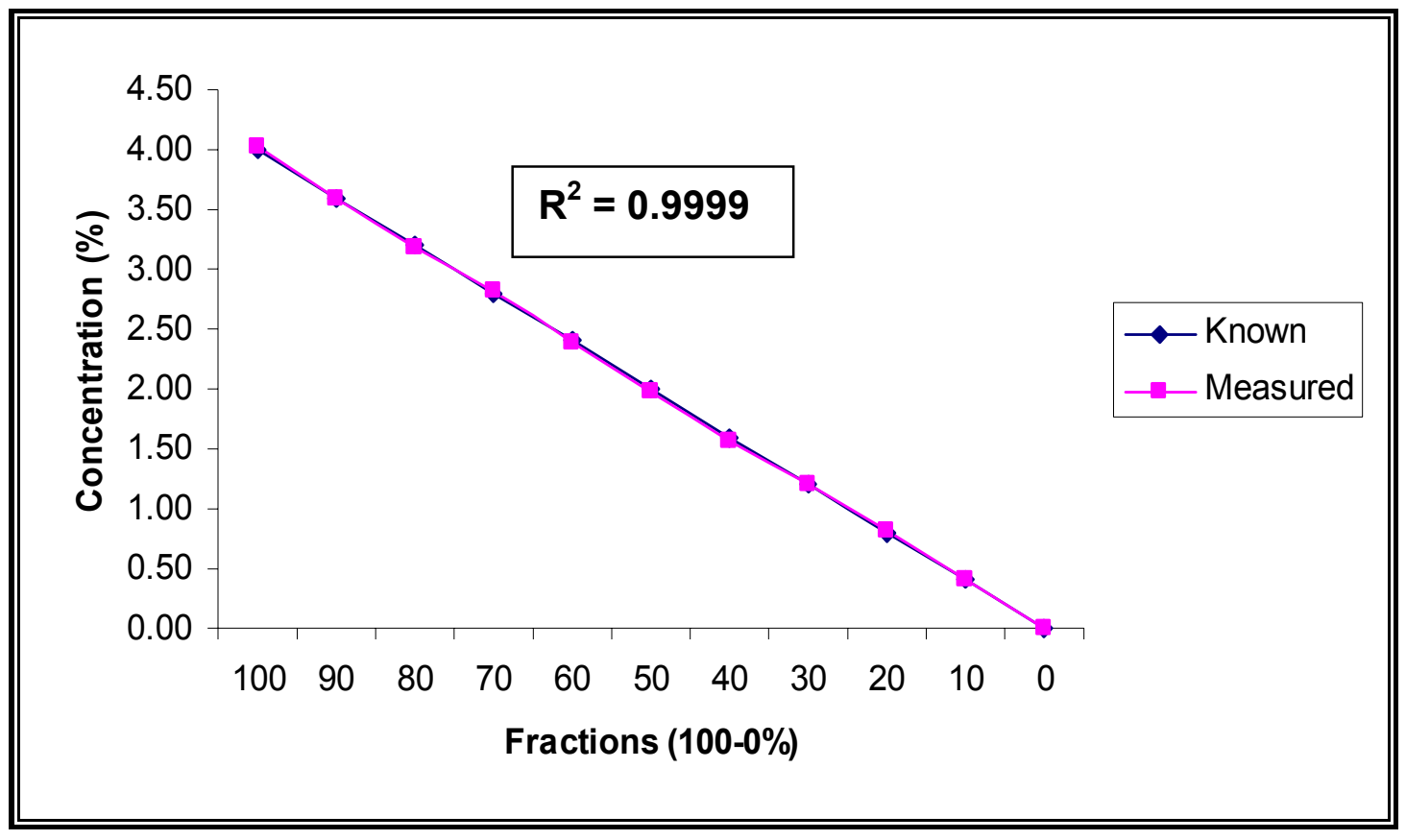

Figure-29 Accuracy and linearity $(100 \%-0)$ for CO

Table-16 Repeatability test result for CO

\begin{tabular}{||c|c|c|c|c|c|c|c|c|c||}
\hline \hline $\begin{array}{c}\text { Bottle } \\
\text { Conc. }\end{array}$ & \multicolumn{10}{|c||}{ Measurement (I,II\& III) } \\
\hline & I & $\begin{array}{c}\% \\
\text { Diff }\end{array}$ & II & $\begin{array}{c}\% \\
\text { Diff }\end{array}$ & III & $\begin{array}{c}\% \\
\text { Diff }\end{array}$ & Mean & $\begin{array}{c}\text { Stand } \\
\text { Dev }\end{array}$ & COV \\
\hline & $(\%)$ & & (\%) & & (\%) & & & & \\
\hline & & & & & & & & & \\
\hline & 0 & 0.00 & 0 & 0.00 & 0 & 0.00 & 0.00 & 0.00 & \\
\hline 2 & 1.98 & 1.00 & 1.98 & 1.00 & 1.99 & 0.50 & 1.98 & 0.29 & 0.15 \\
\hline & & & & & & & & & \\
4 & 4.02 & 0.50 & 4.01 & 0.25 & 4.01 & 0.25 & 4.01 & 0.14 & 0.04 \\
\hline
\end{tabular}


Table-17 Accuracy \& linearity test result for HC

\begin{tabular}{||c|c|c|c|c|c||}
\hline $\begin{array}{c}\text { Bottle } \\
\text { Conc. }\end{array}$ & Measured & \% Diff & $\begin{array}{c}\text { Bottle } \\
\text { Conc. }\end{array}$ & Measured & \% Diff \\
\hline (PPM) & (PPM) & & (PPM) & (PPM) & \\
\hline 0.00 & 0.00 & 0.00 & 1007.00 & 999.41 & 0.75 \\
\hline 100.70 & 94.18 & 6.47 & 906.30 & 899.13 & 0.79 \\
\hline 201.40 & 193.26 & 4.04 & 805.60 & 801.14 & 0.55 \\
\hline 302.10 & 294.68 & 2.46 & 704.90 & 700.12 & 0.68 \\
\hline 402.80 & 400.12 & 0.67 & 604.90 & 601.45 & 0.57 \\
\hline 503.50 & 501.84 & 0.33 & 503.50 & 500.94 & 0.51 \\
\hline 604.20 & 602.18 & 0.33 & 402.80 & 400.48 & 0.58 \\
\hline 704.90 & 700.41 & 0.64 & 302.10 & 296.36 & 1.90 \\
\hline 805.60 & 800.91 & 0.58 & 201.40 & 194.27 & 3.54 \\
\hline 906.30 & 897.24 & 1.00 & 100.70 & 95.28 & 5.38 \\
\hline 1007.00 & 998.34 & 0.86 & 0.00 & 0.00 & 0.00 \\
\hline \multicolumn{7}{|c|}{ Mean } & $\mathbf{0 . 8 6}$ & & Mean & $\mathbf{1 . 6 4}$ \\
\hline & Stand Dev & $\mathbf{0 . 6 9}$ & & Stand Dev & $\mathbf{1 . 8 8}$ \\
\hline \multicolumn{7}{|c|}{} & $\mathbf{0 . 9 9 9 9}$ & & $\mathbf{R}^{2}$ & $\mathbf{0 . 9 9 9 9}$ \\
\hline
\end{tabular}

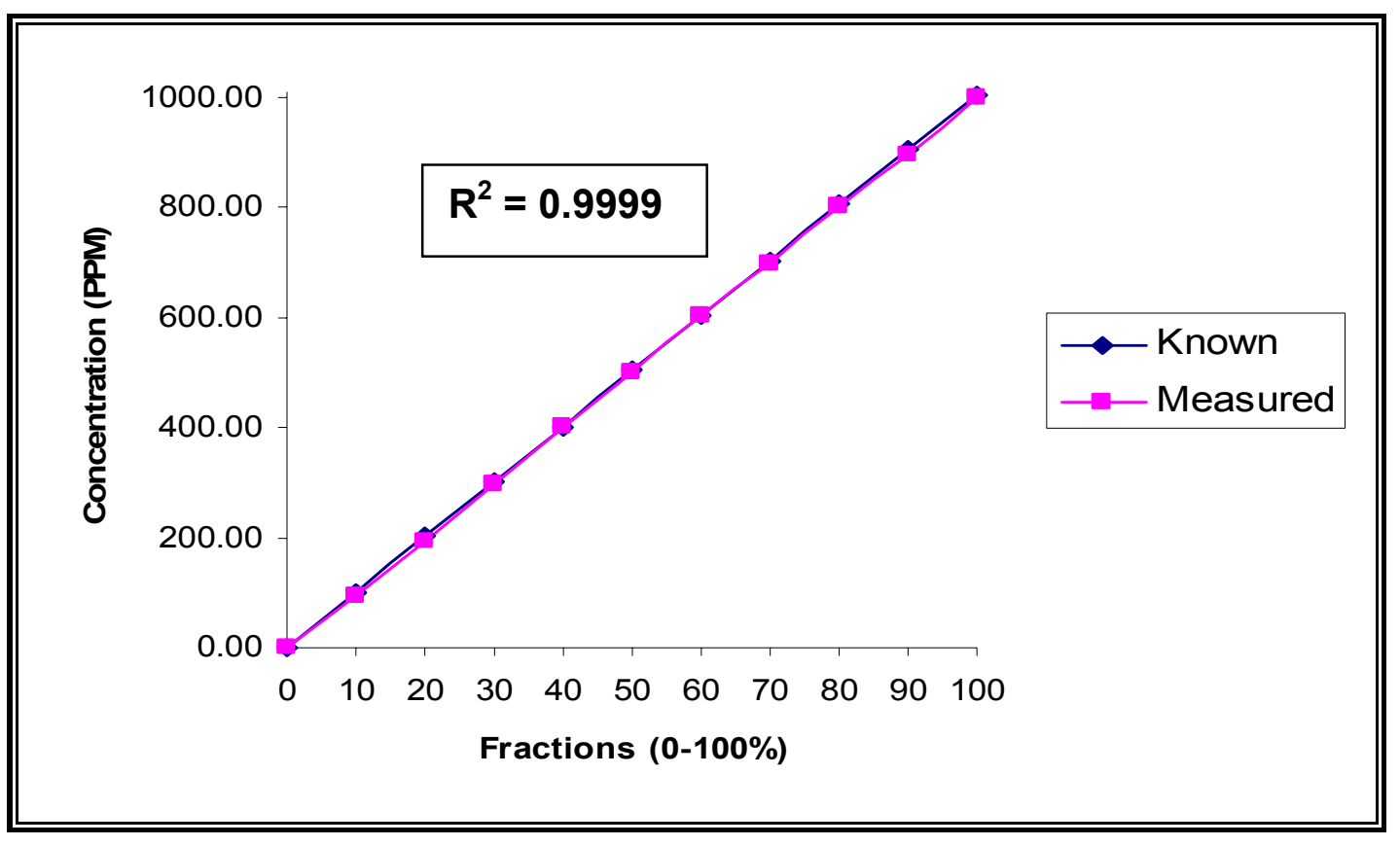

Figure-30 Accuracy and linearity (0-100\%) for HC 


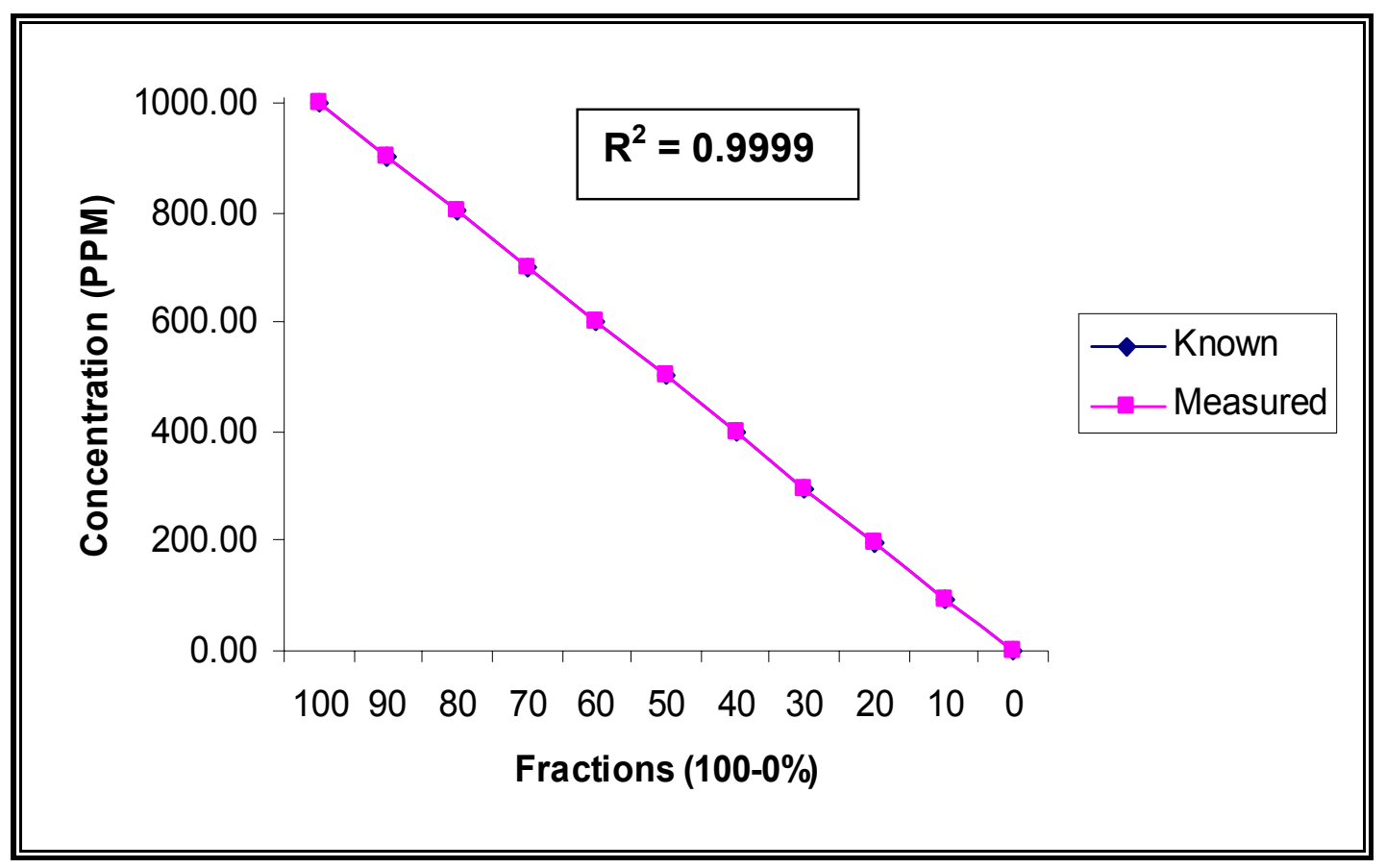

Figure-31 Accuracy and linearity $(100 \%-0)$ for HC

Table-18 Repeatability test result for $\mathrm{HC}$

\begin{tabular}{|c|c|c|c|c|c|c|c|c|c|}
\hline \multirow[t]{2}{*}{$\begin{array}{l}\text { Bottle } \\
\text { Conc. }\end{array}$} & \multicolumn{9}{|c|}{ Measurement (I,II\& III) } \\
\hline & $\mathbf{I}$ & $\begin{array}{c}\% \\
\text { Diff }\end{array}$ & II & $\begin{array}{c}\% \\
\text { Diff }\end{array}$ & III & $\begin{array}{c}\% \\
\text { Diff }\end{array}$ & Mean & $\begin{array}{c}\text { Stand } \\
\text { Dev }\end{array}$ & COV \\
\hline$(\%)$ & $(\%)$ & & (\%) & & $(\%)$ & & & & \\
\hline 0.00 & 0.00 & 0.00 & 0.00 & 0.00 & 0.00 & 0.00 & 0.00 & 0.00 & \\
\hline 503.50 & 501.46 & 0.41 & 502.82 & 0.14 & 502.86 & 0.13 & 502.38 & 0.80 & 0.00 \\
\hline 1007.00 & 1005.93 & 0.11 & 1004.12 & 0.29 & 1004.81 & 0.22 & 1004.95 & 0.91 & 0.00 \\
\hline
\end{tabular}




\subsection{Response Time Test}

Response time of both MEXA720 $\mathrm{NO}_{x}$ and BE150 multi-gas analyzers were tested by alternately passing a component gas and nitrogen at predetermined time intervals. The response time corresponding to $90 \%$ of the span concentration, also known as T-90, was inferred from the plot. T-90 was found to be less than 4 seconds for $\mathrm{NO}_{\mathrm{x}}$ and less than 3 seconds for $\mathrm{CO}_{2}, \mathrm{CO}$ and $\mathrm{HC}$.

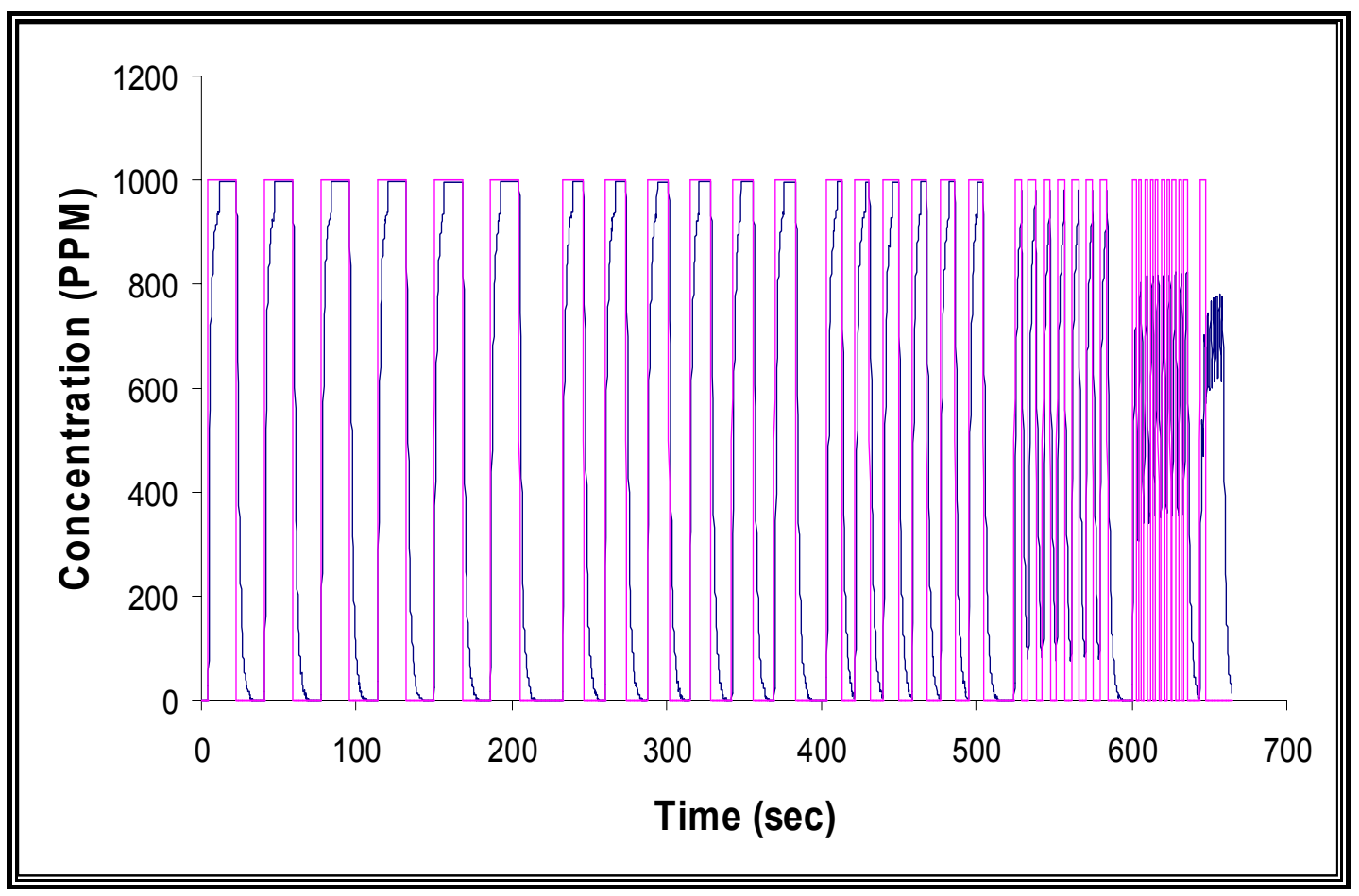

Figure-32 Response time test result for NO 


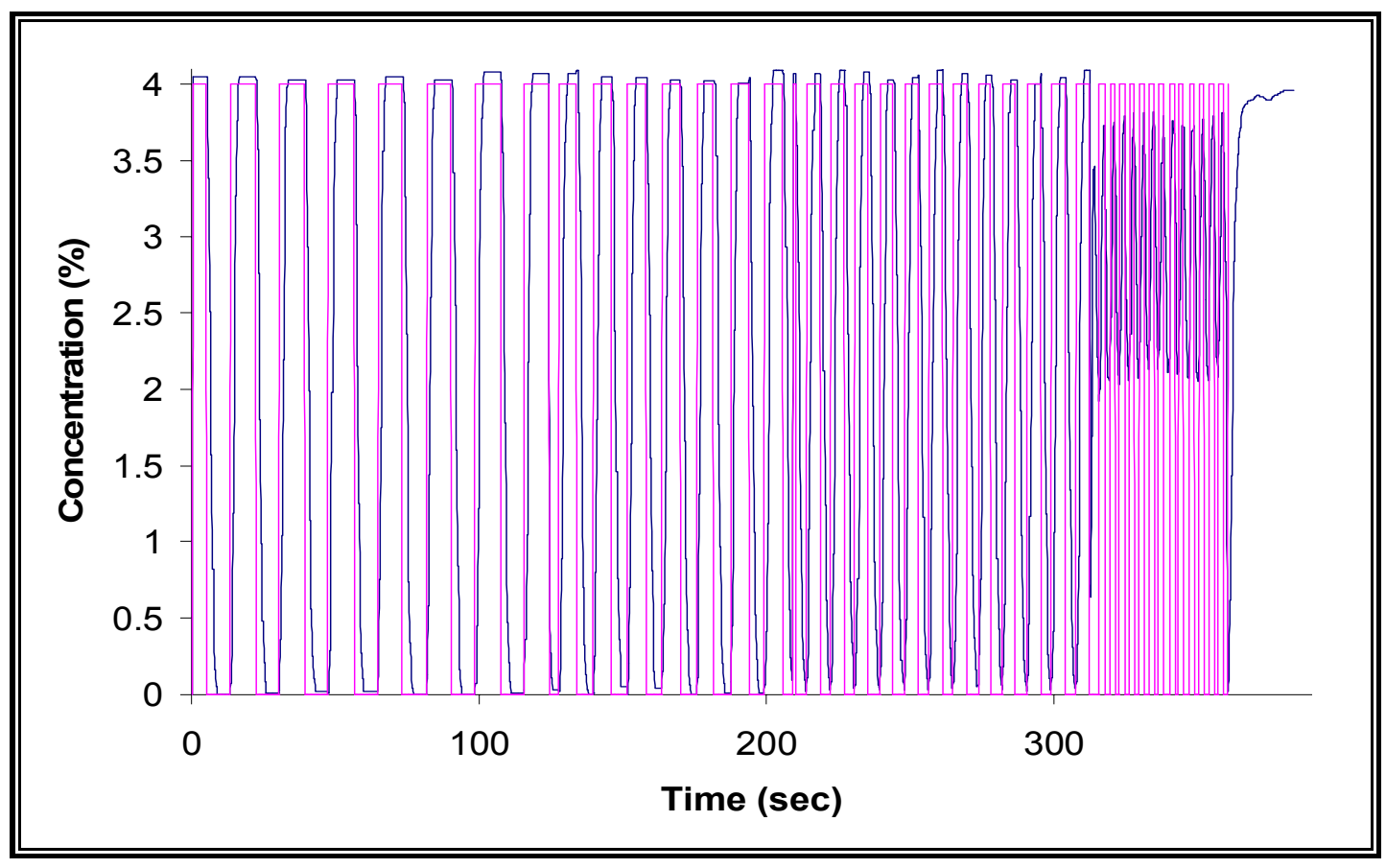

Figure-33 Response time test result for $\mathrm{CO}$

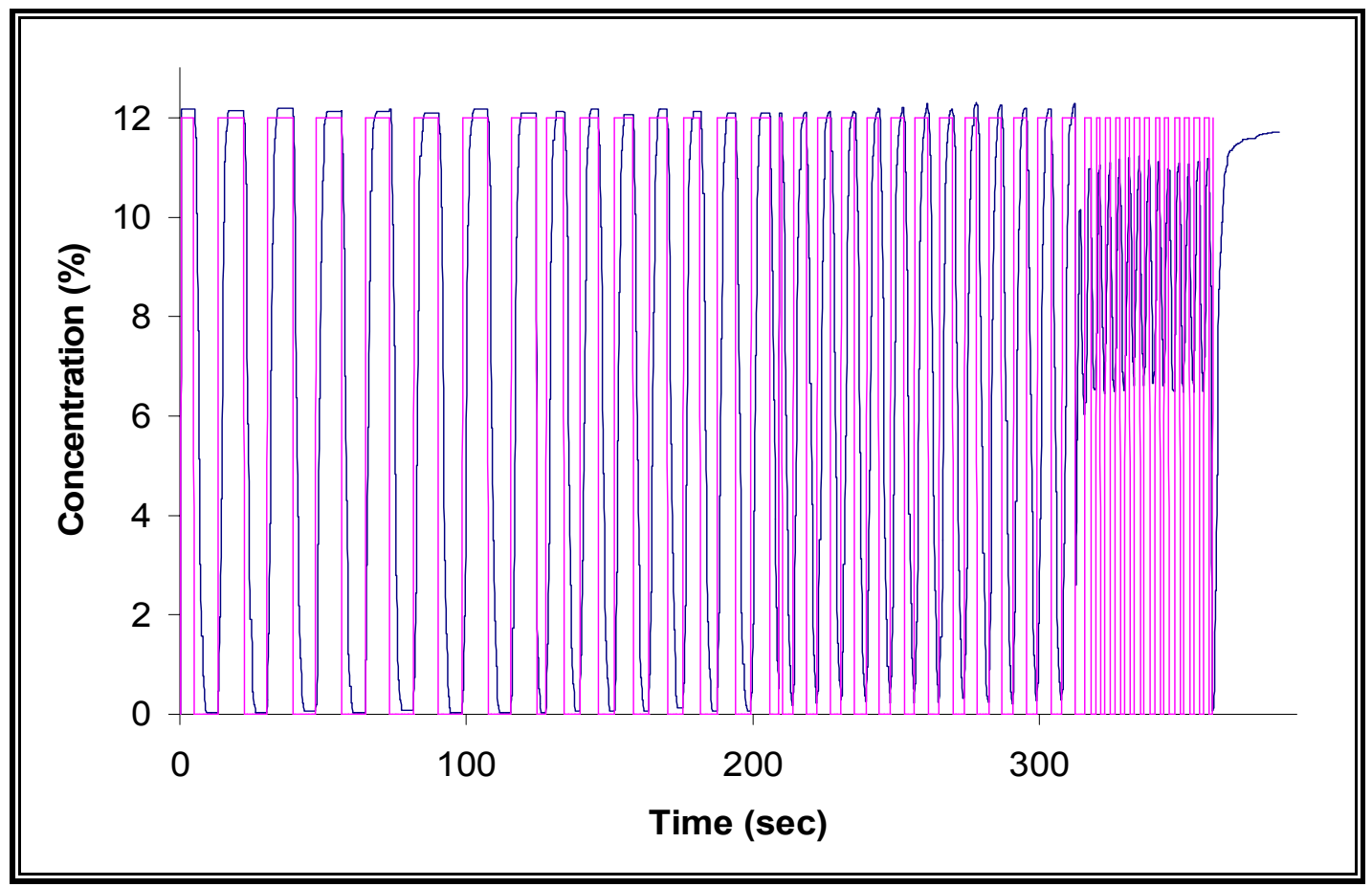

Figure-34 Response time test result for $\mathrm{CO}_{2}$ 


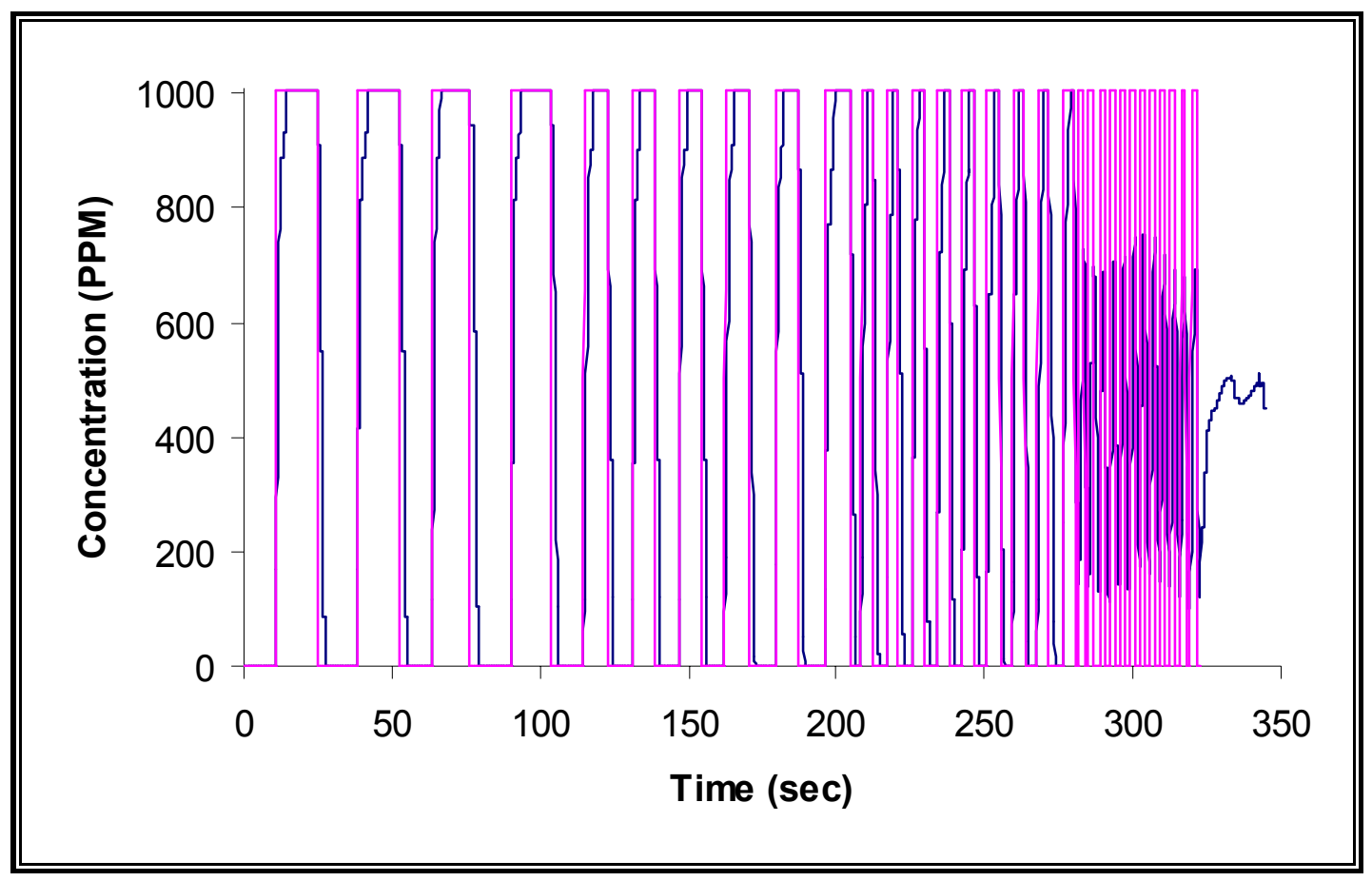

Figure-35 Response time test result for $\mathrm{HC}$

\subsection{Analyzer Drift Test}

Both MEXA720 NO in the experimental test setup and procedures (section 4.3) to record the percentage drift in measurements after a calibration. The objective of the test was to confirm the agreement with the calibration for 8 hours and the drift under $\pm 2 \%$ in compliance with the current CFR part 1065. The results as shown in the following tables recorded no significant drift (observed as flat lines with respect to the time on the x-axis) even after 8 hours of continuous operation. 
Table-19 Analyzer drift test result on the MEXA720 $\mathrm{NO}_{x}$ analyzer

\begin{tabular}{|c|c|c|c|c|c|c|c|c|c||}
\hline $\begin{array}{c}\text { Bottle } \\
\text { Conc. }\end{array}$ & Measured & $\mathbf{1 H r}$ & $\mathbf{2 ~ H r}$ & $\mathbf{3 ~ H r}$ & $\mathbf{4 ~ H r}$ & $\mathbf{5 ~ H r}$ & $\mathbf{6 ~ H r}$ & $\mathbf{7 ~ H r}$ & $\mathbf{8} \mathbf{~ r r}$ \\
\hline 0 & 1 & 1 & 0 & 0 & 0 & 0 & 0 & 0 & 0 \\
\hline 200 & 206 & 205 & 201 & 200 & 200 & 198 & 191 & 191 & 190 \\
\hline 400 & 407 & 405 & 400 & 400 & 401 & 397 & 394 & 393 & 391 \\
\hline 600 & 608 & 608 & 600 & 601 & 598 & 596 & 591 & 589 & 590 \\
\hline 800 & 809 & 808 & 804 & 804 & 798 & 797 & 792 & 792 & 791 \\
\hline 1000 & 1004 & 1007 & 1002 & 1003 & 999 & 998 & 994 & 992 & 991 \\
\hline 1200 & 1207 & 1209 & 1206 & 1206 & 1198 & 1197 & 1196 & 1194 & 1191 \\
\hline 1400 & 1405 & 1408 & 1406 & 1408 & 1400 & 1400 & 1396 & 1394 & 1392 \\
\hline 1600 & 1609 & 1610 & 1606 & 1609 & 1609 & 1608 & 1600 & 1597 & 1594 \\
\hline 1800 & 1806 & 1811 & 1809 & 1810 & 1811 & 1810 & 1807 & 1800 & 1798 \\
\hline 2000 & 2003 & 2005 & 2005 & 2007 & 2006 & 2005 & 2006 & 2003 & 2002 \\
\hline \hline
\end{tabular}

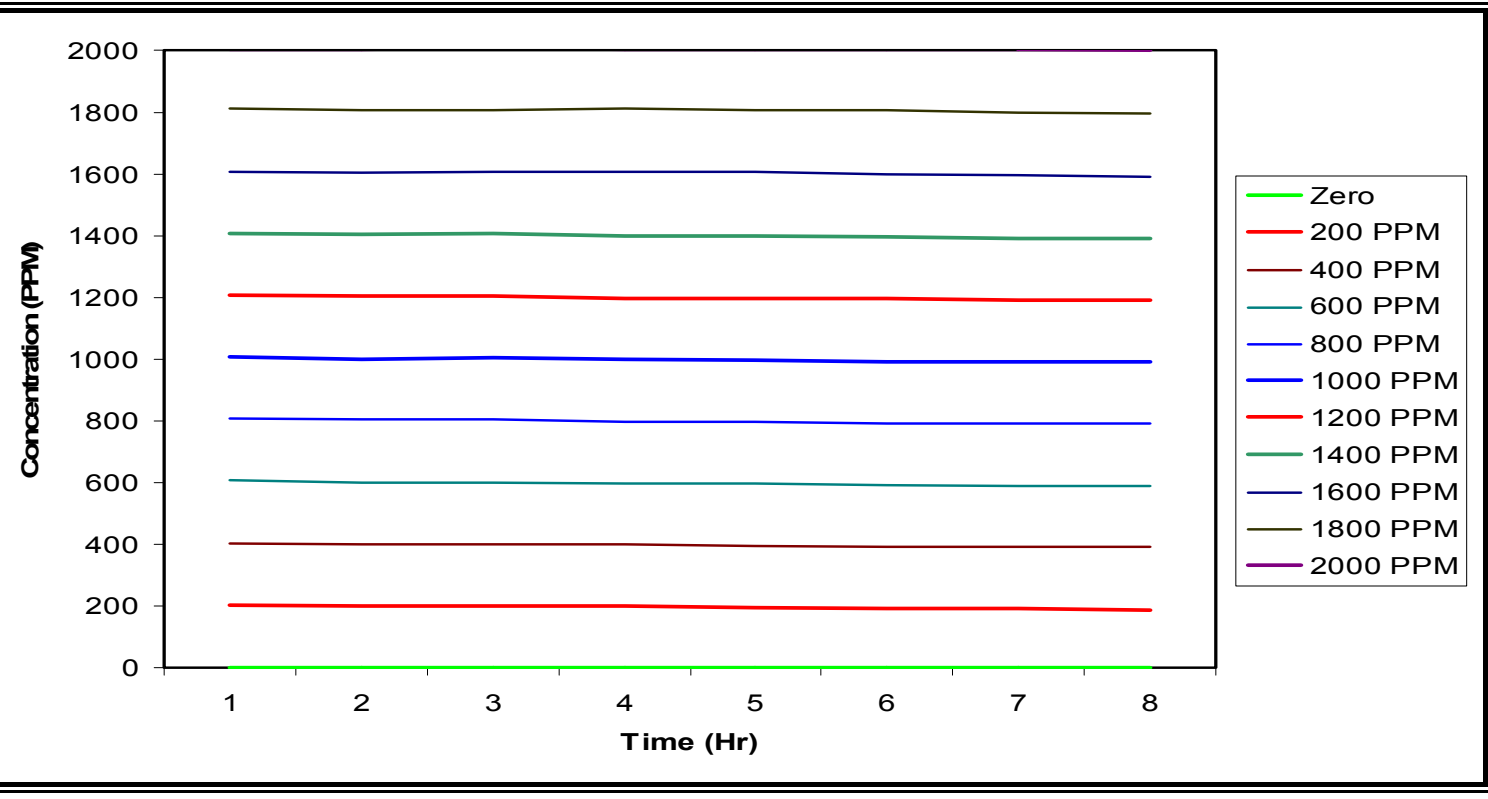

Figure-36 Analyzer drift for NO (0-2000 PPM) 
Table-20 Analyzer drift test result on the BE150 multi-gas analyzer

\begin{tabular}{|l|c|c|c|c|c|c|c|c|c||}
\hline Gas & Points & $\mathbf{1 ~ H r}$ & $\mathbf{2 ~ H r}$ & $\mathbf{3} \mathbf{H r}$ & $\mathbf{4} \mathbf{H r}$ & $\mathbf{5 ~ H r}$ & $\mathbf{6 ~ H r}$ & $\mathbf{7 ~ H r}$ & $\mathbf{8} \mathbf{H r}$ \\
\hline & Zero & 0.00 & 0.01 & 0.02 & 0.00 & 0.01 & 0.02 & 0.02 & 0.03 \\
\hline CO & Mid & 2.05 & 2.09 & 2.10 & 2.11 & 2.12 & 2.12 & 2.11 & 2.1 \\
\hline & Span & 4.05 & 4.09 & 4.09 & 4.06 & 4.07 & 4.05 & 4.07 & 4.08 \\
\hline & Zero & 0.00 & 0.02 & 0.04 & 0.00 & 0.02 & 0.00 & 0.02 & 0.01 \\
\hline CO2 & Mid & 6.06 & 6.14 & 6.17 & 6.19 & 6.14 & 6.18 & 6.19 & 6.19 \\
\hline & Span & 12.01 & 12.09 & 12.09 & 12.08 & 12.08 & 12.08 & 12.09 & 12.09 \\
\hline & Zero & 0.00 & 0.00 & 0.00 & 0.00 & 0.00 & 0.00 & 0.00 & 0.00 \\
\hline HC & Mid & 498.35 & 483 & 458.09 & 451.21 & 452.1 & 448.85 & 450.2 & 451.21 \\
\hline & Span & 998.4 & 978.1 & 968.01 & 954.02 & 956.7 & 951.27 & 949.3 & 946.18 \\
\hline \hline
\end{tabular}

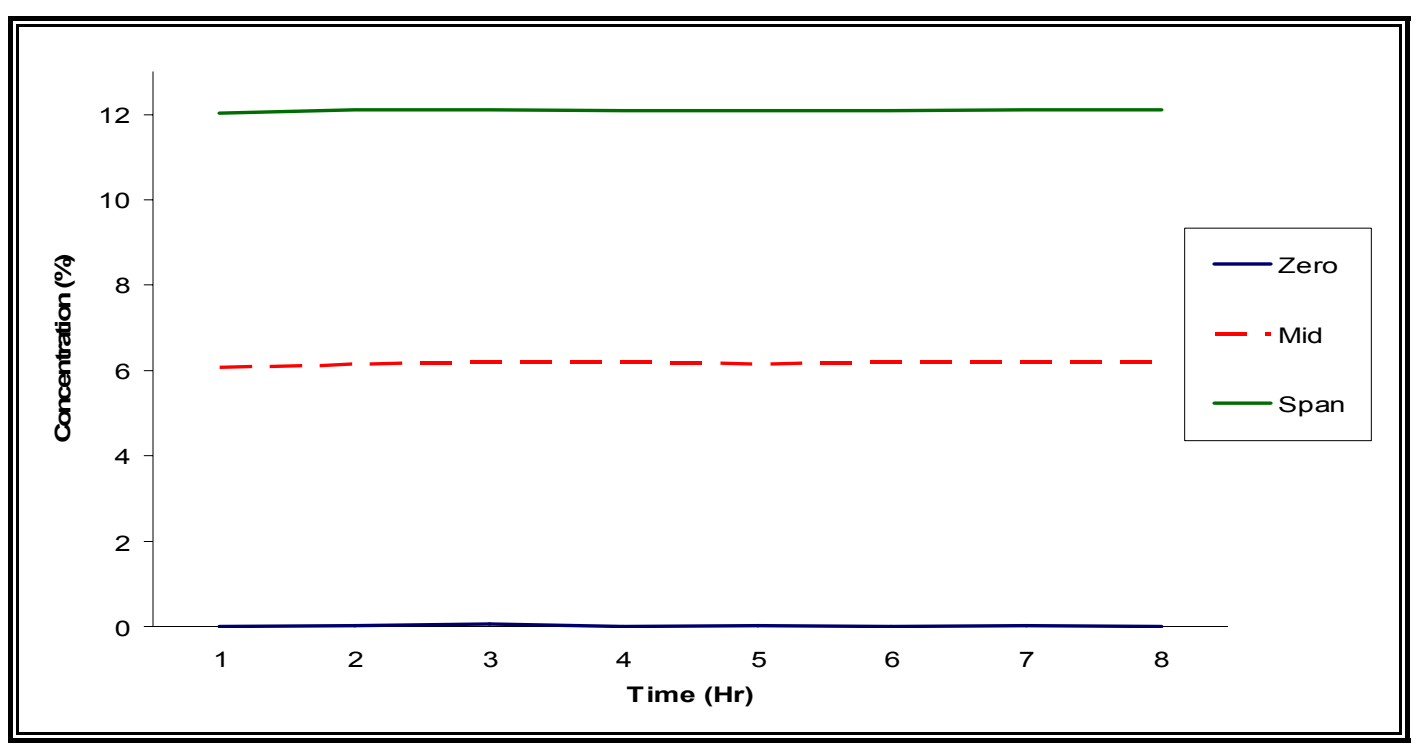

Figure-37 Analyzer drift for $\mathrm{CO}_{2}$ 


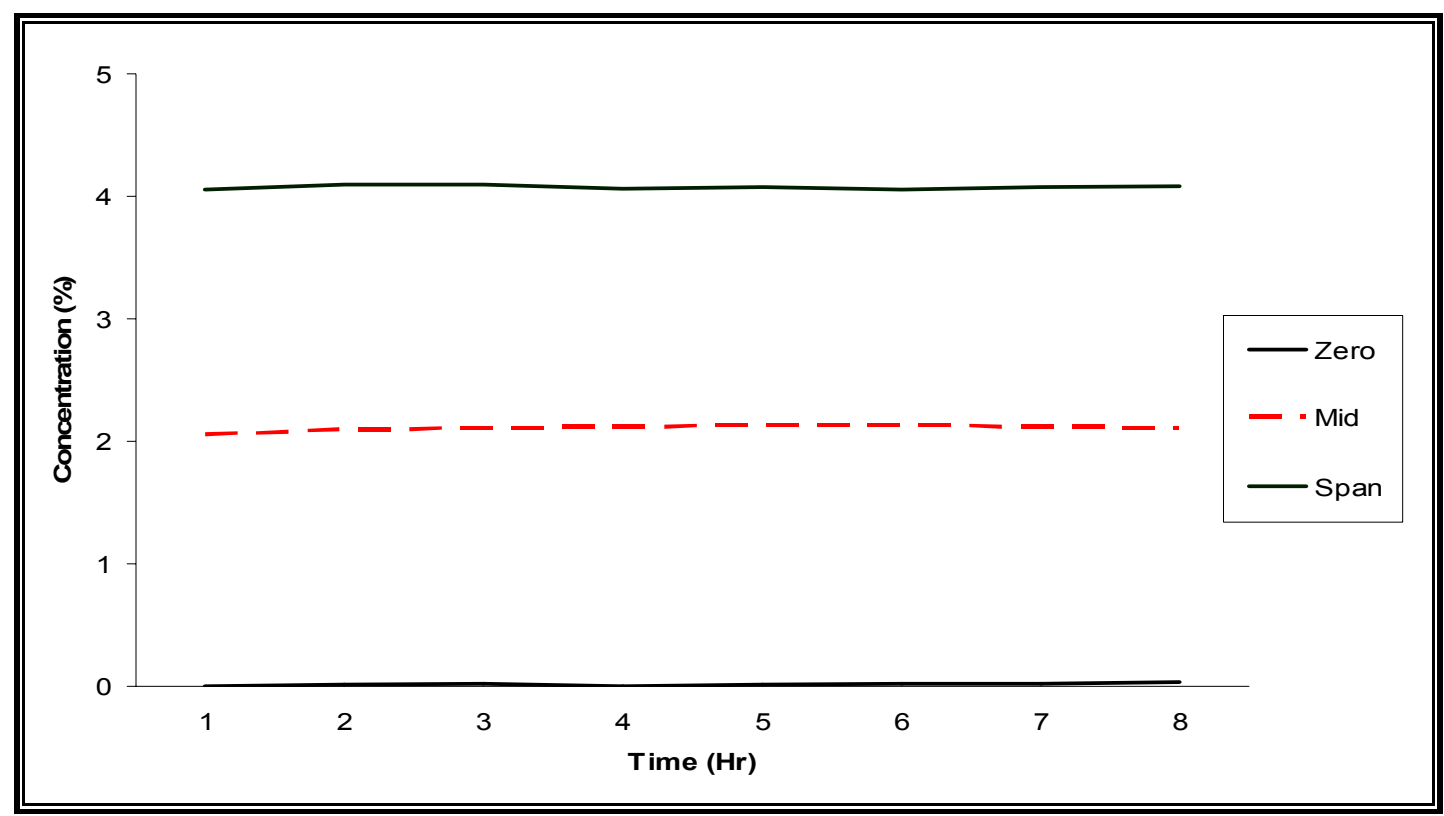

Figure-38 Analyzer drift for CO

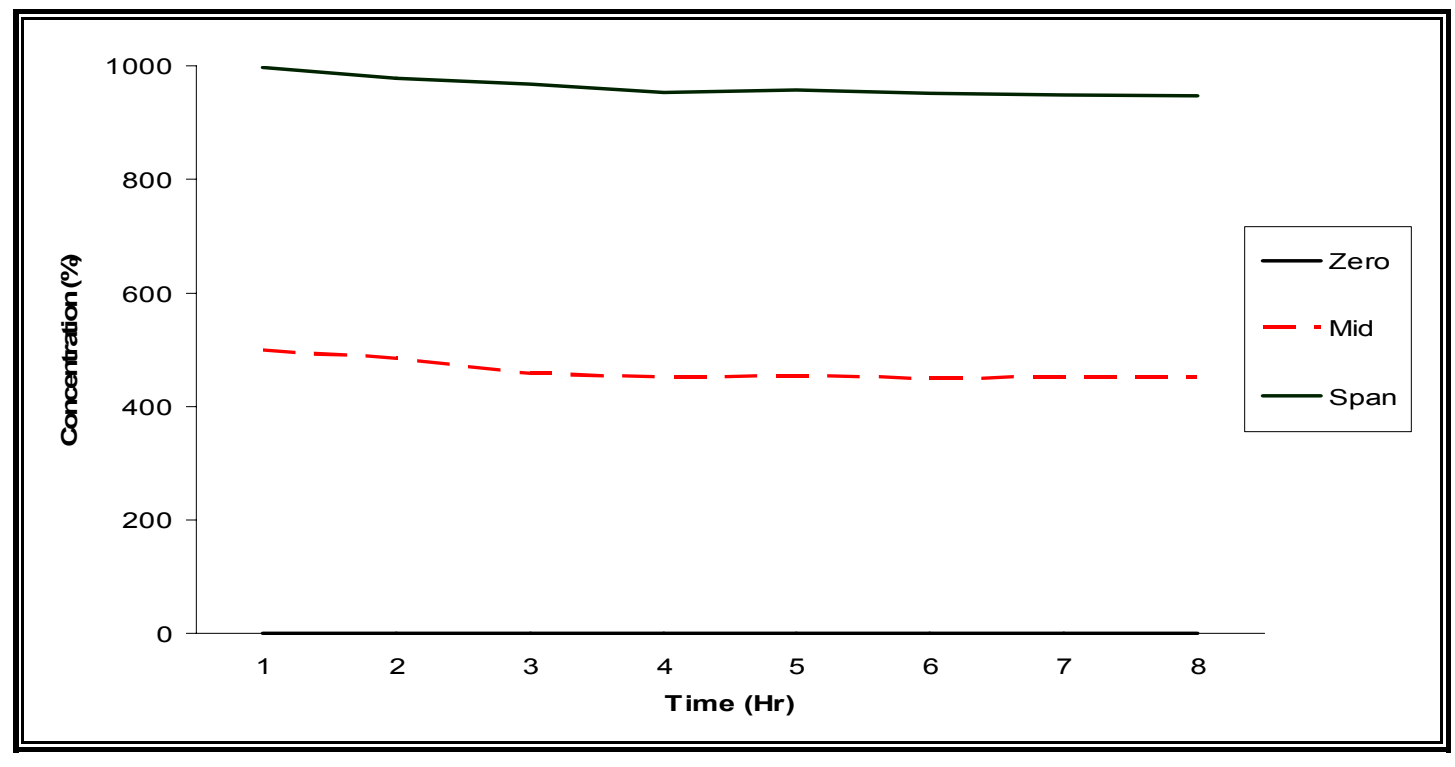

Figure-39 Analyzer drift for HC 


\subsection{Pressure and Flow Rate Variation Test}

Both MEXA720 NO and BE150 multi-gas analyzers were tested as described in the previous section on experimental test setup and procedure (section 4.4). NO measurements were found to be very accurate within the 20-22 PSI range. The span concentration recorded at 22 PSI was 1004 PPM. When the pressure was dropped to $20 \mathrm{PSI}$, the span concentration was recorded as $1001 \mathrm{PPM}$, although at $19 \mathrm{PSI}$, the span concentration dropped significantly to $975 \mathrm{PPM}$. Therefore, in the range of 20-22 PSI, only a low mean percentage difference of $2.62 \%$ was noted on high concentrations of NO. Similarly, on lower concentrations of NO; the span concentration was measured as 101 PPM at 22 PSI. When the pressure was dropped to 20 PSI, the span concentration was recorded as 94 PPM with a high percentage difference of $6.93 \%$. The span concentration dropped significantly to 78 PPM at 19 PSI pressure with the percentage difference of as high as $22.77 \%$. The variation in measurements due to flow rate variations was very similar to the pressure variation. At 2 LPM flow rate, the span concentration of NO was measured as 1004 PPM. When the flow rate was increased to 5 LPM, no difference in the span concentration was noted. However, the mean percentage difference was as high as $1.85 \%$ at lower concentrations of NO.

The BE150 multi-gas analyzer did not record any significant drift at pressures higher than $19 \mathrm{PSI}$ as well. The span concentration of $15.01 \%$ was measured at $22 \mathrm{PSI}$ and was recorded as $14.21 \%$ when the pressure was dropped to $19 \mathrm{PSI}$. For the 19-22 PSI pressure range, the highest mean percentage difference was recorded as low as $1.42 \%$. The analyzer also exhibited great stability in measurements at varying flow rates. At 2 LPM, the span concentration was 
measured as $15.02 \%$ and recorded no difference even when measured at 3 LPM.

The highest mean percentage difference was $0.22 \%$.

Table-21 Pressure variation test result for high NO concentration

\begin{tabular}{|c|c|c|c|c|c|c|c|c|c|}
\hline $\begin{array}{l}\text { Bottle } \\
\text { Conc. } \\
\text { (PPM) }\end{array}$ & $\begin{array}{l}\text { Meas. } \\
22 \text { PSI }\end{array}$ & $\begin{array}{l}\text { Meas. } \\
21 \text { PSI }\end{array}$ & $\%$ Diff & $\begin{array}{l}\text { Meas. } \\
20 \text { PSI }\end{array}$ & $\%$ Diff & $\begin{array}{l}\text { Meas. } \\
19 \text { PSI }\end{array}$ & $\%$ Diff & $\begin{array}{l}\text { Meas. } \\
18 \text { PSI }\end{array}$ & $\%$ Diff \\
\hline 0 & 0 & 0 & 0.00 & 0 & 0.00 & 0 & 0.00 & 0 & 0.00 \\
\hline 100.2 & 106 & 106 & 0.00 & 99 & 6.60 & 70 & 33.96 & 38 & 64.15 \\
\hline 200.4 & 209 & 209 & 0.00 & 199 & 4.78 & 171 & 18.18 & 136 & 34.93 \\
\hline 300.6 & 310 & 310 & 0.00 & 299 & 3.55 & 271 & 12.58 & 224 & 27.74 \\
\hline 400.8 & 411 & 410 & 0.24 & 389 & 5.35 & 361 & 12.17 & 324 & 21.17 \\
\hline 501 & 508 & 508 & 0.00 & 501 & 1.38 & 474 & 6.69 & 441 & 13.19 \\
\hline 601.2 & 605 & 603 & 0.33 & 588 & 2.81 & 563 & 6.94 & 521 & 13.88 \\
\hline 701.4 & 709 & 709 & 0.00 & 699 & 1.41 & 671 & 5.36 & 633 & 10.72 \\
\hline 801.6 & 808 & 808 & 0.00 & 796 & 1.49 & 763 & 5.57 & 741 & 8.29 \\
\hline 901.8 & 911 & 911 & 0.00 & 901 & 1.10 & 878 & 3.62 & 848 & 6.92 \\
\hline \multirow[t]{3}{*}{1002} & 1004 & 1002 & 0.20 & 1001 & 0.30 & 975 & 2.89 & 940 & 6.37 \\
\hline & & Mean & 0.07 & & 2.62 & & 9.82 & & 18.85 \\
\hline & & $\begin{array}{c}\text { Stand } \\
\text { Dev }\end{array}$ & 0.12 & & 2.19 & & 9.51 & & 18.12 \\
\hline
\end{tabular}

Table-22 Pressure variation test for low NO concentration

\begin{tabular}{|c|c|c|c|c|c|c|c|c|c|}
\hline $\begin{array}{l}\text { Bottle } \\
\text { Conc. } \\
\text { (PPM) }\end{array}$ & $\begin{array}{l}\text { Meas. } \\
22 \text { PSI }\end{array}$ & $\begin{array}{l}\text { Meas. } \\
21 \text { PSI }\end{array}$ & $\begin{array}{c}\% \\
\text { Diff }\end{array}$ & $\begin{array}{l}\text { Meas. } \\
20 \text { PSI }\end{array}$ & $\begin{array}{c}\% \\
\text { Diff }\end{array}$ & $\begin{array}{l}\text { Meas. } \\
19 \text { PSI }\end{array}$ & $\begin{array}{c}\% \\
\text { Diff }\end{array}$ & $\begin{array}{l}\text { Meas. } \\
18 \text { PSI }\end{array}$ & $\begin{array}{c}\% \\
\text { Diff }\end{array}$ \\
\hline 0 & 0 & 0 & 0.00 & 0 & 0.00 & 0 & 0.00 & 0 & 0.00 \\
\hline 10 & 11 & 10 & 9.09 & 9 & 18.18 & 6 & 45.45 & 4 & 63.64 \\
\hline 20 & 20 & 20 & 0.00 & 17 & 15.00 & 11 & 45.00 & 9 & 55.00 \\
\hline 30 & 31 & 31 & 0.00 & 28 & 9.68 & 23 & 25.81 & 17 & 45.16 \\
\hline 40 & 41 & 42 & 2.44 & 39 & 4.88 & 29 & 29.27 & 25 & 39.02 \\
\hline 50 & 52 & 52 & 0.00 & 48 & 7.69 & 38 & 26.92 & 37 & 28.85 \\
\hline 60 & 61 & 62 & 1.64 & 58 & 4.92 & 49 & 19.67 & 42 & 31.15 \\
\hline 70 & 71 & 71 & 0.00 & 69 & 2.82 & 58 & 18.31 & 56 & 21.13 \\
\hline 80 & 80 & 82 & 2.50 & 77 & 3.75 & 61 & 23.75 & 57 & 28.75 \\
\hline 90 & 91 & 91 & 0.00 & 86 & 5.49 & 69 & 24.18 & 59 & 35.16 \\
\hline \multirow[t]{3}{*}{100} & 101 & 101 & 0.00 & 94 & 6.93 & 78 & 22.77 & 68 & 32.67 \\
\hline & & Mean & 1.42 & & 7.21 & & 25.56 & & 34.59 \\
\hline & & $\begin{array}{c}\text { Stand } \\
\text { Dev }\end{array}$ & 2.74 & & 5.33 & & 12.42 & & 16.89 \\
\hline
\end{tabular}


Table-23 Flow variation test result for high NO concentration

\begin{tabular}{||c|c|c|c|c|c|c|c|c|c|c|c||}
\hline $\begin{array}{c}\text { Bottle } \\
\text { Conc. } \\
\text { (PPM) }\end{array}$ & $\begin{array}{c}\text { Meas. } \\
\mathbf{2} \\
\text { LPM }\end{array}$ & $\begin{array}{c}\text { Meas. } \\
\mathbf{2 . 5} \\
\text { LPM }\end{array}$ & $\begin{array}{c}\mathbf{\%} \\
\text { Diff }\end{array}$ & $\begin{array}{c}\text { Meas. } \\
\mathbf{3} \\
\text { LPM }\end{array}$ & $\begin{array}{c}\mathbf{\%} \\
\text { Diff }\end{array}$ & $\begin{array}{c}\text { Meas. } \\
\mathbf{3 . 5} \\
\text { LPM }\end{array}$ & $\begin{array}{c}\text { \% } \\
\text { Diff }\end{array}$ & $\begin{array}{c}\text { Meas. } \\
\mathbf{4} \\
\text { LPM }\end{array}$ & $\begin{array}{c}\text { \% } \\
\text { Diff }\end{array}$ & $\begin{array}{c}\text { Meas. } \\
\text { LPM }\end{array}$ & $\begin{array}{c}\text { \% } \\
\text { Diff }\end{array}$ \\
\hline 0 & 0 & 0 & 0.00 & 0 & 0.00 & 0 & 0.00 & 0 & 0.00 & 0 & 0.00 \\
\hline 100.2 & 106 & 106 & 0.00 & 107 & 0.93 & 106 & 0.00 & 107 & 0.93 & 106 & 0.00 \\
\hline 200.4 & 209 & 210 & 0.48 & 209 & 0.00 & 209 & 0.00 & 209 & 0.00 & 210 & 0.48 \\
\hline 300.6 & 310 & 310 & 0.00 & 311 & 0.32 & 310 & 0.00 & 310 & 0.00 & 310 & 0.00 \\
\hline 400.8 & 411 & 411 & 0.00 & 411 & 0.00 & 411 & 0.00 & 412 & 0.24 & 411 & 0.00 \\
\hline 501 & 508 & 508 & 0.00 & 508 & 0.00 & 509 & 0.20 & 509 & 0.20 & 509 & 0.20 \\
\hline 601.2 & 605 & 605 & 0.00 & 606 & 0.17 & 606 & 0.17 & 606 & 0.17 & 605 & 0.00 \\
\hline 701.4 & 709 & 709 & 0.00 & 710 & 0.14 & 710 & 0.14 & 710 & 0.14 & 710 & 0.14 \\
\hline 801.6 & 808 & 809 & 0.12 & 809 & 0.12 & 808 & 0.00 & 810 & 0.25 & 810 & 0.25 \\
\hline 901.8 & 911 & 912 & 0.11 & 912 & 0.11 & 913 & 0.22 & 914 & 0.33 & 913 & 0.22 \\
\hline 1002 & 1004 & 1004 & 0.00 & 1004 & 0.00 & 1004 & 0.00 & 1005 & 0.10 & 1004 & 0.00 \\
\hline & & Mean & $\mathbf{0 . 0 6}$ & & $\mathbf{0 . 1 6}$ & & $\mathbf{0 . 0 7}$ & & $\mathbf{0 . 2 1}$ & & $\mathbf{0 . 1 2}$ \\
\hline & & $\begin{array}{c}\text { Stand } \\
\text { Dev }\end{array}$ & $\mathbf{0 . 1 4}$ & & $\mathbf{0 . 2 8}$ & & $\mathbf{0 . 0 9}$ & & $\mathbf{0 . 2 6}$ & & $\mathbf{0 . 1 6}$ \\
\hline
\end{tabular}

Table-24 Flow variation test result for low NO concentration

\begin{tabular}{|c|c|c|c|c|c|c|c|c|c|c|c||}
\hline $\begin{array}{c}\text { Bottle } \\
\text { Conc. } \\
\text { (PPM) }\end{array}$ & $\begin{array}{c}\text { Meas. } \\
\mathbf{2} \\
\text { LPM }\end{array}$ & $\begin{array}{c}\text { Meas. } \\
\mathbf{2 . 5} \\
\text { LPM }\end{array}$ & $\begin{array}{c}\text { \% } \\
\text { Diff }\end{array}$ & $\begin{array}{c}\text { Meas. } \\
\mathbf{3} \\
\text { LPM }\end{array}$ & $\begin{array}{c}\text { \% } \\
\text { Diff }\end{array}$ & $\begin{array}{c}\text { Meas. } \\
\mathbf{3 . 5} \\
\text { LPM }\end{array}$ & $\begin{array}{c}\text { \% } \\
\text { Diff }\end{array}$ & $\begin{array}{c}\text { Meas. } \\
\mathbf{4} \\
\text { LPM }\end{array}$ & $\begin{array}{c}\text { Meas. } \\
\text { Diff }\end{array}$ & $\begin{array}{c}\mathbf{5} \\
\text { LPM }\end{array}$ & $\begin{array}{c}\text { \% } \\
\text { Diff }\end{array}$ \\
\hline 0 & 0 & 0 & 0.00 & 0 & 0.00 & 0 & 0.00 & 0 & 0.00 & 0 & 0.00 \\
\hline 10 & 10 & 11 & 9.09 & 11 & 9.09 & 11 & 9.09 & 11 & 9.09 & 10 & 0.00 \\
\hline 20 & 20 & 20 & 0.00 & 20 & 0.00 & 20 & 0.00 & 20 & 0.00 & 21 & 4.76 \\
\hline 30 & 30 & 31 & 3.23 & 31 & 3.23 & 30 & 0.00 & 31 & 3.23 & 30 & 0.00 \\
\hline 40 & 40 & 41 & 2.44 & 40 & 0.00 & 40 & 0.00 & 40 & 0.00 & 41 & 2.44 \\
\hline 50 & 50 & 51 & 1.96 & 50 & 0.00 & 51 & 1.96 & 50 & 0.00 & 50 & 0.00 \\
\hline 60 & 60 & 60 & 0.00 & 61 & 1.64 & 60 & 0.00 & 60 & 0.00 & 61 & 1.64 \\
\hline 70 & 70 & 71 & 1.41 & 70 & 0.00 & 71 & 1.41 & 70 & 0.00 & 70 & 0.00 \\
\hline 80 & 80 & 81 & 1.23 & 81 & 1.23 & 80 & 0.00 & 80 & 0.00 & 81 & 1.23 \\
\hline 90 & 91 & 91 & 0.00 & 91 & 0.00 & 91 & 0.00 & 90 & 1.11 & 90 & 1.11 \\
\hline 100 & 100 & 101 & 0.99 & 102 & 1.96 & 100 & 0.00 & 102 & 1.96 & 101 & 0.99 \\
\hline & & Mean & $\mathbf{1 . 8 5}$ & & $\mathbf{1 . 5 6}$ & & $\mathbf{1 . 1 3}$ & & $\mathbf{1 . 4 0}$ & & $\mathbf{1 . 1 1}$ \\
\hline & & $\begin{array}{c}\text { Stand } \\
\text { Dev }\end{array}$ & $\mathbf{2 . 6 4}$ & & $\mathbf{2 . 7 3}$ & & $\mathbf{2 . 7 3}$ & & $\mathbf{2 . 7 7}$ & & $\mathbf{1 . 4 7}$ \\
\hline
\end{tabular}


Table-25 Pressure variation test result for $\mathrm{CO}_{2}$

\begin{tabular}{|c|c|c|c|c|c|c|c|c|c||}
\hline $\begin{array}{c}\text { Bottle } \\
\text { Conc. } \\
\text { (PPM) }\end{array}$ & $\begin{array}{c}\text { Meas. } \\
\mathbf{2 2}\end{array}$ & $\begin{array}{c}\text { PSI } \\
\text { 21 PSI }\end{array}$ & $\begin{array}{c}\mathbf{\%} \\
\text { Diff }\end{array}$ & $\begin{array}{c}\text { Meas. } \\
\text { 20 PSI }\end{array}$ & $\begin{array}{c}\text { \% } \\
\text { Diff }\end{array}$ & $\begin{array}{c}\text { Meas. } \\
\text { 19 PSI }\end{array}$ & $\begin{array}{c}\text { \% } \\
\text { Diff }\end{array}$ & $\begin{array}{c}\text { Meas. } \\
\text { 18 PSI }\end{array}$ & $\begin{array}{c}\text { \% } \\
\text { Diff }\end{array}$ \\
\hline 0.00 & 0.00 & 0.00 & 0.00 & 0.00 & 0.00 & 0.00 & 0.00 & 0.00 & \\
\hline 1.50 & 1.49 & 1.48 & 0.67 & 1.49 & 1.33 & 1.38 & 0.67 & 0.98 & 8.00 \\
\hline 3.00 & 3.01 & 3.00 & 0.33 & 2.89 & 0.00 & 2.67 & 3.67 & 1.90 & 11.00 \\
\hline 4.50 & 4.49 & 4.48 & 0.22 & 4.38 & 0.44 & 4.01 & 2.67 & 3.79 & 10.89 \\
\hline 6.00 & 6.01 & 6.00 & 0.17 & 5.91 & 0.00 & 5.79 & 1.50 & 5.01 & 3.50 \\
\hline 7.50 & 7.49 & 7.49 & 0.13 & 7.40 & 0.13 & 7.06 & 1.33 & 6.89 & 5.87 \\
\hline 9.00 & 8.97 & 8.98 & 0.33 & 8.89 & 0.22 & 8.02 & 1.22 & 7.89 & 10.89 \\
\hline 10.50 & 10.50 & 10.49 & 0.00 & 10.41 & 0.10 & 10.00 & 0.86 & 9.12 & 4.76 \\
\hline 12.00 & 11.97 & 11.96 & 0.25 & 11.89 & 0.33 & 11.48 & 0.92 & 10.56 & 4.33 \\
\hline 13.50 & 13.50 & 13.49 & 0.00 & 13.41 & 0.07 & 12.99 & 0.67 & 11.67 & 3.78 \\
\hline 15.00 & 15.01 & 15.01 & 0.07 & 14.89 & 0.07 & 14.21 & 0.73 & 13.78 & 5.27 \\
\hline & Mean & & $\mathbf{0 . 2 0}$ & & $\mathbf{0 . 2 7}$ & & $\mathbf{1 . 4 2}$ & & $\mathbf{6 . 8 3}$ \\
\hline & Stand Dev & & $\mathbf{0 . 2 0}$ & & $\mathbf{0 . 4 0}$ & & $\mathbf{0 . 9 9}$ & & $\mathbf{3 . 0 9}$ \\
\hline
\end{tabular}

Table-26 Flow variation test result for $\mathrm{CO}_{2}$

\begin{tabular}{||c|c|c|c|c|c|c||}
\hline $\begin{array}{c}\text { Bottle } \\
\text { Conc. (\%) }\end{array}$ & $\begin{array}{c}\text { Meas. } \\
\text { 2 LPM }\end{array}$ & $\begin{array}{c}\text { \% Diff } \\
\text { 2.5 LPM }\end{array}$ & $\begin{array}{c}\text { \% Diff } \\
\text { 3 LPM }\end{array}$ & \% Diff \\
\hline 0.00 & 0.00 & 0.00 & 0.00 & 0.00 & 0.00 & 0.00 \\
\hline 1.50 & 1.51 & 0.67 & 1.51 & 0.67 & 1.51 & 0.67 \\
\hline 3.00 & 3.02 & 0.67 & 3.02 & 0.67 & 3.02 & 0.67 \\
\hline 4.50 & 4.49 & 0.22 & 4.49 & 0.22 & 4.50 & 0.00 \\
\hline 6.00 & 5.98 & 0.33 & 5.98 & 0.33 & 5.98 & 0.33 \\
\hline 7.50 & 7.51 & 0.13 & 7.51 & 0.13 & 7.51 & 0.13 \\
\hline 9.00 & 9.00 & 0.00 & 9.00 & 0.00 & 9.01 & 0.11 \\
\hline 10.50 & 10.51 & 0.10 & 10.51 & 0.10 & 10.51 & 0.10 \\
\hline 12.00 & 11.99 & 0.08 & 11.99 & 0.08 & 12.00 & 0.00 \\
\hline 13.50 & 13.51 & 0.07 & 13.51 & 0.07 & 13.51 & 0.07 \\
\hline 15.00 & 15.02 & 0.13 & 15.01 & 0.07 & 15.02 & 0.13 \\
\hline & Mean & $\mathbf{0 . 2 2}$ & & $\mathbf{0 . 2 1}$ & & $\mathbf{0 . 2 0}$ \\
\hline & Stand Dev & $\mathbf{0 . 2 4}$ & & $\mathbf{0 . 2 4}$ & & $\mathbf{0 . 2 5}$ \\
\hline
\end{tabular}




\subsection{Interference Test}

\subsubsection{Interference Test on $\mathrm{NO}_{x}$ Analyzer}

Interference tests were performed with gases that normally constitute diesel exhaust. Interference test on the analyzer was conducted with interference gases like $\mathrm{CO}_{2}(20 \%), \mathrm{CO}(1000 \mathrm{PPM})$ and $\mathrm{HC}$ as Propane (250 PPM). The analyzer response to all the gases was recorded and no drift in NO measurements were noted. The NO analyzer was also tested to check the ammonia interference. The analyzer was first calibrated using 1002 PPM NO as the component and nitrogen as the diluent. Two gas dividers were used to allow fractions of $\mathrm{NO}$ and ammonia gas to account for interferences at different concentrations. Both NO and ammonia gases were supplied at $22 \mathrm{PSI}$ pressure and the diluent at $18 \mathrm{PSI}$ pressure. The analyzer response was recorded to be within $\pm 2 \%$ of the NO concentration.

Table-27 Interference test result for NO

\begin{tabular}{|c|c|c|c|c|c|c|c|c|c|c|}
\hline $\begin{array}{c}\text { NO } \\
\text { Conc. }\end{array}$ & $\begin{array}{c}\text { Meas. } \\
\text { NO }\end{array}$ & $\mathrm{CO}$ & $\begin{array}{c}\text { Meas. } \\
\text { NO+CO }\end{array}$ & $\begin{array}{c}\% \\
\text { Diff }\end{array}$ & $\mathrm{CO}_{2}$ & $\begin{array}{c}\text { Meas. } \\
\mathrm{NO}+\mathrm{CO}_{2}\end{array}$ & $\begin{array}{c}\% \\
\text { Diff }\end{array}$ & Propane & $\begin{array}{c}\text { Meas. } \\
\text { NO+ } \\
\text { Propane }\end{array}$ & $\begin{array}{c}\% \\
\text { Diff }\end{array}$ \\
\hline (PPM) & (PPM) & (PPM) & (PPM) & & $(\%)$ & (PPM) & & (PPM) & (PPM) & \\
\hline 0 & 0 & 1000 & 0 & 0.00 & 20 & 0 & 0.00 & 250 & 0 & 0.00 \\
\hline 100.2 & 99 & 1000 & 99 & 0.00 & 20 & 99 & 0.00 & 250 & 99 & 0.00 \\
\hline 200.4 & 199 & 1000 & 199 & 0.00 & 20 & 199 & 0.00 & 250 & 199 & 0.00 \\
\hline 300.6 & 296 & 1000 & 296 & 0.00 & 20 & 296 & 0.00 & 250 & 296 & 0.00 \\
\hline 400.8 & 395 & 1000 & 395 & 0.00 & 20 & 395 & 0.00 & 250 & 395 & 0.00 \\
\hline 501 & 497 & 1000 & 497 & 0.00 & 20 & 497 & 0.00 & 250 & 497 & 0.00 \\
\hline 601.2 & 598 & 1000 & 598 & 0.00 & 20 & 598 & 0.00 & 250 & 598 & 0.00 \\
\hline 701.4 & 696 & 1000 & 696 & 0.00 & 20 & 696 & 0.00 & 250 & 696 & 0.00 \\
\hline 801.6 & 795 & 1000 & 795 & 0.00 & 20 & 795 & 0.00 & 250 & 795 & 0.00 \\
\hline 901.8 & 897 & 1000 & 897 & 0.00 & 20 & 897 & 0.00 & 250 & 897 & 0.00 \\
\hline \multirow[t]{3}{*}{1002} & 997 & 1000 & 997 & 0.00 & 20 & 997 & 0.00 & 250 & 998 & 0.10 \\
\hline & & & Mean & 0.00 & & & 0.00 & & & 0.01 \\
\hline & & & $\begin{array}{c}\text { Stand } \\
\text { Dev }\end{array}$ & 0.00 & & & 0.00 & & & 0.03 \\
\hline
\end{tabular}


Table-28 Ammonia interference test result for NO

\begin{tabular}{|c|c|c|c|c||}
\hline NO Conc. & Measured & $\begin{array}{c}\text { Ammonia } \\
\text { Conc. }\end{array}$ & Measured(NO+NH3) & \% Diff \\
\hline (PPM) & (PPM) & (PPM) & (PPM) & \\
\hline 0 & 0 & 25 & 4 & 0.00 \\
\hline 100.2 & 99 & 25 & 104 & 5.05 \\
\hline 200.4 & 198 & 25 & 205 & 3.54 \\
\hline 300.6 & 296 & 25 & 302 & 2.03 \\
\hline 400.8 & 396 & 25 & 402 & 1.52 \\
\hline 501 & 497 & 25 & 501 & 0.80 \\
\hline 601.2 & 598 & 25 & 603 & 0.84 \\
\hline 701.4 & 696 & 25 & 702 & 0.86 \\
\hline 801.6 & 794 & 25 & 800 & 0.76 \\
\hline 901.8 & 897 & 25 & 904 & 0.78 \\
\hline 1002 & 995 & 25 & 1003 & 0.80 \\
\hline & & & Mean & $\mathbf{1 . 5 4}$ \\
\hline & & & Stand Dev & $\mathbf{1 . 4 9}$ \\
\hline & & & CoV & $\mathbf{0 . 9 6}$ \\
\hline
\end{tabular}

Table-29 Ammonia interference test result for different concentrations of Ammonia

\begin{tabular}{|c|c|c|c|}
\hline NO Conc. & $\mathrm{NH}_{3}$ Conc. & $\begin{array}{l}\text { Measured } \\
\left(\mathrm{NO}+\mathrm{NH}_{3}\right)\end{array}$ & $\%$ Diff \\
\hline \multirow[t]{3}{*}{0} & 0 & 0 & \\
\hline & 12.5 & 0 & 0.00 \\
\hline & 25 & 1 & 0.00 \\
\hline \multirow[t]{3}{*}{100.2} & 0 & 98 & \\
\hline & 12.5 & 101 & 3.06 \\
\hline & 25 & 106 & 8.16 \\
\hline \multirow[t]{3}{*}{200.4} & 0 & 194 & \\
\hline & 12.5 & 198 & 2.06 \\
\hline & 25 & 205 & 5.67 \\
\hline \multirow[t]{3}{*}{300.6} & 0 & 294 & \\
\hline & 12.5 & 298 & 1.36 \\
\hline & 25 & 305 & 3.74 \\
\hline \multirow[t]{2}{*}{400.8} & 0 & 392 & \\
\hline & 12.5 & 395 & 0.77 \\
\hline
\end{tabular}




\begin{tabular}{|c|c|c|c|}
\hline & 25 & 403 & 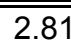 \\
\hline \multirow[t]{3}{*}{501} & 0 & 494 & \\
\hline & 12.5 & 496 & 0.40 \\
\hline & 25 & 504 & 2.02 \\
\hline \multirow[t]{3}{*}{601.2} & 0 & 590 & \\
\hline & 12.5 & 591 & 0.17 \\
\hline & 25 & 596 & 1.02 \\
\hline \multirow[t]{3}{*}{701.4} & 0 & 688 & \\
\hline & 12.5 & 692 & 0.58 \\
\hline & 25 & 701 & 1.89 \\
\hline \multirow[t]{3}{*}{801.6} & 0 & 781 & \\
\hline & 12.5 & 786 & 0.64 \\
\hline & 25 & 794 & 1.66 \\
\hline \multirow[t]{3}{*}{901.8} & 0 & 879 & \\
\hline & 12.5 & 884 & 0.57 \\
\hline & 25 & 893 & 1.59 \\
\hline \multirow[t]{3}{*}{1002} & 0 & 971 & \\
\hline & 12.5 & 976 & 0.51 \\
\hline & 25 & 982 & 1.13 \\
\hline
\end{tabular}

\subsubsection{Interference Test on BE150 Multi-gas Analyzer}

As described in the experimental test setup and procedure section (section 4.7), interference tests were performed on $\mathrm{CO}, \mathrm{CO}_{2}$ and $\mathrm{HC}$ as Propane to record any drift in measurements. Each gas was selected as the candidate gas and other gases as interference. An insignificant percentage difference of $0.11 \%$ for $\mathrm{CO}_{2}, 0.17 \%$ for $\mathrm{CO}$ and $0.06 \%$ for $\mathrm{HC}$ in measurements compared against the known bottle concentrations was recorded by the analyzer detector. In addition, water interference test was also performed to record any drift in measurements caused by water on the $\mathrm{CO}_{2}$. The analyzer recorded less than $1 \%$ drift on the full scale. As seen in Table-31, $\mathrm{CO}_{2}$ 
measurement was also recorded downstream of the chiller. The analyzer reported a very low percentage difference of $0.08 \%$ against the dry $\mathrm{CO}_{2}$ confirming the effective cooling performance of the chiller assembly.

Table-30 Interference test result for $\mathrm{CO}_{2}$

\begin{tabular}{|c|c|c|c|c|c|c|c|c|c|c|c|c|}
\hline $\begin{array}{l}\text { Mixed } \\
\text { Bottle } \\
\text { Conc. }\end{array}$ & & & & & & & & & & & & \\
\hline $\mathrm{CO} 2$ & $\mathrm{CO}$ & Propane & NO & \multicolumn{9}{|c|}{ Measured $\mathrm{CO}_{2}$} \\
\hline$(\%)$ & $(\%)$ & (PPM) & (PPM) & \multicolumn{9}{|c|}{ (I,II \& III) } \\
\hline & & & & $\mathbf{I}$ & $\begin{array}{c}\% \\
\text { Diff }\end{array}$ & II & $\begin{array}{c}\% \\
\text { Diff }\end{array}$ & III & $\begin{array}{c}\% \\
\text { Diff }\end{array}$ & Mean & $\begin{array}{c}\text { Stand } \\
\text { Dev }\end{array}$ & cov \\
\hline 0 & 0 & 0 & 0 & 0.02 & 0.00 & 0.01 & 0.00 & 0.04 & 0.00 & 0.02 & 0.02 & \\
\hline 6 & 2 & 503.5 & 1000 & 6.01 & 0.17 & 6.01 & 0.17 & 6.01 & 0.17 & 6.01 & 0.00 & 0.00 \\
\hline \multirow[t]{3}{*}{12} & 4 & 1007 & 2000 & 12.01 & 0.08 & 12.02 & 0.17 & 12.00 & 0.00 & 12.01 & 0.01 & 0.00 \\
\hline & & & & Mean & 0.08 & & 0.11 & & 0.06 & & & \\
\hline & & & & $\begin{array}{c}\text { Stand } \\
\text { Dev }\end{array}$ & 0.08 & & 0.10 & & 0.10 & & & \\
\hline
\end{tabular}

Table-31 Interference test result for CO

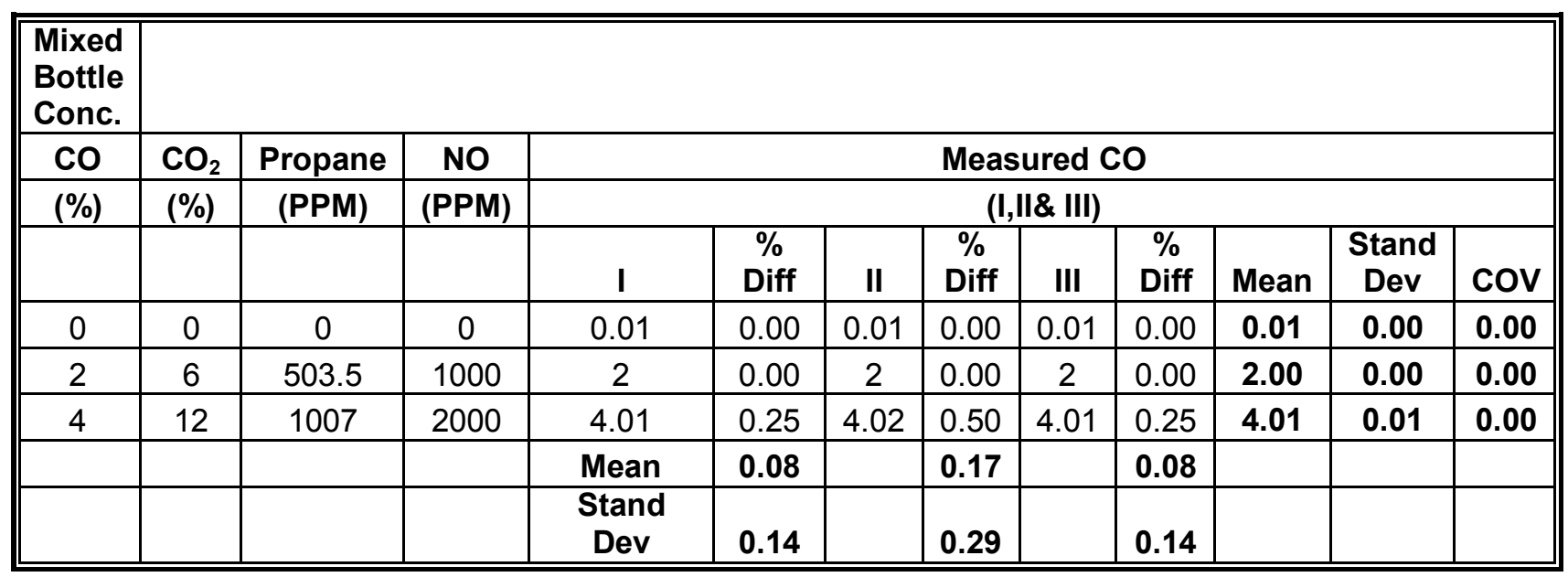


Table-32 Interference test result for HC

\begin{tabular}{|c|c|c|c|c|c|c|c|c|c|c|c|c|}
\hline $\begin{array}{l}\text { Mixed } \\
\text { Bottle } \\
\text { Conc. }\end{array}$ & & & & & & & & & & & & \\
\hline $\mathrm{HC}$ & $\mathrm{CO} 2$ & $\mathrm{Co}$ & No & \multicolumn{9}{|c|}{ Measured HC } \\
\hline (\%) & $(\%)$ & (\%) & (PPM) & \multicolumn{9}{|c|}{ (I,II \& III) } \\
\hline & & & & I & $\begin{array}{c}\% \\
\text { Diff }\end{array}$ & II & $\begin{array}{c}\% \\
\text { Diff }\end{array}$ & III & $\begin{array}{c}\% \\
\text { Diff }\end{array}$ & Mean & $\begin{array}{c}\text { Stand } \\
\text { Dev }\end{array}$ & cov \\
\hline 0 & 0 & 0 & 0 & 0.01 & 0.00 & 0.01 & 0.00 & 0.01 & 0.00 & 0.01 & 0.00 & 0.00 \\
\hline 503.5 & 6 & 2 & 1000 & 503.89 & 0.08 & 503.78 & 0.06 & 503.47 & 0.01 & 503.71 & 0.22 & 0.00 \\
\hline \multirow[t]{3}{*}{1007} & 12 & 4 & 2000 & 1005.89 & 0.11 & 1005.68 & 0.13 & 1005.27 & 0.17 & 1005.61 & 0.32 & 0.00 \\
\hline & & & & Mean & 0.06 & & 0.06 & & 0.06 & & & \\
\hline & & & & $\begin{array}{c}\text { Stand } \\
\text { Dev }\end{array}$ & 0.06 & & 0.07 & & 0.10 & & & \\
\hline
\end{tabular}

Table-33 Interference test result for water on $\mathrm{CO}_{2}$

\begin{tabular}{|c|c|c|c|c|c|c||}
\hline \hline \multirow{2}{*}{$\begin{array}{c}\text { Bottle } \\
\text { Conc. }\end{array}$} & Measured & & Measured & & Measured & \\
& $\mathbf{C O}_{2}$ & & $\mathbf{C O}_{\mathbf{2}}$ & & $\mathbf{C O}_{2}$ & \\
\hline & $\mathbf{( D r y )}$ & \% Diff & (Humidified) & \% Diff & (Post Chiller) & \% Diff \\
\hline 0.0 & 0.01 & 0.00 & 0.01 & 0.00 & 0.00 & 0.00 \\
\hline 1.2 & 1.21 & 0.83 & 1.18 & 2.48 & 1.21 & 0.00 \\
\hline 2.4 & 2.41 & 0.42 & 2.39 & 0.83 & 2.41 & 0.00 \\
\hline 3.6 & 3.62 & 0.56 & 3.59 & 0.83 & 3.62 & 0.00 \\
\hline 4.8 & 4.80 & 0.00 & 4.74 & 1.25 & 4.80 & 0.00 \\
\hline 6.0 & 5.98 & 0.33 & 5.94 & 0.67 & 6.00 & 0.33 \\
\hline 7.2 & 7.19 & 0.14 & 7.11 & 1.11 & 7.19 & 0.00 \\
\hline 8.4 & 8.38 & 0.24 & 8.31 & 0.84 & 8.37 & 0.12 \\
\hline 9.6 & 9.58 & 0.21 & 9.49 & 0.94 & 9.60 & 0.21 \\
\hline 10.8 & 10.78 & 0.19 & 10.70 & 0.74 & 10.78 & 0.00 \\
\hline 12.0 & 11.98 & 0.17 & 11.84 & 1.17 & 12.00 & 0.17 \\
\hline & Mean & $\mathbf{0 . 2 8}$ & & $\mathbf{0 . 9 9}$ & & $\mathbf{0 . 0 8}$ \\
\hline & Stand Dev & $\mathbf{0 . 2 5}$ & & $\mathbf{0 . 6 0}$ & & $\mathbf{0 . 1 2}$ \\
\hline
\end{tabular}




\subsection{Vibration Test on $\mathrm{NO}_{x}$ Analyzer}

As described in the previous chapter (section 4.5), the analyzer was manually shaken and subjected to large amplitude vibrations to record any drift in measurements. The analyzer was also tested on the S-10 pick-up truck of EERL by mounting the analyzer on the back of the truck to account for typical on-road frequency and amplitudes. For the amplitude test, the maximum percentage difference was noted as low as $0.49 \%$ whereas for the frequency test, the maximum percentage difference was noted as $2.30 \%$. This confirmed high stability in measurements recorded by the analyzer due to variation in amplitude and frequency.

Table-34 Amplitude test result on MEXA720 NOx analyzer

\begin{tabular}{|c|c|c|c||}
\hline $\begin{array}{c}\text { Bottle } \\
\text { Conc. }\end{array}$ & Measured & $\begin{array}{c}\text { Measured by } \\
\text { Manually Shaking }\end{array}$ & \% Diff \\
\hline 0 & & & 0 \\
\hline 100.2 & 0 & 102 & 0.00 \\
\hline 200.4 & 102 & 205 & 0.00 \\
\hline 300.6 & 204 & 304 & 0.49 \\
\hline 400.8 & 304 & 408 & 0.00 \\
\hline 501 & 409 & 505 & 0.24 \\
\hline 601.2 & 505 & 603 & 0.00 \\
\hline 701.4 & 603 & 707 & 0.00 \\
\hline 801.6 & 706 & 805 & 0.14 \\
\hline 901.8 & 805 & 906 & 0.00 \\
\hline 1002 & 906 & 1004 & 0.00 \\
\hline & 1004 & Mean & 0.00 \\
\hline & & Stand Dev & $\mathbf{0 . 0 8}$ \\
\hline & & & $\mathbf{0 . 1 6}$ \\
\hline
\end{tabular}


Table-35 Frequency test result on MEXA720 NOx analyzer

\begin{tabular}{|c|c|c||}
\hline Bottle Conc. & Measured & \% Diff \\
\hline 0 & 0 & 0.00 \\
\hline 100.2 & 102 & 1.80 \\
\hline 200.4 & 205 & 2.30 \\
\hline 300.6 & 305 & 1.46 \\
\hline 400.8 & 404 & 0.80 \\
\hline 501 & 508 & 1.40 \\
\hline 601.2 & 607 & 0.96 \\
\hline 701.4 & 710 & 1.23 \\
\hline 801.6 & 811 & 1.17 \\
\hline 901.8 & 909 & 0.80 \\
\hline 1002 & 1008 & 0.60 \\
\hline & Mean & $\mathbf{1 . 1 4}$ \\
\hline & Stand Dev & $\mathbf{0 . 6 2}$ \\
\hline
\end{tabular}

\subsection{Inclination Test on $\mathrm{NO}_{x}$ Analyzer}

The analyzer was tilted at different angles from 0 to 90 degrees horizontally. Results confirmed no significant drift in measurements with a maximum percentage difference of $0.4 \%$ on the mid gas concentration.

Table-36 Inclination test result on MEXA720 NOx analyzer

\begin{tabular}{|c|c|c|c|c|c|c|c|c|c|}
\hline Position & Zero & Measured & \% Diff & Mid & Measured & $\%$ Diff & Span & Measured & $\%$ Diff \\
\hline $90 \mathrm{deg}$ & 0 & 0 & $\mathbf{0}$ & 501 & 503 & $\mathbf{0 . 4 0}$ & 1002 & 1003 & $\mathbf{0 . 1 0}$ \\
\hline $30 \mathrm{deg}$ & 0 & 0 & $\mathbf{0}$ & 501 & 504 & $\mathbf{0 . 4 0}$ & 1002 & 1004 & $\mathbf{0 . 2 0}$ \\
\hline $60 \mathrm{deg}$ & 0 & 0 & $\mathbf{0}$ & 501 & 506 & $\mathbf{0 . 4 0}$ & 1002 & 1003 & $\mathbf{0 . 1 0}$ \\
\hline $0 \mathrm{deg}$ & 0 & 0 & $\mathbf{0}$ & 501 & 505 & $\mathbf{0 . 2 0}$ & 1002 & 1003 & $\mathbf{0 . 1 0}$ \\
\hline
\end{tabular}




\subsection{Calibration Efficiency Test on $\mathrm{NO}_{x}$ Analyzer}

The $\mathrm{NO}_{x}$ analyzer was calibrated using NO gas (2000 PPM) as the component at $22 \mathrm{PSI}$ and nitrogen as the diluent at $18 \mathrm{PSI}$ pressure. A Horiba SGD $710 \mathrm{C}$ gas divider was used to allow the component gas to flow in set fractions of the bottle concentration. The analyzer was calibrated by passing the component gas through a bubbler. As seen in the table below, measurements after a calibration routine without using a bubbler noted a percentage difference of only $0.44 \%$ against the known bottle concentration whereas, a difference of $0.38 \%$ was noted after the analyzer was calibrated using a bubbler. Thus, it was inferred that the analyzer does not mandate the use of a bubbler for calibration routine.

Table-37 Calibration efficiency test result on NO

\begin{tabular}{|c|c|c|c|c||}
\hline $\begin{array}{c}\text { Bottle } \\
\text { Conc. }\end{array}$ & With Bubbler & \% Diff & With out Bubbler & \% Diff \\
\hline (PPM) & Measured (PPM) & & Measured (PPM) & \\
\hline 200 & 199 & 0.50 & 199 & 0.50 \\
\hline 400 & 402 & 0.50 & 403 & 0.75 \\
\hline 600 & 604 & 0.67 & 603 & 0.50 \\
\hline 800 & 805 & 0.63 & 807 & 0.88 \\
\hline 1000 & 1003 & 0.30 & 1005 & 0.50 \\
\hline 1200 & 1200 & 0.00 & 1205 & 0.42 \\
\hline 1400 & 1398 & 0.14 & 1402 & 0.14 \\
\hline 1600 & 1607 & 0.44 & 1605 & 0.31 \\
\hline 1800 & 1808 & 0.44 & 1806 & 0.33 \\
\hline 2000 & 2004 & 0.20 & 2002 & 0.10 \\
\hline & Mean & $\mathbf{0 . 3 8}$ & Mean & $\mathbf{0 . 4 4}$ \\
\hline & Stand Dev & $\mathbf{0 . 2 2}$ & Stand Dev & $\mathbf{0 . 2 4}$ \\
\hline
\end{tabular}




\subsection{Performance Test on Critical Flow Nozzle (CFN)}

Tests were conducted on the CFN using three different pumps, both pressuring and vacuum types (see the section on sample pump), to qualify for system integration. The pressure drop across the CFN was recorded in each case. The CFN was found to be most effective on the Gast manufacturing pump to maintain a constant 3 LPM volumetric flow rate.

Table-38 Performance test results on CFN

\begin{tabular}{||c|c|c|c|c||}
\hline \hline Pumps & $\begin{array}{c}\text { Upstream } \\
\text { Pressure }\end{array}$ & $\begin{array}{c}\text { Downstream } \\
\text { Pressure }\end{array}$ & $\begin{array}{c}\text { Pressure } \\
\text { Drop }\end{array}$ & $\begin{array}{c}\text { Constant } \\
\text { Flow rate }\end{array}$ \\
\hline Thomas Pump & 40 PSIA & 20.8 PSIA & 19.2 PSIA & Yes \\
\hline Gast Mfg. Pump & 41 PSIA & 21.5 PSIA & 19.5 PSIA & Yes \\
\hline $\begin{array}{c}\text { Air Dimensions } \\
\text { Pump }\end{array}$ & 28.92 in. of $\mathrm{Hg}$ & 16.25 in. of $\mathrm{Hg}$ & 12.67 in. of $\mathrm{Hg}$ & No \\
\hline
\end{tabular}

\subsection{Chiller Assembly}

Test was conducted on the chiller assembly to record the effectiveness of cooling using different heat sinks and fans. As the performance of the heat sink was dependent on the orientation, they were tested in different positions. The purpose of the test was to qualify a heat sink for mounting constraint free design and at the same time to allow for low power consumption by a fan. As seen in the table, different combinations of heat sinks and fans were experimented. The smaller aluminum heat sink did not cool the air stream passing through the chiller 
assembly as effectively as the smaller copper heat sink. Although, a high capacity fan (30 CFM) was used, small aluminum heat sinks were found to be ineffective. The smaller heat sinks with refrigerant tubes were found to be very effective and cooled the air stream passing through the assembly to as low as $5 \mathrm{~F}$ even though only a medium capacity fan (20 CFM) was used. These heat sinks were not orientation specific and therefore could be mounted in any position. Therefore, smaller heat sinks with refrigerant tubes were selected. Although larger heat sinks with refrigerant tubes performed effective cooling, they were found to be position sensitive and therefore were not selected.

Table-39 Performance test results on the chiller assembly

\begin{tabular}{|c|c|c|}
\hline & Small Aluminum Heat sink & \\
\hline \multirow[t]{2}{*}{ Position } & Medium Capacity fan & High capacity fan \\
\hline & $\begin{array}{c}\text { Air Stream } \\
\text { Temp(F) }\end{array}$ & $\begin{array}{c}\text { Air Stream } \\
\text { Temp(F) }\end{array}$ \\
\hline Vertical & 20.00 & 14.00 \\
\hline \multirow[t]{2}{*}{ Horizontal } & 21.00 & 15.00 \\
\hline & Small Copper Heat sink & \\
\hline Position & Medium Capacity fan & High capacity fan \\
\hline Vertical & 15.00 & 9.00 \\
\hline \multirow[t]{2}{*}{ Horizontal } & 15.00 & 9.00 \\
\hline & Small Heat sink with refrigerant tubes & \\
\hline Position & Medium Capacity fan & High capacity fan \\
\hline Vertical & 0.00 & -1.00 \\
\hline \multirow[t]{2}{*}{ Horizontal } & 5.00 & 2.00 \\
\hline & Large Heat sink with Refrigerant tubes & \\
\hline Position & Medium Capacity fan & High capacity fan \\
\hline Vertical & -1.00 & -2.00 \\
\hline Horizontal & 24.00 & 18.00 \\
\hline
\end{tabular}




\subsection{Volumetric Flow Rate Measurement using Annubar}

Series of tests were conducted on a 5 inch annubar to measure the volumetric flow rate by passing high volume of air at different pressures. The annubar was placed at different locations on the 5 inch diameter pipe. Measurements were compared against a 800 CFM Laminar Flow Element (LFE) at the EERL. In the first case, the annubar was placed at 10 diameters downstream of the LFE to record the pressure of the fully developed flow. The volumetric flow rate reported a maximum percentage difference of $15.5 \%$ against the LFE. In the second case, the annubar was placed at the center of the elbow and results showed a significant drift as high as $68.12 \%$ in the volumetric flow rates caused due to the pulsatile nature at the elbow. In the third case, the annubar was placed 2 diameters downstream of the elbow and the difference in the flow rate measurements were found to be similar to the first case with maximum percentage difference as $15 \%$. Thus, it was inferred that the annubar can be placed 2 diameters downstream of the elbow with out causing significant drift in the volumetric flow rate measurement. Table-40 Results for the volumetric flow rate measurement in case 1

\begin{tabular}{|c|c|c|c|c|c|}
\hline $\mathbf{A P}(\mathbf{H g})$ & $\mathbf{D P}\left(\mathbf{H}_{\mathbf{2}} \mathbf{0}\right)$ & $\mathbf{T}\left({ }^{\circ} \mathbf{C}\right)$ & LFE(SCFM) & $\begin{array}{c}\text { Annubar } \\
\text { (SCFM) }\end{array}$ & \%Diff \\
\hline 28.70 & 0.00 & 25.80 & 0.36 & 0.30 & 15.50 \\
\hline 28.70 & 1.06 & 25.30 & 124.31 & 110.00 & 11.51 \\
\hline 28.70 & 2.02 & 24.20 & 237.36 & 226.00 & 4.79 \\
\hline 28.70 & 3.10 & 24.20 & 361.86 & 345.00 & 4.66 \\
\hline 28.70 & 4.41 & 25.90 & 505.35 & 490.00 & 3.04 \\
\hline 28.70 & 5.39 & 29.00 & 603.31 & 588.00 & 2.54 \\
\hline 28.70 & 6.14 & 32.30 & 670.99 & 746.00 & 11.18 \\
\hline
\end{tabular}


Table-41 Results for the volumetric flow rate measurement in case 2

\begin{tabular}{|c|c|c|c|c|c||}
\hline $\mathbf{A P}(\mathbf{H g})$ & $\mathbf{D P}\left(\mathbf{H}_{\mathbf{2}} \mathbf{0}\right)$ & $\mathbf{T}\left({ }^{\circ} \mathbf{C}\right)$ & LFE(SCFM) & $\begin{array}{c}\text { Annubar } \\
(\mathbf{S C F M})\end{array}$ & $\%$ Diff \\
\hline 28.70 & 0.49 & 23.60 & 58.17 & 39.20 & 32.62 \\
\hline 28.70 & 1.68 & 73.40 & 199.85 & 84.80 & 57.57 \\
\hline 28.70 & 2.03 & 72.32 & 241.60 & 109.00 & 54.88 \\
\hline 28.70 & 2.52 & 71.78 & 299.42 & 128.00 & 57.25 \\
\hline 28.70 & 3.00 & 71.96 & 354.83 & 157.00 & 55.75 \\
\hline 28.70 & 3.57 & 72.86 & 419.63 & 178.00 & 57.58 \\
\hline 28.70 & 5.63 & 75.74 & 646.23 & 206.00 & 68.12 \\
\hline
\end{tabular}

Table-42 Results for the volumetric flow rate measurement in case 3

\begin{tabular}{|c|c|c|c|c|c||}
\hline $\mathbf{A P}(\mathbf{H g})$ & $\mathbf{D P}(\mathbf{H} 20)$ & $\mathbf{T}\left({ }^{\circ} \mathbf{C}\right)$ & LFE(SCFM) & $\begin{array}{c}\text { Annubar } \\
\text { (SCFM) }\end{array}$ & \% Diff \\
\hline 28.70 & 0.00 & 29.20 & 60.00 & 69.00 & 15.00 \\
\hline 28.70 & 1.03 & 32.60 & 116.46 & 125.00 & 7.33 \\
\hline 28.70 & 1.51 & 31.10 & 171.16 & 169.00 & 1.26 \\
\hline 28.70 & 2.09 & 30.30 & 237.65 & 225.00 & 5.32 \\
\hline 28.70 & 2.65 & 29.60 & 301.02 & 286.00 & 4.99 \\
\hline 28.70 & 3.06 & 29.20 & 347.99 & 327.00 & 6.03 \\
\hline 28.70 & 3.65 & 29.30 & 412.89 & 385.00 & 6.75 \\
\hline 28.70 & 4.25 & 29.80 & 477.38 & 449.00 & 5.95 \\
\hline 28.70 & 4.67 & 30.90 & 519.77 & 486.00 & 6.50 \\
\hline 28.70 & 5.05 & 31.50 & 558.67 & 525.00 & 6.03 \\
\hline
\end{tabular}




\subsection{Test on the performance of RH sensor}

The test set-up used a medium capacity pump (20 LPM) to pressurize the ambient air through a bubbler at 3 LPM flow rate. The humidified air was passed through a heated line maintained at $122,212,302$ \& $392 \mathrm{~F}$. This hot air was passed through the chiller assembly and the relative humidity with the CMEMS Honeywell sensor was measured upstream and downstream of the assembly. Two J-type thermocouples were used to measure upstream and downstream temperatures of the chiller assembly. Measurements recorded by CMEMS Honeywell humidity and temperature sensors reported a percentage difference of $11.16 \%$ against the Edge-Tech humidity analyzer on low temperatures; however, at higher temperatures of $302 \mathrm{~F}$ and $392 \mathrm{~F}$, very small percentage differences of $1.06 \%$ and $1.20 \%$ were reported.

Table-43 Result for the relative humidity measurement before and after chiller

\begin{tabular}{||c|c|c|c|c|c||}
\hline $\begin{array}{c}\text { Heated } \\
\text { Line }\end{array}$ & $\begin{array}{c}\text { RH (\%) } \\
\text { (Upstream of } \\
\text { Chiller) } \\
\text { Honeywell } \\
\text { Sensor }\end{array}$ & $\begin{array}{c}\text { RH (\%) } \\
\text { (Upstream of } \\
\text { Chiller) } \\
\text { Edge-Tech } \\
\text { Analyzer }\end{array}$ & $\begin{array}{c}\text { RH (\%) } \\
\text { (Downstream of } \\
\text { Chiller) } \\
\text { Honeywell } \\
\text { Sensor }\end{array}$ & $\begin{array}{c}\text { RH (\%) } \\
\text { (Downstream } \\
\text { of Chiller) } \\
\text { Edge-Tech } \\
\text { Analyzer }\end{array}$ & \% Diff \\
\hline 122 & 88.75 & 88.45 & 10.25 & 11.35 & 10.73 \\
\hline 212 & 89.25 & 89.67 & 10.75 & 11.95 & 11.16 \\
\hline 302 & 89.90 & 89.68 & 12.25 & 12.38 & 1.06 \\
\hline 392 & 91.50 & 92.05 & 12.50 & 12.65 & 1.20 \\
\hline
\end{tabular}




\subsection{On-road Test Results}

Two on road tests were conducted on the CMEMS after mounting the entire unit on the tail pipe of the Ford F450 pick-up truck. The existing MEMS unit was also installed on the same vehicle to compare on-road $\mathrm{NO}_{\mathrm{x}}$ and $\mathrm{CO}_{2}$ measurements. The duration of both runs was set as one hour to check the robustness of CMEMS. The criteria for the duration and route of the runs were to record the performance of the entire system on transient on-road conditions. The concentration data for $\mathrm{NO}_{\mathrm{x}}$ and $\mathrm{CO}_{2}$ was recorded and compared against MEMS as shown in figures below. In all the data comparison figures, y-axis represents the adjusted time to a common scale which is a numerical value (0-1). As CMEMS occasionally did not record at a constant $5 \mathrm{~Hz}$ frequency, an adjusted common time scale was chosen to account for the lost data points. The maximum percentage difference was noted as $5.18 \%$ for $\mathrm{NO}_{\mathrm{x}}$ and $3.10 \%$ for $\mathrm{CO}_{2}$ to confirm fair agreement with MEMS unit.

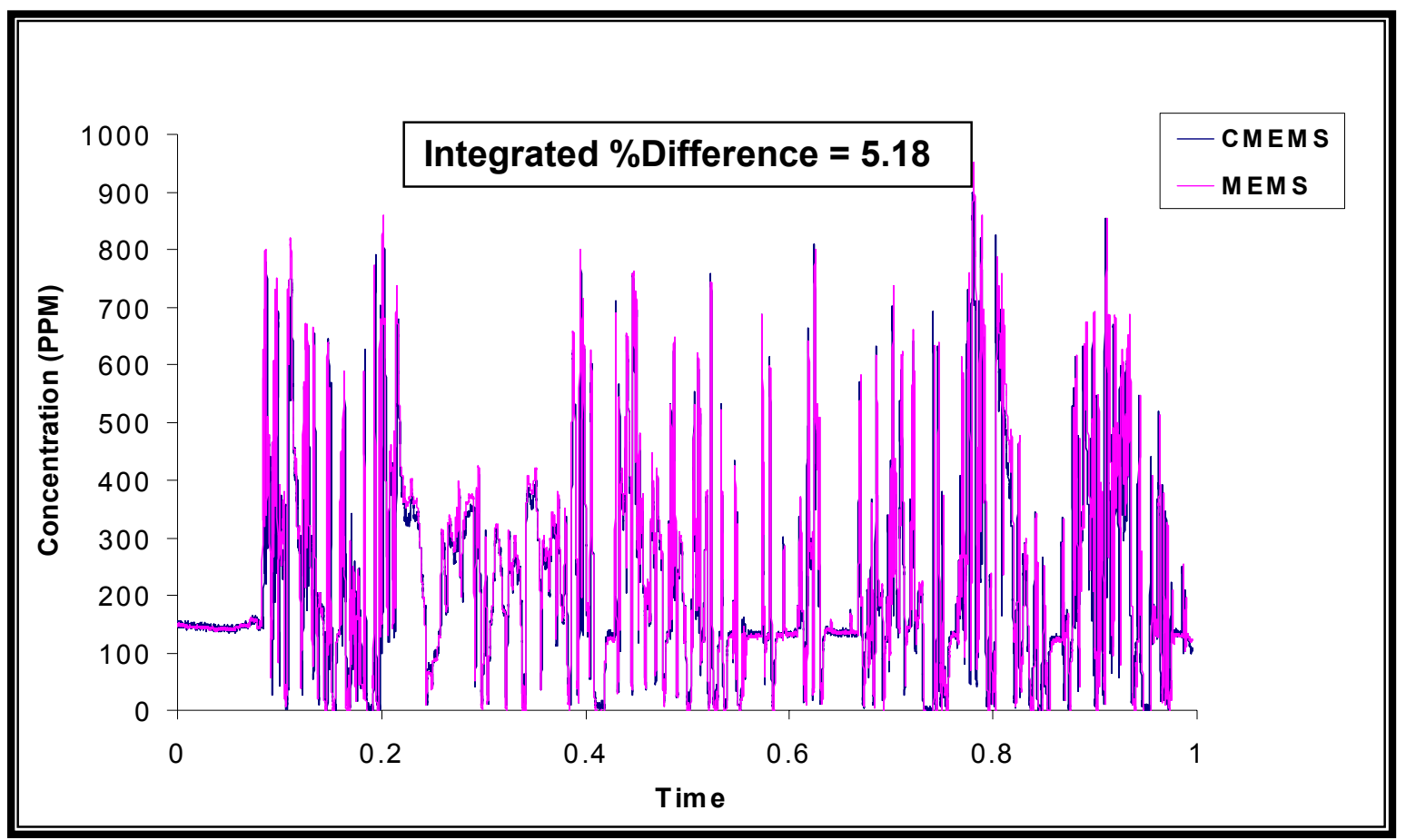

Figure-40 $\mathrm{NO}_{\mathrm{x}}$ comparison for run 1 on a Ford F450 pick-up truck 


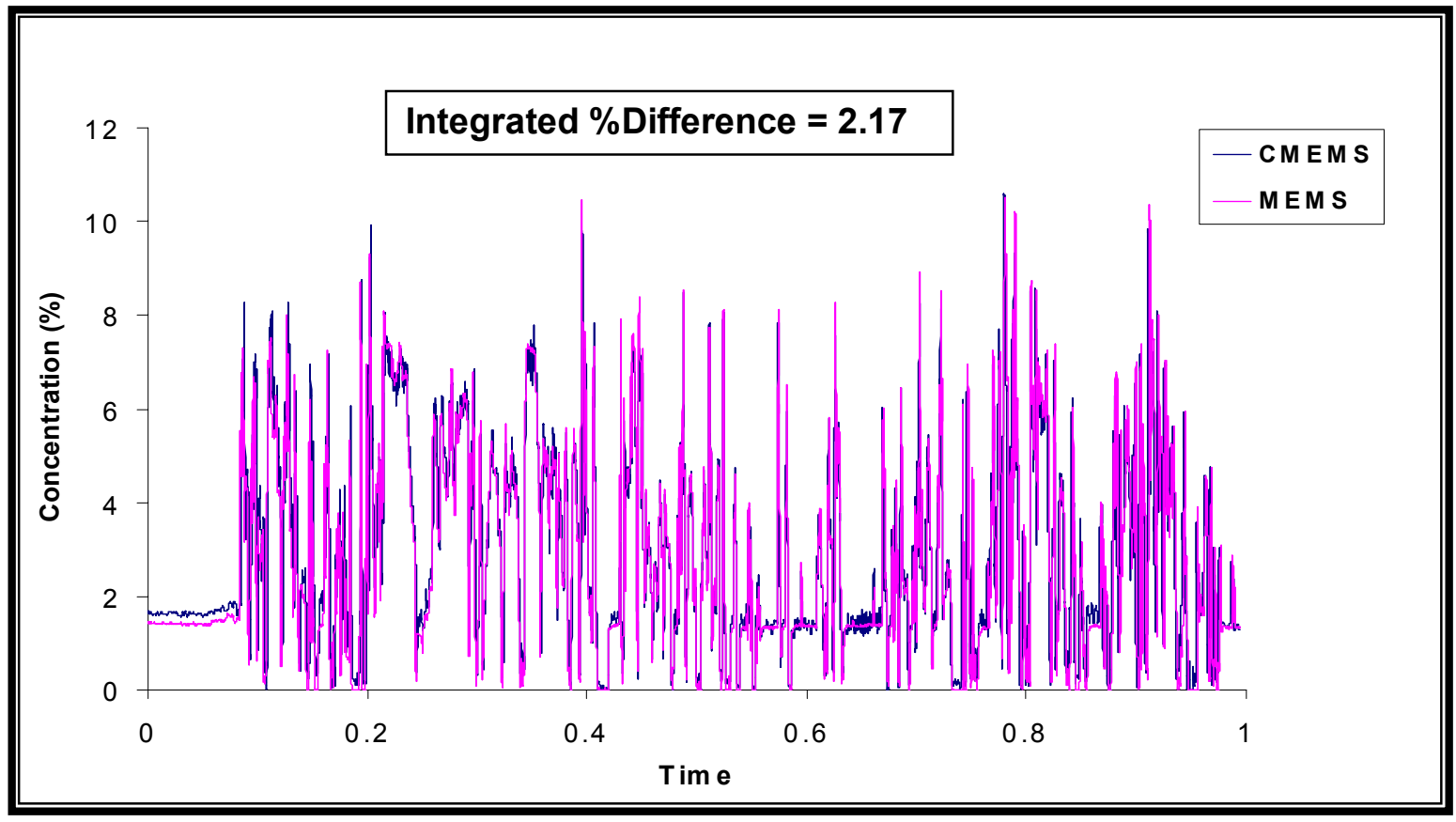

Figure-41 $\mathrm{CO}_{2}$ comparison for run 1 on a Ford F450 pick-up truck

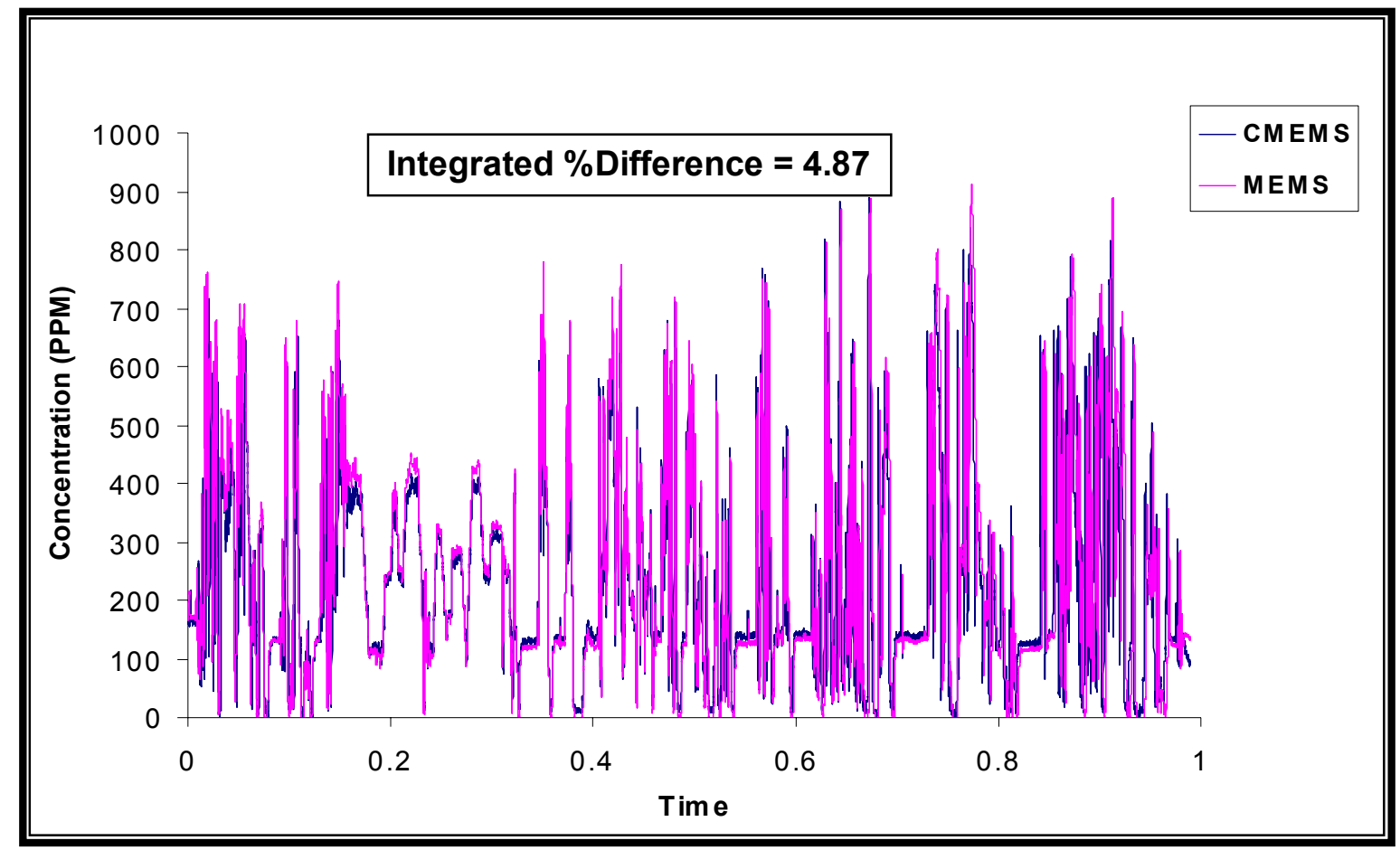

Figure-42 $\mathrm{NO}_{\mathrm{x}}$ comparison for run 2 on a Ford F450 pick-up truck 


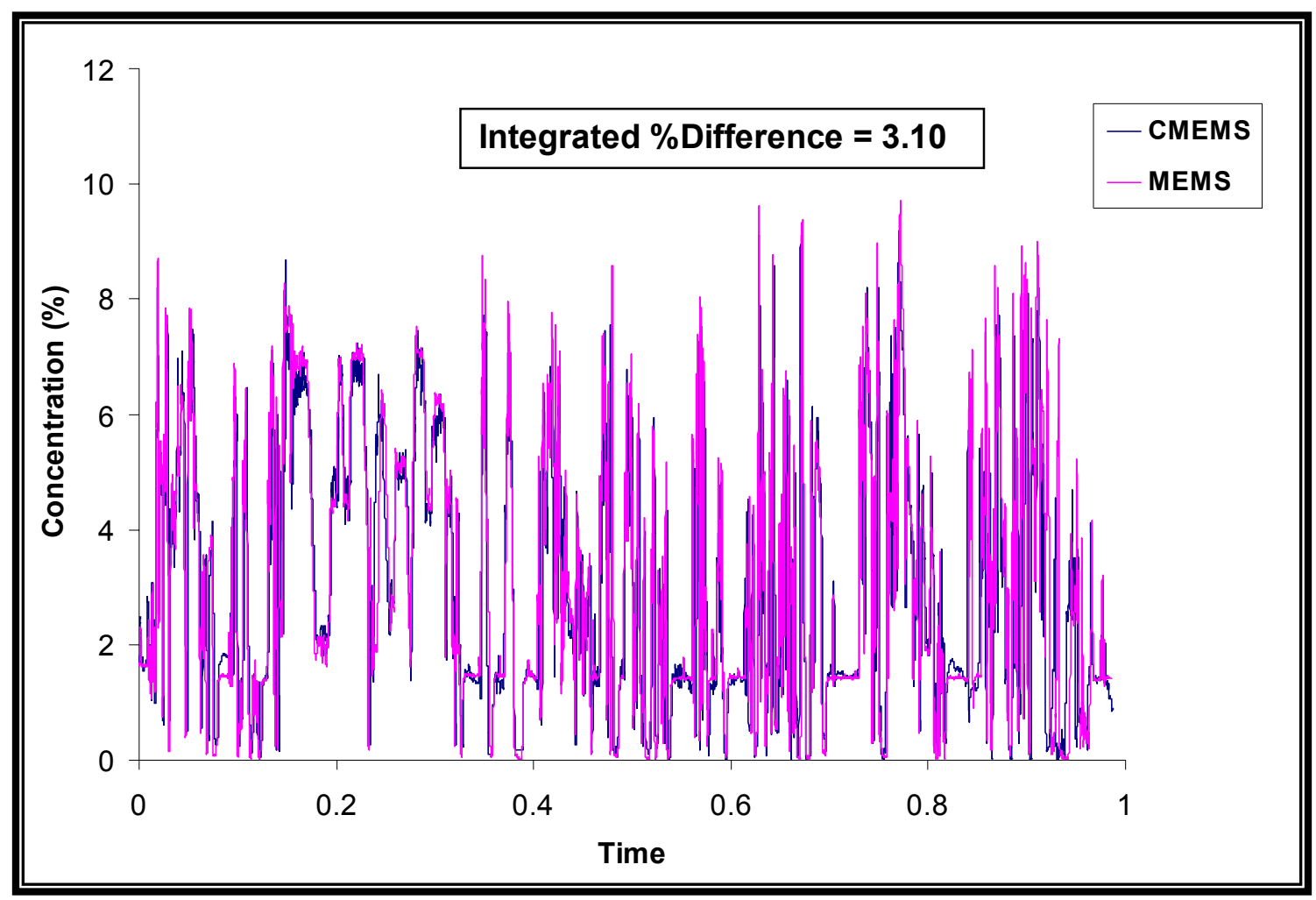

Figure-43 $\mathrm{CO}_{2}$ comparison for run 2 on a Ford F450 pick-up truck

\subsection{Laboratory Test Results}

CMEMS was also tested in the controlled laboratory environment on a 1992 DDC series 60 heavy-duty diesel engine (see Appendix A) on the standard FTP cycle. As this performance test on CMEMS was a part of a fuel testing project at the EERL, measurements were reported for two different fuels. Time-specific $\mathrm{NO}_{\mathrm{x}}$ and $\mathrm{CO}_{2}$ measurements recorded by the CMEMS were compared against the laboratory grade analyzers. Measurements were found to be very accurate with a maximum percentage difference of $2.83 \%$ for $\mathrm{NO}_{x}$ and $3.14 \%$ for $\mathrm{CO}_{2}$. The repeatability was found to be very high as the COV was noted as low as 0.01 for both $\mathrm{NO}_{x}$ and $\mathrm{CO}_{2}$. 
In addition to FTP runs, CMEMS was also tested on the simulated on-road cycle (Sabraton-Bruceton Mills) with four repeated runs on a 1992 DDC series 60 engine. Measurements were found to be very accurate with maximum percentage difference of $1.91 \%$ for $\mathrm{NO}_{x}$ and $2.16 \%$ for $\mathrm{CO}_{2}$ and repeatability was found to be very high with the COV as zero for both $\mathrm{NO}_{x}$ and $\mathrm{CO}_{2}$.

Table-44 Data summary for $\mathrm{NO}_{x}(\mathrm{~g} / \mathrm{s})$ on CMEMS measured against the laboratory analyzer on seven FTP cycle runs on a 1992 DDC series 60 engine

\begin{tabular}{|c|c|c|c|c|c|c|c|}
\hline \multicolumn{4}{|c|}{ Fuel A } & \multicolumn{4}{|c|}{ Fuel B } \\
\hline Run & $\begin{array}{l}\text { CMEMS NO } \\
(\mathbf{g} / \mathbf{s})\end{array}$ & $\begin{array}{c}\text { Lab NO }_{x} \\
(g / s)\end{array}$ & $\%$ Diff. & Run & $\begin{array}{c}\text { CMEMS } \\
N O_{x}(g / s)\end{array}$ & $\begin{array}{l}\text { Lab } \\
N O_{x} \\
(g / s)\end{array}$ & $\%$ Diff. \\
\hline 1 & 106.47 & 104.22 & 2.12 & 5 & 129.98 & 126.62 & 2.58 \\
\hline 2 & 101.27 & 103.35 & 2.05 & 6 & 130.85 & 127.90 & 2.25 \\
\hline 3 & 101.38 & 103.68 & 2.27 & 7 & 130.88 & 127.68 & 2.45 \\
\hline 4 & 100.28 & 103.12 & 2.83 & & & & \\
\hline Mean & 102.35 & 103.59 & 2.32 & Mean & 130.57 & 127.40 & 2.43 \\
\hline $\begin{array}{l}\text { Stand } \\
\text { Dev. }\end{array}$ & 2.79 & 0.48 & & $\begin{array}{l}\text { Stand } \\
\text { Dev. }\end{array}$ & 0.51 & 0.68 & \\
\hline cov & 0.03 & 0.00 & & cov & 0.00 & 0.01 & \\
\hline
\end{tabular}


Table-45 Data summary for $\mathrm{CO}_{2}(\mathrm{~g} / \mathrm{s})$ on CMEMS measured against the laboratory analyzer on seven FTP cycle runs on a 1992 DDC series 60 engine

\begin{tabular}{|c|c|c|c|c|c|c|c||}
\hline Run & $\begin{array}{c}\text { CMEMS } \\
\mathbf{C O}_{2} \\
(\mathbf{g} / \mathbf{s})\end{array}$ & $\begin{array}{c}\text { Lab } \\
\mathbf{C O}_{2} \\
\mathbf{( g / s})\end{array}$ & $\begin{array}{c}\text { \% } \\
\text { Diff. }\end{array}$ & Run & $\begin{array}{c}\text { CMEMS } \\
\mathbf{C O}_{2} \\
\mathbf{( g / s})\end{array}$ & $\begin{array}{c}\text { Lab } \\
\mathbf{C O}_{2} \\
\mathbf{( g / s )}\end{array}$ & \% Diff. \\
\hline 1 & 12158.11 & 12477.51 & 2.63 & 5 & 13171.52 & 13536.54 & 2.77 \\
\hline 2 & 12092.22 & 12414.74 & 2.67 & 6 & 13296.62 & 13562.47 & 2.00 \\
\hline 3 & 12004.22 & 12381.40 & 3.14 & 7 & 13262.34 & 13592.13 & 2.49 \\
\hline 4 & 12010.80 & 12383.80 & 3.11 & & & & \\
\hline Mean & $\mathbf{1 2 0 6 6 . 3 4}$ & $\mathbf{1 2 4 1 4 . 3 6}$ & $\mathbf{2 . 8 9}$ & Mean & $\mathbf{1 3 2 4 3 . 4 9}$ & $\mathbf{1 3 5 6 3 . 7 1}$ & $\mathbf{2 . 4 2}$ \\
\hline $\begin{array}{c}\text { Stand } \\
\text { Dev. }\end{array}$ & $\mathbf{7 3 . 1 1}$ & $\mathbf{4 4 . 7 5}$ & & $\begin{array}{c}\text { Stand } \\
\text { Dev. }\end{array}$ & $\mathbf{6 4 . 6 4}$ & $\mathbf{2 7 . 8 1}$ & \\
\hline Cov & $\mathbf{0 . 0 3}$ & $\mathbf{0 . 0 0}$ & & Cov & $\mathbf{0 . 0 0}$ & $\mathbf{0 . 0 0}$ & \\
\hline \hline
\end{tabular}

Table-46 Data summary for NOx (g/s) on CMEMS measured against the laboratory analyzer on four simulated on-road cycle runs on a 1992 DDC series 60 engine

\begin{tabular}{|c|c|c|c||}
\hline Run & $\begin{array}{c}\text { CMEMS } \\
\text { NOx } \\
\mathbf{( g / s )}\end{array}$ & $\begin{array}{c}\text { Lab } \\
\text { NOx } \\
\mathbf{( g / s})\end{array}$ & \% Diff. \\
\hline 1 & 711.62 & 699.30 & 1.76 \\
\hline 2 & 683.75 & 670.69 & 1.91 \\
\hline 3 & 736.11 & 722.27 & 1.88 \\
\hline 4 & 721.93 & 708.11 & 1.91 \\
\hline Mean & $\mathbf{7 1 3 . 3 5}$ & $\mathbf{7 0 0 . 0 9}$ & $\mathbf{1 . 8 7}$ \\
\hline $\begin{array}{c}\text { Stand } \\
\text { Dev. }\end{array}$ & $\mathbf{2 2 . 1 4}$ & $\mathbf{2 1 . 7 6}$ & \\
\hline Cov & $\mathbf{0 . 0 3}$ & $\mathbf{0 . 0 3}$ & \\
\hline
\end{tabular}


Table-47 Data summary for $\mathrm{CO}_{2}(\mathrm{~g} / \mathrm{s})$ on CMEMS measured against the laboratory analyzer on four on-road cycle runs on a 1992 DDC series 60 engine

\begin{tabular}{||c|c|c|c||}
\hline Run & $\begin{array}{c}\text { CMEMS } \\
\mathbf{C O}_{2} \\
(\mathbf{g} / \mathbf{s})\end{array}$ & $\begin{array}{c}\text { Lab } \\
\mathbf{C O}_{2} \\
\mathbf{( g / s})\end{array}$ & \% Diff. \\
\hline 1 & 57084.65 & 56464.89 & 1.09 \\
\hline 2 & 56391.82 & 55616.49 & 1.37 \\
\hline 3 & 58801.39 & 57528.97 & 2.16 \\
\hline 4 & 57542.18 & 56725.97 & 1.42 \\
\hline $\begin{array}{c}\text { Mean } \\
\text { Stand } \\
\text { Dev. }\end{array}$ & $\mathbf{5 7 4 5 5 . 0 1}$ & $\mathbf{5 6 5 8 4 . 0 8}$ & $\mathbf{1 . 5 1}$ \\
\hline \multicolumn{1}{|c|}{} & $\mathbf{1 0 1 4 . 5 4}$ & $\mathbf{7 8 8 . 1 2}$ & \\
Cov & $\mathbf{0 . 0 2}$ & $\mathbf{0 . 0 1}$ & \\
\hline
\end{tabular}

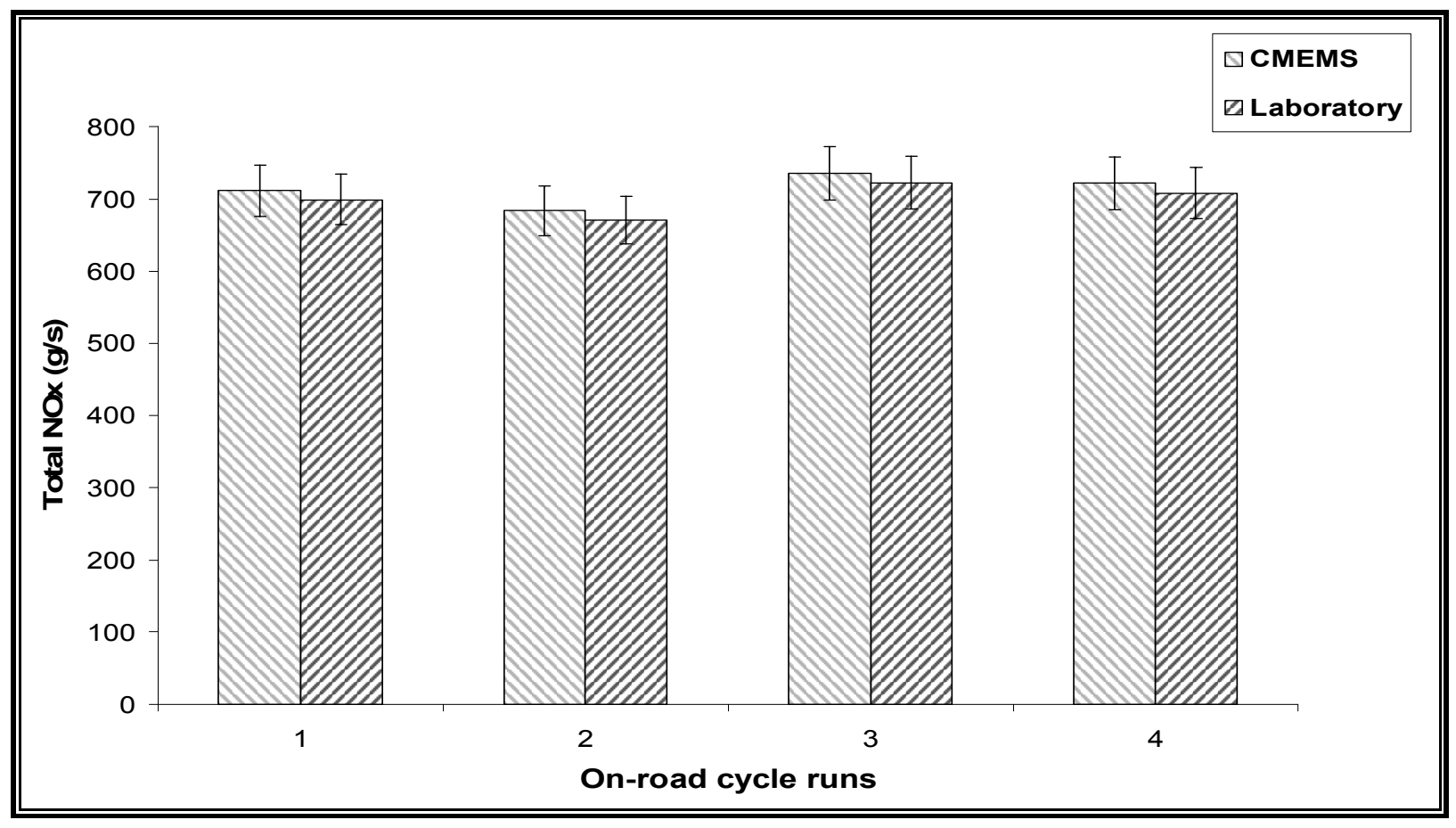

Figure-44 Data summary of the total $\mathrm{NO}_{x}(\mathrm{~g} / \mathrm{s})$ on four on-road cycle runs on a 1992 DDC series 60 engine reported with $95 \%$ confidence 


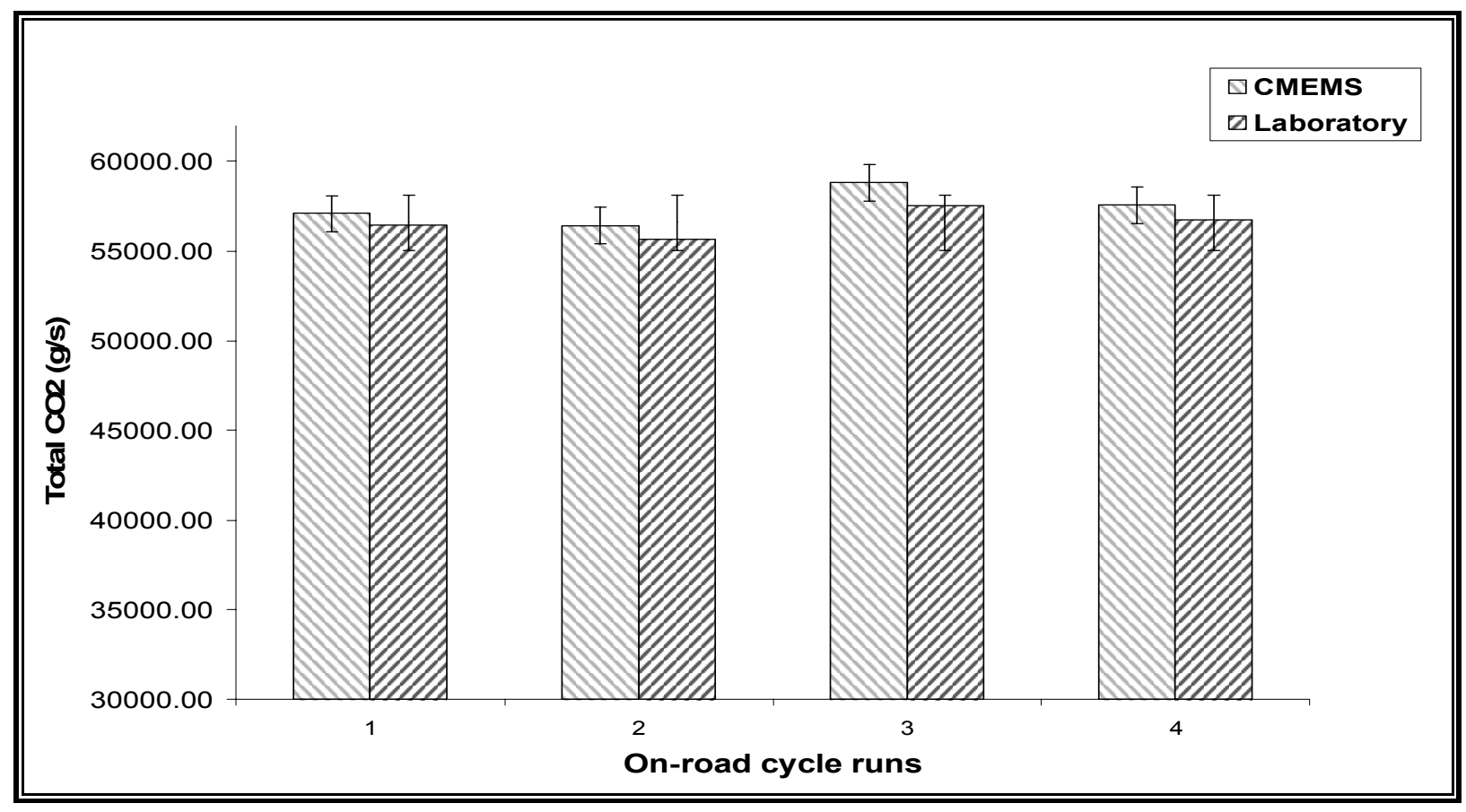

Figure-45 Data summary of the total $\mathrm{CO}_{2}(\mathrm{~g} / \mathrm{s})$ on four on-road cycle runs on a 1992 DDC series 60 engine reported with $95 \%$ confidence

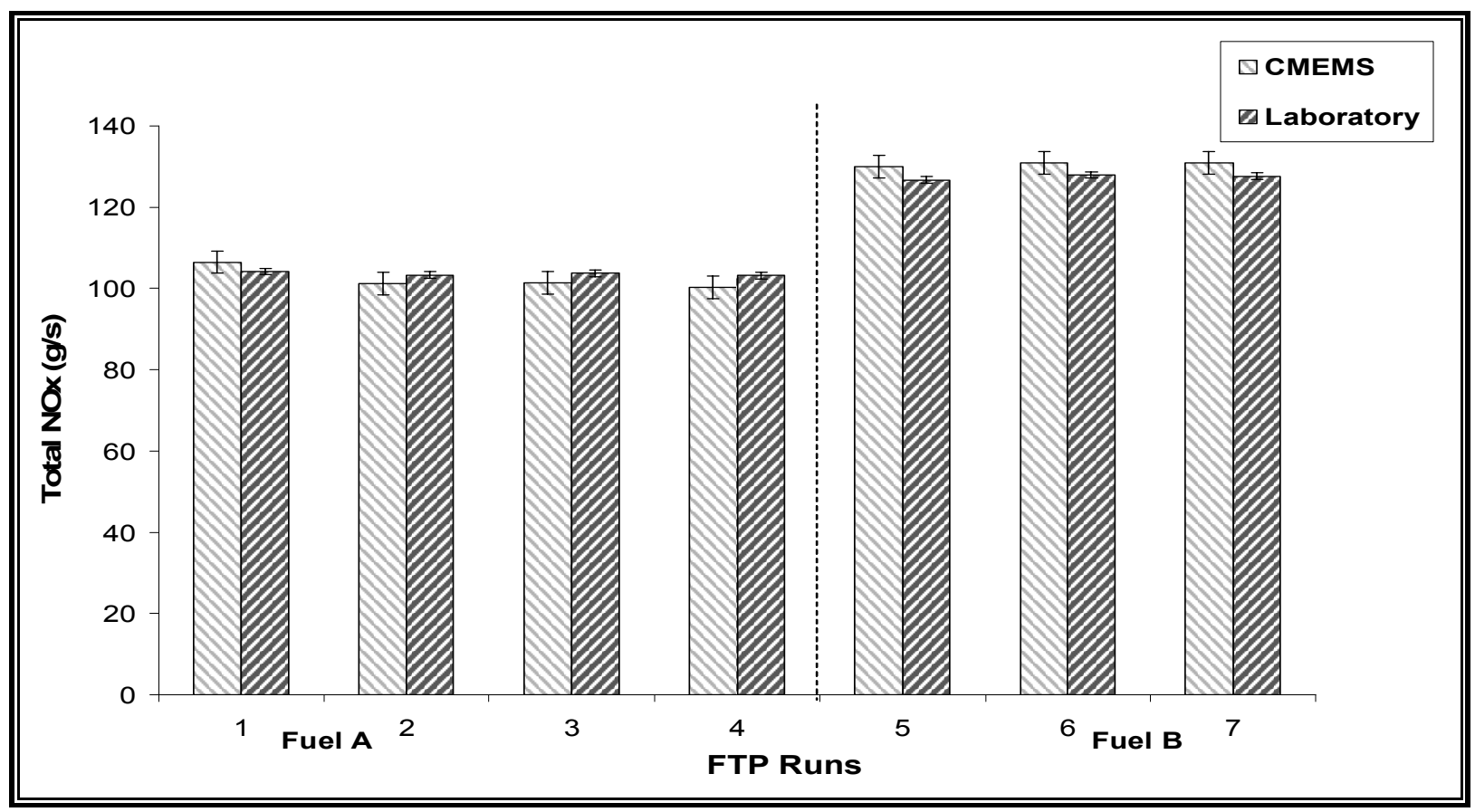

Figure-46 Data summary of the total $\mathrm{NO}_{\mathrm{x}}(\mathrm{g} / \mathrm{s})$ on seven FTP cycle runs on a 1992 DDC series 60 engine reported with 95\% confidence 


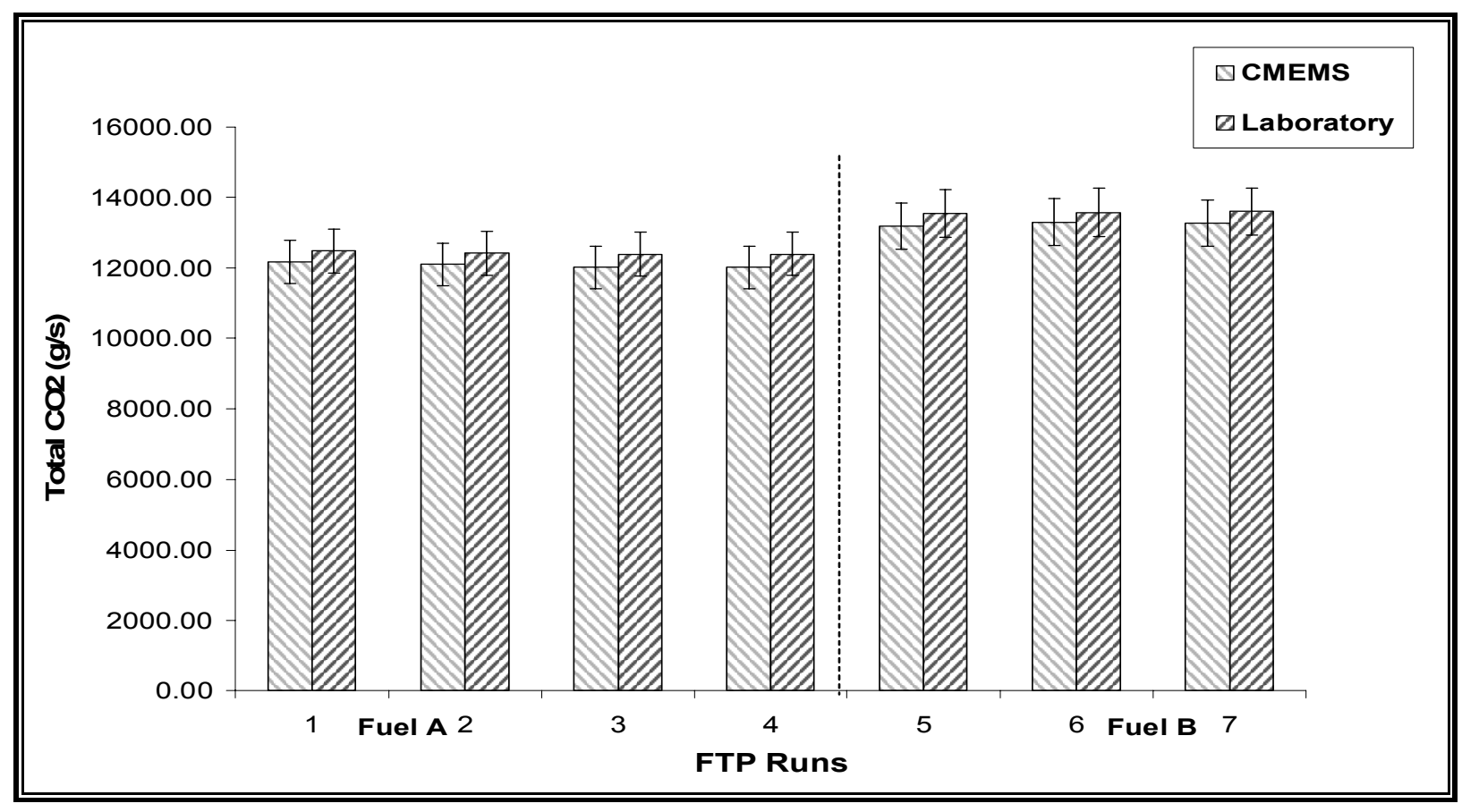

Figure-47 Data summary of the total $\mathrm{CO}_{2}(\mathrm{~g} / \mathrm{s})$ on seven FTP cycle runs on a 1992 DDC series 60 engine reported with $95 \%$ confidence

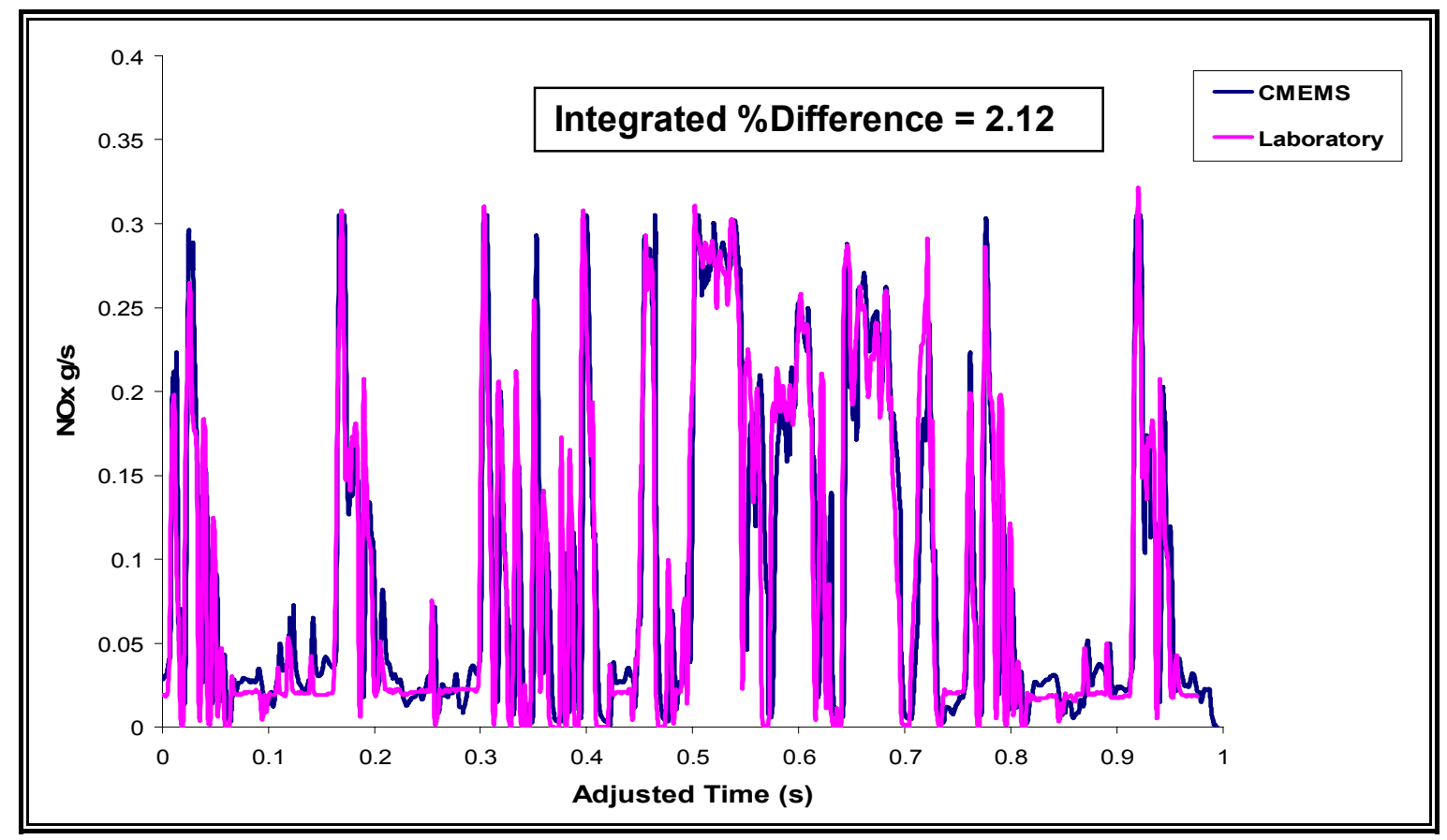

Figure-48 $\mathrm{NO}_{\mathrm{x}}$ comparison for laboratory FTP cycle on a DDC series 60 engine run1 


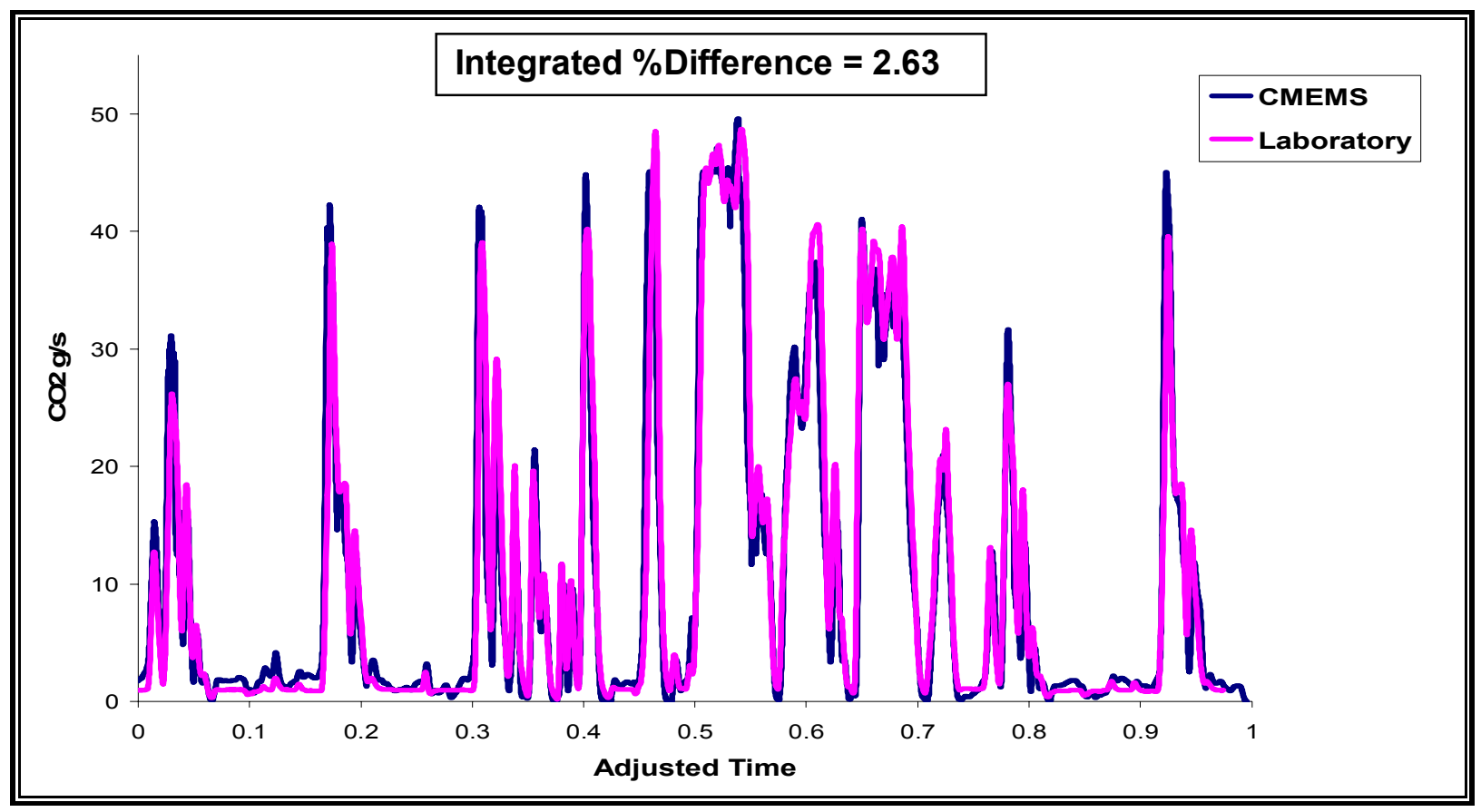

Figure- $49 \mathrm{CO}_{2}$ comparison for laboratory FTP cycle on a DDC series 60 engine run1

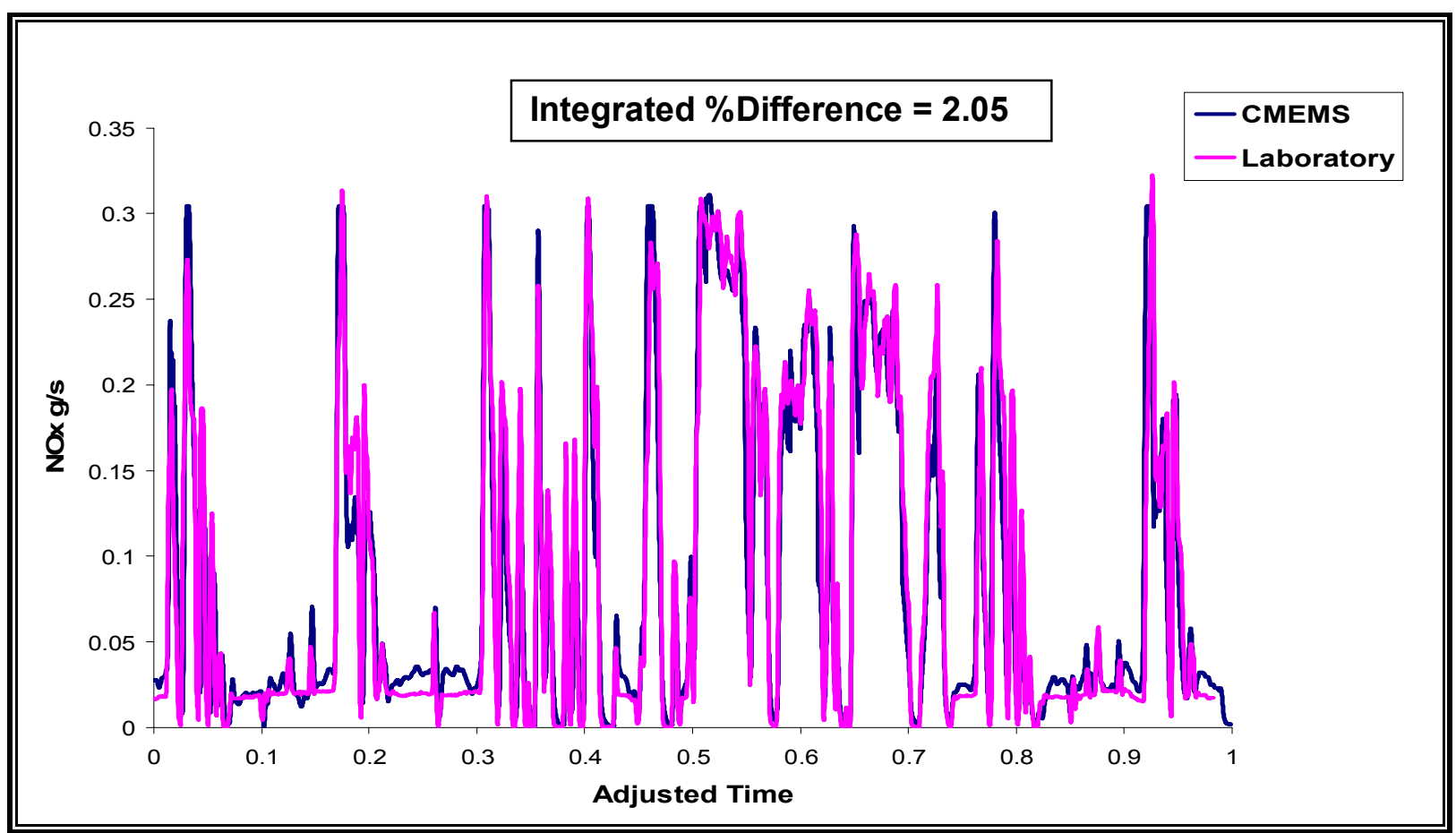

Figure- $50 \mathrm{NO}_{\mathrm{x}}$ comparison for laboratory FTP cycle on a DDC series 60 engine run2 


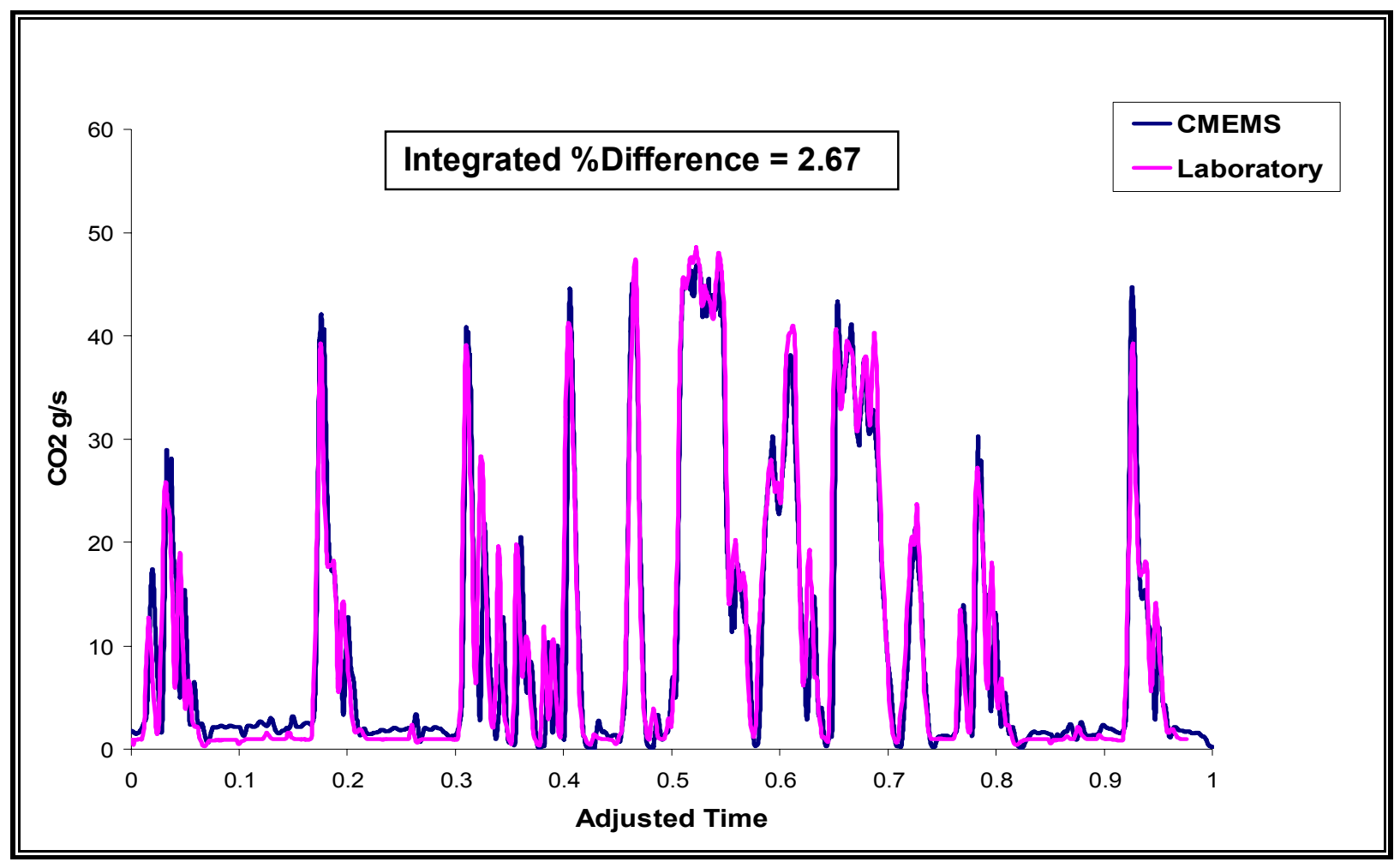

Figure- $51 \mathrm{CO}_{2}$ comparison for laboratory FTP cycle on a DDC series 60 engine run2

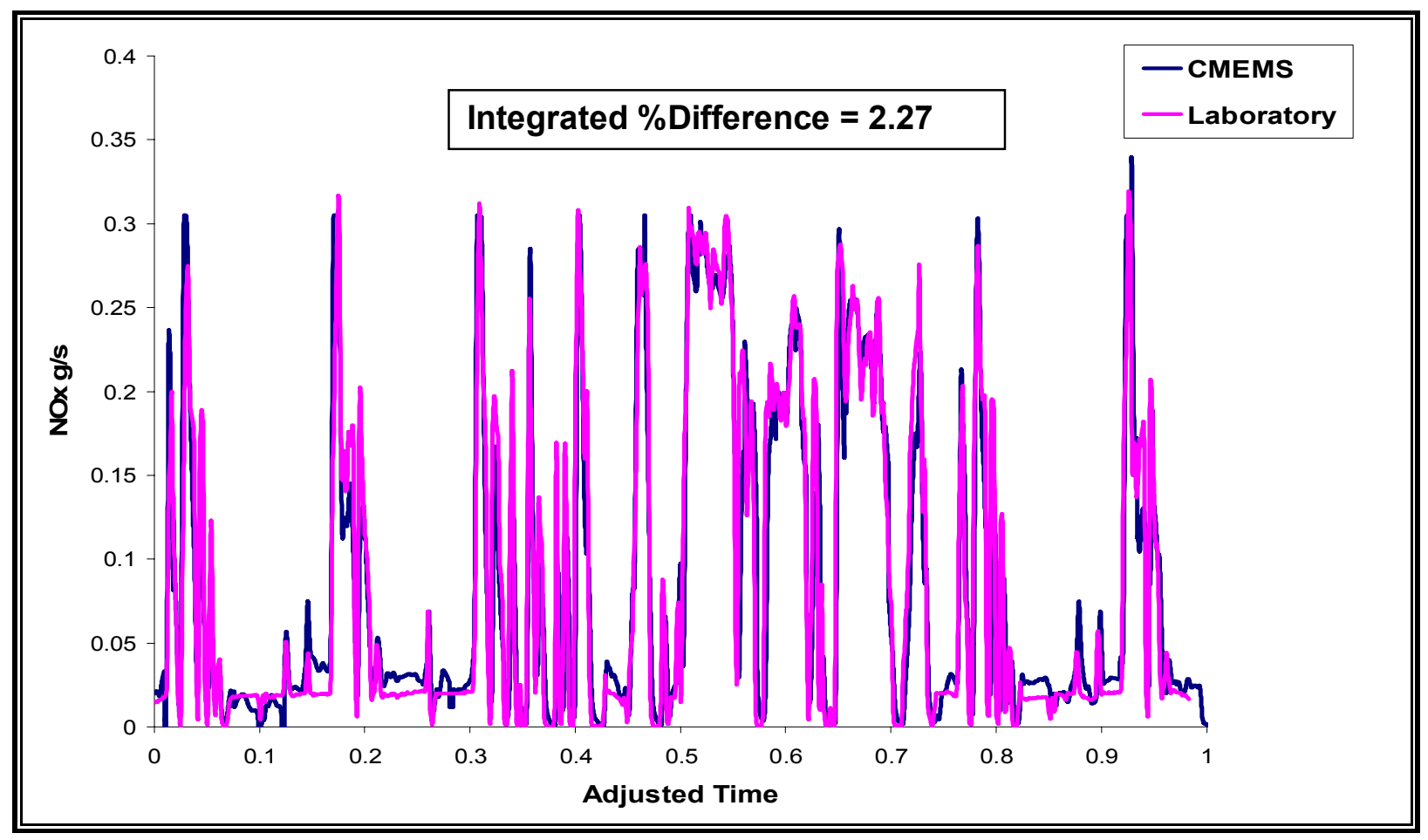

Figure- $52 \mathrm{NO}_{\mathrm{x}}$ comparison for laboratory FTP cycle on a DDC series 60 engine run3 


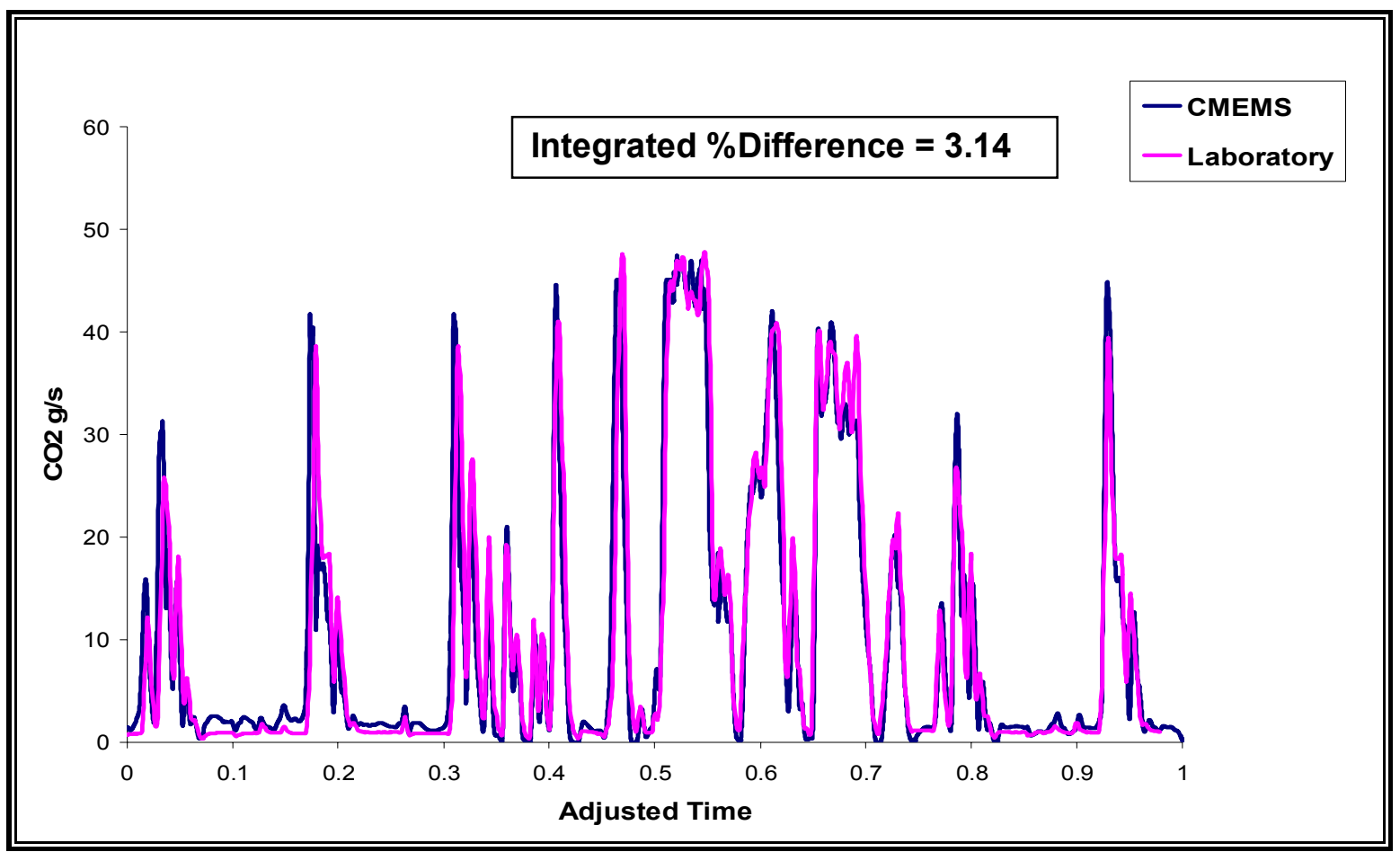

Figure- $53 \mathrm{CO}_{2}$ comparison for laboratory FTP cycle on a DDC series 60 engine run3

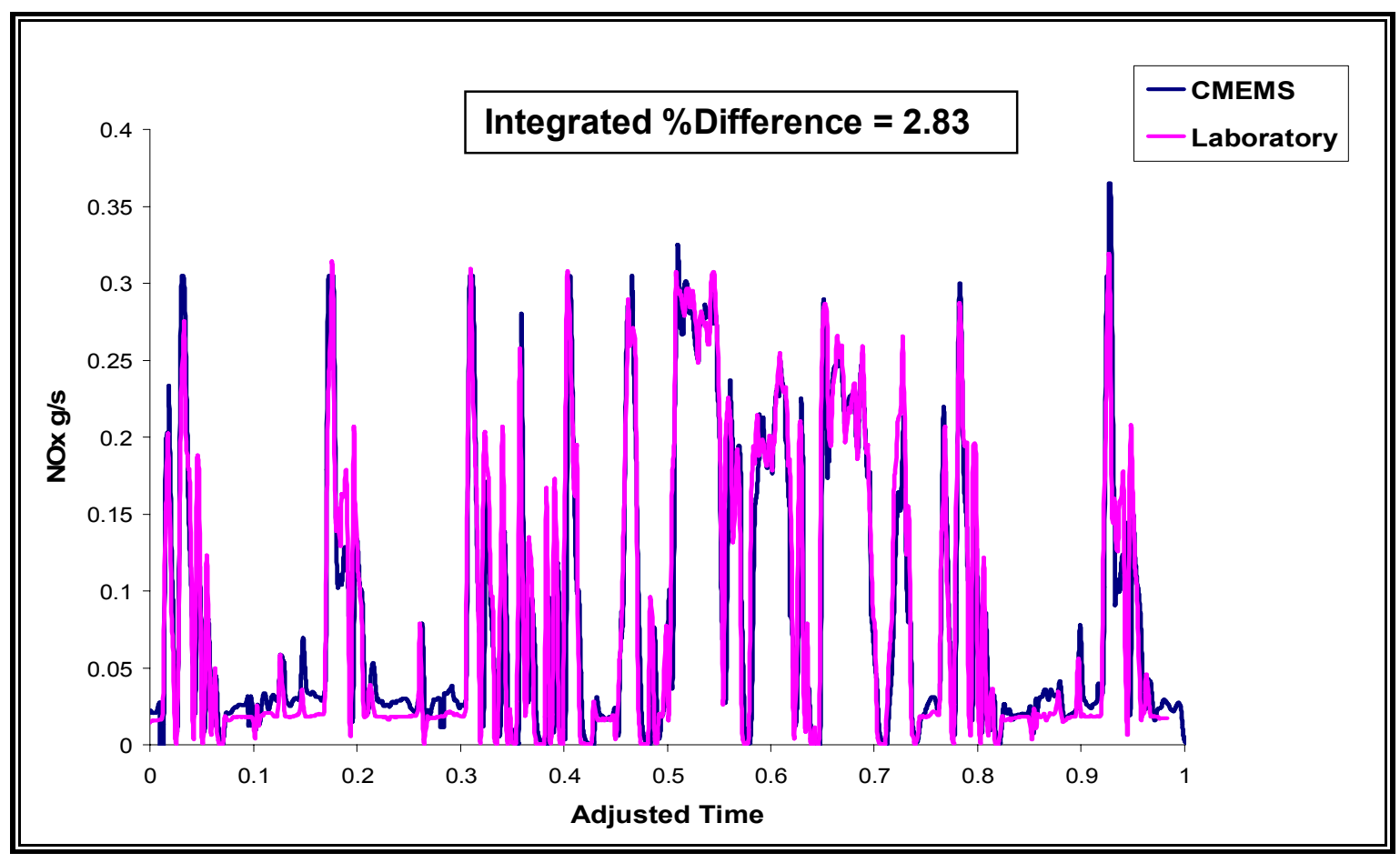

Figure- $54 \mathrm{NO}_{\mathrm{x}}$ comparison for laboratory FTP cycle on a DDC series 60 engine run4 


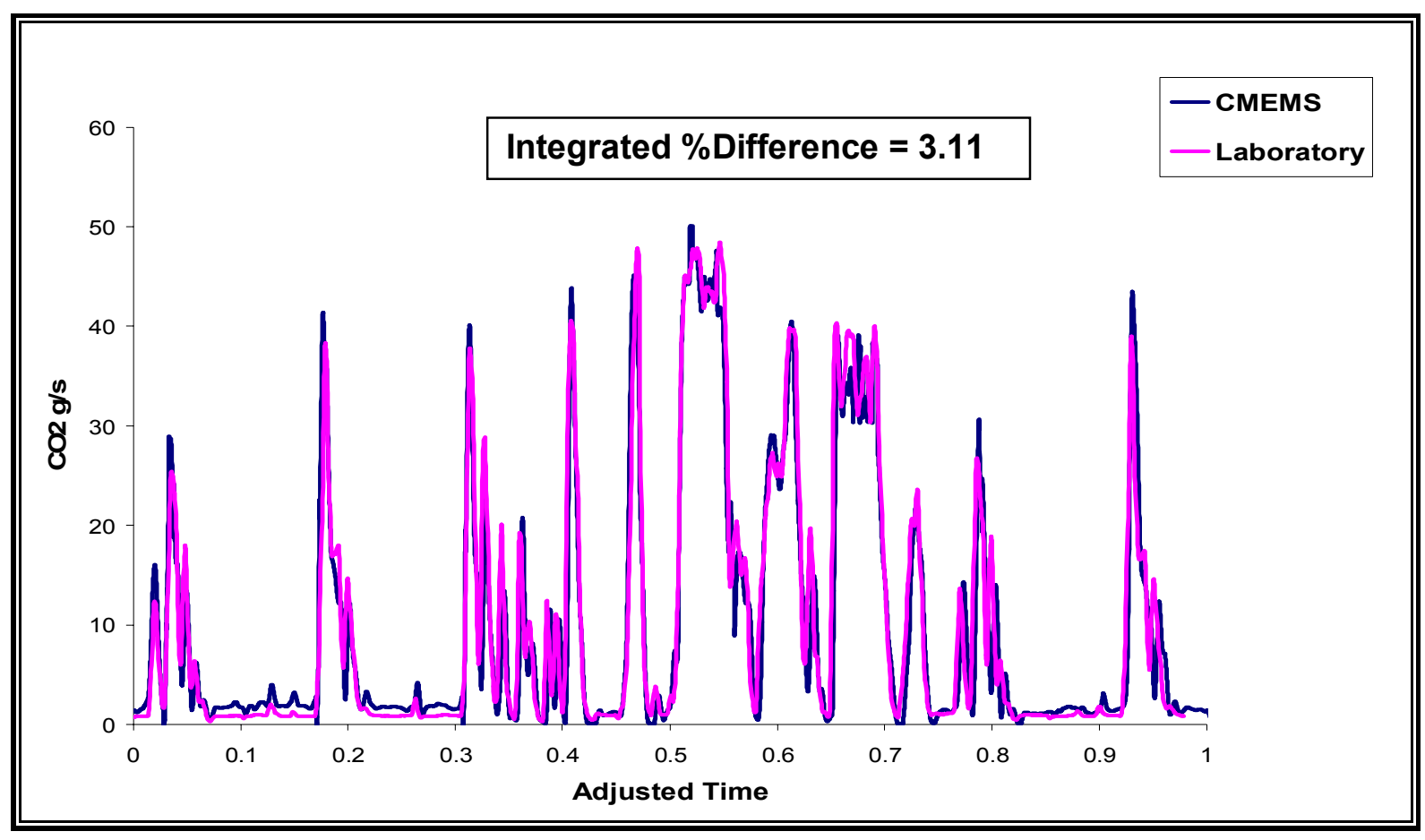

Figure- $55 \mathrm{CO}_{2}$ comparison for laboratory FTP cycle on a DDC series 60 engine run4

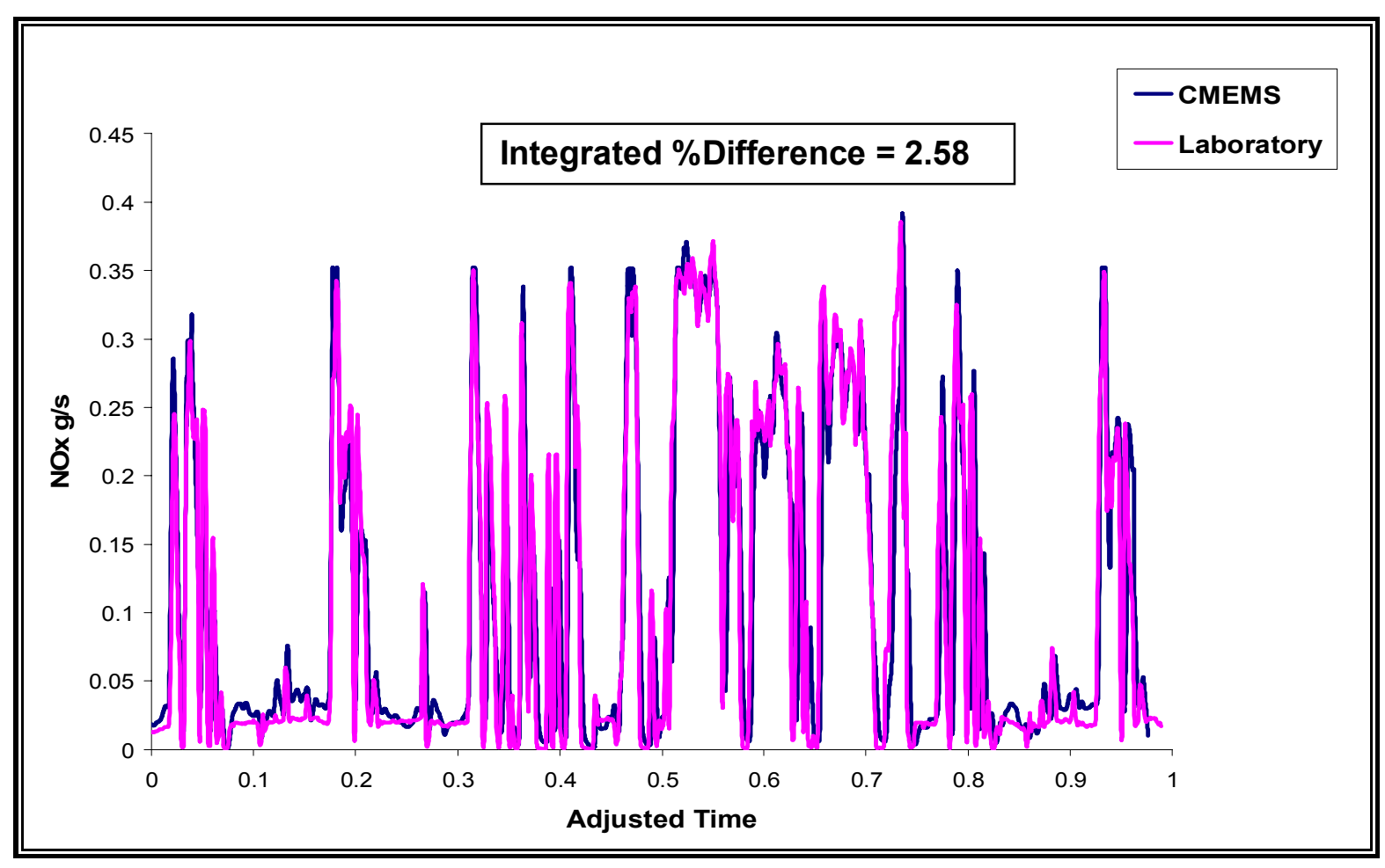

Figure- $56 \mathrm{NO}_{\mathrm{x}}$ comparison for laboratory FTP cycle on a DDC series 60 engine run-5 


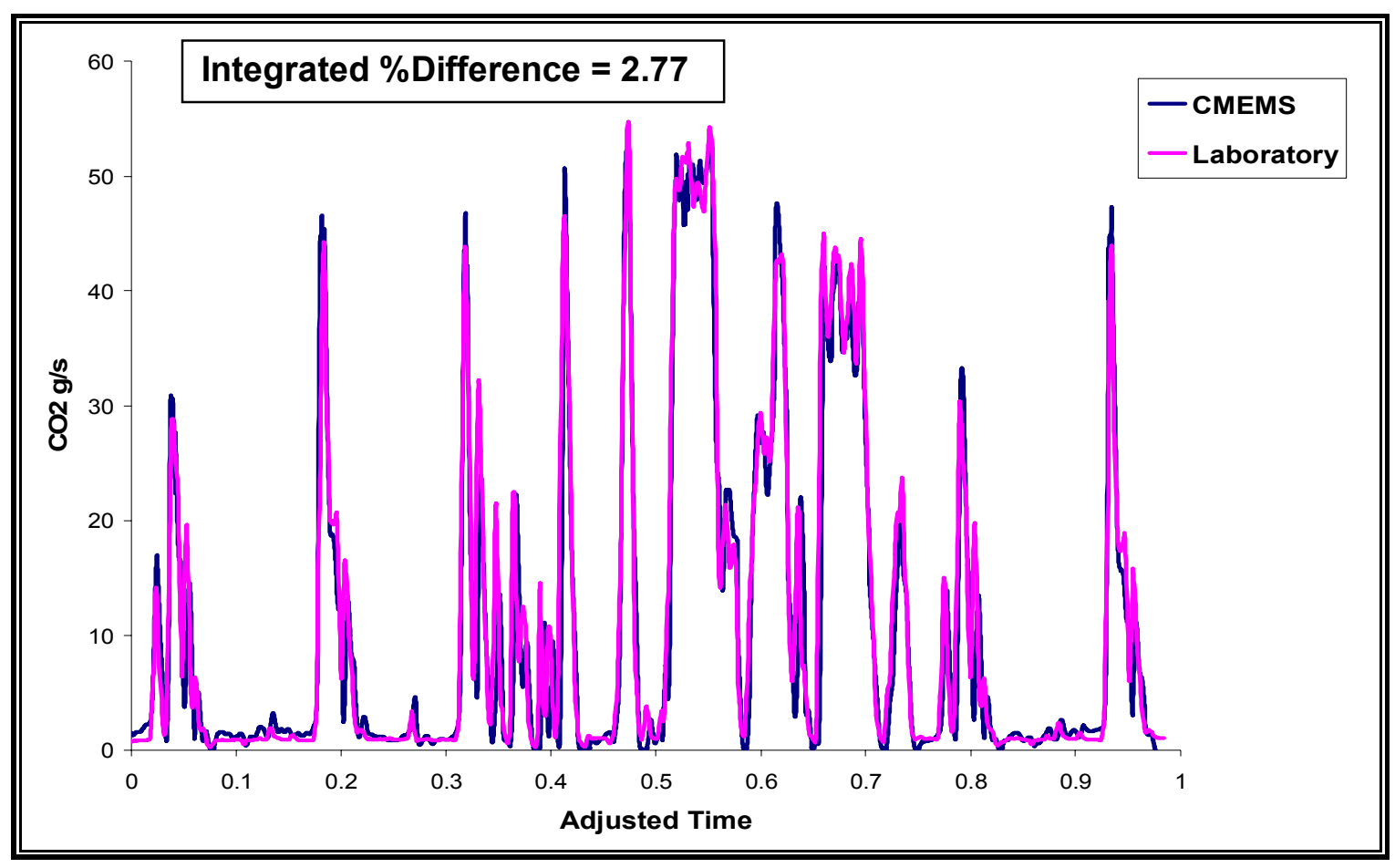

Figure- $57 \mathrm{CO}_{2}$ comparison for laboratory FTP cycle on a DDC series 60 engine run5

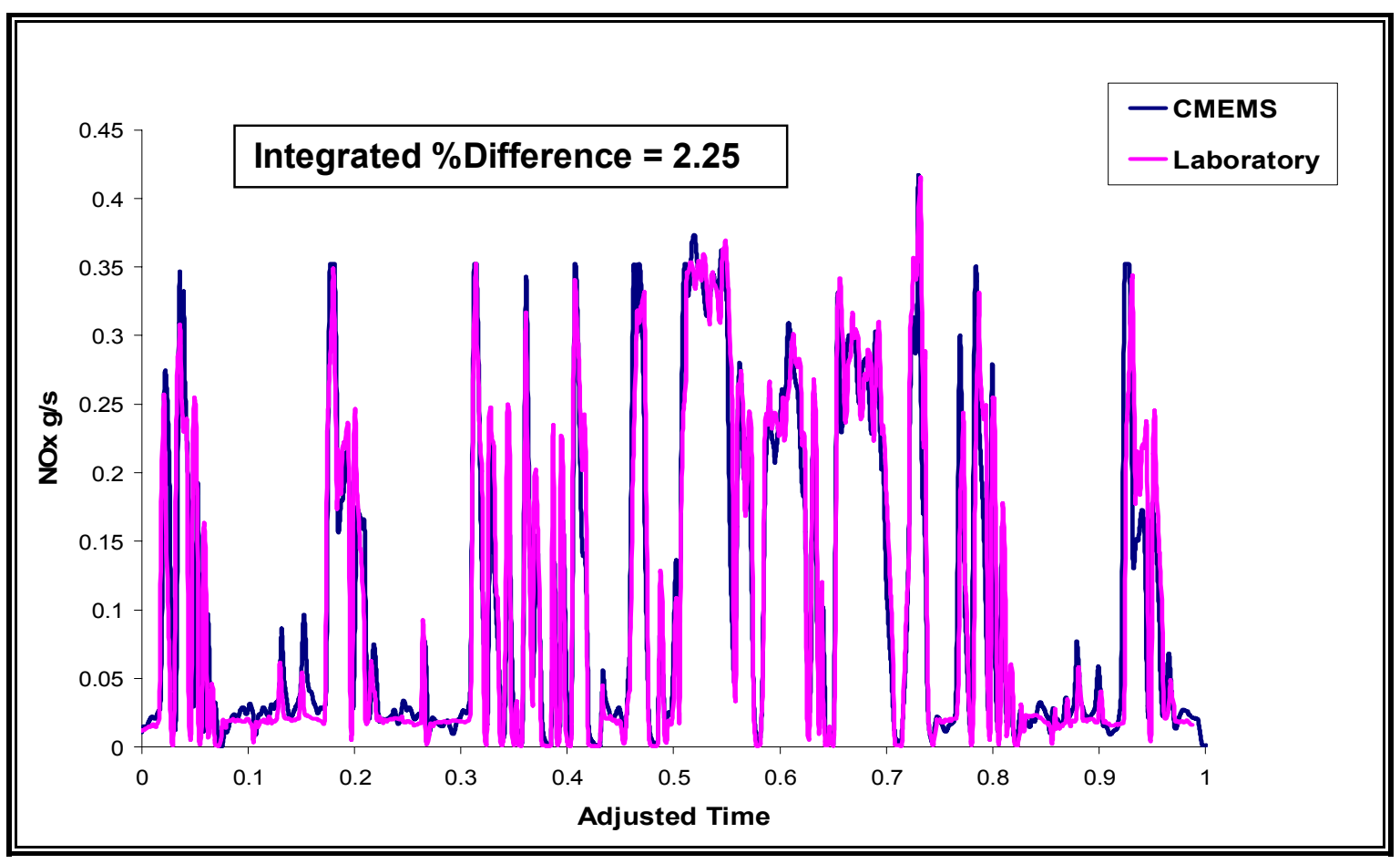

Figure- $58 \mathrm{NO}_{\mathrm{x}}$ comparison for laboratory FTP cycle on a DDC series 60 engine run6 


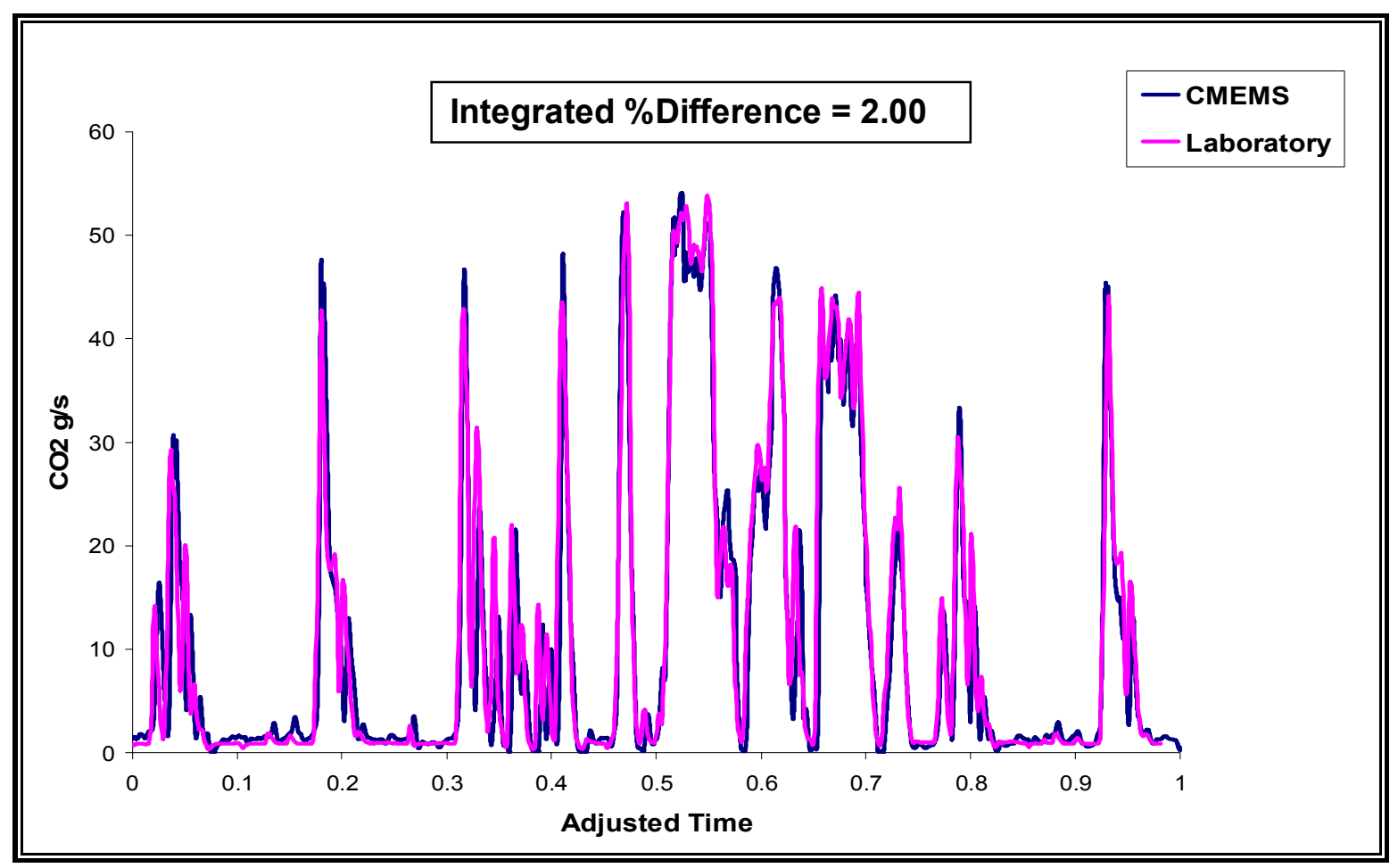

Figure- $59 \mathrm{CO}_{2}$ comparison for laboratory FTP cycle on a DDC series 60 engine run6

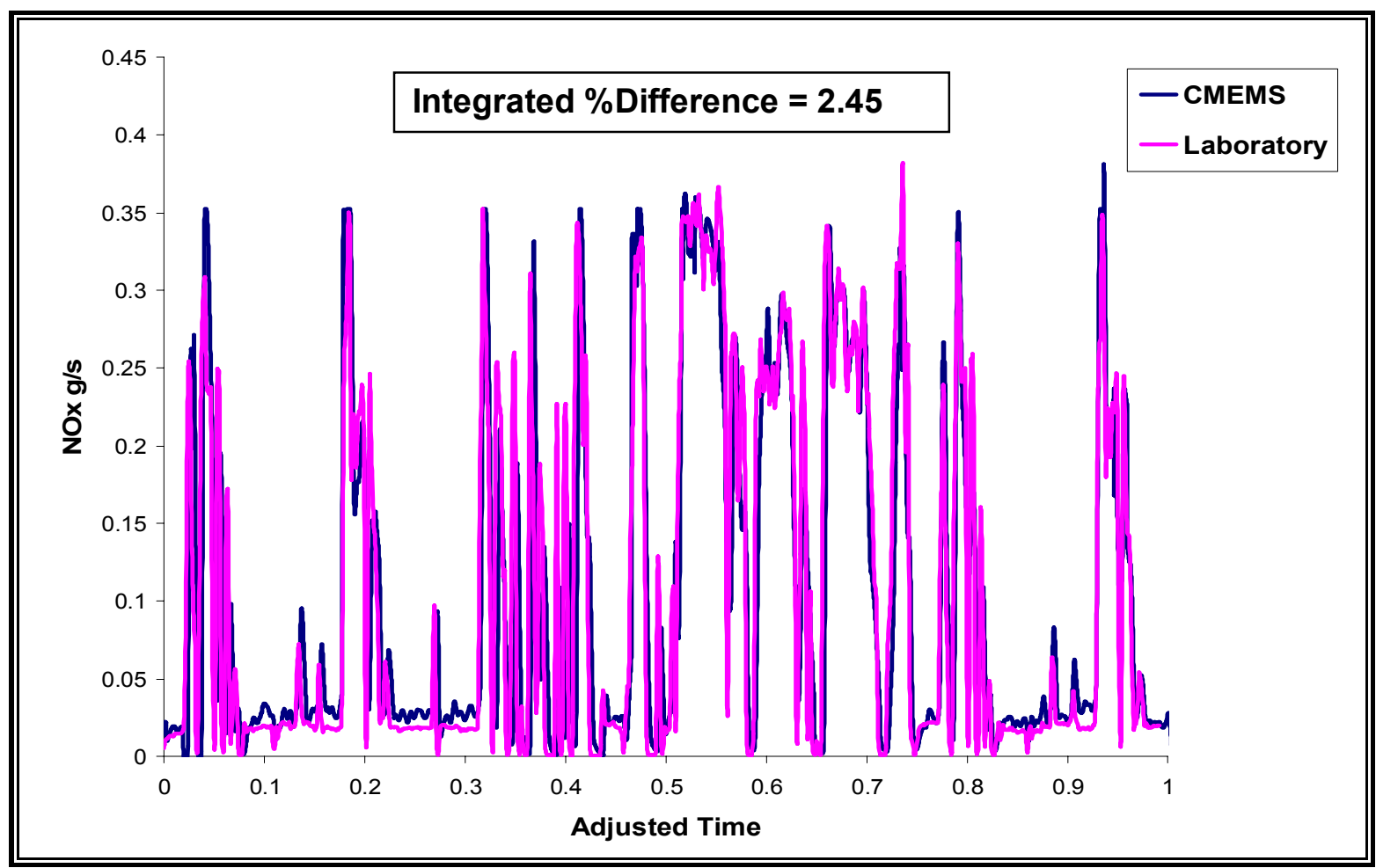

Figure- $60 \mathrm{NO}_{\mathrm{x}}$ comparison for laboratory FTP cycle on a DDC series 60 engine run7 


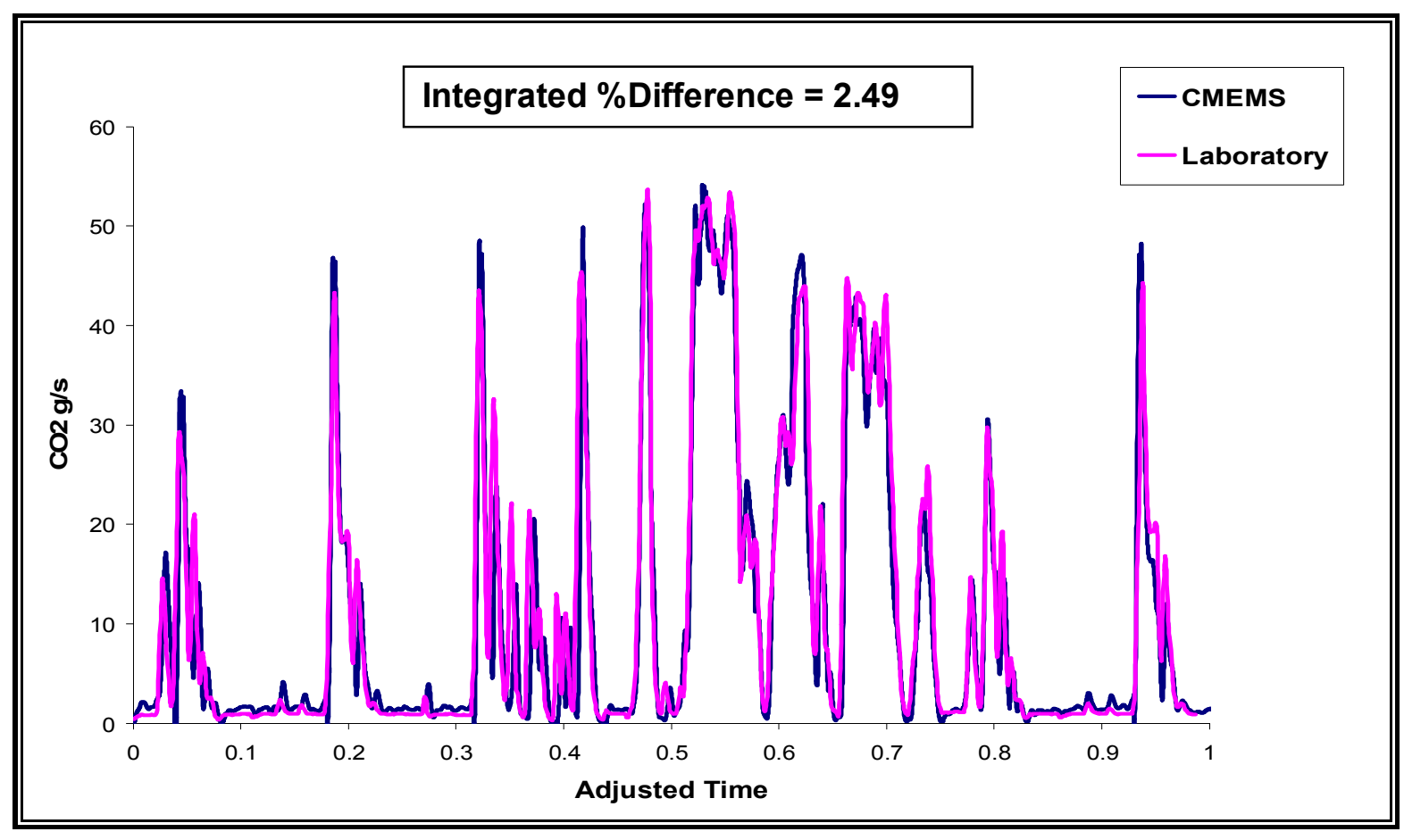

Figure- $61 \mathrm{CO}_{2}$ comparison for laboratory FTP cycle on a DDC series 60 engine run7

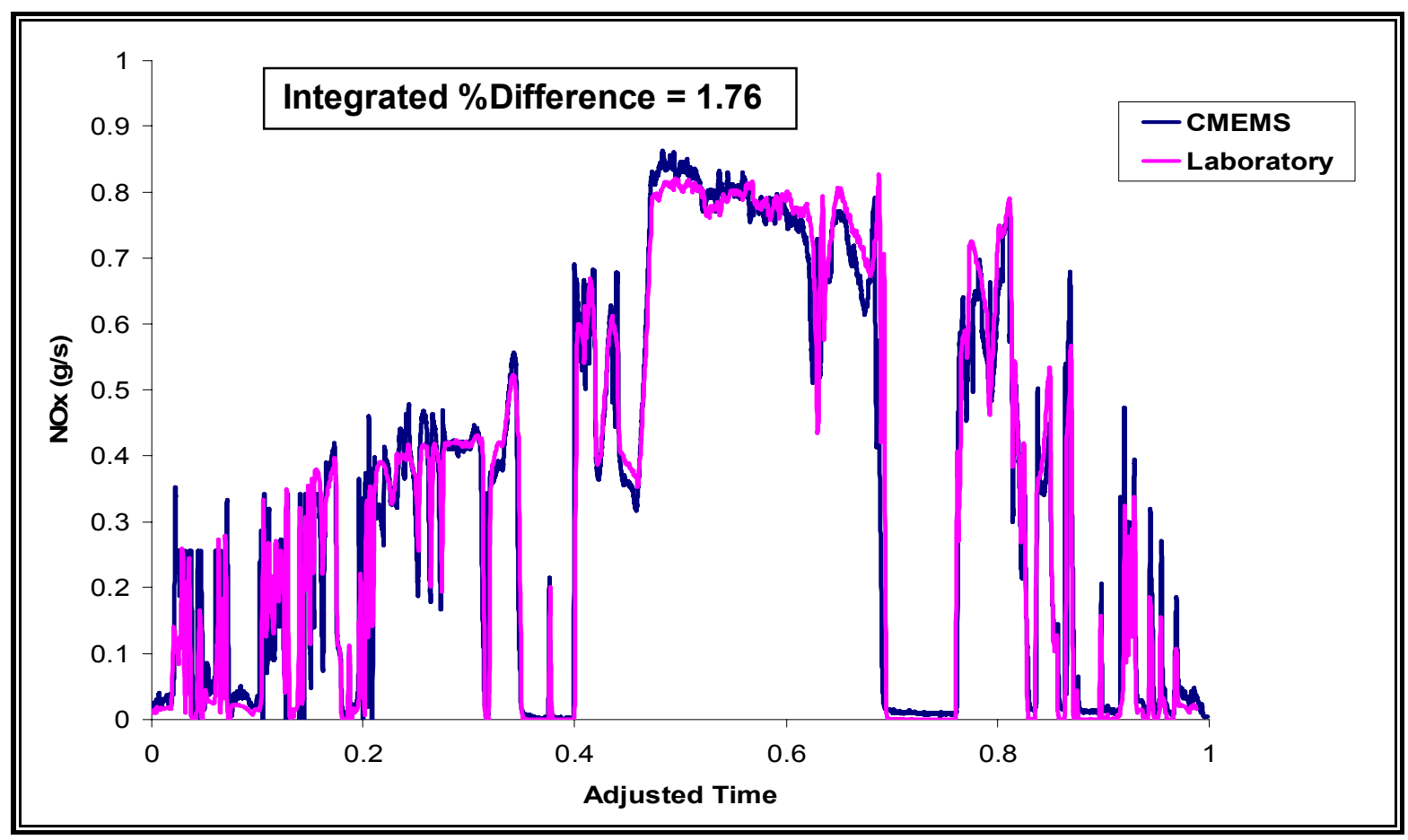

Figure- $62 \mathrm{NO}_{x}$ comparison for on-road cycle on a DDC series 60 engine run1 


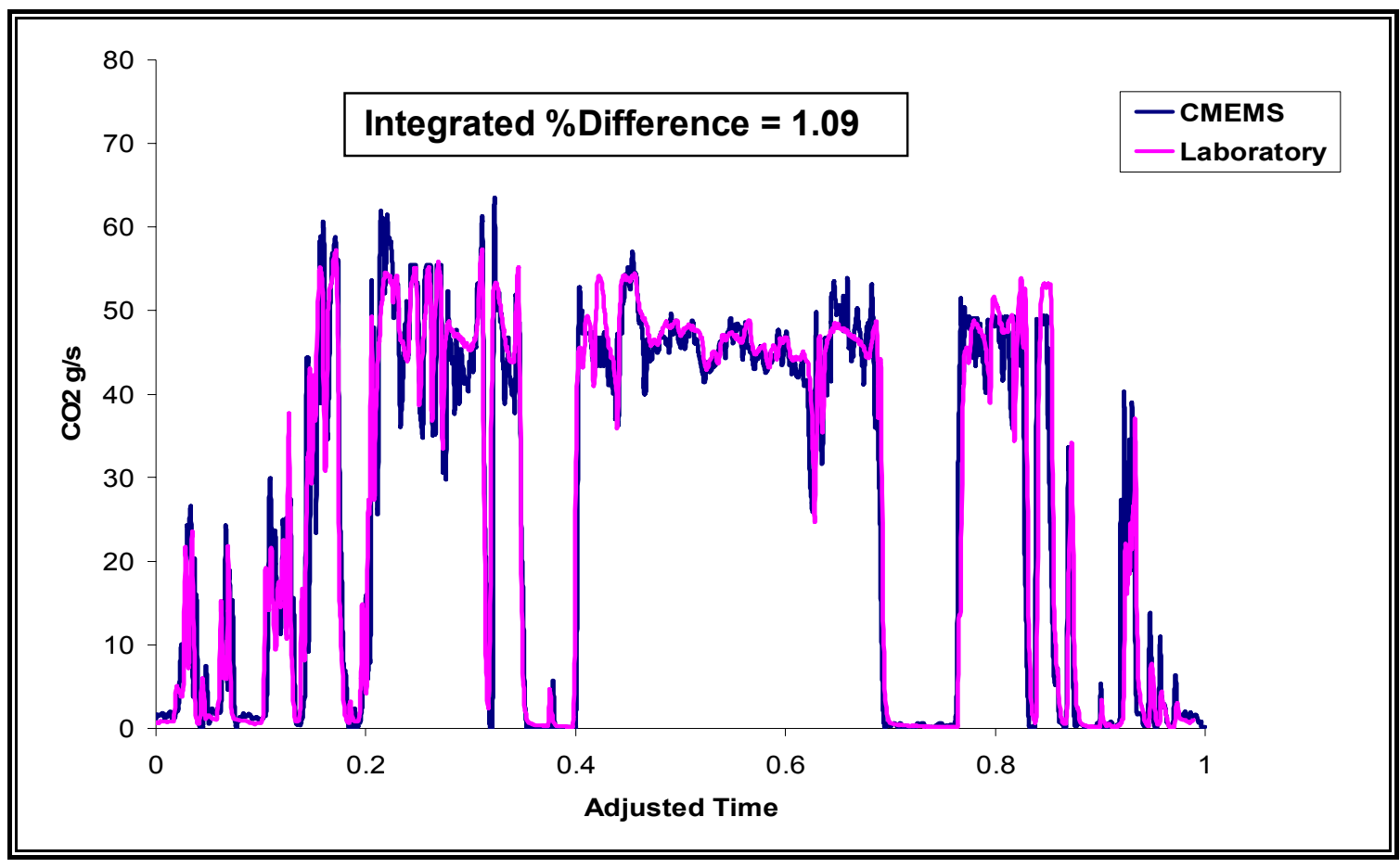

Figure- $63 \mathrm{CO}_{2}$ comparison for on-road cycle on a DDC series 60 engine run1

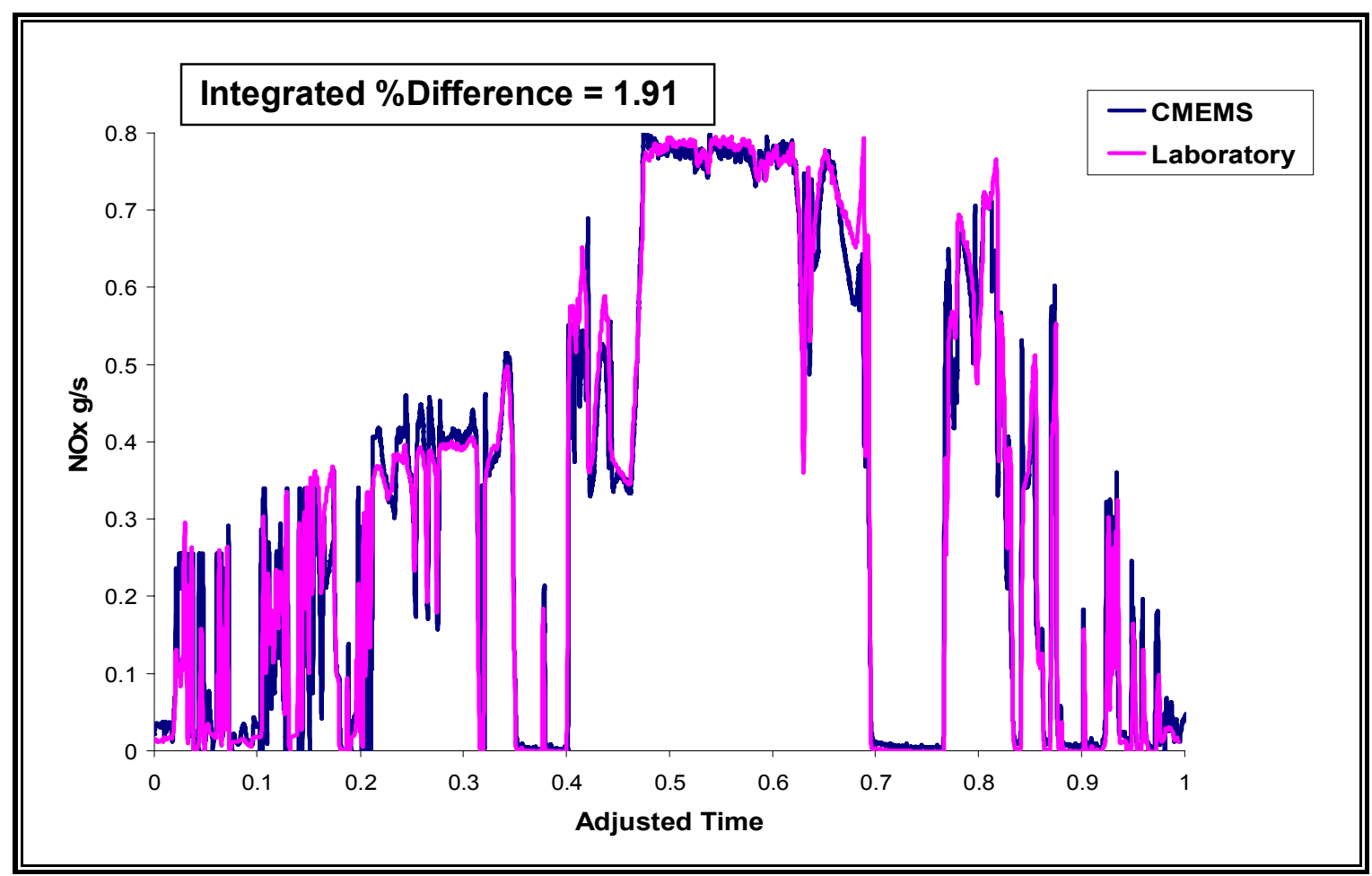

Figure- $64 \mathrm{NO}_{\mathrm{x}}$ comparison for on-road cycle on a DDC series 60 engine run2 


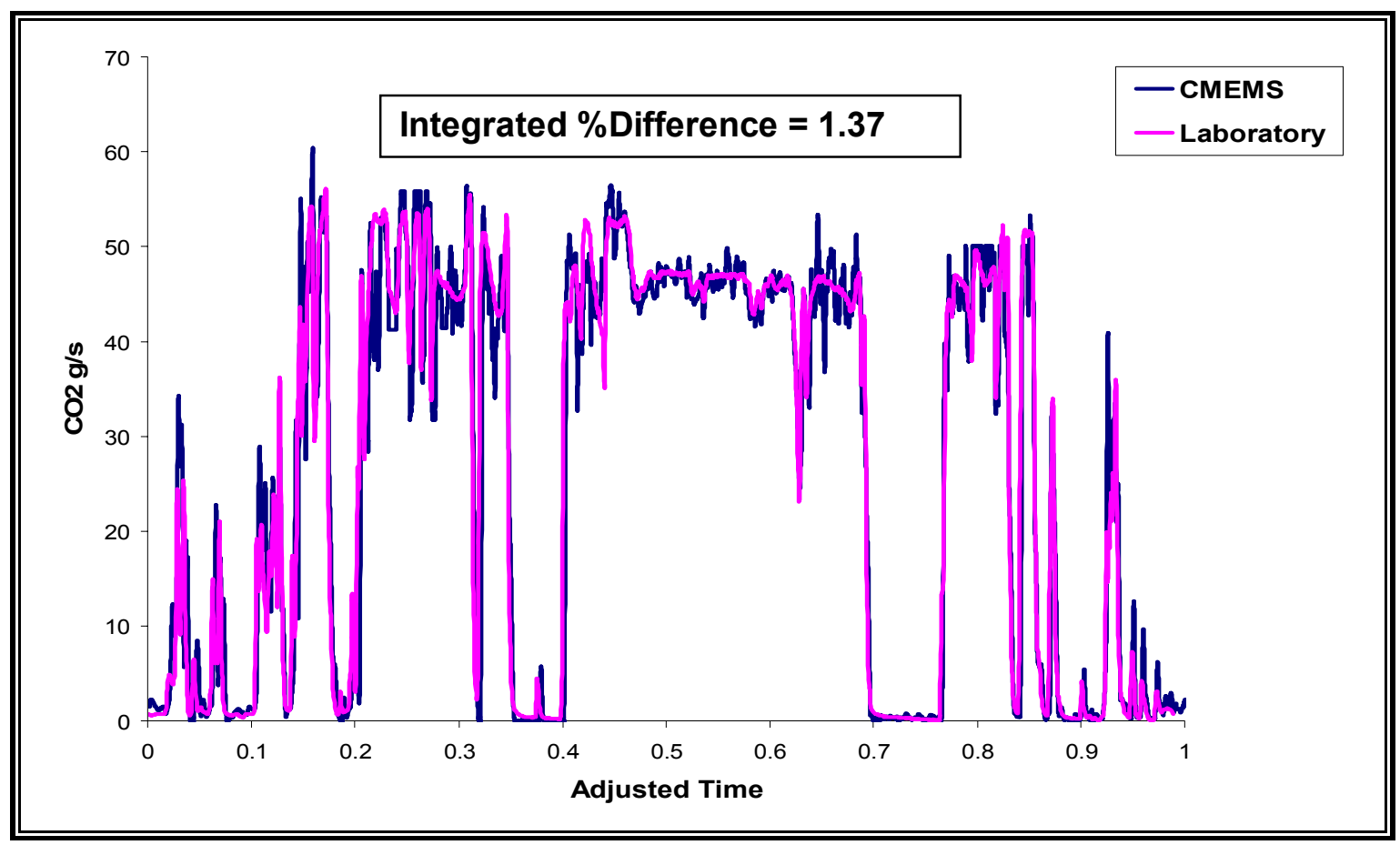

Figure- $65 \mathrm{CO}_{2}$ comparison for on-road cycle on a DDC series 60 engine run2

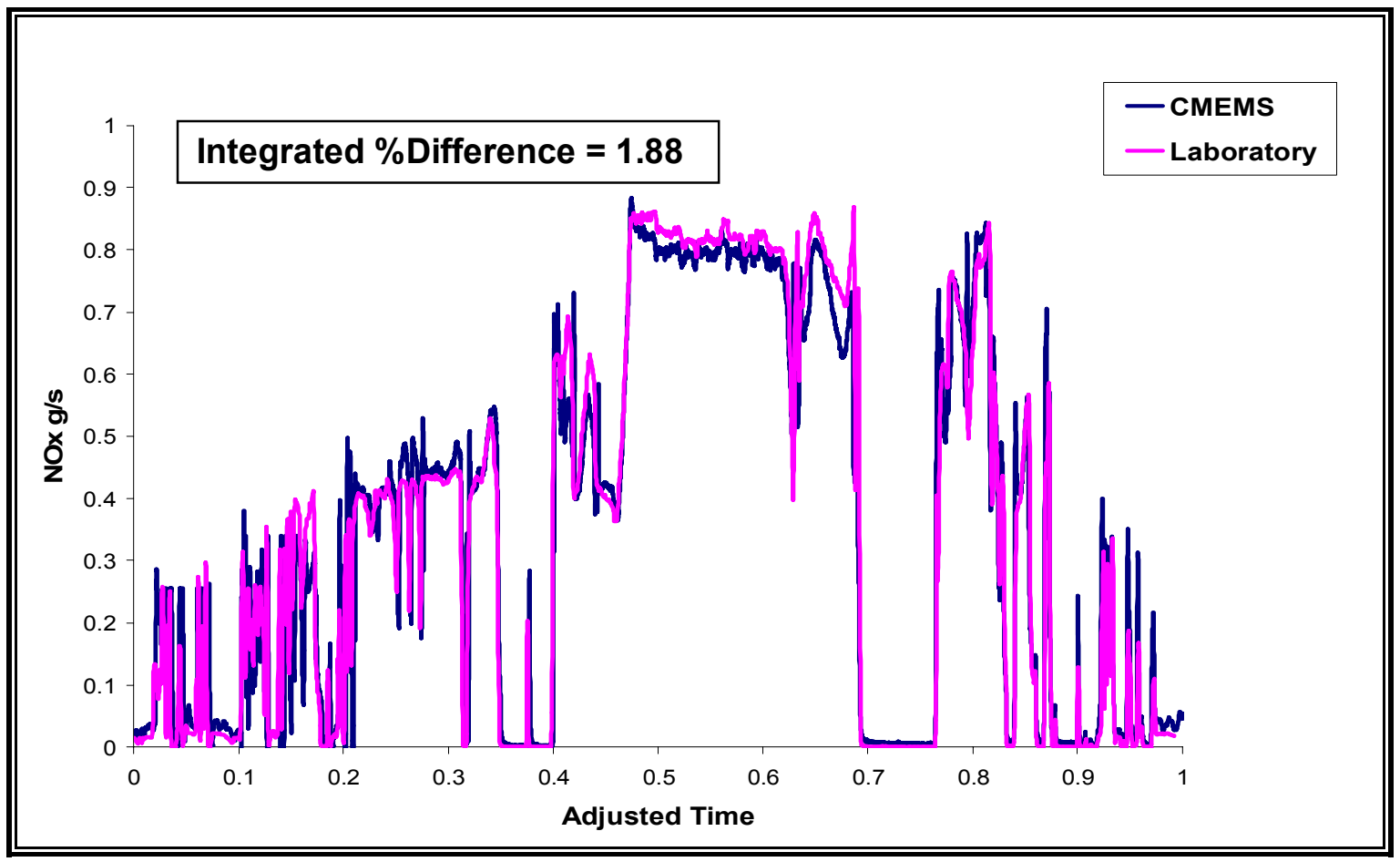

Figure- $66 \mathrm{NO}_{\mathrm{x}}$ comparison for on-road cycle on a DDC series 60 engine run3 


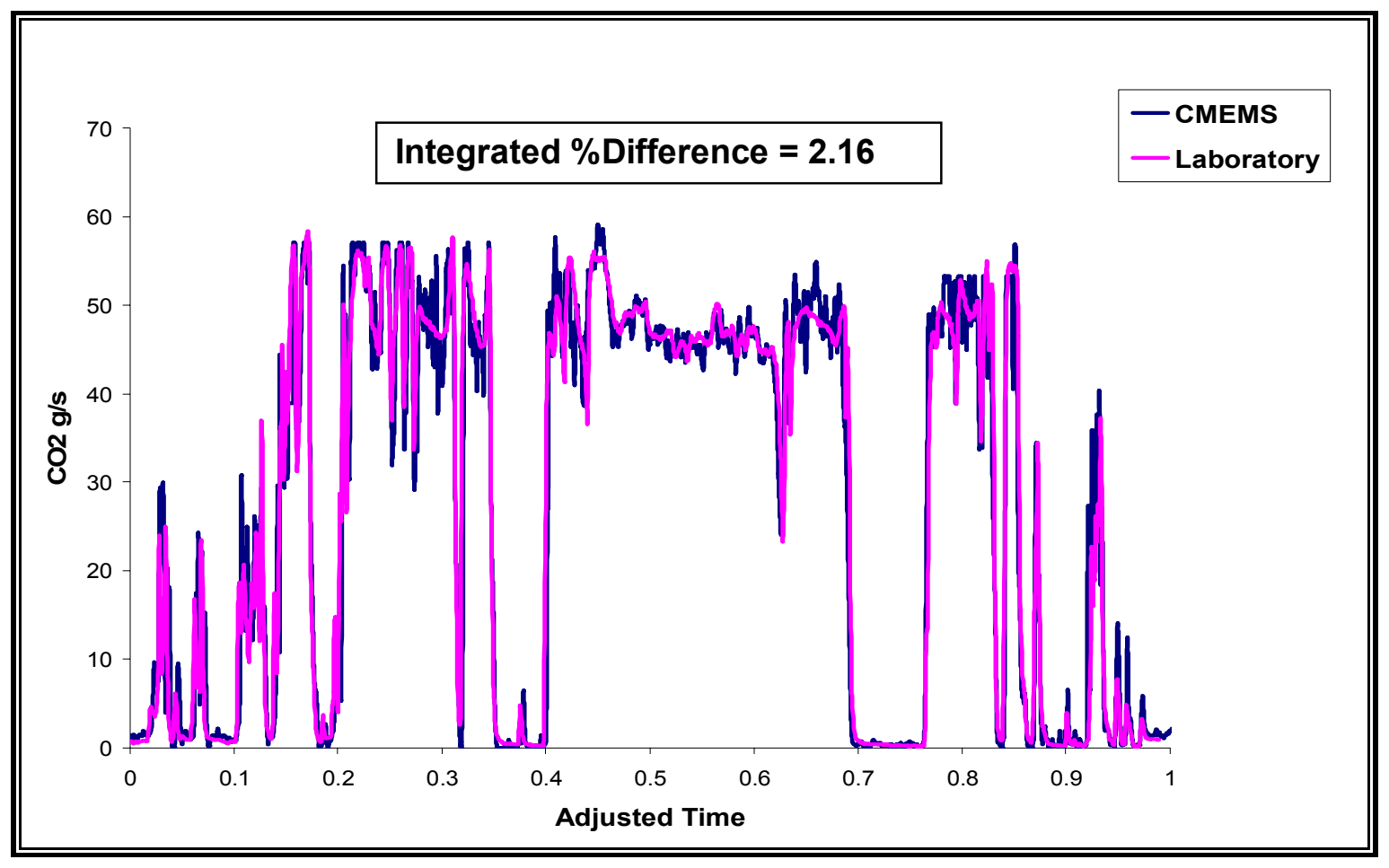

Figure- $67 \mathrm{CO}_{2}$ comparison for on-road cycle on a DDC series 60 engine run3

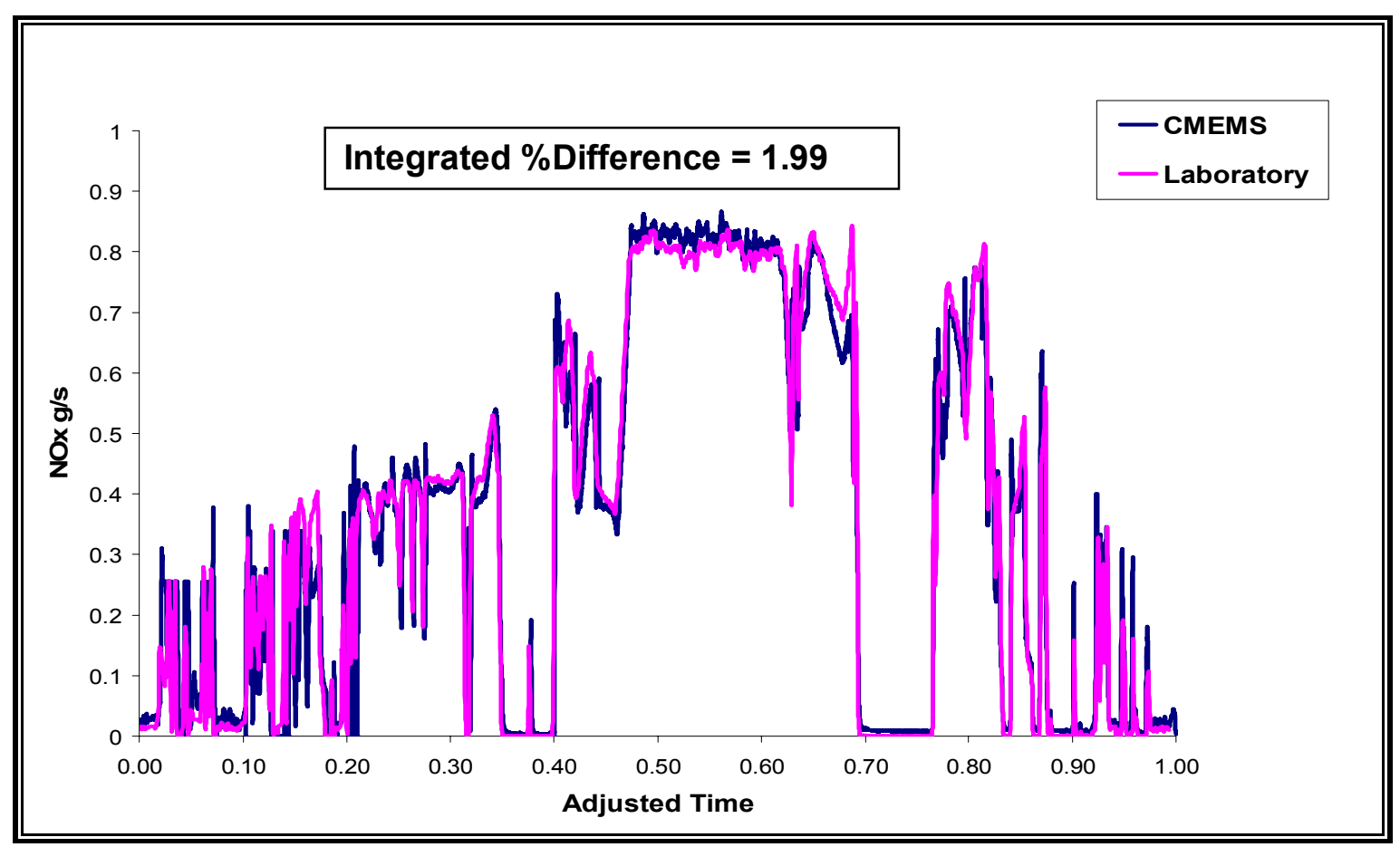

Figure- $68 \mathrm{NO}_{\mathrm{x}}$ comparison for on-road cycle on a DDC series 60 engine run4 


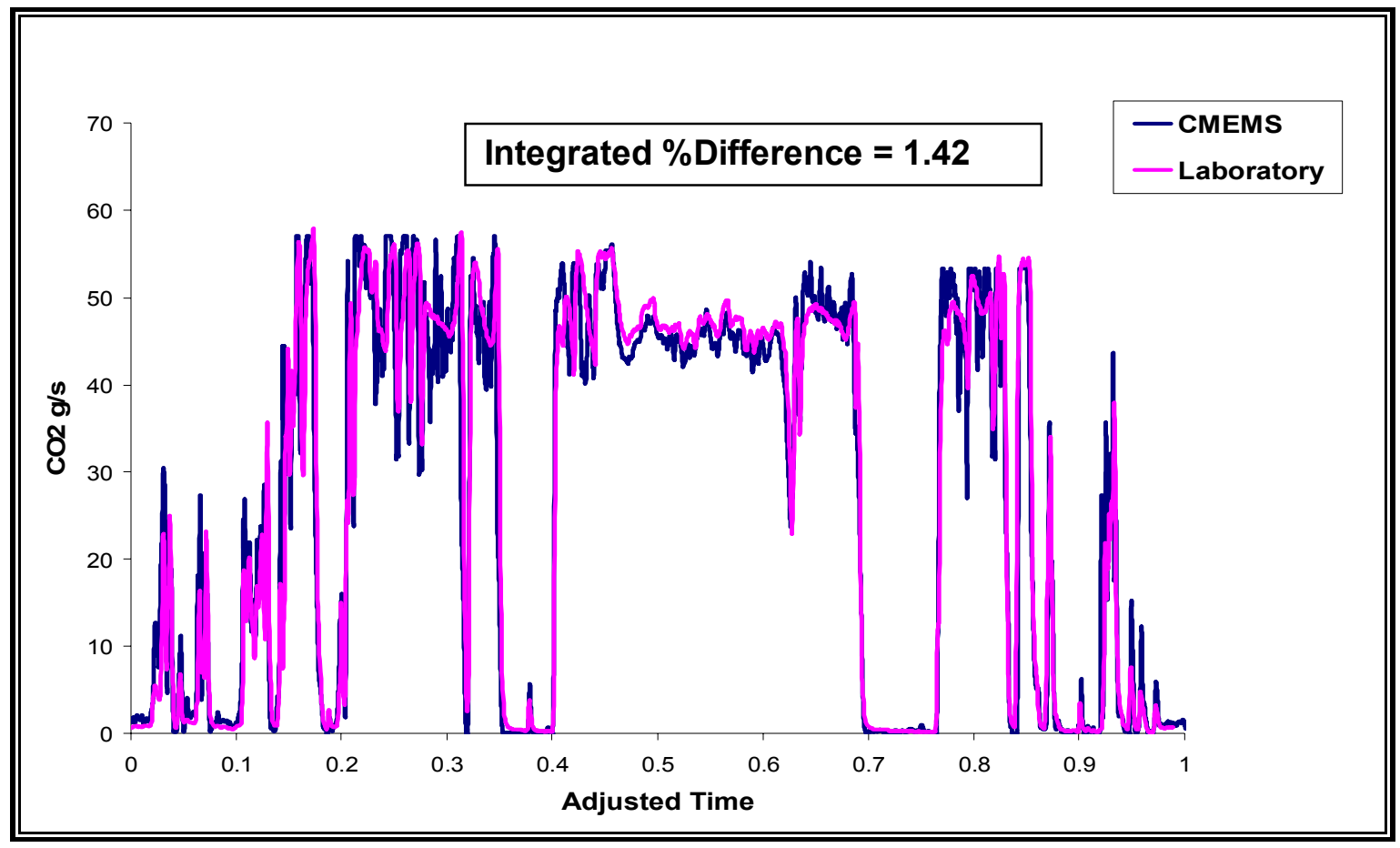

Figure- $69 \mathrm{CO}_{2}$ comparison for on-road cycle on a DDC series 60 engine run4 


\section{Chapter 6 Conclusion and Recommendations}

\subsection{Conclusion}

It was concluded that the CMEMS was more compact and lighter $(60 \mathrm{lb})$ than the existing MEMS unit (all systems adding up to $120 \mathrm{lb}$ ). The entire system could be mounted on the tail pipe of the test vehicle by a single operator thereby reducing the installation time and manpower efforts significantly. The sampling system in CMEMS was significantly smaller than that of MEMS which reduced the power consumption. The sampling system also met other criteria such as ease of handling, robustness and cost. Steady state test results confirmed great agreement with MEMS on accuracy, linearity, repeatability, interference and response time tests. The sampling system of the CMEMS also reported excellent performance on pressure and flow rate variation and vibration and inclination tests to qualify for harsh on-board conditions.

After complete integration of the sampling system and other components, the entire CMEMS was tested on the tail pipe of a Ford F450 pick-up truck and also in an engine laboratory on a 1992 DDC series 60 engine to document the performance against the MEMS and the laboratory. The CMEMS reported a maximum percentage difference of $5.18 \%$ for $\mathrm{NO}_{x}$ and $3.10 \%$ for $\mathrm{CO}_{2}$ against the MEMS in two on-road tests conducted on a Ford F450 pick-up truck. CMEMS also reported a difference of $2.36 \%$ for $\mathrm{NO}_{\mathrm{x}}$ and $2.69 \%$ for $\mathrm{CO}_{2}$ against the laboratory grade analyzers on seven FTP runs. Differences of $1.87 \%$ for $\mathrm{NO}_{x}$ and $1.51 \%$ for $\mathrm{CO}_{2}$ were reported against the laboratory grade analyzers when the series 60 engine was exercised on a simulated on-road cycle. Thus, project objectives were 
fulfilled to develop CMEMS as an effective and robust on-board emission measurement unit.

\subsection{Recommendations}

The following are the recommendations for the future development of CMEMS-

1. ECU data recording capability to report break-specific emissions data as part of Consent Decrees.

2. Data acquisition system equipped with GPS module to report vehicle speed and position to match in-use measurement performance of MEMS.

3. Integration of $\mathrm{HC}$ analyzer to report $\mathrm{THC}$ emissions data to match performances of other commercially available portable units.

4. User-friendly data acquisition and reduction program.

5. Design optimization of the system with respect to space utilization for component handling and trouble shooting. 


\section{Appendix A}

\section{Specification of 1992 DDC Series 60 Engine:}

The specification of a 1992, $360 \mathrm{hp} \mathrm{DDC} \mathrm{Series} 60$ engine areas follows-

Engine Manufacturer - Detroit Diesel Corporation

$\begin{array}{ll}\text { Engine Model - } & \text { Series } 60 \\ \text { Model Year - } & 1992 \\ \text { Displacement - } & 12.7 \text { liters } \\ \text { Power Rating (hp) - } & 360 \mathrm{hp} @ 1800 \mathrm{rpm} \\ \text { Configuration Inline - } & 6 \\ \text { Bore }(\mathrm{m}) \text { x Stroke }(\mathrm{m}) \text { - } & 0.13 \mathrm{~m} \times 0.16 \mathrm{~m} \\ \text { Induction- } & \text { Turbocharged } \\ \text { Fuel Type Diesel - } & \text { Engine Strokes per Cycle Four } \\ \text { Injection- } & \text { Electronically Controlled }\end{array}$

Engine has a peak torque of $1350 \mathrm{ft}-\mathrm{lbs}$ at $1200 \mathrm{rpm}$. 


\section{Appendix B}

1. Laboratory Analyzers

Table-48 Specification of laboratory analyzers

\begin{tabular}{||c|c|c|c|c|c||}
\hline Analyzer & Gas & $\begin{array}{c}\text { Detection } \\
\text { Principle }\end{array}$ & Accuracy & $\begin{array}{c}\text { Zero / } \\
\text { Span Drift }\end{array}$ & Repeatability \\
\hline $\begin{array}{c}\text { Rosemount } \\
955\end{array}$ & $\mathrm{NO}_{x}$ & $\begin{array}{c}\text { Chemilumin } \\
\text { e-scence }\end{array}$ & $\begin{array}{c} \pm 2 \% \text { Full- } \\
\text { scale }\end{array}$ & $\begin{array}{c} \pm 1 \% \\
\text { full scale / } \\
24 \mathrm{hrs}\end{array}$ & $\begin{array}{c} \pm 0.5 \\
\% \text { Full scale }\end{array}$ \\
\hline $\begin{array}{c}\text { Horiba } \\
\text { AlA 210 }\end{array}$ & $\mathrm{CO}_{2}$ & $\begin{array}{c}\text { Non } \\
\text { Dispersive } \\
\text { Infra Red } \\
\text { Radiation }\end{array}$ & $\begin{array}{c} \pm 2 \% \text { Full- } \\
\text { scale }\end{array}$ & $\begin{array}{c} \pm 1 \% \\
\text { full scale/ } \\
8 \mathrm{hrs}\end{array}$ & $\begin{array}{c} \pm 1 \% \\
\text { Full scale }\end{array}$ \\
& & & & \\
\hline
\end{tabular}

2. MEMS Analyzers

2.1 BE 140AD 5-gas Bench:

Table-49 Specification of BE140 AD 5-gas bench [17]

\begin{tabular}{|c|c|c|c|c||}
\hline Gases & Ranges & Resolution & Accuracy & Interference \\
\hline CO & $0-10 \%$ & $0.01 \%$ & $\pm 3 \%$ & $\pm 0.02 \%$ \\
\hline CO2 & $0-20 \%$ & $0.01 \%$ & $\pm 3 \%$ & $\pm 0.2 \%$ \\
\hline HC & $0-10,000$ PPM & 1 PPM & $\begin{array}{c}0-2000- \pm 3 \% \\
\text { to } 5000- \pm 5 \% \\
\text { to } 10,000- \pm \\
10 \%\end{array}$ & \pm 4 PPM \\
\hline NO & $0-5000$ PPM & $0.02 \%$ & - & \pm 20 PPM \\
\hline O2 & $0-25 \%$ & 1 PPM & - & - \\
\hline
\end{tabular}




\subsection{MEXA120 NO Analyzer: $^{2}$}

Table-50 Specification of MEXA120 NO ${ }_{x}$ analyzer [18]

\begin{tabular}{|c|c|}
\hline Range & $\overline{~ 0-5000 ~ P P M ~}$ \\
\hline Response Time (T-90) & Within $1 \mathrm{Sec}$ \\
\hline Accuracy & $\begin{array}{c} \pm 30 \text { PPM or } \pm 3 \% \text { of reading } \\
\text { whichever is larger }\end{array}$ \\
\hline Warm-up Time & 3 minutes \\
\hline Voltage Output & $0-1 \vee D C$ or $0-5 \vee D C$ \\
\hline $\begin{array}{c}\text { Sampling Temperature } \\
\text { Range }\end{array}$ & -7 to $800^{\circ} \mathrm{C}$ \\
\hline
\end{tabular}

\section{CMEMS Analyzers}

\subsection{MEXA720 $\mathrm{NO}_{x}$ Analyzer}

Table-51 Specification of MEXA720 $\mathrm{NO}_{\mathrm{x}}$ analyzer [27]

\begin{tabular}{|c|c|}
\hline Range & $\begin{array}{c}0-1000,1001-2000, \\
2001-3000 \text { PPM }\end{array}$ \\
\hline Accuracy & $\begin{array}{c} \pm 30 \mathrm{PPM}, \pm 3 \%, \\
\pm 5 \%\end{array}$ \\
\hline Response Time & Less than 1 Sec \\
\hline Warm-up Time & 3 minutes \\
\hline Voltage Output & $0-1 \mathrm{~V} \mathrm{DC}$ or $0-5 \mathrm{~V} \mathrm{DC}$ \\
\hline Sampling Temperature Range & -7 to $800^{\circ} \mathrm{C}$ \\
\hline
\end{tabular}




\subsection{BE150 Multi-gas Analyzer}

Table-52 Specification of BE150 multi-gas analyzer [25]

\begin{tabular}{|c|c|c|c|c||}
\hline \hline Gases & Range & Resolution & Accuracy & Repeatability \\
\hline CO & $0-15 \%$ & $0.01 \%$ & $\pm 3 \%$ & $\pm 2 \%$ \\
\hline CO2 & $0-20 \%$ & $0.01 \%$ & $\pm 3 \%$ & $\pm 2 \%$ \\
\hline HC & $0-10,000$ PPM & 1 PPM & to $5000- \pm 5 \%$ & $\pm 2 \%$ \\
& & & to $10,000- \pm 10 \%$ & $\pm 3 \%$ \\
\hline O2 & $0-25 \%$ & $0.02 \%$ & - & - \\
\hline NO & $0-5000$ PPM & 1 PPM & - & - \\
\hline \hline
\end{tabular}

\section{Performance Curves of Sampling Pumps}

\section{a. Thomas Diaphragm Pump}

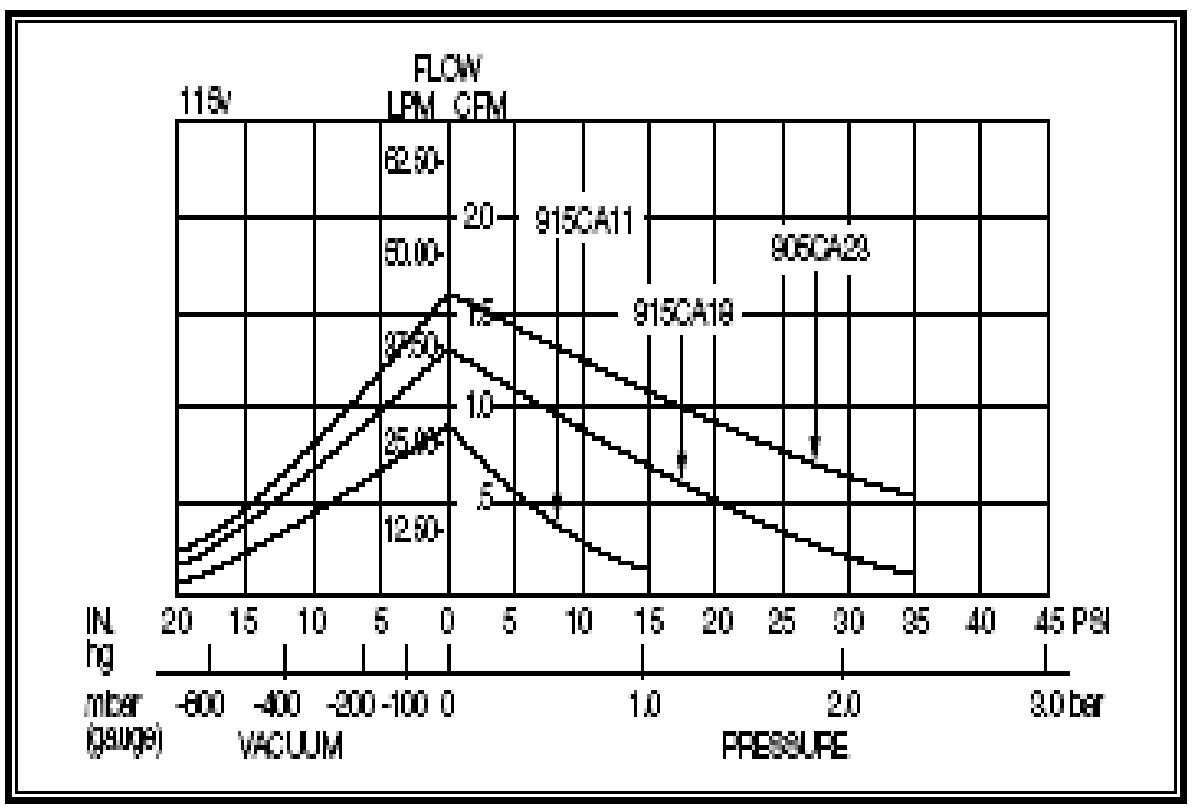

Figure- 70 Performance curve for Thomas diaphragm pump [41]

Note- The 915CA11, 915CA19, 905CA23 are different AC and DC models 


\section{b. Air Dimensions Mini Diaphragm Pump}

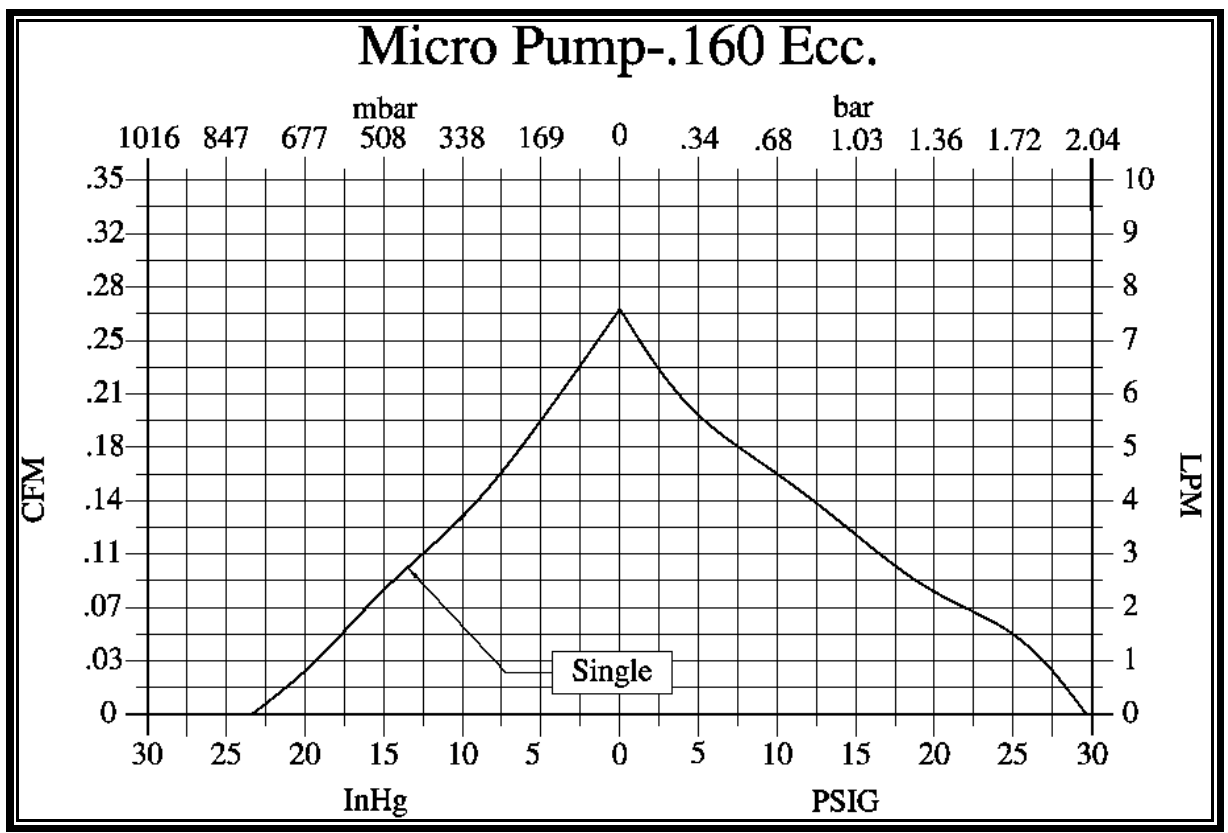

Figure-71 Performance Curve for Air Dimensions mini diaphragm pump [42]

\section{c. Gast Mfg. Diaphragm Pump}

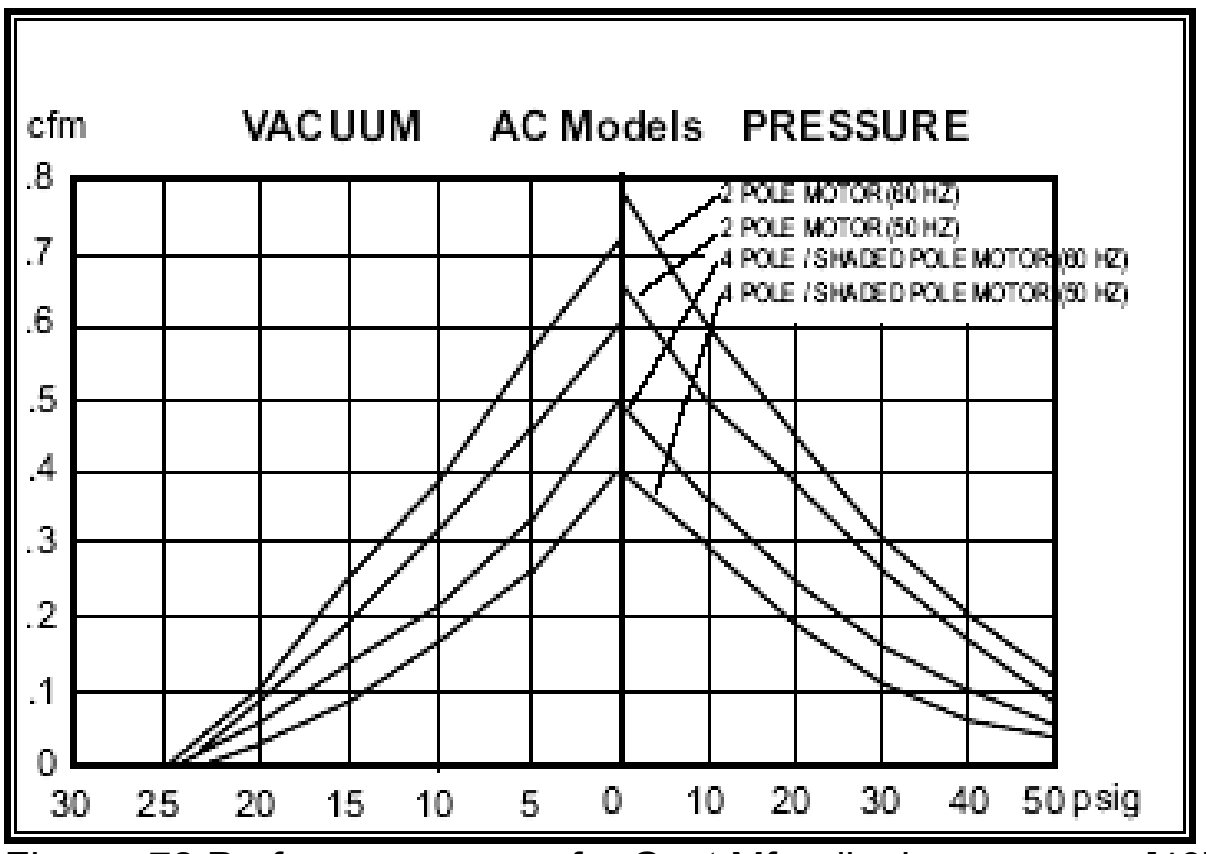

Figure- 72 Performance curve for Gast Mfg. diaphragm pump [43]

Note- the curves represent different options for 2 pole motor (50 and 60 $\mathrm{Hz}$ ) and 4 shaded pole motor $(50$ and $60 \mathrm{~Hz})$ 


\section{Appendix C}

\section{Annubar Flow-rate and Time Specific Emissions Calculation:}

Table-53 Annubar flow-rate and time specific emissions sample calculations

\begin{tabular}{|c|c|}
\hline$\overline{\text { Inside Diameter of 5" OD "Annubar" pipe }}$ & 4.854 inches $=0.4045$ feet \\
\hline Standard Temperature & $68 \mathrm{~F}$ or $20 \mathrm{C}$ or $528 \mathrm{R}$ \\
\hline Standard Pressure & 29.92 " Hg or 14.695 psia \\
\hline Coeff. of thermal expansion for steel (in./ F) & 0.000006 \\
\hline Annubar probe ,d (in.) & 0.3 \\
\hline Ratio of specific heats & 1.4 \\
\hline $\mathrm{B}=4^{*} 0.3 /\left(\mathrm{PI}{ }^{*} 4.854\right)$ & 0.15 \\
\hline Annubar AP "PSI & 14.347 \\
\hline Annubar DP "PSI / in. of $\mathrm{H} 2 \mathrm{O}$ & $0.0189 / 0.522$ \\
\hline Annubar Temp T & 129.39 \\
\hline $\begin{array}{l}\text { Thermal Expansion Factor, Faa } \\
=1+2^{*} 0.000006^{*}(129.39-(528-460))\end{array}$ & 1.00074 \\
\hline $\begin{array}{l}\text { "Annubar" DP Ibf/ft^ } 2 \\
=0.0189^{*} 144.001\end{array}$ & 2.7163 \\
\hline $\begin{array}{l}\text { Expansion factor for gases, Ya } \\
=1-\left(\left((1-0.1548)^{\wedge} 2^{*} 0.011332-\right.\right. \\
\left.0.00342)^{\star} 0.522 /\left(14.347^{*} 1.4\right)\right)\end{array}$ & 0.9998 \\
\hline Air Density slugs $/ \mathrm{ft}^{\wedge} 3$ & 0.0024 \\
\hline Air Density $\mathrm{lbm} / \mathrm{ft}^{\wedge} 3$ & 0.0774 \\
\hline $\begin{array}{c}\text { Annubar flow-rate (ACFM) } \\
=0.8 * 3.414^{*}\left(\left((0.4045)^{\wedge} 2\right) / 4\right)^{*} \text { SQRT }(2 * 2.716 \\
\left.\left.{ }^{*} 32.14 / 0.0774\right)^{*} 60^{*} 1.00074^{*} 0.9998\right)\end{array}$ & 318.568 \\
\hline $\begin{array}{c}\text { Annubar flow-rate (SCFM) } \\
=18.568^{*} 528^{*} 14.347 /\left((129.39+460)^{*} 14.695\right) \\
\end{array}$ & 278.637 \\
\hline Density of $\mathrm{CO}_{2} @ 68 \mathrm{~F}$ and 29.92 " $\mathrm{Hg} \mathrm{g} / \mathrm{ft}^{\wedge} \mathrm{3}$ & 51.81 \\
\hline Density of $\mathrm{NO}_{\mathrm{x}} @ 68 \mathrm{~F}$ and $29.92 \mathrm{Hg} \mathrm{g} / \mathrm{ft}^{\wedge} 3$ & 54.16 \\
\hline dry to wet correction factor for $\mathrm{CO}_{2}, \%$ vol. & 0.92 \\
\hline Humidity correction for $\mathrm{NO}_{\mathrm{x}}$ & 0.96 \\
\hline $\mathrm{NO}_{x}$ concentration (PPM) & 84.25 \\
\hline $\mathrm{CO}_{2}$ concentration (\% vol.) & 1.2 \\
\hline $\begin{array}{c}\mathrm{NO} \mathrm{O}_{\times} \mathrm{g} / \mathrm{s} \\
=\left(84.25^{*} 0.96^{*}(278.637 / 60)^{*} 54.19 / 10^{\wedge} 6\right)\end{array}$ & 0.021 \\
\hline $\begin{array}{c}\mathrm{CO}_{2} \mathrm{~g} / \mathrm{s} \\
=1.2^{*} 0.92^{*}(278.63 / 60)^{*} 51.81 / 100 \\
\end{array}$ & 2.323 \\
\hline
\end{tabular}




\section{References}

1. "National Ambient Air Quality Standards", Environmental Protection Agency, CFR Title 40, part 50 website:http://www.epa.gov/air/criteria.html.

2. U.S Environmental Protection Agency. The Plain English Guide to the Clean Air Act; EPA-400-K-93-001.

3. Code of Federal Regulations, Title 40, Part 1065 Subpart F, Engine Dynamometer Testing Procedures for Heavy-duty Diesel Engines.

4. Riddle, W.C., Design and Evaluation of the Emissions Measurement Components for a Heavy-Duty Diesel Powered Vehicle Mobile Emissions Measurement System (MEMS), M.S Thesis, Department of Mechanical Engineering, WVU, Morgantown, WV, 2001.

5. Gautam, M., Clark, N. N., Thompson, G. J., Carder, D. K., and Lyons, D. W. (2000), Evaluation of In-Use Heavy-Duty Vehicle Emissions Measurement System (MEMS), Phase III Report, Submitted to the Settling Heavy-Duty Diesel Engine Manufacturers by West Virginia University, Morgantown, WV, December 2002.

6. Gautam, M., Riddle, W.C., Thompson G.J., Clark, N. N., Thompson, G. J., Carder, D. K., and Lyons, D. W. (2002), Measurement of Brake-specific $\mathrm{NO}_{\mathrm{x}}$ Emissions Using Zirconia Sensors for In-use, On-board Heavy-duty Vehicle Applications.

7. Code of Federal Regulations, Title 40, Part 86, Subpart N - Emission Regulations for New Otto-Cycle and Diesel Heavy-Duty Engines; Gaseous and Particulate Exhaust Test Procedures, 1998. 
8. Emissions Standards: USA, Heavy Duty Truck and Bus Engines, website:http://www.dieselnet.com/.

9. Krishnamurthy, M., "Characterization of In-Use Emissions from On-Highway Heavy-Duty Diesel Engines," M.S. Thesis, Department of Mechanical and Aerospace Engineering, West Virginia University, Morgantown, WV, 2003.

10. Code of Federal Regulations, Title 40, Part 86 Subpart A, Emission Standards for Heavy Duty Diesel Trucks and Urban Bus Engines.

11. Nayak, G., Development of a Test Method to Measure "In-use" Emissions from Stationary and Portable Diesel Sources, M.S Thesis, Department of Mechanical Engineering, WVU, Morgantown, WV, 2004.

12. "Simple Portable On-vehicle Testing (SPOT) System, Analytical Engineering Inc., Columbus, Indiana, website:http://www.aei-tech.com/home.htm. 13. Instructional Manual- SEMTECH-D System, Sensors Inc., Saline MI, USA, website: http://www.sensors-inc.com/semtechd.htm.

14. Instructional Manual- PG250 Portable Analyzer, Horiba Analytical Instruments, website:http://www.environ.hii.horiba.com/pg250.htm.

15. Instructional Manual- AMBII microbench, Sensors Inc., Saline, MI, USA, 1999, website: http://www.sensors-inc.com/ambii.htm.

16. Shade, B. C., "A Performance Evaluation of the MEMS - An On-Road

Emissions Measurement System Study," M.S. Thesis, Department of Mechanical and Aerospace Engineering, West Virginia University, Morgantown, WV, 2000. 
17. Instructional Manual- BE140AD 5-gas bench, Horiba, Ltd., 1998, website:http://www.emd.horiba.com/engmeas/be140ad/index.htm.

18. Instructional Manual- MEXA120 NO Analyzer, Horiba, Ltd., First Edition, Ver 1.0, September, 1998, Kyoto, Japan.

19. Instructional Manual- Horiba Model BE220 FS NO Analyzer, Horiba, Ltd., First Edition, June, 1997, Kyoto, Japan.

20. Instructional Manual- NDIR Based Detection Technique, Horiba, Ltd., 2003 Web Brochure, Kyoto, Japan.

website:http://www.emd.horiba.com/engmeas/be140ad/index.htm

21. Baronick J.D, Heller B., Lach G., "Evaluation of an UV Analyzer for $\mathrm{NO}_{x}$ Vehicle Emission Measurement", SAE 2001-01-0213.

22. Worthington J.W., ABB, Inc., Lewisburg, WV, "Simultaneous Measurement of Nitric Oxide (NO), Nitrogen Dioxide $\left(\mathrm{NO}_{2}\right)$, and Ammonia $\left(\mathrm{NH}_{3}\right)$ ". 23. Garthe C., Ballik R., Pierburg Instruments GmBH, Hornreich C., Thiel W., BMW AG, "HC Measurements by Means of Flame Ionization: Background and Limits of Low Emission Measurement, SAE 2003-01-0387.

24. Nobuhide Kato, Hiroshi Kurachi, and Yasuhiko Hamada, NGK Insulators, Ltd., "Thick Film ZrO2 $\mathrm{NO}_{x}$ Sensor for the Measurement of Low NO${ }_{x}$ Concentration", 980170.

25. Code of Federal Regulations, Title 40, Part 1065.145, Design Geometry of Exhaust Sampling Probe.

26. Code of Federal Regulations, Title 40, Part 86.110, Operation Specification of Heated Filter for PM Removal. 
27. Instructional Manual- MEXA720 NO Analyzer, Horiba, Ltd., Product Brochure, 2004, Kyoto, Japan, website: http://www.emd.horiba.com/engmeas/mexa720nox/. 28. "American Society of Mechanical Engineers (ASME), Guidelines for Design Layout of a Critical Flow Nozzle", 2004.

29. "Fundamentals of Fluid Mechanics", Munson B.R., Young D.F., Okiishi T.H., $2^{\text {nd }}$ Edition, 1993.

30. Code of Federal Regulations, Title 40, Part 1065.650, Dew-point Temperature Specification for Exhaust Sampling.

31. Instructional Manual- BE150 Multi-gas Analyzer, Horiba, Ltd., Product Brochure, First Edition, 2004, Kyoto, Japan.

32. Specification of Honeywell Relative Humidity Sensor, Honeywell Technologies, website:http://content.honeywell.com/sensing/prodinfo/humiditymoisture/.

33. Specification of Motorola MPX Pressure Sensors, Free-scale Semiconductors Inc. website:http://www.freescale.com/files/sensors/doc/data shaeet/MPX5050.pdf

34. Code of Federal Regulations, Title 40, Part 1065.215, Ambient Temperature, Pressure and Relative Humidity Measurement Procedures.

35. Product Brochure- Compact Field Point, National Instruments, website: http://www.ni.com/compactfieldpoint/.

36. National Institute of Standards and Technology, Documentation on Traceability, website: http://ts.nist.gov/traceability/suppl matls for nist policy rev.htm.

37. Code of Federal Regulations, Title 40, Part 1065.307, Accuracy, Linearity and Repeatability Test Procedures.

38. Code of Federal Regulations, Title 40, Part 86.315, Response Time Test Procedures. 39. Code of Federal Regulations, Title 40, Part 1065.374, Analyzer Drift Test Procedures. 
40. Code of Federal Regulations, Title 40, Part 86.315, Interference Test Procedures. 41. Thomas diaphragm pump performance chart, 907_917 diaphragm pumps. PDF website: http://www.thomspumps.com 42. Air Dimensions micro-diaphragm vacuum performance chart, website: http://www.airdimensions.com/products/performance/micro.aspx 43. Gast manufacturing diaphragm pump, Gast manufacturing Inc. website: http://www.gastmfg.com/pdf/diaphragm/specsht/moa.pdf 